Forest Landscape Restoration and Ecosystem Services in A Luoi District, Thua Thien Hue Province, Vietnam

\author{
DISSERTATION \\ For the award of the degree \\ Doctor rerum naturalium (Dr.rer.nat.) \\ of the Georg-August-Universität Göttingen
}

Within the doctoral program of Geography

of the Georg-August University School of Science (GAUSS)

\author{
Submitted by \\ Nguyen Trong Hung \\ From Vietnam
}

Göttingen, July 2021 


\section{Thesis Committee}

Prof. Dr. Martin Kappas, Department of Cartography, GIS and Remote Sensing; Institute of Geography; University of Göttingen.

Prof. Dr. Renate Bürger-Arndt, Faculty of Forest Sciences and Forest Ecology, University of Göttingen.

\section{Members of the Examination Board}

Reviewer: Prof. Dr. Martin Kappas, Department of Cartography, GIS and Remote Sensing; Institute of Geography; University of Göttingen.

Second Reviewer: Prof. Dr. Renate Bürger-Arndt, Faculty of Forest Sciences and Forest Ecology, University of Göttingen.

Prof. Dr. Ralph Mitlöhner, Tropical Silviculture and Forest Ecology, University of Göttingen. Prof. Dr. Heiko Faust, Human Geography, University of Göttingen.

Dr. Daniel Wyss, Institute of Geography, University of Göttingen.

Prof. Dr. Elke Pawelzik, Department für Nutzpflanzenwissenschaften, University of Göttingen. 


\section{Acknowledgements}

I express my deepest gratitude to my supervisor Prof. Dr. Martin Kappas for his continuous support during my $\mathrm{Ph} . \mathrm{D}$ research as well as for his patience, motivation and immense knowledge. My special thanks go to my second supervisor, Prof. Dr. Renate BürgerArndt for her invaluable advices and comments, and all supports during my study.

I greatly thank the thesis committee: Prof. Dr. Ralph Mitlöhner; Prof. Dr. Heiko Faust; Dr. Daniel Wyss; Prof. Dr. Elke Pawelzik for their deep and insightful comments and encouragement.

I thank all my colleagues at the Institute of Geography, Department of Cartography, GIS and Remote Sensing for supporting and assisting me spiritually and academically during my study, namely: Dr. Uwe Muuss, Dr. Jan Degener, Dr. Ammar Rafiei Eman, Dr. Phan Thanh Noi, Dr. Pham Gia Tung, Dr. Holger Vogt, Msc. Nguyen The Dung, Mr. Sören Merkle, Msc. Timo Pascal Lehmann, and others. Special thanks go to Mrs. Martina Beck for great support in all administrative issues.

I thank the Vietnamese Ministry of Natural Resources and Environment, the Department of Climate Change, and related departments for sending me to Goettingen University. I further express my greatest thanks to the DAAD for sponsoring my scholarship and GAUSS Program for short-term financially support. I thank the Hue University of Agriculture and Forestry for assisting me during my field data collection, namely: Assoc. Prof. Le Van An, Rector of HUAF; Assoc. Prof. Huynh Van Chuong, Vice Rector; Assoc. Prof. Nguyen Hoang Khanh Linh, and other colleagues. I also express my thanks to the colleagues of Sub-FIPI, Sao La Nature Reserve, and DONRE of Thua Thien Hue and A Luoi DPC, the Watershed Forest Management Board of A Luoi District, and the local people in the A Roang Commune for supporting me during the field survey.

I thank the Vietnamese Students Association in Goettingen for many unforgettable memories, especially the family of Dr. rer. nat. Tran Tuoc; Dr. Dao Hoa Hong; Dr. Vu Van Hung; Msc. Van Vien Pham. My special thanks go to the families: Mrs. Ha My and Mr. Uwe Setje-Eilers.

Last but not least, all special thanks go to my beloved family, my wife Pham Thi Vinh Hien and my two sons, Nguyen Trong The Vinh and Nguyen Trong The Ky. Without their encouragement and support, I would not have any achievements. I express my deepest thanks to my parents for their spiritual encouragement in my life. 


\section{Preface}

The present thesis "Forest Landscape Restoration and Ecosystem Services in A Luoi District, Thua Thien Hue Province, Vietnam" has been submitted in partial fulfilment of the requirements for the Ph.D. degree at University of Göttingen (Germany). The main supervisor is Prof. Dr. Martin Kappas and the second supervisor is Prof. Dr. Renate Bürger-Arndt.

The thesis consists of an introduction to the research objectives and questions, a general literature review, the study site's characteristics, four manuscripts and a summary, contributions and recommendations chapters.

The study was conducted at the Department of Cartography, GIS and Remote Sensing at GeorgAugust-University Goettingen, from October 2016 to July 2021.

Göttingen, July 2021

Nguyen Trong Hung 


\section{Table of Content}

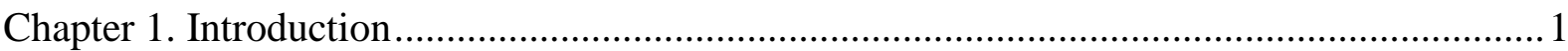

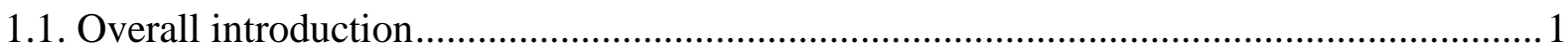

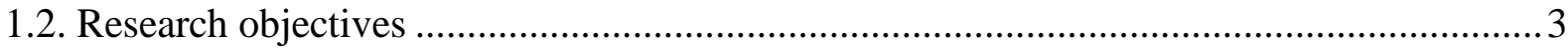

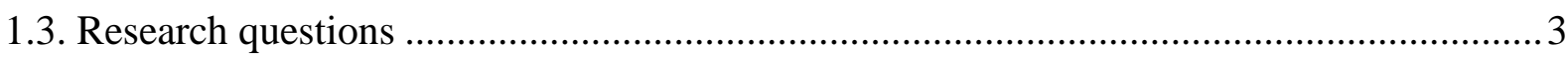

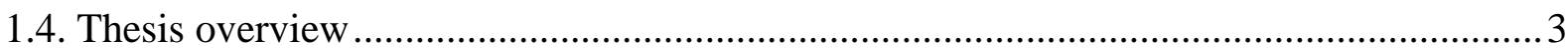

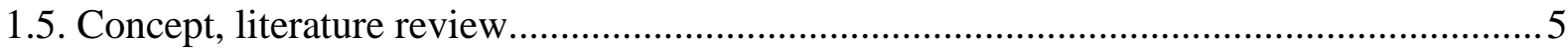

1.5.1. Forest cover and forest land classification..........................................

1.5.2. Forest ecosystem classification .............................................................

1.5.3. Landscape definitions and planning for human well being ....................... 10

1.5.4. Landscape Restoration and Ecosystem Services ..................................... 11

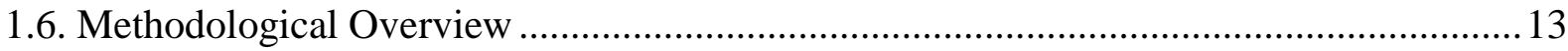

1.6.1. Forest inventory for ground truthing .............................................. 14

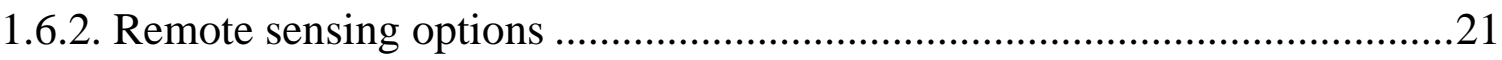

1.6.3. Relevance of ecosystem services and landscape restoration .....................25

1.6.4. Assessment of NTFP potential supply and demand ................................26

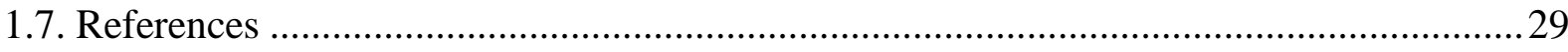

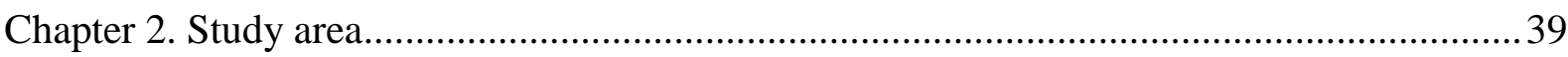

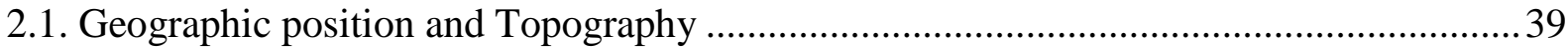

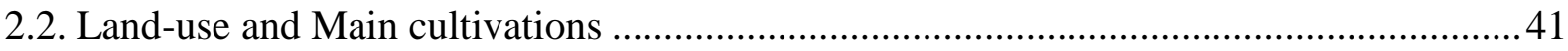

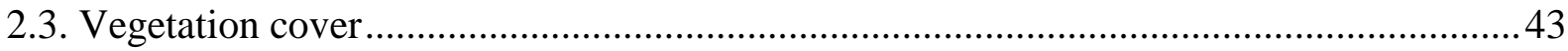

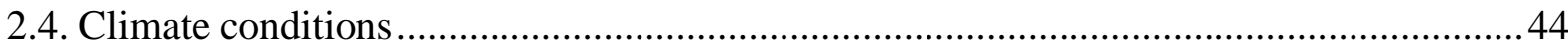

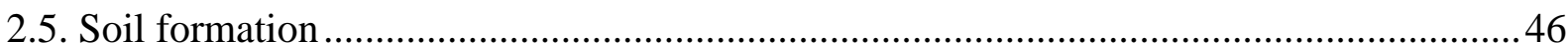

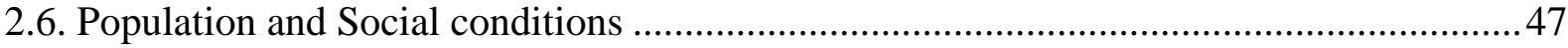

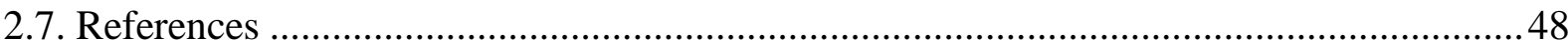

Chapter 3. Evaluating the Influence of Topography on Tree Species Diversity, Distribution

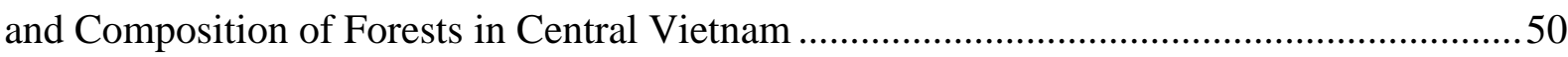

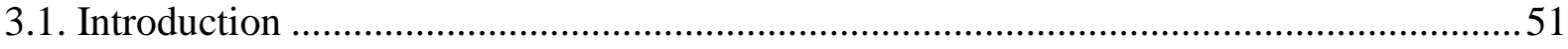

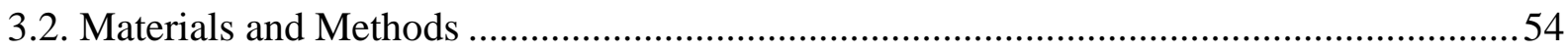

3.2.1. Vegetation sampling and Topographic attribute classification...................54

3.2.2. Species richness and species diversity distribution ...............................54 


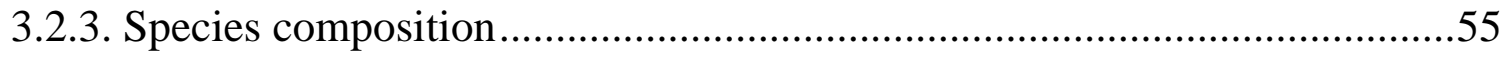

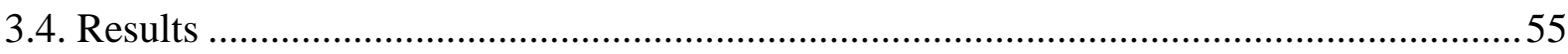

3.4.1. Vegetation distribution over topography ....................................................55

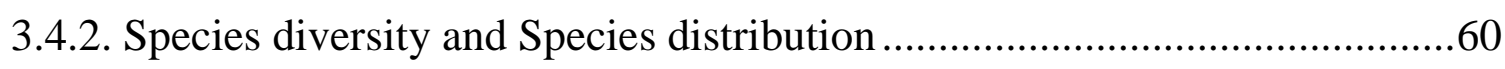

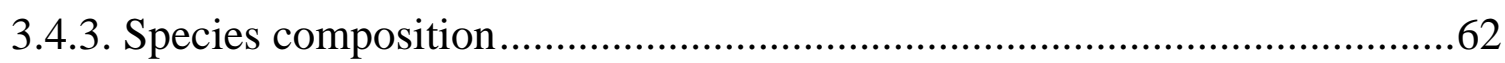

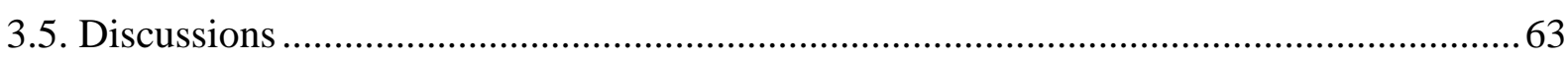

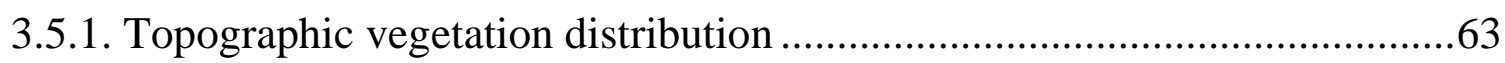

3.5.2. Species diversity and Species distribution ....................................................64

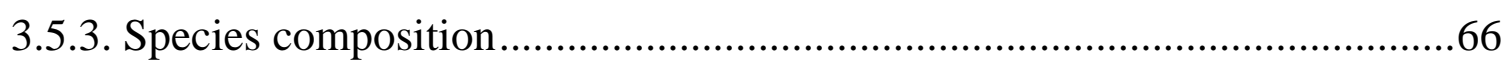

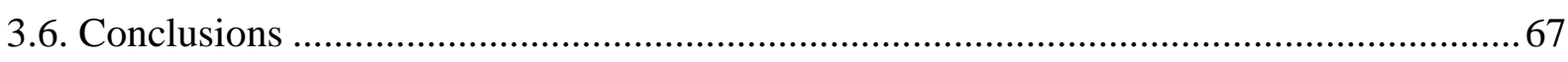

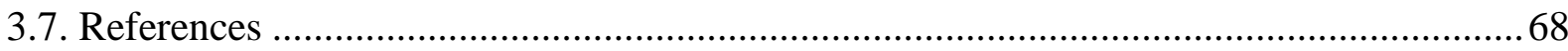

Chapter 4. Land Cover and Forest Type Classification by Values of Vegetation Indices and

Forest Structure of Tropical Lowland Forests in Central Vietnam ...........................................74

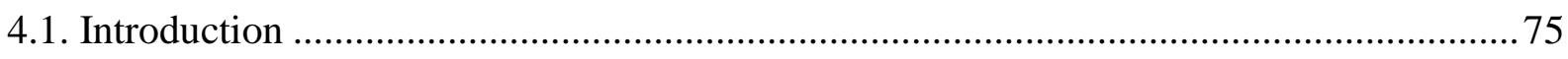

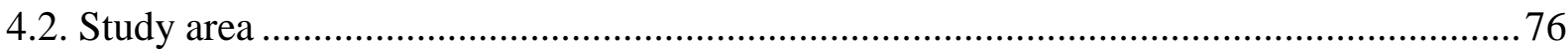

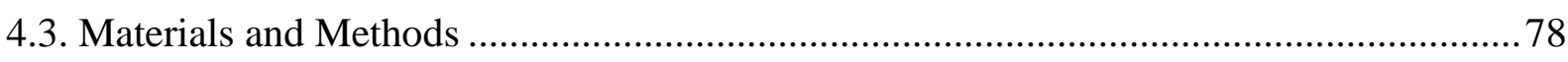

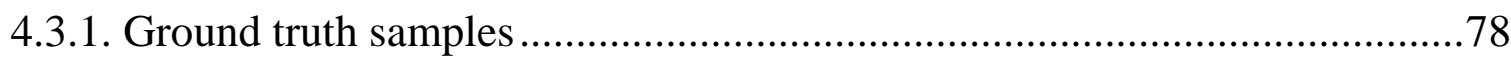

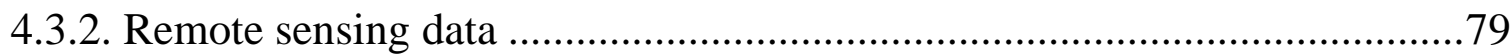

4.3.3. Land Cover Classification Training and Testing Samples ............................8 80

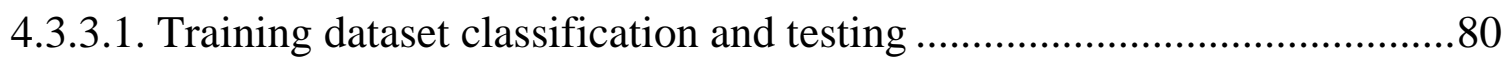

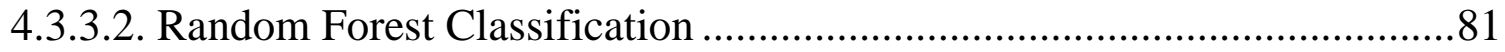

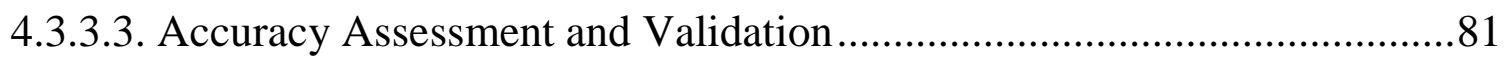

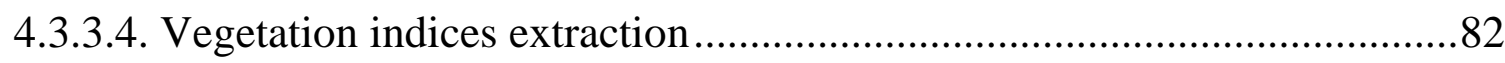

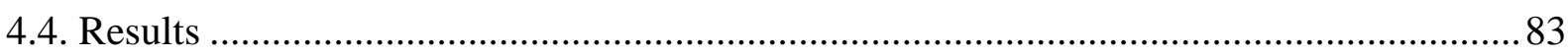

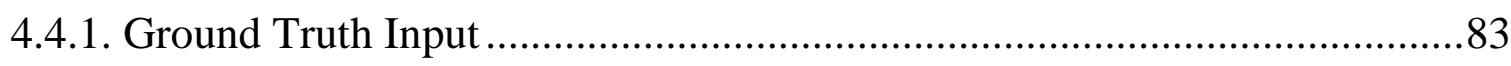

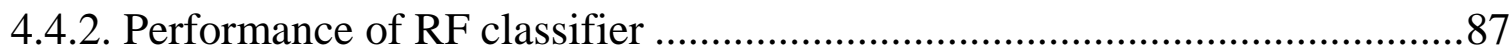

4.4.3. Comparison of sensors over class validation and assessment .......................87

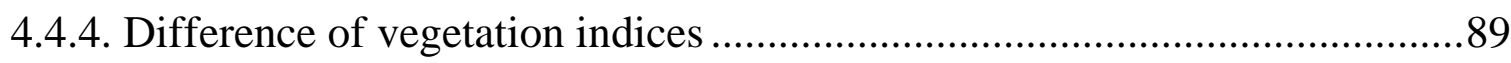

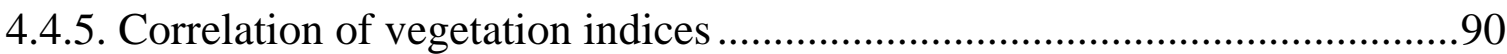

4.4.6. Relationship of VIs with horizontal and vertical structure of dominance

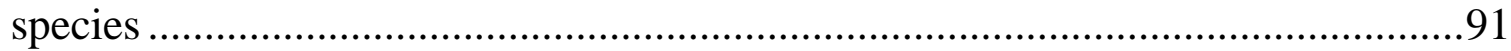

4.4.7. VIs regression with horizontal and vertical structures .................................93 
4.5.1. Species vertical and horizontal structure of different forest types ..............95

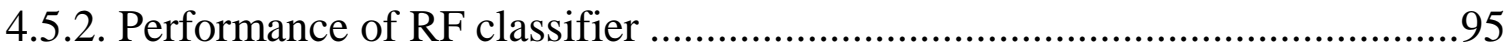

4.5.3. Comparison VIs of ground-truth forest cover with those of training sampled

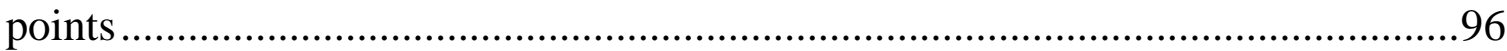

4.5.4. Relationship of VIs with vertical and horizontal forest structure................97

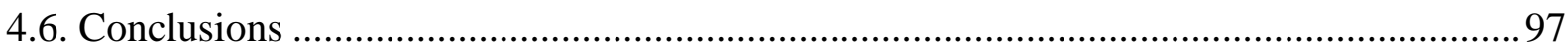

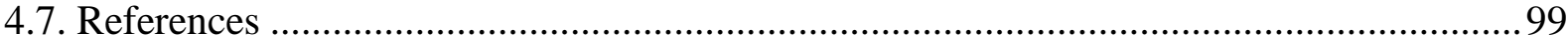

Chapter 5. Assessment of soil quality indicators under different agricultural land uses and

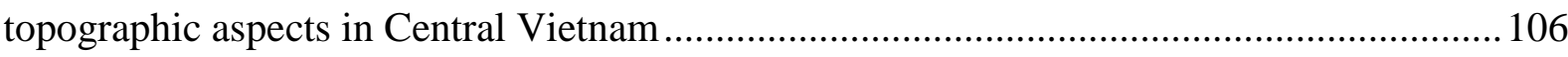

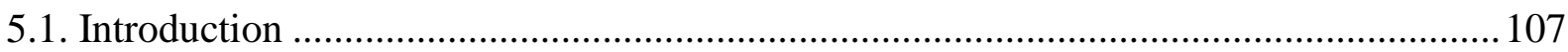

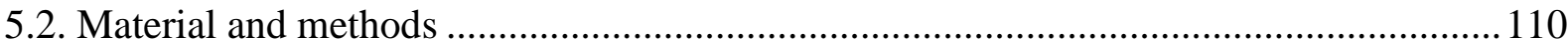

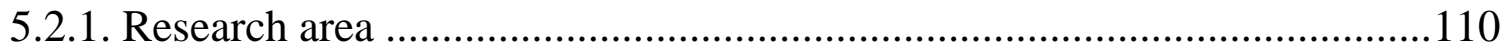

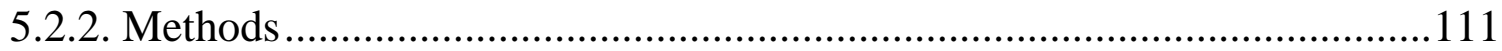

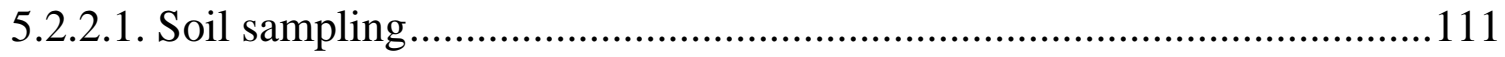

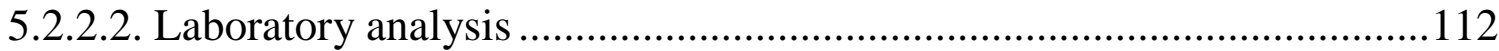

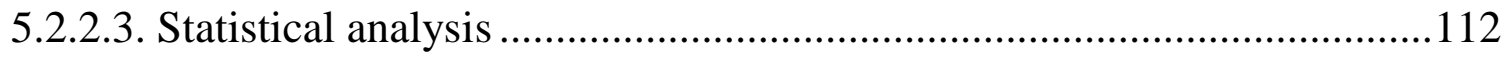

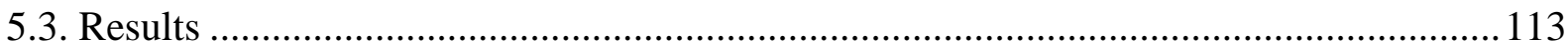

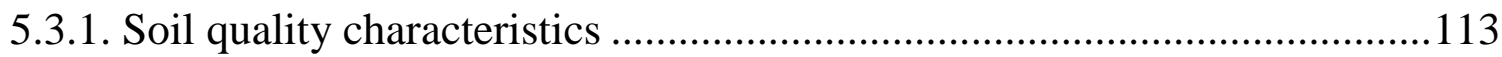

5.3.2. Soil quality indicator under different land use types ............................114

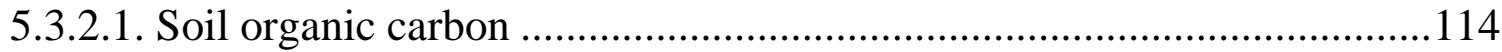

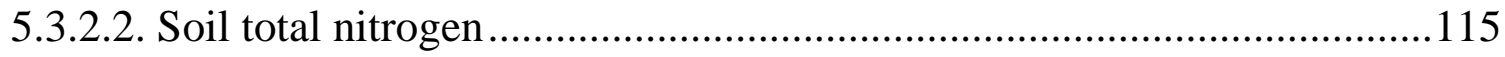

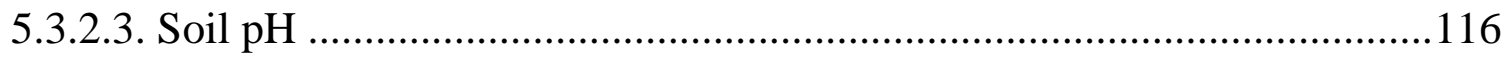

5.3.3. Soil organic carbon under different aspects .......................................116

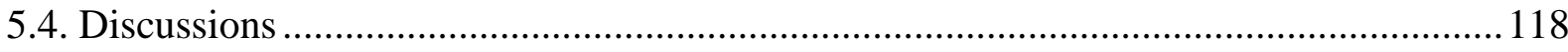

5.4.1. Soil organic carbon and soil total nitrogen under different land use types 118

5.4.2. Soil $\mathrm{pH}$ under different land use types ................................................119

5.4.3. Soil organic carbon of different aspects........................................... 119

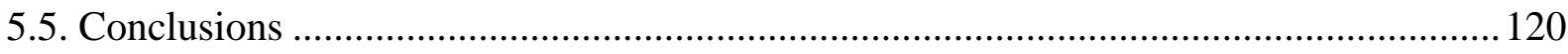

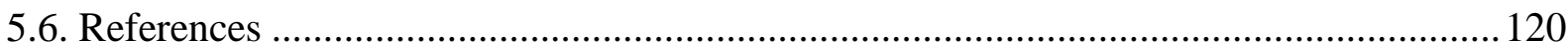

Chapter 6. Non-Timber Forest Products as Potential Ecosystem Provisioning Services for Local People in a Mountainous Region, Central Vietnam 


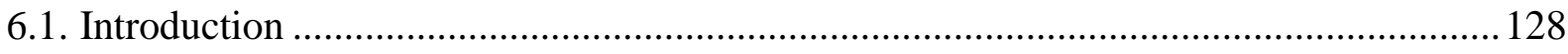

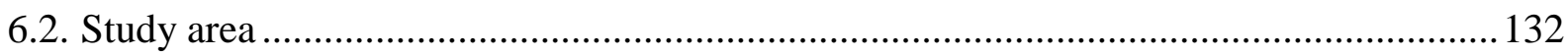

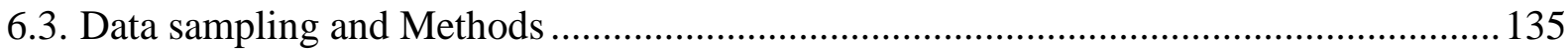

6.3.1. Forest inventory ………………….........................................................135

6.3.2. Identification of use options for NTFP tree species ...................................137

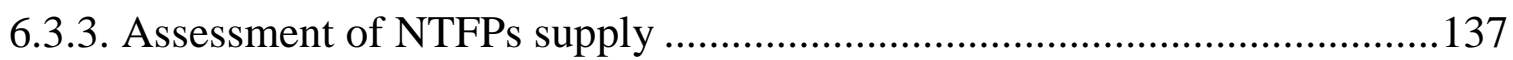

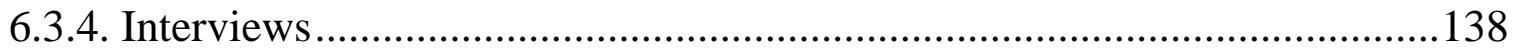

6.3.5. Assessment of NTFPs demand .............................................................138

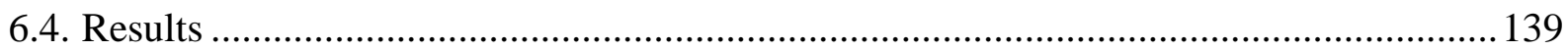

6.4.1. Characteristics of local forest stand structure .............................................139

6.4.2. Use options and potential supply of NTFPs tree species as potential forest

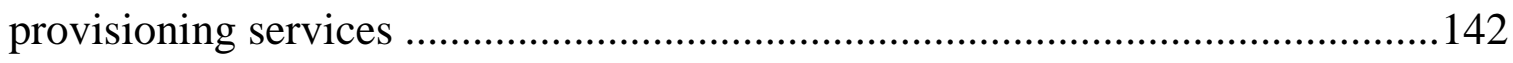

6.4.3. Importance and satisfaction ranking for natural forests and their provisioning

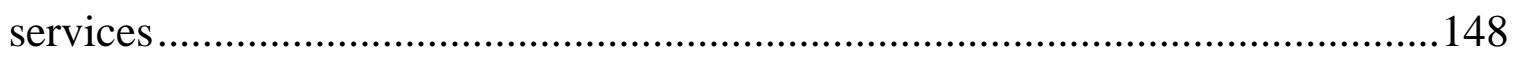

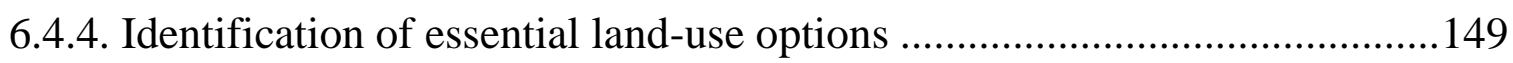

6.4.5. Personal involvement in extracting NTF goods ........................................151

6.4.6. Awareness of natural forest degradation and needs for restoration.............151

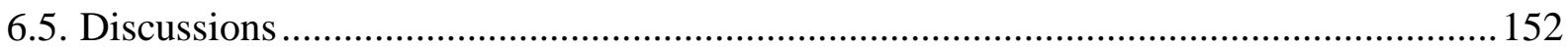

6.5.1. Characteristics of the natural forest stand structures confirm different

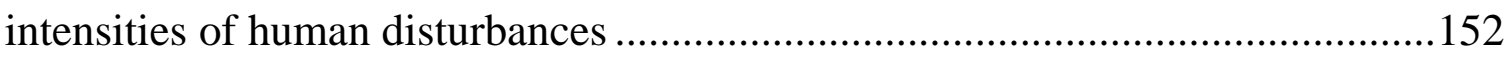

6.5.2. High demand but insufficient supply of NTFPs .........................................153

6.5.2.1. Considerable potential supply from medical tree species........................153

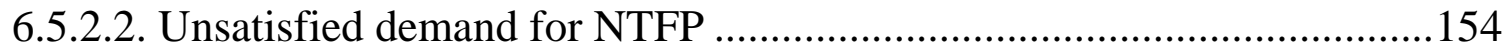

6.5.3. Local people evince high awareness of risks and needs for natural forest

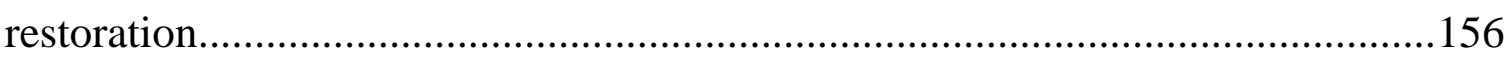

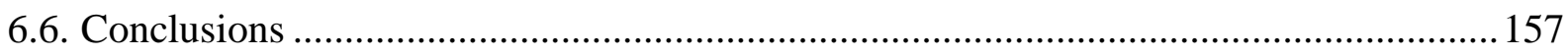

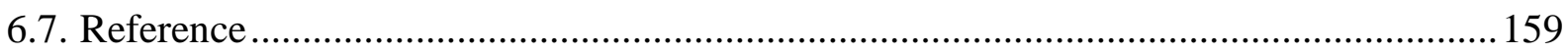

Chapter 7. General Summary, Contributions and Recommendations .................................. 168

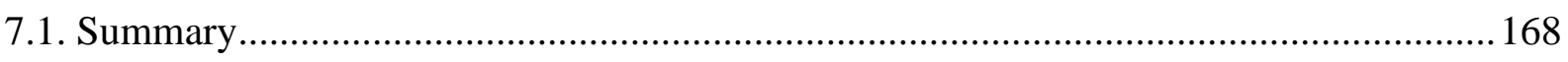

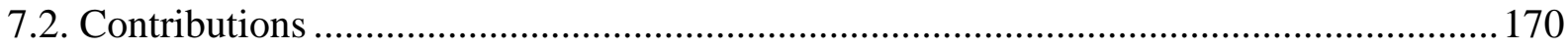

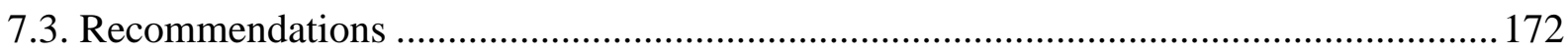

Annex 1. An ecosystem services based-demand questionnaire ...................................... 173 


\section{List of Figures}

Figure 1.1. Flowchart of the thesis structure

Figure 1.2. Conceptual framework linking ecosystem integrity, ecosystem services, and human well-being 13

Figure 1.3. Overview of research concept 14

Figure 1.4. Ground truth sampling 15

Figure 1.5. Study area and lay-out of ground truth sample plots 21

Figure 1.6. Ecosystem provisioning services survey... 27

Figure 1.7. Relationship among potential provisioning services of natural forests, supply and demand assessment for landscape restoration planning and management ..............................28

Figure 2.1. Location of the study area in Thua Thien Hue Province.......................................39

Figure 2.2. The elevations (a) and slopes (b) of A Luoi District........................................... 40

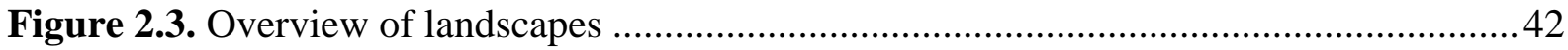

Figure 2.4. Climate diagram for A Luoi District, Thua Thien Hue Province.......................... 46

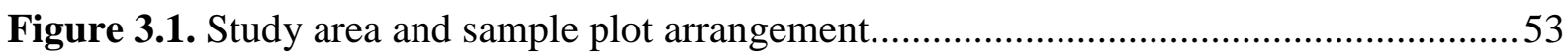

Figure 3.2. Paired correlation between elevation, slope with species, stem density (N), basal area, family

Figure 3.3. Most dominant species accounted in the representative plots of elevation levels (H1 and $\mathrm{H} 2$ ).

Figure 4.1. A key process on land cover classification, vegetation indices extraction and verification of research workflow. .76

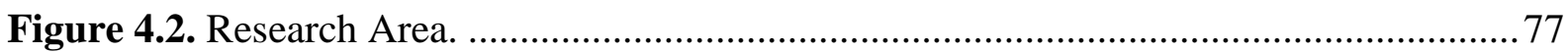

Figure 4.3. Flowchart of satellite data and ground truth data processing methods 79

Figure 4.4. The number of trees and random split number of variables at each node of RF classifiers in Landsat-8 and Sentinel-2 using the same training sample data.....

Figure 4.5. The OOB error (y-axis) and ntree in (x-axis) of RF classifier of Landsat-8 and Sentinel-2 using the same training sample data.

Figure 4.6. Explanation of each class prediction of Landsat-8 and Sentinel-2 using square matrix.

Figure 4.7. Classification map by random forest presenting results of the best accuracy of classifiers in Landsat-8 and Sentinel-2

Figure 4.8. The negative linear regression results of EVI, PVI, DVI and TNDVI extracting from Sentinel-2 with basal area, and height

Figure 5.1. Chemical, biological, and physical benefits in soil to which soil organic carbon (SOC) contributes [28]. 
Figure 5.2. Agricultural land use map in 2015 and showing soil sampling position 111

Figure 5.3. Location of sampling sites on a slope aspect map

Figure 5.4. Correlation of SOC content changed by land use type between topographic aspects

Figure 6.1. Overview of methodological approach used in this study

Figure 6.2. Relative location of the study area in the A Roang Commune of A Luoi District in Thua Thien Hue Province, Central Vietnam 133

Figure 6.3. Land use types in the study site in A Roang Commune 135

Figure 6.4. Data sample arrangement for the forest types: 137

Figure 6.5. The relationship between diameter at breast height $(\mathrm{DBH})$ and top height in different forest types and elevations:

Figure 6.6. Percentages of people who gave high importance and satisfaction ranking 149 


\section{List of Tables}

Table 1.1. National forest area classified based on functions in Vietnam in 2017 (in Mio ha) 8

Table 1.2. Forest land in the North Central Coast of Vietnam in 1000 hectare 9

Table 2.1. Land use distribution in A Luoi District and A Roang Commune in 2017 (in ha) 41

Table 2.2. The climatic data of A Luoi District. Thua Thien Hue Province

Table 3.2. Species composition of the representative plots and of the entire topographic attribute.

Table 3.3. The abundant and dominant species in different topographic attributes. 59

Table 3.1. Species richness, diversity, density over respective topographic attributes 61

Table 4.1. Land cover training and testing samples 80

Table 4.2. Vegetation Radiometric Indices 83

Table 4.3. Parameters of different forest types 84

Table 4.4. Dominance and Abundance Species of Horizontal Structure in different forest types

Table 4.5. Dominance and Abundance Species of Vertical Structure in different forest types

Table 4.6. Accuracy assessment of land cover classes of Landsat-8 88

Table 4.7. Accuracy assessment of land cover classes of Sentinel-2 88

Table 4.8. Mean vegetation indices of forest types in ground truth and training sample plots extracted from Sentinel-2 imagery dated on 22 March 2017. 90

Table 4.9. Correlation of Vegetation Indices with BA and height in ground-truth plots ........91

Table 4.10. Correlation of VIs with dominance species in horizontal structure.....................92

Table 4.11. Correlation of VIs with dominance species in vertical structure .93

Table 5.1. Agricultural land use. 111

Table 5.2. Distribution of the soil samples by slope and elevation 113

Table 5.3. Soil quality characteristic of soil samples 114

Table 5.4. Mean value of SOC (\%) under different land use types at two soil depths 115

Table 5.5. Mean value of STN (\%) under different land use types at two soil depths 115

Table 5.6. Mean value of soil $\mathrm{pH}$ under different land use types at two soil depths 116

Table 5.7. Mean value of SOC content of the topsoil layer under different topographic aspects

Table 5.8. Number of soil samples by topographic aspects and soil texture 120

Table 6.1. The mean parameters and standard deviations of the forest stand in different forest types: 
Table 6.2. Use options of NTFP species.

Table 6.3. The stand parameters and standard deviations of NTFP species in different forest types and elevations:

Table 6.4. The relative share (\%) between NTFP tree species in different forest types and elevations with the means of those the entire forest stand:

Table 6.5. Ranking of the importance of natural forests and their provisioning services and of the satisfaction 148

Table 6.6. Identification of essential land use options by the percentage of people in different target groups. 150

Table 6.7. Perceptions of human induced risks (landslides and decline of forest goods) and needs for natural forest restoration by different target groups $(\%)$. 


\section{Abbreviation and Synonyms}

a.s.l. Above Sea Level

AAC Annual Allowable Cut

AL Arable Land

ARVI Atmospherically Resistant Vegetation Index

BA Basal Area

CLVIs Sub-stratified Forest Type Vegetation Indices

DAAD German Academic Exchange Service

dbh Diameter at Breast Height (1.3m above ground)

DEM Digital Elevation Model

DF Heavily Disturbed Forest

DVI Normalized Difference Index

ES Ecosystem Services

EVI Enhanced Vegetation Index

FAO Food Agriculture Organization

FIPI Forest Inventory and Planning Institute

GIS Geographic Information Systems

GL Grassland

GNDVI Green Normalized Difference Vegetation Index

GPS Global Positioning System

GTVIs Ground-Truth Vegetation Indices

ha Hectare

i.a. Inter alia

IPVI Infrared Percentage Vegetation Index

IVI Important Value Index

LF Less Disturbed Forest

LS Lower story

LU/LC Land Use/Land Cover

MA Millennium Ecosystem Assessment

MARD Ministry of Agricultural and Rural Development

ME Mean Error

Mio Million

MONRE Ministry of Natural Resources and Environment

MS Middle story

NCC North Central Coast

NDI45 Normalized Difference Index 45

NDVI Normalized Difference Vegetation Index 


\begin{tabular}{|c|c|}
\hline NF & Natural Forest \\
\hline NIR & Near-Infrared \\
\hline NP & National Park \\
\hline NR & Nature Reserve \\
\hline NTFPs & Non-Timber Forest Products \\
\hline NW & Northwest \\
\hline $\mathrm{OC}$ & Organic Carbon \\
\hline PA & Protected Area \\
\hline PCT & Potential Crop Tree \\
\hline $\mathrm{PF}$ & Production Forest \\
\hline $\mathrm{pH}$ & Soil Acidity level \\
\hline PVI & Perpendicular Vegetation Index \\
\hline $\mathrm{RF}$ & Random Forest Algorithm \\
\hline RRD & Red River Delta \\
\hline RS & Remote Sensing \\
\hline RVI & Ratio Vegetation Index \\
\hline SCC & South-Central Coast \\
\hline SE & Southeast \\
\hline SOC & Soil Organic Carbon \\
\hline Spp & Species \\
\hline SRTM & Shuttle Radar Topography Mission \\
\hline STN & Soil Total Nitrogen \\
\hline SUF & Special-Use Forest \\
\hline TGs & Target groups \\
\hline TNDVI & Transformed Normalized Difference Vegetation Index \\
\hline TOA & Top of Atmosphere Reflectance \\
\hline UF & Undisturbed Forest \\
\hline US & Upper story \\
\hline USD & United States Dollar \\
\hline USGS & United States Geological Survey \\
\hline VIs & Vegetation Indices \\
\hline VND & Vietnam Dong \\
\hline WPF & Watershed Protection Forest \\
\hline SE & Southeast \\
\hline
\end{tabular}




\section{Abstract}

The Government of Vietnam has invested efforts to increase the forest cover, and to conserve biodiversity through different forest development projects and programs. Losing natural forests and landscapes in the context of the "exhaust" of ecosystem services has been seen as burden in many mountainous areas. The Decision No.16 on ecosystem restoration, which was adopted by the Conference of the Parties to the Convention on Biological Diversity $(\mathrm{CBD})$ at the $11^{\text {th }}$ meeting (December $5^{\text {th }}, 2012$ ) stated that ecosystem restoration requires the application of suitable technologies and the fully-effective participation of local entities. This serves to identify obstacles while attempting to restore, regenerate ecosystem services and biodiversity, which have been degraded and lost in the recent decades. Furthermore, Vietnam's National Forest Development Strategy targeted to achieve a forest area of 16.2 million hectares by the year 2020. Local people living adjacent to forests depend on the forest ecosystem services supplied from various natural forest landscapes in the area. This holds true especially for the people of Central Vietnam where the terrestrial area is narrow due to the country shape. In this area, agriculture practices play an essential role although the agricultural land is very limited due to the topographic conditions. The distinct land-uses reflect the natural distribution of plant and animal species as well as human interventions. In Vietnam, the forest ecosystems have been classified into three categories according to their main functions: special-use forest for nature conservation; protection forest for the watershed and protective measures; and production forest for commercial operations. This study was conducted in the A Luoi District, Thua Thien Hue Province. Ground truth samples were inventoried in three forest types from $150 \mathrm{~m}$ to $1162 \mathrm{~m}$ above sea level (a.s.l.) and steep slopes from 5 to 48 degrees. The elevation range was divided into the lower elevation level $\mathrm{H} 1$ ranging from $150 \mathrm{~m}-699 \mathrm{~m}$ and into the higher elevation level H2 from 700 m-1162 m a.s.1.. The slopes were stratified into level S1 from 5-20 degrees, and into S2 from 21-48 degrees. The forest cover was classified into the types: undisturbed forest (UF), low disturbed forest ( $L F)$, and heavily disturbed forest (DF). To strengthen the classification of forest types, a t-test of extracted vegetation indices between ground truth plots and training sample plots was done.

Up to date, no remote sensing-based work on ecological stratification of the natural forest landscapes has been conducted. Finding the tree species distribution, species diversity, and species composition over the sub-stratification of the elevations, slopes, and the forest types by applying remote sensing - are necessary to classify the land-use types and to map out the availability of natural resources, especially the ecosystem services supply and demand of local people. Land-use and forest type classification may contribute remarkably to long-term 
planning, which has been assigned to local authorities, and which should include local communities.

The entire study consists of four main parts. The first part aimed at evaluating the influence of topography on tree species diversity, distribution, and composition of the forests in Central Vietnam. A significant difference of species richness and species diversity was found in shallower and steeper slopes $(\mathrm{p}<0.05)$ and a relatively high correlation of the species distribution, the number of stems, and the number of tree families with the elevation factor was found. The lower elevation and shallower slope showed higher species richness $(\mathrm{p}<0.05)$ but not a significant difference between the number of families and the evenness. The dominance and the abundance of tree species among the topographic attributes were significantly different $(\mathrm{p}<0.05)$. Lower elevation and shallower slope showed higher species richness and species diversity than the higher elevation and steeper slope. The most dominant and abundant tree families from different elevations and slopes included the Myrtaceae, Dipterocarpaceae, Burseraceae, Fagaceae, Moraceae, Cornaceae, Apocynaceae, Sapindaceae, Cannabaceae, Juglandaceae, Lauraceae, Myristicaeae, Annonaceae, Ebenaceae, Meliaceae, Rubiaceae, and the Rosaceae.

The second part aimed at assessing the soil qualities, which belong to the most essential elements for land-use planning and agricultural production. 155 soil samples from different land-use types and topographic aspects were collected in order to compare information on soil organic carbon (SOC), soil total nitrogen ( $\mathrm{STN})$, and soil acidity $(\mathrm{pH})$ at two soil depths. The SOC of arable land and forest plantation land was found to be higher than those of grassland and of natural forests $(\mathrm{p}<0.05)$. The total nitrogen in the natural forests was significantly less, compared to the other land-use types. No significant differences in the total nitrogen content $(\mathrm{p}<0.05)$ were found among arable land, plantation forest, and grassland. The soil organic carbon and the total nitrogen were high in the upper soil and less downwards, within all landuse types. The soil $\mathrm{pH}$ in the plantation forest and the arable land-use types showed no significant change among soil depth categories. Significant differences were not found in topographic aspects and the soil organic carbon content; however, differing trends of soil organic carbon and land-use types and aspects were found. The impact of the slope, elevation, farming system and soil texture accounted for the main differences of soil indicators under varying land-use types in the A Luoi District.

The third part of this study was designed to apply remote sensing data from Landsat-8 and Sentinel-2 sources in order to classify land-cover and land-use classes (including three forest types UF, LF, and DF) in the study area by using machine learning algorithms. Further, 
vegetation indices were applied to find possible correlations and regressions of both, vertical and horizontal structures of the dominant forest tree species within different forest types. It was found that the vegetation indices between the ground-truth plots and the training sample plots were significantly different $(\mathrm{p}<0.05)$. The most dominant and abundant tree families in the context of the vertical structure were the Dipterocaparceae, Combretaceae, Moraceae, Leguminosae, Burseraceae, and the Polygalaceae. These, in the context of the horizontal structure were the Fagaceae, Lauraceae, Leguminosae, Dipterocaparceae, Myrtaceae, Myristicaceae, Euphorbiaceae, and the Clusiaceae. The results of the land cover and the landuse classification of Sentinel-2 were found to be more precise than those of Landsat- 8 with the Random Forest algorithm: (Sentinel-2 with out-of-bag error of $14.3 \%$, overall accuracy of $85.7 \%$, kappa of $83 \%$ and Landsat- 8 with out-of-bag error $31.6 \%$, overall accuracy of $68 \%$, kappa of $67.5 \%$ ). The study found relationships (from $43 \%$ up to $66 \%$ ) between four (out of ten) vegetation indices within horizontal and vertical structures of the forest stands: the Enhanced Vegetation Index (EVI), the Difference Vegetation Index (DVI), the Perpendicular Vegetation Index (PVI), and the Transformed Normalized Difference Vegetation Index (TNDVI).

The fourth part evaluated potential provisioning services of the current natural forests apart from wood and timber supply. It (i) assessed and compared the amount of non-timber forest tree species (NTFP species) in the different investigated forest types and elevations as potential resources; explored (ii) the respective demands of local people and (iii) their personal views concerning the importance of natural forests and the satisfaction with their provisioning services; and finally (iv) gathered their awareness of limited consequences of former forest development and requirements for forest landscape restoration.

Thirty-nine NTFP tree species were found for various uses such as food, medicine, and resin or oil. Random on-site interviews of 120 out of 627 local households were conducted in a commune with high dependency on local natural forest products. Their importance and satisfaction ranking of natural forests - considering different target groups with respect to gender, income, age-class, and education - was commenced. Multiple methods were used to assess an array of gathering information, which are related to (a) the forest resources importance and (b) the local people satisfaction. These were set into context with the involvement of nontimber forest goods extraction, landslides, goods declination, and the perception for natural forest landscapes restoration, in order to clarify perspectives on forest provisioning services. The results revealed remarkable differences among target groups, adjustment, perceptions. The insufficient supply of NTFPs, particularly profitable natural medicine provision, urges for 
adapted silvicultural measures. The results imply that NTFPs from natural forests are not only very important to the local communities, but also contribute to the enrichment of biodiversity. The participation of local people in practical forest management and forest improvement should be considered in the decision-making process for natural forest landscape restoration of remote mountainous areas.

The findings of this study can support sustainable forest management; natural forest landscape restoration with the involvement of local communities; conservation practices of biodiversity, based on topographic conditions; land-use planning; identification of dominant tree species using vegetation indices' values, and land cover and land-use classification using open source satellite images. This final component will be aided by application of machine learning algorithms in the current study area and in the central mountainous area of Vietnam. 
Chapter 1. Introduction

\subsection{Overall introduction}

Tropical forests, which are the "house" of biodiversity on our planet in terms of provisioning habitats for many fauna and flora species, are located between the Tropic of Cancer $\left(23^{\circ} 27^{\prime} \mathrm{N}\right)$ and the Tropic of Capricorn $\left(23^{\circ} 27^{\prime} \mathrm{S}\right)$ [1]. Many of their tree species are endemic [2,3]. Tropical Moist Forests, which cover around 115 Mio ha and about seven percent of the total land area in the world, consist of many different forest types. Some forest types contain a variety of different mixed species, but other types may have one or some dominant species [4]. In Asia, the tropical moist forest cover totals about 22 Mio ha and extends from Bhutan, Myanmar, and Bangladesh in the north, across parts of India, through continental SE Asia and the Malay Peninsula, and across the islands of Indonesia and the Philippines. Tropical lowland forests cover about 14.7 Mio ha of this area, and about 20 Mio ha is closed broadleaved forest in which the crowns of trees form a continuous canopy [4]. According to FAO [5], the natural forests are composed of indigenous trees in difference to plantation forests. The natural forests themselves consist of forest stands sub-stratified into various vegetation stories dominated by different species in each story respectively [6,7]. In this study, we refer to the natural forests as being composed of the original vegetation species that immigrated naturally and that consist of indigenous and native tree species. The natural forests persist in their structures, and variations in species composition are still recognized through different vertical layers such as upper, middle, lower, and shrubs. However, even these layers have been strongly impacted or heavily disturbed $[7,8]$.

Vietnam, an S-shaped tropical country in the Southeast Asia, covers a total natural area of 33,1 Mio ha [9], and is situated between $102^{\circ} 08^{\prime}-109^{\circ} 28^{\prime} \mathrm{E}$ and $8^{\circ} 02^{\prime}-23^{\circ} 23^{\prime} \mathrm{N}$. The country has about 3,260 kilometers of coastline. Vietnam has formally recognized eight different agricultural-ecology regions. These are North West, North East, Red River Delta, North Central Coast, South Central Coast, Central Highlands, South East, and Mekong River Delta [10]. The total area is classified into three different land-use categories which are (1) agricultural land of 27,3 Mio ha, (2) non-agricultural land of 3,7 Mio ha, and (3) unused land 
of 2,1 Mio ha [9]. About three-quarters of the territory is a hilly area spreading from the coastal area to the plain, midland, central highlands, and mountainous regions. Vietnam is a tropical monsoon climate country with a sub-tropical monsoon season and a high mountainous temperate climate. According to Toan [11], it has three climate zones: the north and the east of the Truong Son range, and the south. This excludes the east sea climatic zone with ten typical climatic regions each representing different ecological regions. Soil types in the mountainous regions consist of a typical tropical and sub-tropical mix of brown and black Ferralit and Podzoluvisols [12]. The (floristic and faunistic) biodiversity of forests in Vietnam was highly ranked worldwide and within Southeast Asia. Apart from Vietnam 's indigenous and endemic features, the flora was found streamlining from China, India - Himalaya, Malaysia - Indonesia, and other regions, including temperate ones $[3,6]$. The diversity of Vietnam's natural forest ecosystems is a determining factor in the diversity of plant and animal species [13]. According to Thin [14], the country hosts around 19,357 plant species (including about 15,000 vascular plants), which belong to 2,524 genera and 378 families. The endemic species account for around $30 \%$ of plants in the north and about $25 \%$ of the total number of plants across the country [15]. Most of the tree species reach a large size and can be used for commercial timber production. The abundance of biodiversity has given the forests of Vietnam tremendous value in economics terms as well as for sciences. Various products are provided by forests such as timber, fuelwood, and fodder; all contributing to the economy. Many forest tree species also provide potential sources for non-timber forest products (NTFPs) such as fruits, nuts, gums, resin, pods, and medicinal plants for human well-being [16,17]. It is estimated that 3,950 vascular plants have now been discovered and used for herbal treatment, which help in curing fatal diseases in Vietnam [18-20].

Deforestation and forest degradation were most notable in the north-central, northeast, central highland, and northwest areas of the nation. These are then converted into different other land uses, mostly into agricultural land to achieve income $[21,22]$. The decline of natural forest areas causes the loss of potential supply of respective goods to local people as potential ecosystem provisioning services and leads to natural disaster risks such as landslides, drought 
or flooding. Therefore, the restoration of the natural forest landscapes for human livelihoods and general well-being is essential. This can be successful with good communication, application of spatial data, and efforts aimed at engaging local people [23-25].

I conducted our study in the mountainous part of the North Central Coast (NCC) of Vietnam where most of the natural forests have been highly degraded and local people have big demands for forest products and ecosystem services provision [26].

\subsection{Research objectives}

The overall objective of this thesis is to characterize the state of natural forests in the research area by applying open source remote sensing technologies and to assess the supply and demand concerning NTFPs as potential forest provisioning services, in order to identify better solutions for appropriate restoration of the natural forest areas.

\subsection{Research questions}

Accordingly, attempts will be made to answer the following specific research questions:

i) What are the influences of topographical conditions on (a) tree species distribution, (b) stand structures, (c) species biodiversity and (d) soil quality?

ii) How is the performance of different optical satellite images for land cover and forest type classification using machine learning algorithms?

iii) How does the potential supply of NTFPs of the natural forests correspond to the demands of local people in the study area and what is awareness of local people concerning the needs for forest improvement?

\subsection{Thesis overview}

This cumulative dissertation includes seven chapters in total which have been elaborated throughout the study process on "Forest Landscape Restoration and Ecosystem Services in A Luoi District, Thua Thien Hue Province, Vietnam". Chapters 3, 4, 5 and 6 have been written as scientific manuscripts, of which chapters 3,4 , and 5 have already been published in academic journals. Chapter 6 was submitted in May and has been under review. 
Chapter 1 presents key information on tropical forests, forest cover and forest land, forest ecological systems, forest landscape classifications, ecosystem provisioning services, current applications of remote sensing in forest classification, and forest landscape restoration in connection to ecosystem services. Furthermore, it spells out the overall research objectives, research questions, the key concepts, and the methodologies of the research.

Chapter 2 introduces the relevant information related to the study area, namely location information, a description of the study area, land-use planning data, general geographical characteristics, vegetation cover data, climate conditions, and soil data, and data on social and economic conditions.

Chapter 3 presents and discusses how topographic conditions of natural forests in Central Vietnam do influence tree species diversity, species distribution, and species composition. Use of Scatter Plot Matrices was applied to evaluate the correlation distribution of tree species, families, stem individuals, and basal area among ranked topographic elevations and slopes. The composition of the most dominant species of the representative plots from each topographic attribute was compared with those of the entire topographic attributes.

Chapter 4 aims to (i) optimize the application of multiple bands of satellite images for land cover classification by using Random Forest algorithms and (ii) assess correlations and regression of vegetation indices of a better-performed land cover classification image. Vertical and horizontal structures of tropical lowland forests in Central Vietnam are considered using Sentinel-2 and Landsat-8 imagery to classify seven land cover classes (of which three forest types were sub-stratified natural forests) and different values of vegetation indices.

Chapter 5 addressed the primary objectives of this study on (i) determining the content of SOC, STN, and pH values for different land-use types and (ii) studying the differences in SOC, STN, and pH under different land-use types, soil depths, and topographic aspects in A Luoi District.

Chapter 6 (i) assessed the forest resources with respect to their potential provisioning services concerning non-timber forest products that can be used as foods, medicine, resins, or 
oil; (ii) evaluated the demands of local people for non-timber forest products (NTFPs) as potential provisioning services from different natural forest types and at different elevations in the research area, by considering the respective importance and satisfaction ranking of different target groups of local people; and (iii) assessed local people's perceptions of natural risks and shortages to evaluate their awareness and readiness for restoring the natural forest landscapes and (iv) to give recommendations as basic implications for restoration of natural forest landscapes in the remote mountainous regions in Vietnam.

Chapter 7 summarizes the main results, their relevance, contributions of the research, and further research recommendations.

The flowchart of the thesis structure is illustrated in figure 1.1.

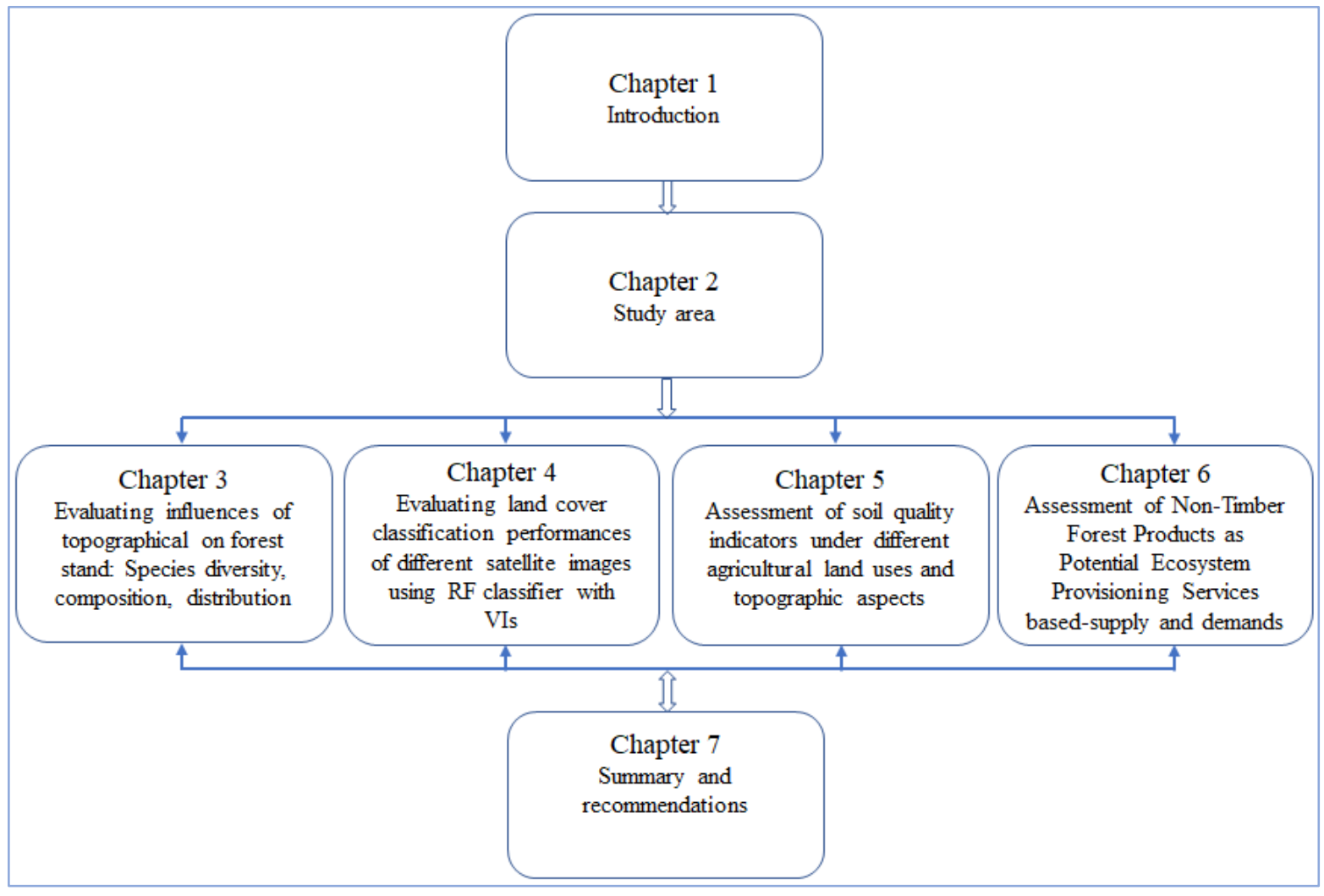

Figure 1.1. Flowchart of the thesis structure

\subsection{Concept, literature review}

According to Maginnis [25], forest landscape restoration was first conceived in 2001 and was defined as "a process that aims to regain ecological integrity and enhance human well- 
being in deforested or degraded forest landscapes". The rate of deforestation and degradation of natural forests in Vietnam in general, and on the North Central Coast of Vietnam in particular, has become a big concern for the Vietnamese Government. Only small natural forest areas have somehow remained undisturbed resulting in tremendous losses of forest products and and a consistent provision of forest ecosystem services to local people living near the forests. Finding the most appropriate and consistent alternatives for a compromised strategic alignment is a challenge when it comes to goods decision making based on scientific and technical perspectives $[27,28]$. The decline of the different natural forest types at different elevations and inclinations of slopes in the A Luoi District poses questions of how to restore the natural forests and their provisioning services for local people who live nearby. Many studies on species diversity, species distribution, and species composition are available [29]. However, they do not consider the influence of geographical conditions such as slopes, elevations, and forest types. Furthermore, only few studies have applied the geographic information system (GIS) and remote sensing (RS) technology. A comparison of the performances of different satellite imageries of Landsat-8 and Sentinel-2 in land cover classification by machine learning algorithms is still missing. The payment for ecosystem services has been implemented with the focus on places where forests are impacted by hydraulic power systems or tourism activities but not for provisioning services of forest ecosystems in connection to different targeted groups of people. Natural forest landscape restoration focuses on opportunities to restore natural forest landscape sites considering perceptions and choices of local people. This is done by analyzing vegetation and land-use types and evaluating ecosystem service potentials based on satellite images to characterize the different land cover types and geographical conditions with respect to their ecosystems provisioning services [30]. In order to assess the natural forests and their potential of ecosystem provisioning services for the local stakeholders in the communes of the A Luoi District, Thua Thien Hue Province, respective satellite data and ground truthing are needed for the forests. The forest products with the most potential are timbers, fuelwood, materials for cultivation tools, and various Non-Timber Forest Products (NTFPs) for medicines, resin or oil, food and handicrafts. All are to be seen as forest 
ecosystem services, which contribute to human well-being. However, logging activities from the natural forests for timber production have been banned since November 2017 [31,32]. Urgent accompanying activities include investigating the current status quo of the forests, the current natural forest management, and the recent provision of ecosystem services to elaborate a sound scientific basis for adapted forest management concepts that halts the ongoing forest landscape deterioration and destruction. Identifying the most adaptive species for restoration of the coastal disaster-prone landscapes is essential.

\subsubsection{Forest cover and forest land classification}

According to Decision No. 1819/QĐ-BNN-TCLN dated May 16, 2017 by the Ministry of Agricultural and Rural Development [33], the total forest land occupied around14,4 Mio ha, accounting for $43 \%$ of the total natural area of the country. 10,2 Mio ha of this forest land were classified as natural forests, equivalent to $31 \%$ of the total natural area. Plantation forest area was 4,3 Mio ha representing $13 \%$ of the total natural area. Forests in Vietnam are classified by functions into three categories: the biggest ratio is production forests (PF) with 6.7 Mio ha occupying $46 \%$ of the total forest area for goods production; the second category is protection forest (WPF) with 4.5 Mio ha equivalent to $32 \%$ of the total forest area for watershed, soil erosion protection; the third category is special use forest (SUF) with 2.1 Mio ha occupying $15 \%$ of the total forest area for biodiversity conservation and research. Additionally, there are other side areas which are used for different purposes such as roads, watch houses, etc. with 1.0 Mio ha and equivalent to $7 \%$ of the total forest area. These are presented in (Table 1.1). 
Table 1.1. National forest area classified based on functions in Vietnam in 2017 (in Mio ha)

\begin{tabular}{|c|c|c|c|c|c|c|}
\hline \multirow[b]{2}{*}{ No } & \multirow[b]{2}{*}{ Forest types } & \multirow[b]{2}{*}{$\begin{array}{c}\text { Total } \\
\text { (Mio. ha) }\end{array}$} & \multicolumn{4}{|c|}{ Forest classification by functions } \\
\hline & & & $\begin{array}{l}\text { Special-Use } \\
\text { Forest }\end{array}$ & $\begin{array}{c}\text { Watershed } \\
\text { Protection } \\
\text { Forest }\end{array}$ & $\begin{array}{l}\text { Production } \\
\text { Forest }\end{array}$ & Others \\
\hline $\mathrm{I}$ & Forestry area & 14,38 & 2,14 & 4,54 & 6,67 & 1,03 \\
\hline 1 & Natural forests & 10,24 & 2,10 & 3,87 & 3,92 & 0,40 \\
\hline 2 & Plantation forests & 4,14 & 8,20 & 0,67 & 2,76 & 0,63 \\
\hline II & Geographical sites & 14,38 & 2,14 & 4,54 & 6,67 & 1,03 \\
\hline 1 & Forests on soiled mountain & 13,2 & 1,84 & 3,94 & 6,46 & 0,96 \\
\hline 2 & Forests on rocky mountain & 0,93 & 0,26 & 0,46 & 0,15 & 0,50 \\
\hline 3 & Swamp forests & 0,20 & 0,33 & 0,12 & 0,45 & 1,0 \\
\hline 4 & Forests on sandy area & 0,46 & 0,46 & 0,19 & 0,15 & 0,12 \\
\hline III & Forest vegetation & 10,24 & 2,1 & 3,87 & 3,92 & 0,40 \\
\hline 1 & Woody forests & 8,84 & 1,86 & 3,41 & 3,24 & 0,32 \\
\hline 2 & Bamboo & 0,24 & 0,29 & 0,65 & 0,13 & 0,20 \\
\hline 3 & $\begin{array}{l}\text { Mixed woody - bamboo } \\
\text { forest }\end{array}$ & 1,16 & 0,17 & 0,39 & 0,54 & 0,57 \\
\hline 4 & Palm forests & 0,48 & 0,15 & 0,16 & 0,35 & 0,13 \\
\hline IV & Forests by volumes & 8,84 & 1,86 & 3,41 & 3,24 & 0,32 \\
\hline 1 & Rich forest & 0,77 & 0,39 & 0,22 & 0,16 & 0,31 \\
\hline 2 & Medium forest & 2,17 & 0,62 & 0,80 & 0,72 & 0,25 \\
\hline 3 & Poor forest & 2,97 & 0,55 & 1,23 & 1,1 & 0,10 \\
\hline 4 & Exhausted forest & 0,59 & 0,91 & 0,22 & 0,25 & 0,30 \\
\hline 5 & Regeneration forest & 2,34 & 0,20 & 0,95 & 1,02 & 0,16 \\
\hline
\end{tabular}

(Source: Decision No. 1819/QĐ-BNN-TCLN dated 16 May 2017 by MARD)

The forest vegetation cover is divided into four categories, namely woody, mixed woody and bamboo, bamboo, and palm forests. With $86 \%$ the woody forest occupies the greatest percentage, followed by mixed woody and bamboo forest with $11 \%$. The ratio of forest functions of the forest vegetation covers $20 \%$ of SUF, and $38 \%$ of both PF and WPF. Forest classification based on the existing standing volume for forest production classified forests into five categories: rich, medium, poor, exhausted, and regeneration forests (Table 1.1). According to the Circular No. 34 [34] from 2009, the PF occupied 37\% of the total area based on forest volume smaller than those in WPF. The ratios of PF in rich, medium, poor, exhausted, and regeneration forests were $21 \%, 33 \%, 37 \%, 42 \%$, and $44 \%$ respectively. The exhausted and regeneration forests had volumes of below $10 \mathrm{~m}^{3} \mathrm{ha}^{-1}$ to $50 \mathrm{~m}^{3} \mathrm{ha}^{-1}$ [35]. The North Central 
Coast of Vietnam (NCC) had a total forest area of 3,1 thousand ha, of which the natural forest was 2,2 thousand ha, and occupied $43 \%$ of the natural area (Table 1.2). Thua Thien Hue has a total natural area of 502.929 ha and the natural forests account for $42 \%$ of that [33].

Table 1.2. Forest land in the North Central Coast of Vietnam in 1000 hectare

\begin{tabular}{lcccc}
\hline \multicolumn{1}{c}{ Provinces } & $\begin{array}{c}\text { Forest area } \\
(\text { ha })\end{array}$ & $\begin{array}{c}\text { Natural forest } \\
\text { (ha) }\end{array}$ & $\begin{array}{c}\text { Plantation forest } \\
\text { (ha) }\end{array}$ & $\begin{array}{c}\text { Cover } \\
(\%)\end{array}$ \\
\hline Thanh Hoa & 626,73 & 394,02 & 232,71 & 52.9 \\
Nghe An & 988,47 & 786,93 & 201,53 & 57.0 \\
Ha Tinh & 325,52 & 218,43 & 107,09 & 52.4 \\
Quang Binh & 591,41 & 480,21 & 111,20 & 67.5 \\
Quang Tri & 254,33 & 143,33 & 111,01 & 49.6 \\
Thua Thien Hue & 312,34 & 212,17 & 100,17 & 56.3 \\
\hline Total area & 3,099 & 2,235 & 864 & 56.5 \\
\hline
\end{tabular}

(Source: Decision No. 1819/QĐ-BNN-TCLN dated 16 May 2017 by MARD)

According to Thai [7], the lowland evergreen broadleaf forests are mostly dominated in Vietnam. Four forest types were introduced by Löschau have been commonly used since in 1961 [36,37]. Those forest types are: (1) primary or less impacted forests, including natural ecosystems whose structure is seen as a product of ecological factors; (2) natural forests have been impacted in different intensities and are divided into three subtypes (high, medium, and minor interventions of humans); (3) natural forests that have been heavily deforested and are being rehabilitated; and (4) forest lands with scattered potential crop trees or land with low vegetation cover. Plantation forest occupies smaller proportion comparing with natural forest due to the narrow shape and high elevations and steep slopes.

\subsubsection{Forest ecosystem classification}

Vietnam has eight ecological forestry regions: Northwest, Northeast, Northern Delta, North Central Coast, South Central Coast, Central Highland, Southeast and Southwest, as well as 47 ecological sub-regions [12]. The two main ecological zones are divided into North and South with the boundary being the Hai Van Pass and the Bach Ma Mountain ranges. The major 
tropical forest formation is composed of various forest species, including primary and secondary forests with different tree species that are essential for predicting the biological productivity [38]. The range of forest vegetation types includes evergreen closed tropical rain forest; semi-deciduous closed tropical humid forest; ever-green broad-leaved forests on limestone; natural needle-leaved forests; dry dipterocarp forest; mangrove forest; swamp forests, and bamboo forests [5,7]. According to Thai [7], the major forest types in Vietnam are moist evergreen forests, deciduous semi-moist evergreen forest, mangrove forest, coniferous forest, broadleaved forests, and montane forests; of which the most dominant are moist evergreen forests. The typical natural ecosystems are evergreen closed tropical rain forests. This vegetation type is very diversified and abundant and is distributed throughout Vietnam from Quang La, Tien Yen of Quang Ninh, Cao Bang, Lang Son, Phu Tho, Yen Bai, Tuyen Quang, Lao Cai, Ninh Binh, Thanh Hoa, Nghe An, Ha Tinh, Quang Binh, Quang Tri, Thua Thien Hue, and Quang Nam provinces, Bach Ma mountain, and Kon Tum, Dak Lak of the Central Highlands. Forest ecosystems are distributed at an area of elevation below $700 \mathrm{~m}$ in the north and less than $1.000 \mathrm{~m}$ a.s.l. in the south, where there is an average temperature of $20-25^{\circ} \mathrm{C}$ and annual rainfall ranging from $1200 \mathrm{~mm}$ to $2500 \mathrm{~mm}$.

\subsubsection{Landscape definitions and planning for human well being}

According to Forman and Godron [39], landscape was defined as a heterogeneous land area composed of a cluster of interacting ecosystems that repeat in similar form throughout, and Turner et al [40] defined landscape as an area that is spatially heterogeneous in at least one factor of interest. Meanwhile, the process of making decisions in different landscapes requires diligent management that effectively develops a consensus of involved local communities in order to achieve prioritized objectives and corresponding choices [41,42]. According to Déjeant-Pons [43], the European Landscape Convention defined landscape as an area that the character results from the action and interaction of natural and human factors, where biodiversity plays a key role in providing benefits [44]. A loss of biodiversity reduces both, quantity and quality of ecosystem services supply as well as the resilience of these systems. Community involvement is considered as a precondition for sustainable landscapes and 
thoroughly promoted as an outstanding tool for successful landscape planning $[45,46]$. Furthermore, providing information on how environmental services flow from different vegetation covers of landscapes, different topographies, etc. is crucial [47-51].

\subsubsection{Landscape Restoration and Ecosystem Services}

Forests play very important roles for not only human beings but also for the Earth 's ecosystems, especially in our current lifetimes. It was reported that there are about $32 \%$ Vietnamese people who depend on forests and forest products for their livelihoods through collecting food, vegetables, fuelwood, and medical plants either for their daily use or for sales [52]. Forests, where assessible, are an essential supply of goods for forest-dependent people. The forest goods that local people are allowed to use as provisioning services of natural forests are regulated and limited under Decision No. 178/2001/QD-TTg. This Decision deals with the use options and obligations of households and individuals related with assigned, leased, or contracted forests and forestry land [53]. Decision No. 49/2016/QĐ-TTg deals with production forest management [54]. The procedures for the exploitation of forest goods are stipulated at the Circular No 21/2016/TT-BNNPTNT dated 28 June 2016 [55]. The Millennium Ecosystem Assessment (MA) defined ecosystem services as the benefits people derive from natural ecosystems [56]. This idea was developed based on the intentions of both scientists and policymakers to manage and enhance the natural environment in a sustainable way [57]. In this context, it was stated that the concept of ecosystem services aimed to encourage nature conservation efforts and sustainable land-use planning in both ecological and social-related aspects of land-use practices [58,59]. The MA 2005 also defined different categories of services, originally: provisioning, regulating, cultural and supporting services, emphasizing that all of them depend on "life on earth", and thus on biodiversity. Provisioning services supply

natural goods, such as food, freshwater, fuelwood, biochemical or genetic resources; while regulating services lead to benefits obtained from natural ecosystem processes, such as climate, disease or water regulations, water purification, and pollination. Cultural services do launch further non-material benefits obtained from ecosystems such as spiritual and religious beliefs, recreation, health, tourism, aesthetic enjoyment, inspiration, perception as well as sense of 
place, and cultural heritage; Supporting services such as soil formation, nutrient cycling or primary production had been introduced as a further category since they are essential for allowing all the afore mentioned ecosystem services; later, they were realized to be implicit characteristics or functions of ecosystem [56] and basic prerequisite to supply ecosystem services. Life itself, as well as the entire human economy, depends on the goods and services provided by earth's natural systems. Humans have changed ecosystems more rapidly and extensively in the last decades than in any comparable period of human history [60]. Natural forest areas have decreased considerably, a fact that affects local people's lives, especially those who live adjacent to and depend on forests for their livelihoods. The decrease causes an imbalanced supply of natural resources compared to their primary living resources $[61,62]$. According to Burkhard and Maes [63], human well-being is benefited from the contribution of ecosystem services. implying that ecosystem services are key elements for policy and decision making at various scales from global to local. Assessing and considering them will allow for numerous most useful applications such as sustainable natural resources management, land-use planning, environmental protection, nature conservation, and landscape restoration, as well as mitigation of natural disasters. Furthermore, non-timber forest products would contribute to sustainable forest management and development of communities because tropical forests contain enormous value per unit of area [64], Ranking such multi-dimensional values of ecosystem services based on natural assets for policy decision making is a complex process $[65,66]$. Restoration of forest landscapes has been conceived with the goal of meeting both, human needs and ecological priorities [67]. The regional supply of ecosystem goods and services is directly determined by the regional ecological integrity. This however is influenced by human actions and decisions such as land-use, land cover change, and technical progress. Human well-being (economic, social, and personal well-being) is based on the benefits derived from the people's actual use of ecosystems, i.e. of potential goods and services they can offer (Figure 1.2). The ecosystem services reflect the demand for goods and services by human society which relates to capacity of supply from ecosystems in which land-use are considered interventions by human well-being. The respective impacts on the ecosystems are manifold and 
can include policies, population dynamics, economic factors, marketing trends, advertising, cultural norms, and governance [47].

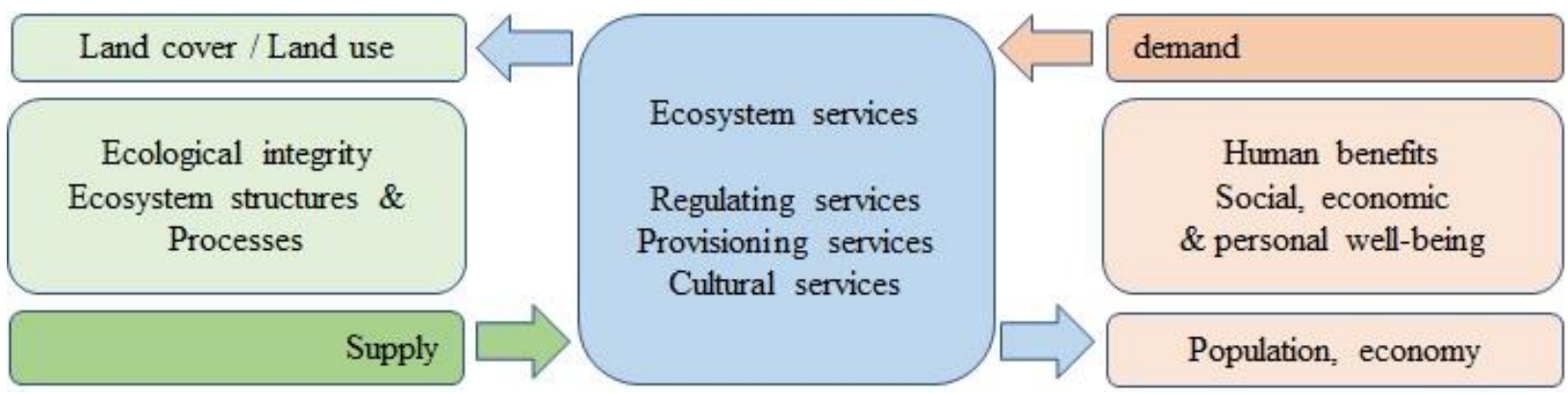

Figure 1.2. Conceptual framework linking ecosystem integrity, ecosystem services, and human well-being as supply and demand sides in human-environmental systems

Understanding the interactions between humans and their natural environment, one needs to address respective theories, concepts, models, as well as perceptions. This requires multidisciplinary approaches and paying special attention to natural and human ecology as well as landscape changes and their implications for modeling an integrated social-ecological economical system [68].

In Vietnam, ecosystem services-related research and programs have increased only in recent years. Most of them are focused primarily on the evaluation of some marketable goods that can undergo economic assessments (such as wood and NTFPs provision, water supply and water regulation, climate-related services such as carbon sequestration, landscapes, and amenities for tourism). The ecosystem provisioning services as a supply source for the local people and their living conditions must be legalized in connection with returning or rebuilding natural resources via forest landscape restoration, some efforts have been realized but there are not many achievements to date [60].

\subsection{Methodological Overview}

The combination of methods for the study is presented in Figure 1.3. 


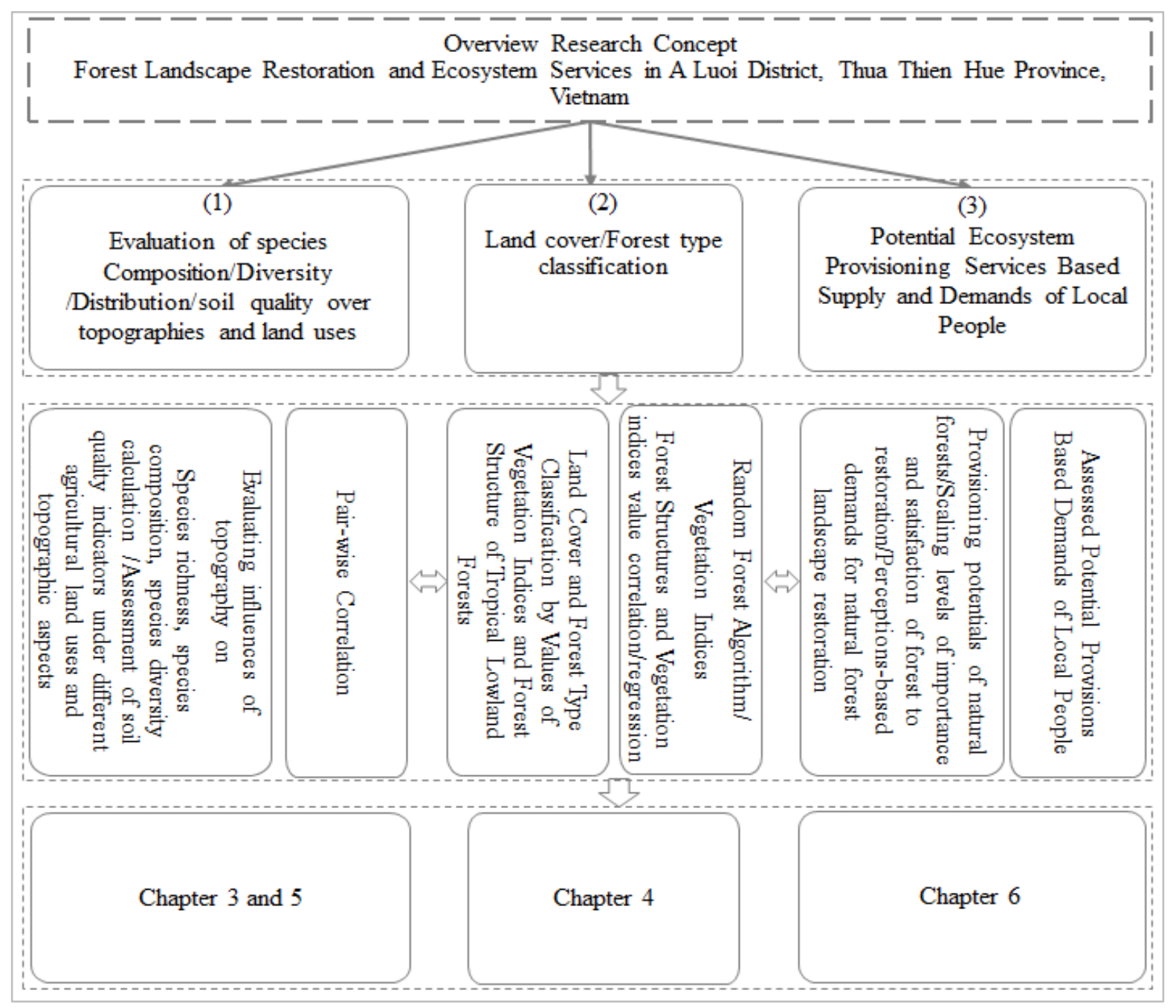

Figure 1.3. Overview of research concept

1.6.1. Forest inventory for ground truthing

The natural forest area was defined using the existing forest status map of the national forest inventory from the Forest Inventory and Forest Planning (FIPI) [35]. The natural forest area was then stratified into three forest types namely: rich forest as undisturbed forest (UF), medium forest as low disturbed forest (LF) and poor forest as disturbed forest (DF) based on the preexisting classifications [34]. Simple random sampling of points using the ArcGIS 10.5 in WGS 84/UTM zone 48N was employed [69,70]. The square sample compartments were laid out in $200 \mathrm{~m}$ intervals from the plot center of the two compartments in order to avoid double-counting and population bias. The square compartments are optimal for practical application because square plots are much easier to implement in the field than the triangle form $[71,72]$. The base 
map and sampled points were transferred to the Global Positioning System (GPS) devices for ground-truth implementation in the field (Figure 1.4).
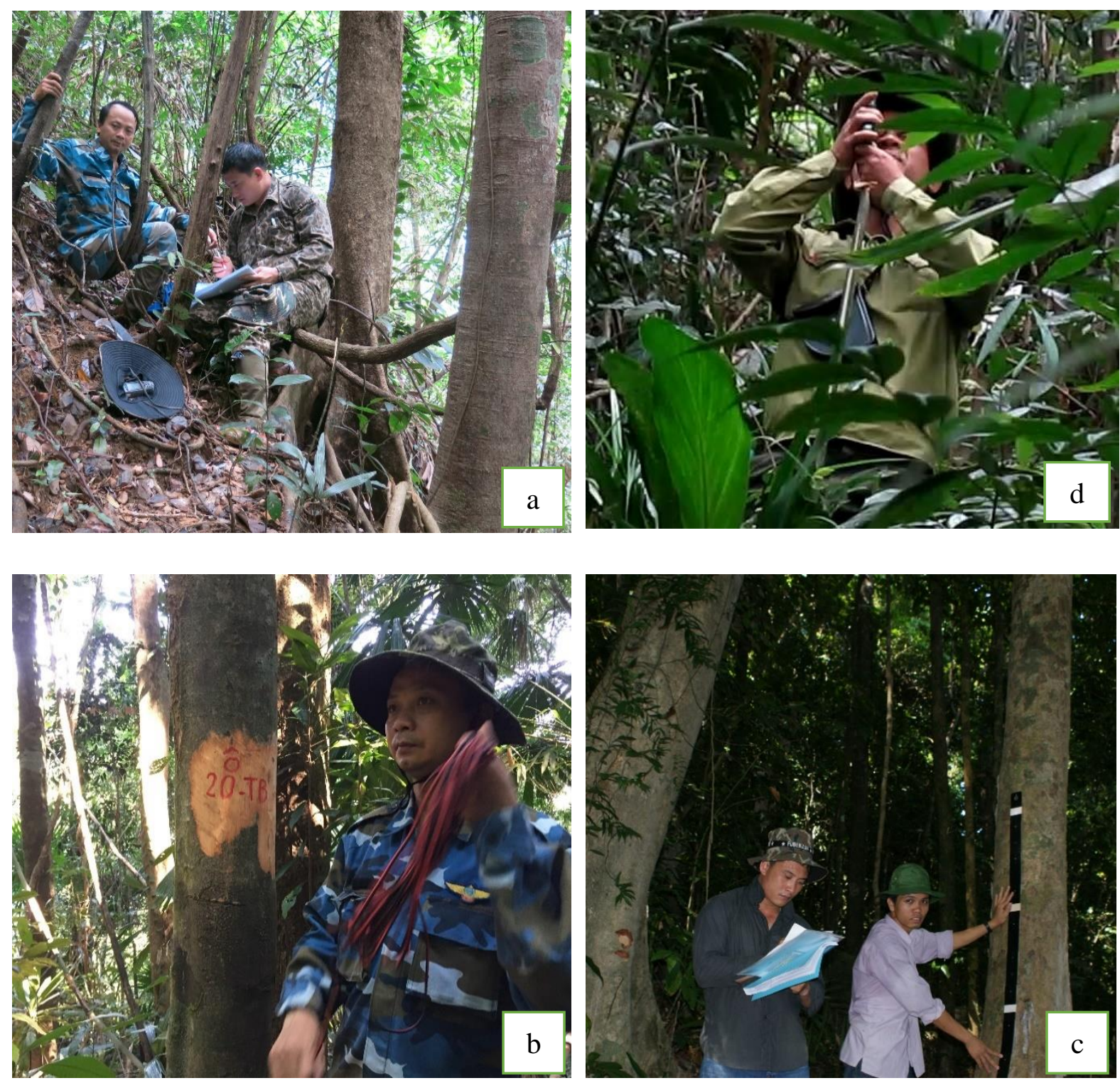

Figure 1.4. Ground truth sampling (a) Positioning plot location, (b) Plot-size arrangement, (c) and (d) tree height measurement.

The appropriate data from a classical forest inventory, which were conducted for different purposes including ground truthing of satellite images, in accordance with conventional forest inventory techniques and added the respective information about NTFP tree species. A total of 90 plots with the size of $30 \times 33.3$ m were randomly sampled in the natural forests of the three forest types (UF, LF and DF). Each forest type had 30 sample plots, two elevations $(\mathrm{H} 1=50$ plots, $\mathrm{H} 2=40$ plots), and two slope degrees ( $\mathrm{S} 1=38$ plots, $\mathrm{S} 2=52$ plots), (Figure 1.5). The top 
height $(\mathrm{H})$ in meters and the diameter at breast height $(\mathrm{DBH})$ of all living trees were recorded. The tree species were recorded in the Vietnamese language in the field by local tree dendrologists and were later translated to their scientific names [73]. The names of all tree species were checked to avoid synonyms in the Plantlist [74]. Coordinates, elevations, and slopes of all sample plots were recorded on-site with GPS devices with reference to the Shuttle Radar Topography Mission - Digital Elevation Model (SRTM - DEM). The overviewed calculation is presented as follows:

\section{a) Sample size and normal distribution}

Tree sample population is expressed as:

The total tree population: $\phi=x_{1}+x_{2}+. .+x_{N}$

The mean value: $\mu=\frac{x_{1}+x_{2}+. .+x_{N}}{N}$

Where: $\mathrm{N}$ is the total number of samples, $\mathrm{x}$ is the tree sample.

Normal distribution of tree height and tree diameter are expressed as:

$$
f(x)=\frac{1}{\sigma_{x} \sqrt{2 \pi}} e^{-\frac{1}{2}\left(\frac{x-\mu}{\sigma}\right)^{2}}
$$

Where: $\mu$ is the mean

$\sigma$ is the standard deviation

The distribution of the number of stems per diameter class gives an insight into the forest stand structure [75]. These values are usually presented in the graphical form [1]. The distribution of the number of trees in relation to diameter is a useful tool to describe forest structure [76]. The distribution of stems per diameter class is important and the distribution of species per diameter class of each forest type and the geographical features are necessary to evaluate the changes in forest stands [37].

Stand height distribution expresses the height of tree species in different stories, usually upper story (US), middle story (MS), and lower story (LS) [1]. 


\section{b) Individual tree}

Parameters of each individual tree were computed by:

- Basal area in $\mathrm{m}^{2}$

$$
g_{i}=\frac{\pi}{4} d_{i}^{2}
$$

- Volume of each tree individual $\mathrm{m}^{3}$

$$
v_{i}=0.0002326 * d_{i}^{2.3457}
$$

Where: $d_{i}$ is the diameter at breast height of the individual tree measured at $1.3 \mathrm{~m}$

\section{c) Stand parameter calculation}

The stand parameters such as the density of stems ha- ${ }^{-1}$, basal area $\mathrm{ha}^{-1}$, volume $\mathrm{ha}^{-1}$ were calculated. The mean height is also used to estimate the stand volume since the mean stand height $\bar{h}$ is a useful target variable for early analysis and evaluation of stand structures [69].

- Density of stem ha ${ }^{-1}$

$$
N_{h a}=N_{i} * \frac{10000}{S_{i}}
$$

Where:

$N_{h a}$ is the number of trees $\mathrm{ha}^{-1}$

$N_{i}$ is the number of trees per sampled plot

$S_{i}$ is the area of the sampled plot.

- Forest inventory parameters $\left(\mathrm{m}^{2} \mathrm{ha}^{-1}\right)$

$$
G_{h a}=\sum_{i=1}^{n}\left(g_{i} \frac{10000}{S_{i}}\right)
$$

Where:

$G_{h a}$ is the total basal area ha ${ }^{-1}$

$g_{i}$ is the basal area of each individual tree.

$S_{i}$ is the area of the sampled plot.

- Volume per hectare $\left(\mathrm{m}^{3} \mathrm{ha}^{-1}\right)$

$$
V_{h a}=\sum_{i=1}^{n}\left(v_{i} \frac{10000}{S_{i}}\right)
$$

Where:

$V_{h a}$ is volume of forest stand

$v_{i}$ is volume of each tree individual 
- Mean diameter

The mean diameter was calculated based the arithmetic mean diameter of the forest stand $\bar{d}$

$$
\bar{d}=\frac{\sum_{i=1}^{N} d_{i}}{N}
$$

Where: $\quad d_{\mathrm{i}}=$ diameter of the individual tree

$N=$ total number of trees of the stand

- Mean height

The mean diameter was calculated based on the arithmetic mean diameter of the forest stand $\bar{h}$

$$
\bar{h}=\frac{\sum_{i=1}^{N} h_{i}}{N}
$$

Where: $\quad h_{\mathrm{i}}=$ diameter of the individual tree

$N=$ total number of trees in the stand

- Standard error of means

The standard error is the measure of the variability of estimation and it is the square root of the error variance [72]. The parameters of the population were estimated from the results of each sample plot. However, the precision of an estimate depends on the sampling method, sample size, and the variation within the population of investigated data [69]. The standard error of the mean (and the coefficient of variation of the mean) is used to evaluate an investigation's reliability and to predict the precision of the vegetation assessment. If the standard error does not exceed the desired value, it implies that the given number of samples and the sample size is sufficient [78]. According to Akça [79], standard error $\left(S_{\bar{x}}\right)$ and standard error of the mean $\left(S_{\bar{x}} \%\right)$ can be calculated as follows:

$$
S_{\bar{x}}=\frac{S_{x}}{\sqrt{n}}
$$

Where: $\quad S_{\mathrm{x}}=$ standard deviation

$$
\mathrm{n} \quad=\text { number of samples }
$$

The standard error of the mean as a percentage $\left(S_{\bar{x}} \%\right)$ was calculated as follows:

$$
S_{\bar{x}} \%=\frac{S_{\bar{x}}}{\bar{x}} \cdot 100
$$

Where: $\quad \bar{x}=$ mean

\section{d) Tree species composition}


The Important Value Index (IVI) designed by Curtis and McIntosh [80] is used to rank the importance of species. Species composition and stand structure of rich, medium, and poor forests differ from each other. Assessing the stand differences (based on the floristic composition and the ecological importance of species) is the most well-known method used to compare the ecological significance of a species in a given forest type. The same (or at least similar) stand composition and structure, site requirements, and comparable dynamics can be obtained if the IVI of the species is more or less the same [1]. The Importance Value Index was calculated by adding relative abundance, relative dominance, and relative frequency of each species [81]. The Importance Value Index lists the top ranked species based on their IVI of the forest stands.

Where: $\quad$ Species dominance $=$ basal area $\left(\mathrm{m}^{2} / \mathrm{ha}\right)$

Species abundance $=$ number of individuals per ha

Species frequency $=\%$ of subplots in which the species is represented

- Species dominance

$$
\text { Dominance }=\frac{\text { Total basal area of the species }}{\text { Total basal area of all species in all plots of each forest stand }}
$$

- Species abundance

$$
\text { Abundance }=\frac{\text { Number of tree individuals of the species }}{\text { Total number of all tree individuals of each forest stand }}
$$

- Species Frequency

$$
\text { Frequency }=\frac{\text { Number of plots in which species occurs }}{\text { Total number of all plots in each forest stand }}
$$

Species Importance Value Index $=$ relative dominance + relative abundance + relative frequency [81].

\section{e) Tree species richness and diversity}

In general, higher values of biodiversity (as described by indices such as species diversity and species dominance) indicate larger species richness [82].

The Shannon Index $(\mathrm{H})$ of species was calculated based on [83]: 


$$
\text { Shannon Index }(H)=-\sum_{i=1}^{s} p_{i} \ln \left(p_{i}\right)
$$

where; $\mathrm{p}^{\mathrm{i}}$ is the proportion of $\mathrm{S}$ made up of the $\mathrm{i}^{\text {th }}$ species.

The Evenness (Eq) calculation is based [84] on the species equitability and is proportional to the individual based number of species. It expresses the information content per individual within an infinite population at:

$$
E q=\frac{H}{\ln (S)}
$$

where $\mathrm{H}$ is Shannon Index and $\ln (\mathrm{S})$ is the natural logarithm of the total number of species in the attribute.

\section{f) Correlation coefficient}

The linear relation between two variables is defined by a given correlation coefficient in a set of observations $\left(x_{1}, y_{1}\right),\left(x_{2}, y_{2}\right), \ldots\left(x_{n}, y_{n}\right)$ and is denoted in a formula:

$$
r=\frac{1}{n-1} \sum\left(\frac{x-\bar{x}}{S_{x}}\right)\left(\frac{y-\bar{y}}{S_{y}}\right)
$$

The value of the correlation coefficient ranges between -1 and 1 . It means that the correlation can either negative or positive within that range. 


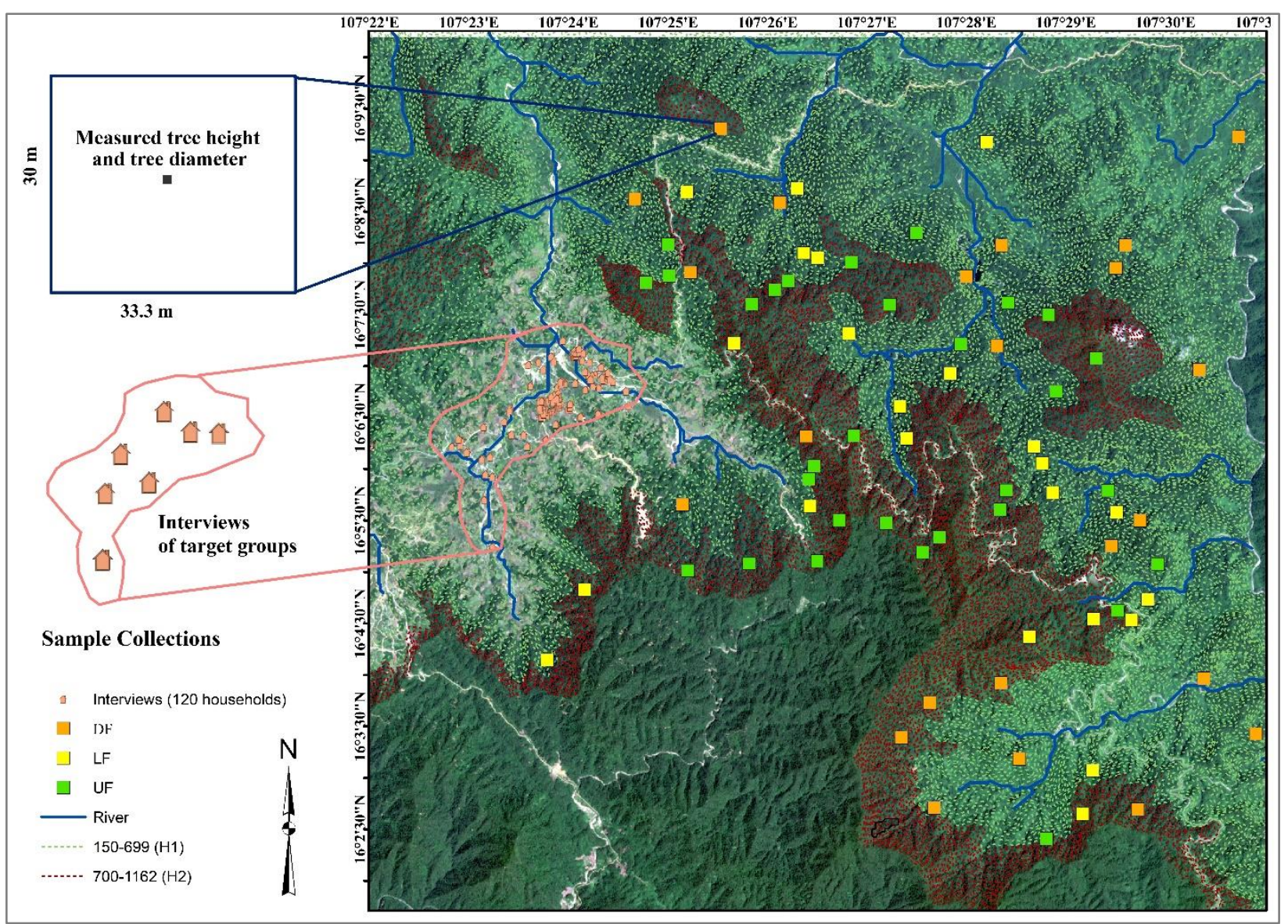

Figure 1.5. Study area and lay-out of ground truth sample plots

Data sample arrangement for the forest types: UF = Undisturbed forest (green), LF = Less disturbed forest (yellow), DF = Disturbed forest (orange); For elevations above sea level: $\mathrm{H} 1=150-699 \mathrm{~m}$ indicated by the light-blue dotted line, and $\mathrm{H} 2=700-1162 \mathrm{~m}$ indicated by the dark-brown dotted lines and the area for household interviews in the light-orange circle where local people have been inhabited.

\subsubsection{Remote sensing options}

A forest monitoring system must be considered as a fundamental tool to support the management of landscapes, land uses, ecosystems, as well as biodiversity for multiple production purposes at the national and local scales [85-89]. The use of remote sensing data (especially in the tropical countries) for mapping land cover and land uses, the management of natural resources, monitoring processes, and strategy development is increasing. Yet, many questions have not been solved, especially concerning discrete classes or continuous land cover attributes [90]. Remote sensing images provide potential information on tropical forest 
landscapes and land use types [91]. However, ground-based assessment (ground truthing) is essential for applying remote sensing imagery and enhancing land cover and land use classification [92]. In this respect, one of the most important parameters of the forest is its structure, which provides information to improve the estimation of forest stand variables [93]. The structure of a forest reflects the spatial distribution. It is an important factor in forest ecological processes, which affect the occurrences of taxa and the resistance of the stands to disturbance [94,95]. Sentinel-2 imagery from the European Space Agency (ESA) and Landsat8 imagery from the United States Geological Survey (USGS) are two important open data sources. They were developed to support vegetation mapping, land cover mapping, land use mapping, environmental monitoring, among other uses such as biophysical and geographical resources mapping $[96,97]$. Sentinel-2 imagery measures reflected radiance within 13 spectral bands, whereas Landsat- 8 has eleven bands. Multi-spectral bands help to map the vegetation types at a regional scale $[98,99]$. The use of vegetation indices from remote sensing images contributes to effective land use planning as well as informed natural resources management and policymaking in general [100-103]. The overview of spatial data processing is presented below:

\section{a) Atmospheric correction of satellite images}

The satellite images were acquired at the time of the ground truth-data collection and were downloaded from the United States Geological Survey [104]. All bands were converted to radiance, top-of-atmosphere (TOA) reflectance, and surface reflectance and resampled to 10 m x 10 m resolution using nearest neighbor resampling method was applied in this study $[105,106]$. The Shuttle Radar Topography Mission (SRTM) Digital Elevation Model (DEM) referencing was performed before any further processing and calculation, except on band 10 of Sentinel- 2 imagery and bands 8 and 9 of Landsat- 8 imagery. The imagery was atmospherically corrected by using the Sen2Cor version 2.8 tool in compatibility with the platform of Sentinel Application Platform (SNAP) toolbox [107] to perform the corrected image as Level-1C output product which was further resampled to a relevant resolution. The Simplified Method for Atmospheric Corrections of satellite measurements can also be applied with the described 
algorithm for the atmospheric correction of satellite imagery in the solar spectrum introduced by Rahman [108].

$$
S=\frac{1-1}{\alpha_{0}-\alpha_{1} * \delta_{550}}
$$

Where: the spherical albedo, $\mathrm{S}$, is expressed as a function of the aerosol optical depth at $550 \mathrm{~nm}$ and $\alpha_{0}$ and $\alpha_{1}$ are parameters that need to be determined for a given spectral band and aerosol model.

The conversion from TOA radiance $\left(L_{\mathrm{TOA}}\right)$ to TOA reflectance $\left(R_{\mathrm{TOA}}\right)$ is expressed:

$$
R_{T O A}(\lambda)=\frac{\pi L_{T O A}(\lambda)}{E_{0}(\lambda) \cos (\theta)}
$$

Where: $E_{0}$ and $\theta$ are the solar spectral irradiance and the sun zenith angle, respectively.

For Landsat-8, the conversion digital number (DN) to radiance is expressed:

$$
L_{\lambda}=\operatorname{gain} * D N+\text { bias }
$$

Where: $\quad \mathrm{DN}=$ digital number

gain = gain value for a specific band

bias $=$ bias value for a specific band

And the spectral radiance scaling is expressed:

$$
\begin{gathered}
L_{\lambda}=\left(\left(L M A X_{\lambda}-L_{\lambda} M I M_{\lambda}\right) /(Q C A L M A X-Q C A L M I N)\right) *(Q C A L-Q C A L M I N) \\
+L_{\lambda} I N_{\lambda}
\end{gathered}
$$

Where: $\mathrm{L}_{\lambda=\text { cell value as radiance }}$

QCAL $=$ digital number

$\operatorname{LMIN}_{\lambda}=$ spectral radiance scales to QCALMIN

$\operatorname{LMAX}_{\lambda}=$ spectral radiance scales to QCALMAX

QCALMIN = the minimum pixel value

QCALMAX $=$ the maximum pixel value

The radiance to TOA reflectance according to the Landsat user handbook expresses:

$$
\rho_{\lambda}=\frac{\pi * L_{\lambda} * d^{2}}{\operatorname{ESUN}_{\lambda} * \cos \theta_{s}}
$$

Where: $\rho_{\lambda}=$ Unitless planetary reflectance 
$\mathrm{L}_{\lambda}=$ spectral radiance

$\mathrm{d}=$ Earth-Sun distance

$\mathrm{ESUN}_{\lambda}=$ mean solar irradiances

$\theta_{\mathrm{s}}=$ solar zenith angle

The resampling of the Sentinel-2 imagery was done by using SNAP and that of Landsat- 8 by using ArcGIS 10.5.

\section{b) Land cover classification algorithms}

Many studies have tried to optimize the use of information from remote sensing (RS) by using machine learning algorithms such as: support vector machine, k-Nearest Neighbor, and Random Forest; all of which are non-parametric classifiers to classify land cover [109-111]. Maps of land cover can also be made from different sources of remote sensing data such as multispectral imagery, hyperspectral imagery, and radar aperture [112-115]. Of those the algorithms mentioned above, Random Forest (RF) is the most used artificial methodologies for land cover and land use classification, according to Raczko and Zagajewski [116] and Breiman [117]. The Random Forest classifier is a set of combinations of tree classifiers and features in selection measures used for trees. It uses the Gini Index as an attribute selection measure, which measures the impurity of an attribute concerning land cover classes. For a given training set D, one selects the respective pixel at random which belongs to a class $\mathrm{K}_{i}$. The Gini index can be expressed:

$$
\sum \sum_{j \neq i}\left(f\left(K_{i}, D\right) /|D|\right)\left(f\left(K_{j}, D\right) /|D|\right)
$$

Where: (f $\left(\mathrm{K}_{\mathrm{i}} \mathrm{D}\right) /\left(|\mathrm{D}|\right.$ is the probability that the selected case belongs to class $\mathrm{K}_{\mathrm{i}}$

The number of features used at each node to generate a tree and the number of trees to be grown are two user-defined parameters required to generate a Random Forest classifier. At each node, only selected features are searched for the best split. Therefore, the classifier of Random Forest contains $N$ trees, where $N$ is the number of trees to grow, that can be any value of a random pixel defined by the user to classify a new dataset and select the most voted trees [118]. The sampling classification was done for seven different land use and land cover classes that 
are Residential and Constructions (RC); Water and River (WR); Agriculture (Agr); Slash and Burnt (SB); Disturbed Forest (DF); Low Disturbed Forest (LF) and Undisturbed Forest (UF) [119].

\section{c) Vegetation indices and forest structures}

Spatial resolution is dependent on the particular spectral bands, but $10 \mathrm{~m}$ resolution of Sentinel-2 imagery can provide feasible phenological values for different landscapes [120]. Several studies applied multi-spectral bands of Landsat- 8 imagery with a resolution of $30 \mathrm{~m}$ to assess vegetation dynamics [121]. Vegetative cover via the Vegetation Index (VI) is one of the most important variables for vegetation cover classification since VI is captured from the radiometric biophysical derivation and vegetation structure. High-resolution images with the support of promising techniques can potentially capture forest status data but may not obtain data on productivity, which can partially reflect forest structure [93]. The values of ten VIs were calculated from different combinations of spectral bands (mostly from NIR and red bands) and were derived from the better-performed images [122-124]. The study compares the values of vegetation indices between the ground truth data and the training sample plots of VIs from the best-performing satellite images. The study also evaluated the correlation and regression of vegetation indices in terms of vertical and horizontal structures in the tropical lowland forests, based on the above-mentioned two sensors.

\subsubsection{Relevance of ecosystem services and landscape restoration}

The Millennium Ecosystem Assessment [56] stated that ecosystem services provided by forests have drawn enormous attention and concerns from different players such as institutional organizations, the media, the public, and private interest groups. It emphasized further that $60 \%$ of the ecosystem services in the world were already degraded. According to FAO [125], global forest degradation and deforestation rates remain alarming. Even though the forest cover increased in recent decades, the decline of forest quality accounted for big portions of forest degradation while deforestation rates remained high globally. The quality loss of also affects forest habitats and biodiversity, as well as the provision of ecosystem services [126,127]. Ecosystem service integrity have been considered as great global concerns, especially by 
scientists and governors. The loss of forest biodiversity in Vietnam has been influenced by the exhausting harvest of forest products (including non-timber forest products), land-use changes, and the lack of a sustainable management $[58,128]$. The study of De Groot showed that among the values of ecosystem services in 10 different biomes, tropical forests occupied $14 \%$ of the total, equivalent to around $10.000 \mathrm{USD} /$ ha/year-2007 [129]. The supply of ecosystem services from forests could particularly provide people who live close to the natural forests. They could contribute to the economic and living conditions of the local communities where innumerous lives rely on the respective forest products, aside from their small paddy land which cannot produce sufficient food quantities $[130,131]$.

Ecosystem restoration is seen as key to ensure the sustainable use of natural resources and secure the adaptability of natural systems to disasters and climate change. According to the handbook on the restoration opportunities assessment methodology [132], the restoration options for forest landscapes can be assessed at both, national and sub-national levels. The principles for restoration involve everything from entire landscapes to individual sites. By focusing on habitats and their functionality sustainable generation of forest products and ecosystem services can be achieved. This requires the involvement of communities and the promotion of forest landscape restoration strategies, with the goal of avoiding the declination of natural forest cover, the loss, and the conversion of forests. However, only few studies have attempted to establish empirical data for the dependence of local communities on nearby natural forest areas so far.

\subsubsection{Assessment of NTFP potential supply and demand}

A questionnaire was developed and used for surveying the land-use perspectives of land users and related stakeholders in communes near the natural forest landscape. The survey was conducted in October 2017 (Figure 1.6). A total of 120 households were randomly chosen based on pre-selected villages where local people's lives are known to dependent on natural forest resources to some extent. The surveys were conducted in a mountainous area in A Roang Communes and considered different target groups such as gender, income, age-class, and education levels. The objective was to identify NTFP supply in study ecosystem provisioning 
services related to a cluster of indicators of goods [133-135]. As documented in Figure 1.6 the survey was conducted by a team (a) on household level (b), supported by groups of household consultancy (c), and accompanied by a forest management board (d).
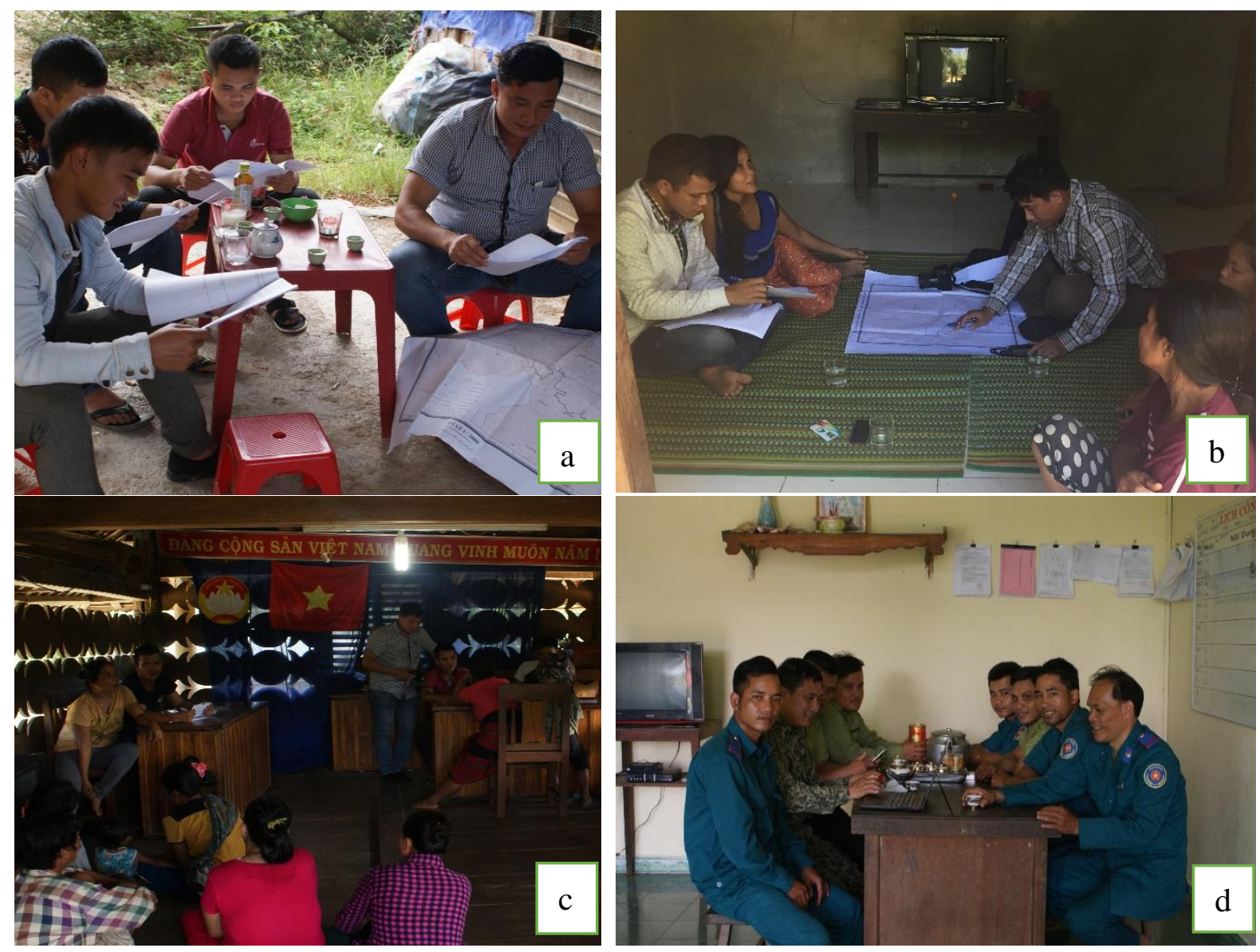

Figure 1.6. Ecosystem provisioning services survey (a) giving introduction and training to the team, (b) household interview, (c) group interview, (d) discussion with forest rangers.

The clustered sample of the interviewed households is denoted in formula (24). The necessary sample size of the interviewed households was calculated based on Slovin's formula $[136,137]$.

$$
n=\frac{N}{1+N e^{2}}
$$

Where: $\mathrm{n}$ is the number of samples;

$\mathrm{N}$ is the total number of households in the area

e is the margin of error at $5 \%$ equivalent to the assumed value of confidence at $95 \%$ where the estimates of indicator to be measure assuming is of around $26 \%$. 
Where natural forests have been seriously degraded, local people have faced a shortage of forest products as the natural ecosystem capital declined [26]. As a result the flows of ecosystem provisioning services from the natural forests got lower [138], a fact which causes an imbalance between the NTFPs supply and the demand of local people on ecosystem services. Participatory Rural Appraisal (PRA) was used to obtain the information on cultivational practices as well as the perceived importance of forests, satisfaction obtained from the forest, and general observations by local people related to ecosystem provisioning services $[139,140]$.

The relationship between the potential of natural forest ecosystems to offer provisioning services and the needs for landscape restoration is illustrated in Figure 1.7. Where the planning and management of natural forest landscape restoration was in focus, the demands and supply of ecosystem provisioning services are in balance [141]. Therefore, restoration of the natural forest landscape and proper management are considered to be crucial for the preservation and enhancement of the sustainable capacity of ecosystem services.

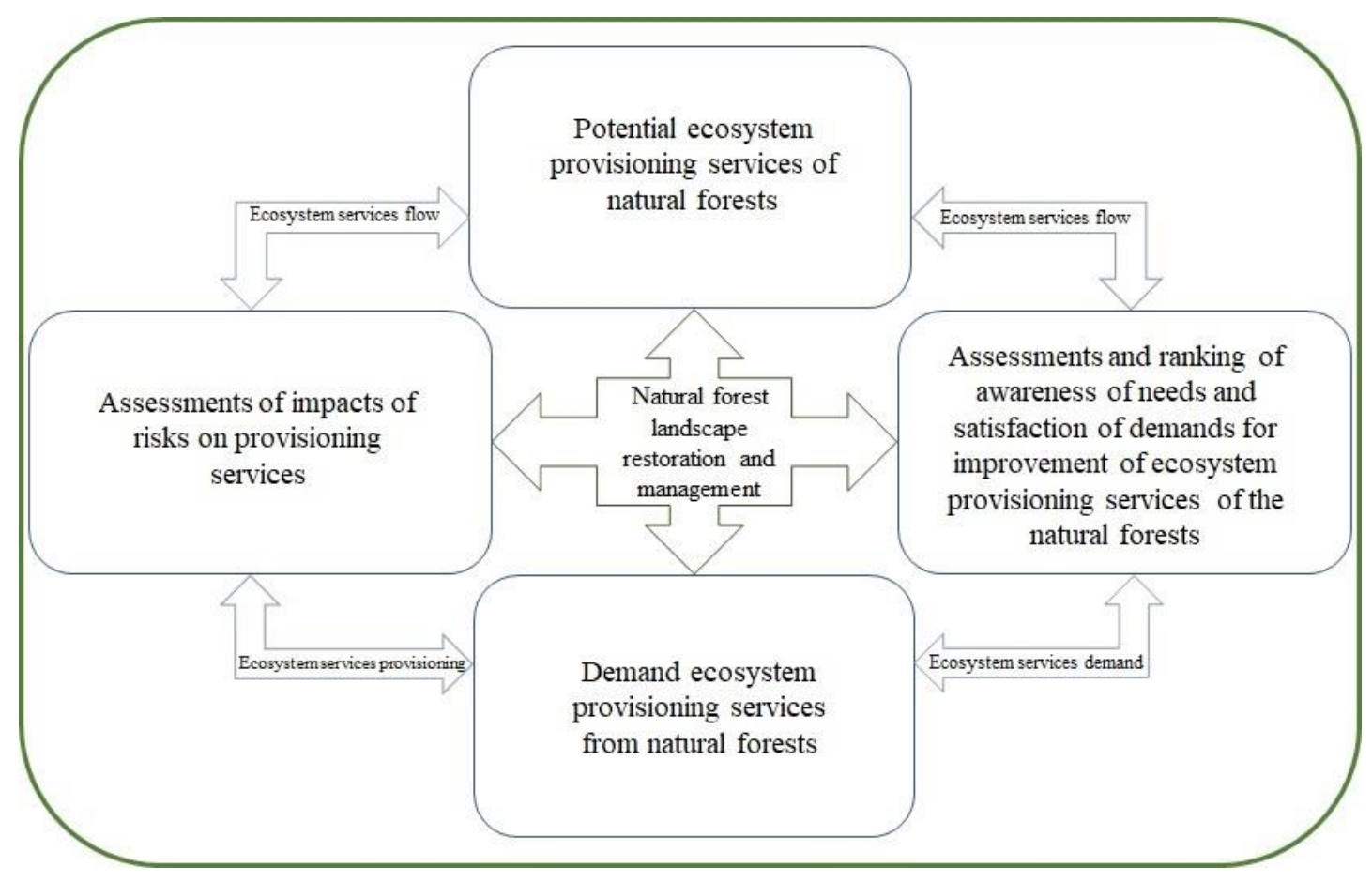

Figure 1.7. Relationship among potential provisioning services of natural forests, supply and demand assessment for landscape restoration planning and management

The assessment of perceptions of local people was obtained with a participation and observation-based participatory approach throughout the process of forest landscape 
restoration. In this respect, the pre-assessment of local perceptions concerning the importance of forests and the satisfaction obtained from natural forests, combined with the perceptions of potential ecosystem services was a critical part of this study. It can be very useful to balance supply and demand and support raising awareness of environmental contributions to human well-being.

\subsection{References}

1. Lamprecht, H. Silviculture in the tropics: Tropical forest ecosystems and their tree species: possibilities and methods for their long-term utilization; Deutsche Gesellschaft für Technische Zusammenarbeit GTZ: Eschborn, 1989.

2. Vaglio Laurin, G.; Puletti, N.; Hawthorne, W.; Liesenberg, V.; Corona, P.; Papale, D.; Chen, Q.; Valentini, R. Discrimination of tropical forest types, dominant species, and mapping of functional guilds by hyperspectral and simulated multispectral Sentinel-2 data. Remote Sensing of Environment 2016, 176, 163-176, doi:10.1016/j.rse.2016.01.017.

3. Pham, D. Demography of threatened tree species in Vietnam; Utrecht University, 2006.

4. Allaby, M.; Day, T.; Moore, P.D. Biomes of the Earth; Chelsea House: New York, 2006.

5. FAO. Global Ecological Zoning for the Global Forest Resources Assessment. Final Report, 2000.

6. Thai, V. Forest vegetation cover of Vietnam, 2nd ed.; Science and Technics Publishing House: Ha Noi, 1978.

7. Thai, V. Ecosystems of tropical forests in Vietnam; Science and Technics Publishing House: Ha Noi, 1998.

8. Park, C.C. Tropical rainforests; Routledge: New York, 2003.

9. Approval and Announcement of National Land Classification 2018; MONRE, Ed.; Ministry of Natural Resources and Environment, Vietnam: Ha Noi, 2019.

10. Van, S.; Boyd, W.; Slavich, P.; Van, T. Agriculture and Climate Change: Perceptions of Provincial Officials in Vietnam. J. Basic Appl. Sci. 2015, 11, 487-500, doi:10.6000/19275129.2015.11.66.

11. Toan, P.N.; Dac, P.T. The climate of Vietnam. Science and Technology, Hanoi (in Vietnamese) 1993.

12. Lung, N.N.; Quat, N.X.; Lien, T.V.; Que, N.D.; van Con, T.; Ky, N.D.; Cam, L.V. Final Report on Forest Ecological Stratification in Vietnam. Ha Noi, 2011,136.

13. Lan, P.N.; Hong, P.N.; Hung, T.V.; Thin, N.N.; Chan, L.T. Natural Forest Ecosystems Viet Nam. Ministry of Agriculture and Rural Development of Vietnam: Hanoi, Vietnam 2006.

14. Thin, N.N. Flora and species diversity: Hệ thực vật và đa dạng loài. $N X B Đ H Q G H a ̀$ Nội 2008, 146. 
15. Chan, L.T.; Ty, N.; Tu H.; Nhung, H.; Phuong, D.; Van, T.T. Some basis characters of Vietnam flora. Science and Technics Publishing House; Ha Noi, 1999.

16. Wetterwald, O.; Zingerli, C.; Sorg, J.-P. Non-timber Forest Products in Nam Dong District, Central Vietnam: Ecological and Economic Prospects. Schweizerische Zeitschrift fur Forstwesen 2004, 155, 45-52, doi:10.3188/szf.2004.0045.

17. Yaduv, V.K.; Srivastava, A.K.; Khare, P.K. Tropical Forest and Ecosystem Services in Indian Context. Curr. World Environ 2018, 13, 151-158, doi:10.12944/CWE.13.1.14.

18. Zahra, W.; Rai, S.N.; Birla, H.; Singh, S.S.; Rathore, A.S.; Dilnashin, H.; Keswani, C.; Singh, S.P. Economic Importance of Medicinal Plants in Asian Countries. In Bioeconomy for Sustainable Development; Keswani, C., Ed.; Springer Singapore: Singapore, 2020; pp 359-377.

19. Bioeconomy for Sustainable Development; Keswani, C., Ed.; Springer Singapore: Singapore, 2020.

20. Woerdenbag, H.J.; Nguyen, T.M.; van Vu, D.; Tran, H.; Nguyen, D.T.; van Tran, T.; Smet, P.A.G.M. de; Brouwers, J.R.B.J. Vietnamese traditional medicine from a pharmacist's perspective. Expert Rev. Clin. Pharmacol. 2012, 5, 459-477, doi:10.1586/ecp.12.34.

21. Forests, inclusive and sustainable economic growth and employment; José, J.C.A., Ed. Forests and sustainable development goals. United Nations Forum on Forests, 2019.

22. Khuc, V.Q.; Tran, B.Q.; Meyfroidt, P.; Paschke, M.W. Drivers of deforestation and forest degradation in Vietnam: An exploratory analysis at the national level. Forest Policy and Economics 2018, 90, 128-141, doi:10.1016/j.forpol.2018.02.004.

23. Boissière, M.; Sheil, D.; Basuki, I.; Wan, M.; Le, H. Can engaging local people's interests reduce forest degradation in Central Vietnam? Biodivers Conserv 2009, 18, 2743-2757, doi:10.1007/s10531-009-9627-1.

24. Paudyal, K.; Samsudin, Y.B.; Baral, H.; Okarda, B.; Phuong, V.T.; Paudel, S.; Keenan, R.J. Spatial Assessment of Ecosystem Services from Planted Forests in Central Vietnam. Forests 2020, 11, 822, doi:10.3390/f11080822.

25. Maginnis, S.; Rietbergen-McCracken, J.; Sarre, A. The forest landscape restoration handbook; Routledge, 2012.

26. Thai, H.H.D. Restoration of degraded natural forests in the North Central Coast region of Vietnam, University of Freiburg.

27. Triantaphyllou, E. Multi-Criteria Decision Making Methods. In Multi-criteria Decision Making Methods: A Comparative Study; Pardalos, P.M., Hearn, D., Triantaphyllou, E., Eds.; Springer US: Boston, MA, 2000; pp 5-21.

28. Triantaphyllou, E.; Parlos, P.M. Multi-criteria decisio-making methods: A comparative study; Kluwer Academic Publishers: Dordrecht, 2010, 320.

29. Ito, S.; Nakayama, R.; Buckley, G. Effects of previous land-use on plant species diversity in semi-natural and plantation forests in a warm-temperate region in southeastern Kyushu, Japan. Forest Ecology and Management 2004, 196, 213-225, doi:10.1016/j.foreco.2004.02.050. 
30. Chazdon, R.L.; Uriarte, M. Natural regeneration in the context of large-scale forest and landscape restoration in the tropics. Biotropica 2016, 48, 709-715, doi:10.1111/btp.12409.

31. Issuing detailed plan of GoV on implementing the Directive No. 13-CT/TW dated 12 January 2017 of the Secretariat of the Central Committee Communist Party on increasing Party leadership in forest management, protection and development; GoV, Ed.;

Government of Vietnam: Hanoi, 2017.

32. Announcement on implementing conclusions of Prime Minister at the national conference on increasing forest management, protection and measures for the near future; GoV, Ed.; Government Office: Hanoi, 2017.

33. Forest area classified based functions of Vietnam; MARD, Ed.; MARD: Hanoi, 2017.

34. Circular No. 34/2009 / TT-BNNPTNT on the criteria for determining and classifying forests, 2009.

35. Circular 33/2018/TT-BNNPTNT on Regulation on Forest Inventory and Monitoring; MARD, Ed.; MARD: Hanoi, 2018.

36. Phuong, V.T.; Anh, H.V.; Lung, N.N.; Sam, D.D.; Ky, N.D.; Lien, T.V. Forest ecological stratification in Vietnam. Techniques and Science Publishing House, Hanoi, Vietnam 2012, 139.

37. Hung, N.T. Dynamics and Management of the Natural Forests in Quang Ngai, Southern Coastal Centre, Vietnam. Msc Dissertation, Göttingen, 2010.

38. Vu, T.P.; Nguyen, N.L.; Do, D.S.; Nguyen, X.Q.; Tran, V.L.; Tran, V.C.; Nguyen, D.K.; Lai, V.C.; Do, H.T.; Ngo, T.G. Final report on forest ecological stratification in Vietnam. UN-REDD Program Vietnam: Hanoi, Vietnam 2011.

39. Forman, R.T.T.; Godron, M. Landscape ecology; Wiley: New York, Chichester, 1986.

40. Turner, M.G. Landscape Ecology: What Is the State of the Science? Annu. Rev. Ecol. Evol. Syst. 2005, 36, 319-344, doi:10.1146/annurev.ecolsys.36.102003.152614.

41. Hartnett, T. Consensus-oriented decision-making: The CODM model for facilitating groups to widespread agreement; New Society; Gazelle: Philadelphia, Pa., Lancaster, 2011.

42. Calderon, C.; Butler, A. Politicising the landscape: a theoretical contribution towards the development of participation in landscape planning. Landscape Research 2019, 36, 1-12, doi:10.1080/01426397.2019.1594739.

43. Déjeant-Pons, M. The European landscape convention. Landscape Research 2006, 31, 363-384.

44. Balvanera, P.; Quijas, S.; Martín-López, B.; Barrios, E.; Dee, L.; Isbell, F.; Durance, I.; White, P.; Blanchard, R.; Groot, R.S. de. The links between biodiversity and ecosystem services. Handbook of Ecosystems Services; Earthscan, 2015.

45. Jones, M. The European landscape convention and the question of public participation. Landscape Research 2007, 32, 613-633, doi:10.1080/01426390701552753.

46. Selman, P.H. Sustainable landscape planning: The reconnection agenda; Routledge: Milton Park, Abingdon, Oxon, 2012. 
47. Burkhard, B.; Kroll, F.; Nedkov, S.; Müller, F. Mapping ecosystem service supply, demand and budgets. Ecological Indicators 2012, 21, 17-29, doi:10.1016/j.ecolind.2011.06.019.

48. Drakou, E.G.; Willemen, L.; Maes, J.; Dunbar, M.B.; Egoh, B. Indicators for mapping ecosystem services: A review; Publications Office: Luxembourg, 2012, 107.

49. Helian, L.; Shilong, W.; Guanglei, J.; Ling, Z. Changes in land use and ecosystem service values in Jinan, China. Energy Procedia 2011, 5, 1109-1115, doi:10.1016/j.egypro.2011.03.195.

50. Costanza, R.; Groot, R. de; Sutton, P.; van der Ploeg, S.; Anderson, S.J.; Kubiszewski, I.; Farber, S.; Turner, R.K. Changes in the global value of ecosystem services. Global Environmental Change 2014, 26, 152-158, doi:10.1016/j.gloenvcha.2014.04.002.

51. Schmidt, K.; Sachse, R.; Walz, A. Current role of social benefits in ecosystem service assessments. Landscape and Urban Planning 2016, 149, 49-64, doi:10.1016/j.landurbplan.2016.01.005.

52. Jong, W. de; Sam, D.D.; van Hung, T. Forest Rehabilitation in Vietnam: Histories, realities and future; Harapan Prima: Jakarta, Indonesia, 2006.

53. On the benefits and obligations of households and individuals assigned, leased or contracted forests and forestry land; GoV, Ed.; Government: Hanoi, 2001.

54. Promulgating the regulation production forest management; GoV, Ed.; Hanoi, 2016.

55. Circular 21/2016/TT-BNNPTNT on providing for the main exploitation full utilization full collection of forest products; MARD, Ed.; MARD: Hanoi, 2016.

56. MA. Ecosystems and human well-being; Island press United States of America, 2005.

57. Braat, L.C.; Groot, R. de. The ecosystem services agenda: Bridging the worlds of natural science and economics, conservation and development, and public and private policy. Ecosystem Services 2012, 1, 4-15, doi:10.1016/j.ecoser.2012.07.011.

58. Queiroz, C.; Meacham, M.; Richter, K.; Norström, A.V.; Andersson, E.; Norberg, J.; Peterson, G. Mapping bundles of ecosystem services reveals distinct types of multifunctionality within a Swedish landscape. Ambio 2015, 44, 89-101.

59. Andersson, E.; Nykvist, B.; Malinga, R.; Jaramillo, F.; Lindborg, R. A social-ecological analysis of ecosystem services in two different farming systems. Ambio 2015, 44 Suppl 1, S102-12, doi:10.1007/s13280-014-0603-y.

60. Summers, J.K.; Smith, L.M.; Case, J.L.; Linthurst, R.A. A review of the elements of human well-being with an emphasis on the contribution of ecosystem services. Ambio 2012, 41, 327-340.

61. Cunningham, S.C.; Mac Nally, R.; Baker, P.J.; Cavagnaro, T.R.; Beringer, J.; Thomson, J.R.; Thompson, R.M. Balancing the environmental benefits of reforestation in agricultural regions. Perspectives in Plant Ecology, Evolution and Systematics 2015, 17, 301-317, doi:10.1016/j.ppees.2015.06.001.

62. Lamb, D.; Erskine, P.D.; Parrotta, J.A. Restoration of degraded tropical forest landscapes. Science 2005, 310, 1628-1632, doi:10.1126/science.1111773.

63. Burkhard, B.; Maes, J. Mapping Ecosystem Services; Pensoft Publishers, 2017. 
64. Lawrence, A. No forest without timber? int. forest. rev. 2003, 5, 87-96, doi:10.1505/IFOR.5.2.87.17411.

65. Srdjevic, Z.; Lakicevic, M.; Srdjevic, B. Approach of decision making based on the analytic hierarchy process for urban landscape management. Environ. Manage. 2013, 51, 777-785, doi:10.1007/s00267-012-9990-7.

66. Kangas, J.; Store, R.; Kangas, A. Socioecological landscape planning approach and multicriteria acceptability analysis in multiple-purpose forest management. Forest Policy and Economics 2005, 7, 603-614, doi:10.1016/j.forpol.2003.12.001.

67. Mansourian, S.; Dudley, N.; Vallauri, D. Forest Landscape Restoration: Progress in the Last Decade and Remaining Challenges. Ecological Rest. 2017, 35, 281-288, doi:10.3368/er.35.4.281.

68. Kamlun, K.U.; Bürger-Arndt, R. A Conceptual Framework Approach on Mapping Multiple Ecosystem Services in Tropical Wetland Areas On A Local Scale. Asia-Pacific Journal of Innovation in Hospitality and Tourism APJIHT 2016, 183.

69. van Laar, A.; Akça, A. Forest mensuration; Springer Netherlands: Dordrecht, 2007, 377.

70. Köhl, M.; Magnussen, S.S.; Marchetti, M. Sampling methods, remote sensing and GIS multiresource forest inventory; Springer Science \& Business Media, 2006.

71. Matérn, B. Spatial variation-stochastic models and their application to some problems in forest surveys and other sampling investigations. Meddelanden fran statens skogsforskningsintitut, Almaenna foerlaget, Stockholm. (1986), 49 (5); Springer, Berlin, 1960.

72. Kleinn, C. Lecture notes for the teaching module forest inventory, 2007.

73. Nguyen, T.; Tran, H. Namina Vernacula plantarum silvaticarum Vietnamicarum: Tên cây rùng Việt Nam; Agriculture Publishing House: Hanoi., 1971.

74. Kalwij, J.M. Review of 'The Plant List, a working list of all plant species'. Journal of Vegetation Science 2012, 23, 998-1002, doi:10.1111/j.1654-1103.2012.01407.x.

75. Apel, U. Der Dorfwald von Moxie: traditionelle Dorfwaldbewirtschaftung in Xishuangbanna, Südwest-China, und ihre soziokulturellen Hintergründe, 1996.

76. Loetsch, F.; Haller, K.E. Statistics of forest Inventory and Information from aerial photographs; BLV-Verlag-Ges, 1964.

77. Sola, G.; Inoguchi, A.; Garcia-Perez, J.; Donegan, E.; Birigazzi, L.; Henry, M. Allometric Equations at National Scale for Tree Biomass Assessment in Vietnam. Context, methodology and summary of the results, UN-REDD Programme, Ha Noi, Viet Nam 2014.

78. Altman, D.G.; Bland, J.M. Standard deviations and standard errors. BMJ 2005, 331, 903, doi:10.1136/bmj.331.7521.903.

79. Akça, A. Waldinventur; Sauerländer, 2000.

80. Curtis, J.T.; McIntosh, R.P. An upland forest continuum in the prairie-forest border region of Wisconsin. Ecology 1951, 32, 476-496.

81. Weiher, E.; Keddy, P.A. Relative abundance and evenness patterns along diversity and biomass gradients. OIKOS 1999, 355-361. 
82. Adekunle, V.; Olagoke, A.; Akinele, S. Tree species diversity and structure of a Nigerian strict nature reserve. Journal of Tropical Ecology 2013, 54, 275-289.

83. Shannon, C.E. The Mathematical Theory of Comunication. In The Mathematical Theory of Communication; Shannon, C.E., Warren Weaver, Eds.; The University of Illinois Press: Urbana, 1964; pp 29-125.

84. Pielou, E.C. The measurement of diversity in different types of biological collections. Journal of Theoretical Biology 1966, 13, 131-144, doi:10.1016/0022-5193(66)90013-0.

85. Toranza, C.; Lucas, C.; Ceroni, M. Distribución espacial y cobertura arbórea del bosque serrano y de quebrada en Uruguay Los desafíos de mapear ecosistemas parchosos. Agrociencia Uruguay 2019, 23, doi:10.31285/AGRO.23.85.

86. Mitchell, A.L.; Rosenqvist, A.; Mora, B. Current remote sensing approaches to monitoring forest degradation in support of countries measurement, reporting and verification (MRV) systems for REDD. Carbon Balance Manag. 2017, 12, 9, doi:10.1186/s13021-017-00789.

87. Mori, A.S.; Lertzman, K.P.; Gustafsson, L. Biodiversity and ecosystem services in forest ecosystems: a research agenda for applied forest ecology. J Appl Ecol 2017, 54, 12-27, doi:10.1111/1365-2664.12669.

88. Lefsky, M.A.; Cohen, W.B.; Spies, T.A. An evaluation of alternate remote sensing products for forest inventory, monitoring, and mapping of Douglas-fir forests in western Oregon. Can. J. For. Res. 2001, 31, 78-87, doi:10.1139/cjfr-31-1-78.

89. Nguyen Trong, H.; Nguyen, T.D.; Kappas, M. Land Cover and Forest Type Classification by Values of Vegetation Indices and Forest Structure of Tropical Lowland Forests in Central Vietnam. International Journal of Forestry Research 2020, 2020, 1-18, doi: $10.1155 / 2020 / 8896310$.

90. Colditz, R.R.; Schmidt, M.; Conrad, C.; Hansen, M.C.; Dech, S. Land cover classification with coarse spatial resolution data to derive continuous and discrete maps for complex regions. Remote Sensing of Environment 2011, 115, 3264-3275, doi:10.1016/j.rse.2011.07.010.

91. Butt, M.J.; Waqas, A.; Iqbal, M.F.; Muhammad, G.; Lodhi, M.A.K. Assessment of Urban Sprawl of Islamabad Metropolitan Area Using Multi-Sensor and Multi-Temporal Satellite Data. Arab J Sci Eng 2012, 37, 101-114, doi:10.1007/s13369-011-0148-3.

92. Huang, C.; Goward, S.N.; Masek, J.G.; Thomas, N.; Zhu, Z.; Vogelmann, J.E. An automated approach for reconstructing recent forest disturbance history using dense Landsat time series stacks. Remote Sensing of Environment 2010, 114, 183-198, doi:10.1016/j.rse.2009.08.017.

93. Fischer, R.; Knapp, N.; Bohn, F.; Shugart, H.H.; Huth, A. The Relevance of Forest Structure for Biomass and Productivity in Temperate Forests: New Perspectives for Remote Sensing. Surv Geophys 2019, 40, 709-734, doi:10.1007/s 10712-019-09519-x. 94. Finke, D.L.; Snyder, W.E. Conserving the benefits of predator biodiversity. Biological Conservation 2010, 143, 2260-2269, doi:10.1016/j.biocon.2010.03.022. 
95. Schall, P.; Gossner, M.M.; Heinrichs, S.; Fischer, M.; Boch, S.; Prati, D.; Jung, K.; Baumgartner, V.; Blaser, S.; Böhm, S.; et al. The impact of even-aged and uneven-aged forest management on regional biodiversity of multiple taxa in European beech forests. Journal of Applied Ecology 2018, 55, 267-278, doi:10.1111/1365-2664.12950.

96. Hansen, M.C.; Loveland, T.R. A review of large area monitoring of land cover change using Landsat data. Remote Sensing of Environment 2012, 122, 66-74, doi:10.1016/j.rse.2011.08.024.

97. Roy, D.P.; Wulder, M.A.; Loveland, T.R.; C.E., W.; Allen, R.G.; Anderson, M.C.; Helder, D.; Irons, J.R.; Johnson, D.M.; Kennedy, R.; et al. Landsat-8: Science and product vision for terrestrial global change research. Remote Sensing of Environment 2014, 145, 154 172, doi:10.1016/j.rse.2014.02.001.

98. Xie, Y.; Sha, Z.; Yu, M. Remote sensing imagery in vegetation mapping: a review. Journal of Plant Ecology 2008, 1, 9-23, doi:10.1093/jpe/rtm005.

99. Jones, H.G.; Vaughan, R.A. Remote sensing of vegetation: Principles, techniques, and applications, First edition; Oxford University Press: Oxford, 2010.

100. Bounoua, L.; DeFries, R.; Collatz, G.J.; Sellers, P.; Khan, H. Effects of Land Cover Conversion on Surface Climate. Climatic Change 2002, 52, 29-64, doi:10.1023/A:1013051420309.

101. White, J.C.; Wulder, M.A.; Hobart, G.W.; Luther, J.E.; Hermosilla, T.; Griffiths, P.; Coops, N.C.; Hall, R.J.; Hostert, P.; Dyk, A.; et al. Pixel-Based Image Compositing for Large-Area Dense Time Series Applications and Science. Canadian Journal of Remote Sensing 2014, 40, 192-212, doi:10.1080/07038992.2014.945827.

102. Brown, M.E.; Pinzon, J.E.; Didan, K.; Morisette, J.T.; Tucker, C.J. Evaluation of the consistency of long-term NDVI time series derived from AVHRR,SPOT-vegetation, SeaWiFS, MODIS, and Landsat ETM+ sensors. IEEE Trans. Geosci. Remote Sensing 2006, 44, 1787-1793, doi:10.1109/TGRS.2005.860205.

103. Matsushita, B.; Yang, W.; Chen, J.; Onda, Y.; Qiu, G. Sensitivity of the Enhanced Vegetation Index (EVI) and Normalized Difference Vegetation Index (NDVI) to Topographic Effects: A Case Study in High-density Cypress Forest. Sensors (Basel) 2007, 7, 2636-2651, doi:10.3390/s7112636.

104. United States Geological Survey. USGS. Available online: https://earthexplorer.usgs.gov/ (accessed on Accessed 22 September 2019).

105. Studley, H.; Weber, K.T. Comparison of image resampling techniques for satellite imagery. Final Report: Assessing Post-Fire Recovery of Sagebrush-Steppe Rangelands in Southeastern Idaho 2011, 252, 185-196.

106. Baboo, S.S.; Devi, M.R. An analysis of different resampling methods in Coimbatore, District. Global Journal of Computer Science and Technology 2010.

107. Clevers, J.; Kooistra, L.; van den Brande, M. Using Sentinel-2 Data for Retrieving LAI and Leaf and Canopy Chlorophyll Content of a Potato Crop. Remote Sensing 2017, 9, 405, doi:10.3390/rs9050405. 
108. Rahman, H.; Dedieu, G. SMAC: a simplified method for the atmospheric correction of satellite measurements in the solar spectrum. International Journal of Remote Sensing 1994, 15, 123-143.

109. Rosenqvist, Å.; Milne, A.; Lucas, R.; Imhoff, M.; Dobson, C. A review of remote sensing technology in support of the Kyoto Protocol. Environmental Science \& Policy 2003, 6, 441-455, doi:10.1016/S1462-9011(03)00070-4.

110. Patenaude, G.; Milne, R.; Dawson, T.P. Synthesis of remote sensing approaches for forest carbon estimation: reporting to the Kyoto Protocol. Environmental Science \& Policy 2005, 8, 161-178, doi:10.1016/j.envsci.2004.12.010.

111. Wulder, M.A.; Coops, N.C.; Roy, D.P.; White, J.C.; Hermosilla, T. Land cover 2.0. International Journal of Remote Sensing 2018, 39, 4254-4284, doi:10.1080/01431161.2018.1452075.

112.Zafari, A.; Zurita-Milla, R.; Izquierdo-Verdiguier, E. Evaluating the Performance of a Random Forest Kernel for Land Cover Classification. Remote Sensing 2019, 11, 575 , doi:10.3390/rs11050575.

113. Carrão, H.; Gonçalves, P.; Caetano, M. Contribution of multispectral and multitemporal information from MODIS images to land cover classification. Remote Sensing of Environment 2008, 112, 986-997, doi:10.1016/j.rse.2007.07.002.

114. Craig Dobson, M.; Ulaby, F.T.; Pierce, L.E. Land-cover classification and estimation of terrain attributes using synthetic aperture radar. Remote Sensing of Environment 1995, 51, 199-214, doi:10.1016/0034-4257(94)00075-X.

115.Pal, M.; Foody, G.M. Feature Selection for Classification of Hyperspectral Data by SVM. IEEE Trans. Geosci. Remote Sensing 2010, 48, 2297-2307, doi:10.1109/TGRS.2009.2039484.

116. Raczko, E.; Zagajewski, B. Comparison of support vector machine, random forest and neural network classifiers for tree species classification on airborne hyperspectral APEX images. European Journal of Remote Sensing 2017, 50, 144-154, doi:10.1080/22797254.2017.1299557.

117. Breiman, L. Random Forests. Machine Learning 2001, 45, 5-32, doi:10.1023/A:1010933404324.

118. Pal, M. Random forest classifier for remote sensing classification. International Journal of Remote Sensing 2005, 26, 217-222, doi:10.1080/01431160412331269698.

119. Lillesand, T.M.; Kiefer, R.W.; Chipman, J.W. Remote sensing and image interpretation, Seventh edition / Thomas M. Lillesand, Ralph W. Kiefer, Jonathan W. Chipman; Wiley: Hoboken, 2015.

120. Vrieling, A.; Meroni, M.; Darvishzadeh, R.; Skidmore, A.K.; Wang, T.; Zurita-Milla, R.; Oosterbeek, K.; O'Connor, B.; Paganini, M. Vegetation phenology from Sentinel-2 and field cameras for a Dutch barrier island. Remote Sensing of Environment 2018, 215, $517-$ 529, doi:10.1016/j.rse.2018.03.014. 
121. Frost, G.V.; Epstein, H.E.; Walker, D.A. Regional and landscape-scale variability of Landsat-observed vegetation dynamics in northwest Siberian tundra. Environ. Res. Lett. 2014, 9, doi:10.1088/1748-9326/9/2/025004.

122. Steven, M.D.; Malthus, T.J.; Baret, F.; Xu, H.; Chopping, M.J. Intercalibration of vegetation indices from different sensor systems. Remote Sensing of Environment 2003, 88, 412-422, doi:10.1016/j.rse.2003.08.010.

123. Deepak, M.; Keski-Saari, S.; Fauch, L.; Granlund, L.; Oksanen, E.; Keinänen, M. Leaf Canopy Layers Affect Spectral Reflectance in Silver Birch. Remote Sensing 2019, 11, 2884, doi:10.3390/rs11242884.

124. Glenn, E.P.; Huete, A.R.; Nagler, P.L.; Nelson, S.G. Relationship Between Remotelysensed Vegetation Indices, Canopy Attributes and Plant Physiological Processes: What Vegetation Indices Can and Cannot Tell Us About the Landscape. Sensors (Basel) 2008, 8, 2136-2160, doi:10.3390/s8042136.

125. FAO. Global forest resources assessment 2010: Main report. In.

126. Buys, P. At loggerheads?: agricultural expansion, poverty reduction, and environment in the tropical forests; World Bank Publications, 2007.

127. Norris, K. Biodiversity in the context of ecosystem services: the applied need for systems approaches. Philosophical Transactions of the Royal Society B: Biological Sciences 2012, 367, 191-199.

128. Queiroz, A.C.M. de; Rabello, A.M.; Braga, D.L.; Santiago, G.S.; Zurlo, L.F.; Philpott, S.M.; Ribas, C.R. Cerrado vegetation types determine how land use impacts ant biodiversity. Biodivers Conserv 2020, 29, 2017-2034.

129. Groot, R. de; Brander, L.; van der Ploeg, S.; Costanza, R.; Bernard, F.; Braat, L.; Christie, M.; Crossman, N.; Ghermandi, A.; Hein, L.; et al. Global estimates of the value of ecosystems and their services in monetary units. Ecosystem Services 2012, 1, 50-61, doi:10.1016/j.ecoser.2012.07.005.

130. Queiroz, J.S. de; Griswold, D.; Nguyen, D.T.; Hall, P. Vietnam tropical forest and biodiversity assessment. Quito: Sun Mountain International and Cadmus Group, Inc. 2013.

131. Gilmour, D.A.; Nguyen, V.S. Buffer zone management in Vietnam; IUCN Hanoi, 1999.

132. IUCN and WRI. A guide to the restoration opportunities assessment methodology (ROAM): assessing forest landscape restoration opportunities at the national or subnational level. IUCN, Gland, Switzerland 2014.

133. Clark, R.G.; Steel, D.G. Sampling within households in household surveys. Journal of the Royal Statistical Society: Series A (Statistics in Society) 2007, 170, 63-82.

134. United Nations. Statistical Division. Designing household survey samples: practical guidelines; United Nations Publications, 2008.

135. Aryal, K.P.; Poudel, S.; Chaudhary, R.P.; Chettri, N.; Chaudhary, P.; Ning, W.; Kotru, R. Diversity and use of wild and non-cultivated edible plants in the Western Himalaya. $J$. Ethnobiol. Ethnomed. 2018, 14, 10, doi:10.1186/s13002-018-0211-1.

136. Ryan, T.P. Sample size determination and power; John Wiley \& Sons, 2013. 
137. Asaduzzaman, M.; Salma, U.; Ali, H.S.; Hamid, M.A.; Miah, A.G. Problems and prospects of turkey (Meleagris gallopavo) production in Bangladesh. Research in Agriculture Livestock and Fisheries 2017, 4, 77-90.

138. Maes, J.; Teller, A.; Erhard, M.; Liquete, C.; Braat, L.; Berry, P.; Egoh, B.; Puydarrieux, P.; Fiorina, C.; Santos, F. Mapping and Assessment of Ecosystems and their Services. An analytical framework for ecosystem assessments under action 2013, 5, 1-58.

139. Velasquez, M.; Hester, P.T. An analysis of multi-criteria decision making methods. International journal of operations research 2013, 10, 56-66.

140. Mardani, A.; Jusoh, A.; MD Nor, K.; Khalifah, Z.; Zakwan, N.; Valipour, A. Multiple criteria decision-making techniques and their applications - a review of the literature from 2000 to 2014. Economic Research-Ekonomska Istraživanja 2015, 28, 516-571, doi:10.1080/1331677X.2015.1075139.

141. Ji, Y.-W.; Zhang, L.; Liu, J.; Zhong, Q.; Zhang, X. Optimizing Spatial Distribution of Urban Green Spaces by Balancing Supply and Demand for Ecosystem Services. Journal of Chemistry 2020, 2020, 1-8, doi:10.1155/2020/8474636. 
Chapter 2. Study area

\subsection{Geographic position and Topography}

The study area is situated between $107^{\circ} 22^{\prime} \mathrm{E}$ to $107^{\circ} 30^{\prime} \mathrm{E}$ and $16^{\circ} 02^{\prime} \mathrm{N}$ to $16^{\circ} 10^{\prime} \mathrm{N}$ in the western part of Thua Thien Hue Province (Figure 2.1). The A Luoi District borders on Dakrong of the Quang Tri Province, Phong Dien of Thua Thien Hue to the north, Huong Tra, Huong Thuy, and Nam Dong Districts to the east, Tay Giang of Quang Nam Province to the south, and the Salavan and Sekong Provinces of Laos' People Democracy Republic (PDR) to the west. The greater area is a part of the Truong Son Mountain Range bordering on Laos.

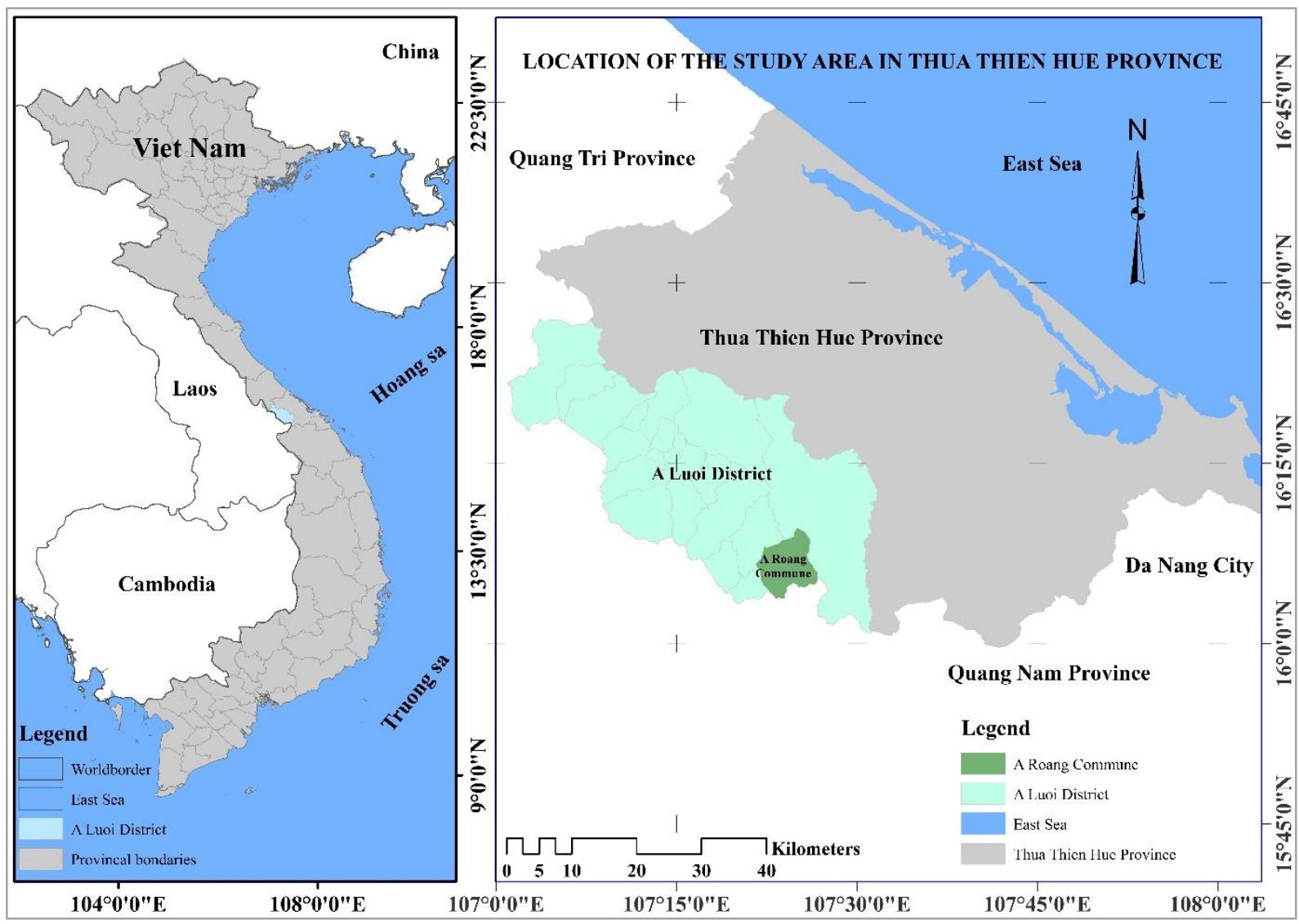

Figure 2.1. Location of the study area in Thua Thien Hue Province

The study area is hilly and mountainous and is often affected by landslides and heavy rains as part of typical tropical weather events. This is especially true in the NCC of Vietnam where the width of off-shore land is narrow and steep [1,2]. The Truong Son Annamite Range, in the study area, extends for almost $1200 \mathrm{~km}$ from the north to the south along the Vietnamese border with Laos and Cambodia. The northern part of the Truong Son Range, situated within 
the narrowest part of Vietnam, contains the highest peaks. Some of which reach above $1300 \mathrm{~m}$ and within some passes below 500 m a.s.1. [3,4], as presented in Figure 2.2a. The slope gradient is considered as the principal causative or triggering factor in landslide intensity [5], as presented in Figure 2.2b.
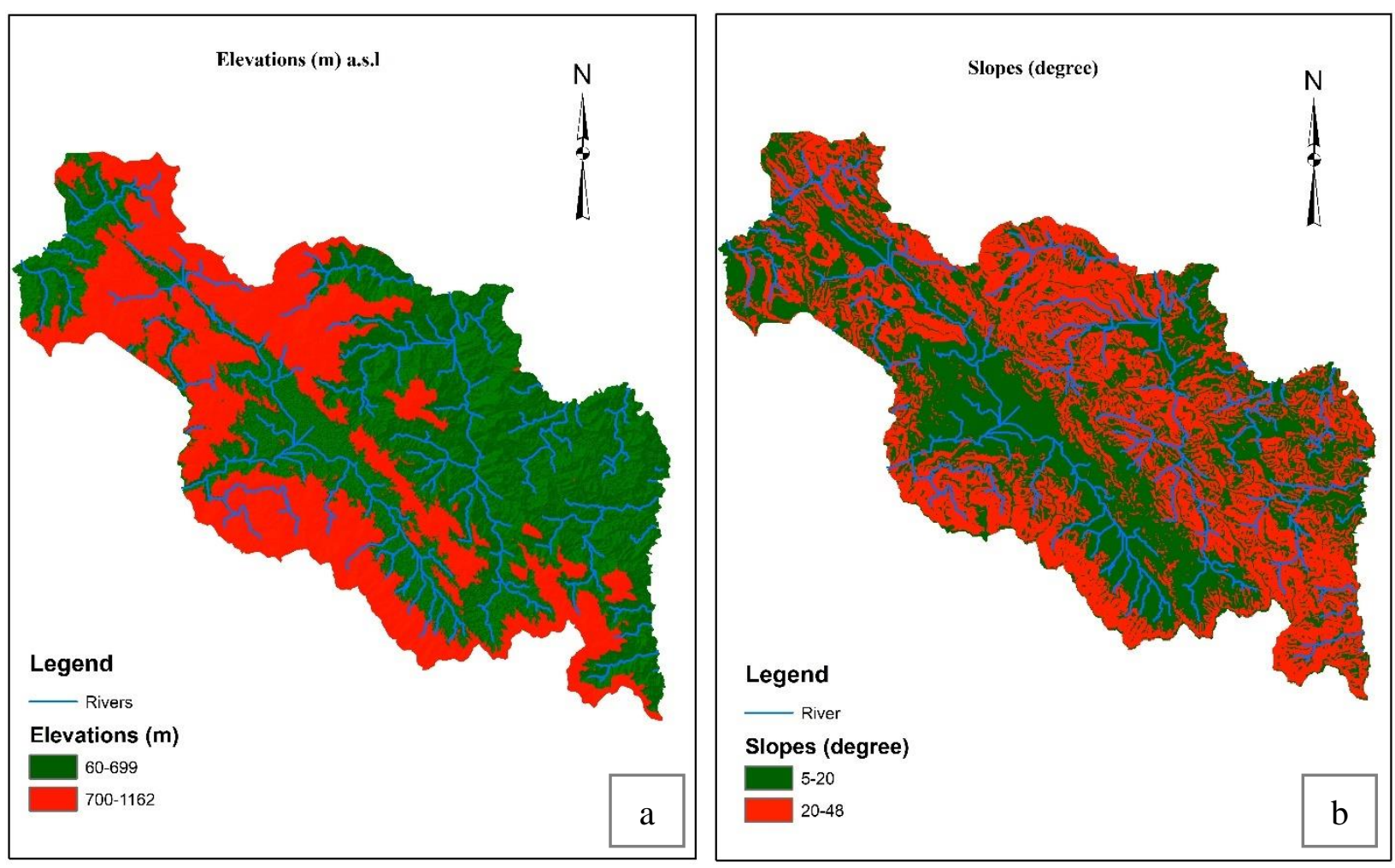

Figure 2.2. The elevations (a) and slopes (b) of A Luoi District

A Luoi District consists of undulating topographies with the steepest hillside reaching 48 degrees in continuous mountains with the elevation of more than $1162 \mathrm{~m}$ a.s.l. The district contains secondary forests in upper stream areas. The conversion of the secondary forest to plantations of fast-growing tree species like Acacia spp., Hevea brasiliensis, rubber, and cassava is affected through slash and burn techniques. This also occurs in the hillsides or in the lower zones of streams where local people grow rice and fruit trees. The above cultivational practices are also common to most people living in the mountainous area. Such topography in the study area can be considered as a trigger or principle factor for landslide occurrence, which results in potential risks for local inhabitants and their belongings [6,7]. Slope gradients can be evaluated and depicted spatially by using the digital elevation model (DEM) [8] as presented in 
Figure 2.3. Any negative impacts on the existing natural forest landscapes may result in tangible and/or intangible losses in the area [7].

\subsection{Land-use and Main cultivations}

The total natural land area (Table 2.1) in A Luoi District is 122,521 ha, of which forest land occupies more than $89 \%$ (109,633 ha). The Watershed Protection Forest land (WPF) has the biggest ratio of the total forest land in the district with $44 \%$, the next biggest percentage is held by Production Forest Land (PF) with 42\%, and finally Special Use Forest land (SUF) with $14 \%[9]$.

Table 2.1. Land use distribution in A Luoi District and A Roang Commune in 2017 (in ha)

\begin{tabular}{clcc}
\hline No & \multicolumn{1}{c}{ Land Uses in year 2017 (ha) } & $\begin{array}{c}\text { A Luoi } \\
\text { district }\end{array}$ & $\begin{array}{c}\text { A Roang } \\
\text { commune }\end{array}$ \\
\hline I. & Agricultural land & 115,836 & 5,511 \\
\hline 1 & Land for agricultural cultivation & 5,972 & 810.16 \\
1.1. & Land for annual crops & 2,491 & 350.85 \\
& Rice paddy fields & 1,150 & 80.00 \\
& - Other land for annual crops & 1,342 & 270.85 \\
1.2 & Land for cultivation of perennial trees & 3,481 & 459.31 \\
2 & Forestry land & 109,632 & 4,563 \\
2.1. & Land for protection forests & 48,420 & 2,503 \\
2.2. & Land for special-use forests & 15,337 & - \\
2.3. & Land for production forests & 45,875 & 2,060 \\
3 & Land for aquaculture & 229.11 & 30.23 \\
4 & Other agricultural land & 2.42 & 107.90 \\
\hline II. & Non-agricultural land & $5,212.06$ & 218.96 \\
\hline 1 & Residential land & 523.49 & 28.96 \\
1.1. & Rural residential land & 432.91 & 28.96 \\
1.2. & Urban residential land & 90.58 & - \\
2 & Specialized land & 3,453 & 182.29 \\
2.1. & Land for office construction & 22.73 & 0.83 \\
2.2. & Land for national defense & 139.73 & 1.66 \\
2.1. & Non-agricultural production & 90.39 & - \\
2.2. & Land for public purposes & 3,200 & 5.58 \\
3 & Religion-based land & 1.13 & 2.13 \\
4 & Land for cemeteries. graveyards. cremation & 113.49 & \\
5 & Land covered by water & 1,101 & \\
6 & Other non-agricultural lands & 19.18 & \\
\hline III. & Unused land & 1,473 & \\
& & & \\
\hline
\end{tabular}


A Roang Commune, where the study was conducted, has 4,563 ha of natural forests, more than 2,059 ha of which is classified as production forest which has full capacity of forest goods that can be considered for ecosystem services, except timber extraction from natural forest which are currently banned by law. Figure 2.3 illustrates the overview of landscapes in the area.
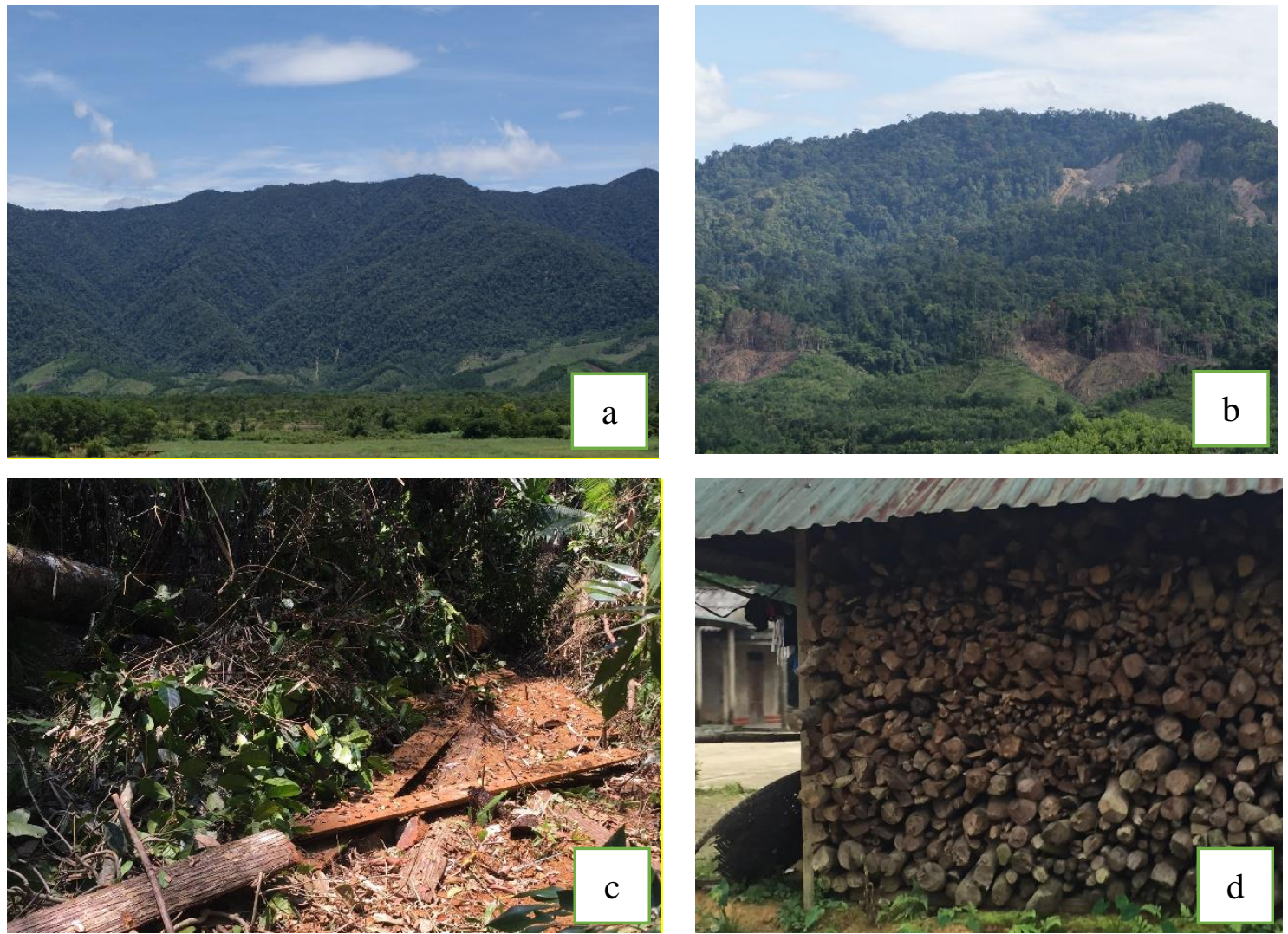

Figure 2.3. Overview of landscapes (a), forest disturbances; (b), illegal logging; (c) and fuelwood extraction (d)

There are four main land-use types in A Luoi District: grassland, natural forest, plantation forest, and agricultural land. Agricultural cultivation is the primary activity of the local people in the area. Their cultivation is very scattered and fragmented due to the non-unique land availability. The key crops are rice, cassava, peanuts, vegetables, maize, and bananas. Rice is the main crop even though the area occupied by paddy fields is relatively small compared to other land uses (Table 2.3). Rice cultivation is mainly rainfed. In addition, cassava is a traditional crop in this area and common in the mountainous regions. There are also fruit tree plantations such as Mango, Orange, Longan, Litchi, and Pineapple. Besides that, people plant numerous forest tree species such as Acacia spp, Hevea brasiliensis, Hopea odorata, Cinnamomum cassia, etc. Acacia spp and Hevea brasiliensis occupy the biggest ratio in 
plantation forests. The potential risk of planting some forest trees on the hillsides (such as Acacia spp) is that landslides can result because the plantation of this species will be clear-cut after 5-7 years. Meanwhile the normal cost for plantation of Hevea brasiliensis is high; thus, plantation of Hevea brasiliensis is not affordable for local farmers. Other forest tree species are mostly long-term rotations to feed the short-term income of local people in the area.

\subsection{Vegetation cover}

The study area mainly consists of primary and secondary closed evergreen broadleaved lowland forests [10]. Fagaceae, Myrtaceae, Lauraceae, Cannabaceae, Leguminosae, Dipterocarpaceae, Malvaceae, Meliaceae, Myristacaeae, Burseraceae, and Annonaceae are the most dominant species in the study area $[10,11]$. Around $30 \%$ of all Vietnamese endemic plant species are found in the Greater Annamite Landscape [2], in which A Luoi District is located. These species forms part of endemic taxa comprising of Orchidaceae, Fagaceae, Euphorbiaceae, Rubiaceae, Annonaceae families as well as Styracaceae, Anacardiaceae, Dipterocarpaceae [12]. The forest ecosystem consists of multiple stories with different dominant species in each vertical story. For example, in the highest vertical structure up to 40$50 \mathrm{~m}$ Dipterocarpaceae, Moraceae, Combrataceace, and Leguminosae are found. The other dominant species in the second-highest story belong to Lauraceae Fagaceae, Magnoliaceae, Sapindaceae, Papilionaceae, Burseraceae, Meliaceae, Caesalpiniaceae, and Mimosaceae. The third story, where tree species normally have heights of $8-15 \mathrm{~m}$, is dominated by the Myristicaceae, Clusiaceae, Ulmaceae, Annonaceae, and Flacourtiaceae families. The rest of the stories, which have a tree height of $2 \mathrm{~m}$ to $8 \mathrm{~m}$, are dominated by Apocynaceae, Rubiaceae, Rutaceae, Annonaceae, Melastomaceae, Araliaceae, Euphorbiaceae, Acanthaceae, and Urticaceae [13]. The forest flora differs in subzones [14]. The flora in the northern part of Vietnam distributes throughout lowland forests with elevations of less than $700 \mathrm{~m}$ a.s.1; in the southern part of Vietnam, flora distributes in the lower humid area of less than $1.000 \mathrm{~m}$ a.s.l., including the study area. The major dominant species are Fagaceae, Lauraceae, Magnoliaceae, Leguminosae, Meliaceae, Moraceae, Anacardiaceae, Burseraceae, Sapotaceae, and Sapindaceae. The flora in the southern part of Vietnam is influenced by Malaysia and Indonesia 
with the dominance of the Dipterocarpus genus in the upper story. The species composition of forests under smaller sub-geographical conditions of less than $700 \mathrm{~m}$ a.s.l. and above $1000 \mathrm{~m}$ a.s.l. has not yet been clearly classified.

The vegetative assessment of this study focused on three types of natural forests for ground-truth inventories. The first type, called undisturbed forest (UF), is known as rich forest and had a basal area of about $30 \mathrm{~m}^{2} \mathrm{ha}^{-1}[15]$. The second forest type, less disturbed forest (LF), is classified as a medium forest. This forest type was slightly logged and disturbed and features some canopy fragmentation; however, its structure was more or less maintained. The third type is secondary poor forest, which is classified as disturbed forest (DF) [16]. The three forest types are believed to provide local people with a diverse range of ecosystem services apart from other provisioning services of the natural forest landscapes.

\subsection{Climate conditions}

A Luoi is generally characterized by a tropical monsoon climate with two clearly distinguished seasons. The dry season lasts from February to March, with an average rainfall of around $60 \mathrm{~mm}$ per month. Most of the precipitation falls in the rainy season. The average annual temperature is $21.9^{\circ} \mathrm{C}$; the warmest months are May and June with an average high temperature of $25.3^{\circ} \mathrm{C}$ and the coldest month is January with an average temperature of $16.9^{\circ} \mathrm{C}$. The average moisture content varies from $81 \%$ to $94 \%$, and it is typically influenced by the inter-tropical convergence zone which causes tropical low-pressure systems, monsoons, and typhoons, leading to a total average annual rainfall of $3502 \mathrm{~mm}$. The rainy season with an average rainfall of $367 \mathrm{~mm}$ per month lasts from April to December, and most of the rainfall falls between the months of August and December. The highest average rainfall of the year occurs in October with nearly $1000 \mathrm{~mm}$. There is an average of 200 rainy days a year in the country as a whole (Table 2.2). 
Table 2.2. The climatic data of A Luoi District. Thua Thien Hue Province

\begin{tabular}{lccccc}
\hline Month & $\begin{array}{c}\text { Rainfall } \\
(\mathrm{mm})\end{array}$ & $\begin{array}{c}\text { Max Temp } \\
\left({ }^{\circ} \mathrm{C}\right)\end{array}$ & $\begin{array}{c}\text { Min Temp } \\
\left({ }^{\circ} \mathrm{C}\right)\end{array}$ & $\begin{array}{c}\text { Average Temp } \\
\left({ }^{\circ} \mathrm{C}\right)\end{array}$ & $\begin{array}{c}\text { Aridity Index } \\
(\mathrm{Al})\end{array}$ \\
\hline January & 92,0 & 21,9 & 15,5 & 16,9 & 40,7 \\
February & 39,0 & 26,1 & 16,9 & 20,4 & 15,3 \\
March & 69,0 & 27,5 & 18,8 & 21,9 & 25,9 \\
April & 157,6 & 29,7 & 20,5 & 23,7 & 56,1 \\
May & 232,7 & 31,1 & 21,1 & 25,0 & 79,0 \\
June & 128,0 & 30,6 & 22,1 & 25,3 & 43,5 \\
July & 172,7 & 30,2 & 21,7 & 24,7 & 59,6 \\
August & 190,2 & 29,0 & 21,4 & 24,0 & 67,1 \\
September & 420,5 & 27,0 & 20,5 & 22,7 & 154,3 \\
October & 970,8 & 24,3 & 18,9 & 20,8 & 378,3 \\
November & 718,5 & 22,4 & 17,2 & 19,5 & 292,0 \\
December & 311,1 & 21,6 & 15,7 & 17,7 & 134,5 \\
\hline Year & 3.502 & 26,8 & 19,2 & 21,9 & 1,346 \\
\hline
\end{tabular}

(Source: Climate data was from the National Weather Forecast Center)

The aridity index is used to identify the dry months of a region [17]. It can be calculated by the following formula:

$$
A I_{m}=\frac{12 n}{T_{m}+10}
$$

Where; $\mathrm{AI}_{\mathrm{m}}=$ mean monthly aridity index

$$
\begin{aligned}
& \mathrm{n} \quad=\text { mean monthly rainfall in } \mathrm{mm} \\
& \mathrm{T}_{\mathrm{m}} \quad=\text { mean monthly temperature in }{ }^{0} \mathrm{C}
\end{aligned}
$$

In which, a month is identified as a dry month when the aridity index goes below 20 . On the other hand, the climatic diagram is also used to illustrate the relationship between monthly rainfall and monthly temperature and to identify the number of dry months in a year [18]. A month is defined as a dry month when the rainfall curve is below the temperature curve in the diagram. According to [15,19], forests lying at elevations between 700-1000 m a.s.1., with an average temperature of $21.9^{\circ} \mathrm{C}$, and a total annual precipitation recorded as more than $2500 \mathrm{~mm}$, are classified as Moist Lowland Evergreen. The aridity index (AI) and the climate diagram show that there are three dry months from January to March. The forests in this region are classified as Moist Evergreen Forests because the total annual precipitation recorded in the area 
is $3502 \mathrm{~mm}$ as presented in Figure 2.4.

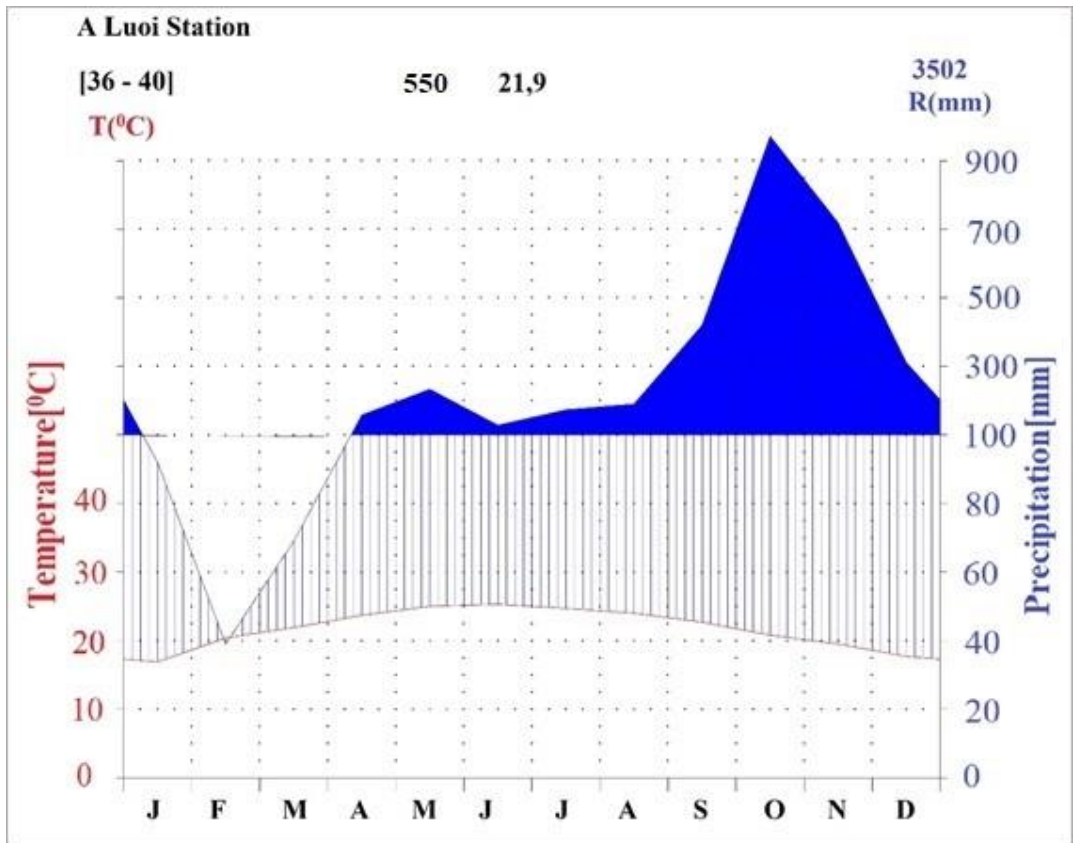

Figure 2.4. Climate diagram for A Luoi District, Thua Thien Hue Province where the elevation of the weather forecast is $550 \mathrm{~m}$ a.s.l, features 36 years of temperature observation data (19812016) and 40 years of precipitation observation data (1977-2016).

\subsection{Soil formation}

Soil is one of the vital elements in the forest ecosystem, contributing to forest structure and providing a foundation for trees. Soil helps regulate critical ecosystem processes of nutrient uptake, soil enrichment via decomposition of forest debris, and water storage [20]. The relationship between soils and forests is very significant and plays a major role in the growth of individual trees. The soil classification is based on many factors such as terrain, climate, microorganisms, mother materials, time, and human impacts but climate and microorganisms are essential elements [21,22]. The predominant soil types are Humic Acrisols (6\%), Hyperdystrict Acrisols (5\%), Arenic Acrisols (14\%), and Ferralic Acrisols (75\%). Ferralic Acrisols can be found throughout the district area. Arenic Acrisols are mainly found in the eastcentral parts of the district and less frequently in the north-central region. The Hyperdystrict Acrisols are exclusively found in the northwest and southeast valleys of the district. Humic Acrisols are mainly present in limited areas of the northwestern part of the district [23]. Soil depth and soil acid in natural forests were also measured. The weathering process of Acrisols, 
Ferralsols, Alisols occurs from granitic material which is rapidly degraded [24]. The Ferralic Acrisols constitute the largest soil group in the mountainous and hilly communes, which are relatively poor in nutrients with medium organic matter contents. However, these soils are suitable for afforestation and cultivation of perennial crops as well as fruit crops with appropriate improvement and protection measures [25]. This type of soil is mainly deposited across the Truong Son Range, which extends into Laos. It also stretches along the coastline of NCC from Thanh Hoa to Thua Thien Hue Provinces. When the natural forest cover is impacted on the higher-sloped mountains or hilly landscapes, landslides commonly occur. This is especially true in the numerous crowded narrow ridges over flat sandy and alluvial valleys $[3,26]$.

\subsection{Population and Social conditions}

The district contains 20 communes and a town, hosting over 627 households [27], while non-agricultural and unused lands occupy $4 \%$ of the total area. 20 communes have 110 villages and a total population of 49,466 people, the density of people being 40.7 per sq. $\mathrm{km}$. The population is mostly found in the central part of the district and along the long narrow national trafficway known as Ho Chi Minh trail. The total population in the district 49.466 persons. The working-age population accounts for $50 \%$ of the total, of which males account for $50.5 \%$ and females $49.5 \%$. The district's population growth rate is $1.56 \%$ compared to $1.18 \%$ in the province as a whole, which is due to bigger ratios of ethnic minority groups (75\%). Four ethnic minorities found in A Luoi are Ta Oi, Co Tu, Van Kieu, and Pa Ko [9]. The district's poverty rate is $37.40 \%$, lower than that recorded in the whole province of A Roang (at $49.26 \%$ ).

The poverty criteria [27] applied to a household is divided into three income levels: (1) households with a total income of less than 35 USD per person per month are considered poor; (2) households whose monthly income ranges from 35 to 50 USD per person are considered pro-poor, and (3) those households with a monthly income ranging from 50-75 USD person are considered medium. The average monthly income of local people in A Luoi is around 50 USD per person. The average income differs from commune to commune. A Roang Commune has 
a total household count of 627 with a total of 2.732 individuals. Most of the local people in A Roang Commune live close to forests and the income of $80 \%$ of the local people in the area depends on agricultural cultivation and forestry activities [9].

\subsection{References}

1. Sikor, T.; Truong, D.M. Agricultural policy and land use changes in a Black Thai commune of northern Vietnam, 1952-1997. Mountain Research and Development 2002, $22,248-255$.

2. Averyanov, L.V.; Loc, P.K.; Hiep, N.T.; Harder, D.K. Phytogeographic review of Vietnam and adjacent areas of Eastern Indochina. Komarovia 2003, 3, 1-83.

3. Rundel, P.W. Conservation priorities in Indochina-WWF Desk Study. Forest habitats and flora in Lao PDR, Cambodia, and Vietnam. World Wide Fund for Nature, Indochina Programme Office, Hanoi 1999.

4. Schmid, M. Vietnam, Kampuchea and Laos. Floristic Inventory of Tropical Countries. New York: New York Botanical Garden 1989, 83-90.

5. Thanh, L.N.; Smedt, F. de. Application of an analytical hierarchical process approach for landslide susceptibility mapping in A Luoi district, Thua Thien Hue Province, Vietnam. Environ Earth Sci 2012, 66, 1739-1752.

6. Lohnes, R.A.; Handy, R.L. Slope angles in friable loess. The Journal of Geology 1968, 76, 247-258.

7. Ballard, T.M.; Willington, R.P. Slope instability in relation to timber harvesting in the Chilliwack Provincial Forest. The forestry chronicle 1975, 51, 59-63.

8. Gao, W.; Hung, J.C. Variable structure control of nonlinear systems: A new approach. IEEE transactions on Industrial Electronics 1993, 40, 45-55.

9. A Luoi Statistics Office, Ed. Statistical Yearbook 2017; Statistics Office: A Luoi, 2018.

10. Averyanov, L.; Phan, L.; Nguyen, H.; Nguyen, V.; Pham, T.; Do, D.; Thao, V.; Tran, M.; Ngo, T.; Duong, V.; et al. Lowland flora and vegetation preliminary survey, Part 1: Green Corridor Project in Thua Thien Hue Province, 2005.

11. Le, N. Adding some vascular plants to the list of plants in Thua Thien Hue Province. Journal of Research and Development 2016, 4, 96-107.

12. Averyanov, L.; Cribb, P.; Loc, P.K.; Hiep, N.T. Slipper orchids of Vietnam; Timber Press (OR), 2003.

13. Thai, V. Forest vegetation cover of Vietnam, 2nd ed; Science and Technics Publishing House: Ha Noi, 1978.

14. Balboa Smithsonian Tropical Research Institute. Studying forest canopies from above: the International Canopy Crane Network; Smithsonian Tropical Research Inst, 2003. 
15. Lamprecht, H. Silviculture in the tropics: Tropical forest ecosystems and their tree species: possibilities and methods for their long-term utilization; Deutsche Gesellschaft für Technische Zusammenarbeit GTZ: Eschborn, 1989.

16. Nguyen Trong, H.; Nguyen, T.D.; Kappas, M. Land Cover and Forest Type Classification by Values of Vegetation Indices and Forest Structure of Tropical Lowland Forests in Central Vietnam. International Journal of Forestry Research 2020, 2020, 1-18.

17. Martonne, E. de. Une Nouvelle fonction climatologique: L'Indice d'aridité; Impr. Gauthier-Villars, 1926.

18. Walter, H. Ergaenzende Betrachtungen zu der im Klinmadiagramm-Weltatlas Verwendeten Klimadarstellung. Erdkunde 1970, 24, 145-149.

19. Thai, V. Ecosystems of tropical forests in Vietnam; Science and Technics Publishing House: Ha Noi, 1998.

20. FAO, Ed. Soils are the foundation for vegetation; Food and Agriculture Organization of the United Nations: Rome, 2015.

21. Glinka, K.D.; Marbut, C.F. Great soil groups of the world and their development 1927.

22.Zonn, S.V. Geomorphology and soil conditions of forest growth in the Tellermann experimental forest.-Transac tions of the Forest Institute, 3: 19-65; Nauka, Moscow.(In Russian.), 1950.

23. Pham, T.G.; Nguyen, H.T.; Kappas, M. Assessment of soil quality indicators under different agricultural land uses and topographic aspects in Central Vietnam. International Soil and Water Conservation Research 2018, 6, 280-288.

24. Jordanova, N. Magnetism of soils with clay-enriched subsoil. In Soil Magnetism: Elsevier, 2017, pp. 65-138.

25. Jong, W. de; Sam, D.D.; van Hung, T. Forest Rehabilitation in Vietnam: Histories, realities and future; Harapan Prima: Jakarta, Indonesia, 2006.

26. Dovzikov, A.E. Geological map of Vietnam 1: 500000. Hanoi, Main Geological Department of DRV 1965.

27. GoV, Ed. GoV, Promulgating multidimensional poverty levels applicable for period 20162020, 59th ed; GoV: Hanoi, 2015. 
Chapter 3. Evaluating the Influence of Topography on Tree Species Diversity, Distribution and Composition of Forests in Central Vietnam

Hung Nguyen Trong ${ }^{1,2 *}$, Tung Pham Gia ${ }^{1,3}$, Martin Kappas ${ }^{1}$

${ }^{1}$ Cartography, GIS and Remote Sensing Department, Göttingen University, Germany; mkappas@gwdg.de

${ }^{2}$ Ministry of Natural Resources and Environment, Vietnam; tronghung2128@gmail.com

${ }^{3}$ University of Agriculture and Forestry, Hue University, Vietnam; phamgiatung@huaf.edu.vn

\section{Abstract}

Objectives: This study focused on evaluating the influence of topography conditions on species richness, diversity, distribution and species composition as dependent variables at different micro topographic attributes in Central Vietnam. Methods/Statistical Analysis: Trees with diameter at breast height $\geq 6.0 \mathrm{~cm}$ of 90 quadratic plots $\left(1000 \mathrm{~m}^{2}\right)$ were inventoried to assess species richness, diversity, and distribution. Scatterplot Matrices: Pairs-sample test was applied to evaluate the multiple correlations between ranked elevations and slopes with dependent variables. The composition of most abundant, dominant species including Importance Value Index at the midpoint of each topographic attribute was compared with those of the entire topographic attribute. Findings: A total of 4297 tree individuals were recorded representing 122 species from 47 families. We found a significant difference of species richness, diversity, stem density and basal area in different topographic attributes $(\mathrm{p}<0.05)$. The lower elevation and shallower slope had more species richness and diversity than those in the higher elevation and steeper slope. Elevation had more influence on the distribution of species, stand density, species diversity, basal area and family than those of the slope. The species composition between slopes was not remarkably distinguishable which helps to confirm that slopes do not contribute to species distribution, composition. Fagaceae, Myrtaceae, Lauraceae, Cannabaceae, Meliaceae, Sapindaceae, Dipterocarpaceae, Leguminosae, Burseraceae and Malvaceae were the most dominant. The composition of the most abundant and dominant species at the midpoint plots objected to those of the entire topographic attribute. Difference of species composition between elevations may have subjected due to disturbance or successional processes of different forest ecological habitats in the current study area. 
Application/Improvements: Mapping micro-site natural forest disturbances based topographic conditions of dominant, endemic species for conservation and management of different ecological habitats with support of high-resolution satellite images.

Keywords: Composition, Central Vietnam, Species Diversity, Topography

\section{Citation}

Trong, Hung Nguyen*; Gia, Tung Pham; Kappas, Martin (2019): Evaluating the Influence of Topography on Species Diversity, Distribution and Composition of Forests in Central Vietnam. In Indian Journal of Science and Technology 12 (19). DOI: 10.17485/ijst/2019/v12i19/142622

* Correspondence author

\subsection{Introduction}

Tropical forests host the most species richness and complex plant communities of all forests $[1,2]$. Species diversity is an indicator that shows substantial links between the richness and abundance of individual tree species, reflecting the heterogeneity or existence of vegetation [3]. The diversity of tree species is fundamental to entire forest biodiversity because individuals of tree species give resources and formation of habitat for the forest ecosystem [4-6]. Factors that influence forest species richness at different scales could be comprising soil, parent materials, air temperature, light and even altitudes [7]. The spatial distribution of trees in the tropical forest ecosystem or forest habitat has been a major interest for plant ecologists because of its potential role in explaining the coexistence of different tree species in species-rich forests [8]. Understanding forest species richness, diversity, species distribution in the current study area where the taxon spatially aligned and species composition in where different species are favored in a community, is necessary for forest sustainability, species conservation, management of forest ecosystems, and natural forest landscape restoration [9].

Tree species composition is also a very important indicator for assessing the Importance Value Index (IVI) of a species within a forest stand, providing information on abundance, dominance and frequency thereby providing information on the contribution of the species to vegetation formation [10]. Natural forests in Vietnam have declined dramatically as a result of the Vietnam War, population growth, overexploitation, and the transformation of forested areas 
into arable land [11]. Forest covers of Vietnam was around $43 \%$ in 1943 and declined to below $28 \%$ in 1990s [12]. The forests of the Northern and Southern Truong Son Mountain Range have been highlighted as global eco-regions by the World Wide Fund for Nature [13].

The tropical evergreen forests are geographically classified below $700 \mathrm{~m}$ a.s.l. (above sea level) in the north and below $1000 \mathrm{~m}$ a.s.l. (above sea level) in the south. The subtropical evergreen forests are classified above $700 \mathrm{~m}$ a.s.l. in the north and above $1000 \mathrm{~m}$ a.s.l. in the south of Vietnam. Vegetation communities are further identified by edaphic condition, the level of disturbance and floristics, and finally by the dominant species.

Numerous researchers have documented that plant species composition and abundance are related to the heterogeneity of soil properties, topography and stage (i.e. age) of forest succession [14-19]. In Vietnam, some studies have simply described the spatial distribution of trees in forests $[20,21]$. While the influence of topographic conditions as topographic attributes on tree diversity, composition and distribution has not been studied [22], no study has been conducted on the influence of topographic features (such as elevations and slopes) on tree species distribution, species diversity and composition.

To fill the gapped knowledge about the tropical evergreen forests in the Northern Central Truong Son Mountain Range in the Central Vietnam, this study aims to evaluate the influence of topographic attributes on species richness, species distribution and comparing the species composition of the most dominant species of the representative plots with those of the entire topographic attribute respectively.

The study area is located in the North Central Truong Son Mountain Range and of the A Luoi District in Vietnam (Figure.3.1), which borders [23] from $107^{\circ} \mathrm{E}$ to $107^{\circ} 30^{\prime} \mathrm{E}$ and from $16^{\circ} \mathrm{N}$ to $16^{\circ} 30^{\prime} \mathrm{N}$ in the western part of the Thua Thien Hue province. The climate consists typical tropical monsoon characteristics. The area is frequently influenced by an intertropical convergence zone that typically causes tropical low pressures and typhoons, leading to annual rainfall of about $3500 \mathrm{~mm}$ with an average of 200 rainy days per year, most of the rainy days accumulate between September and December [21]. The average annual temperature is $21.9^{\circ}$ $\mathrm{C}$, the average high temperature is $25.3^{\circ} \mathrm{C}$, and the average low temperature is $16.9^{\circ} \mathrm{C}$. 
Moisture content varies from $86 \%$ to $96 \%$. The typical topography in this mountainous region features complex, steep slopes ranging from 5 to $48^{\circ}$. The elevation of the study area is from 150 to $1162 \mathrm{~m}$ a.s.l thus the landscape of A Luoi is usually affected by landslides [24].

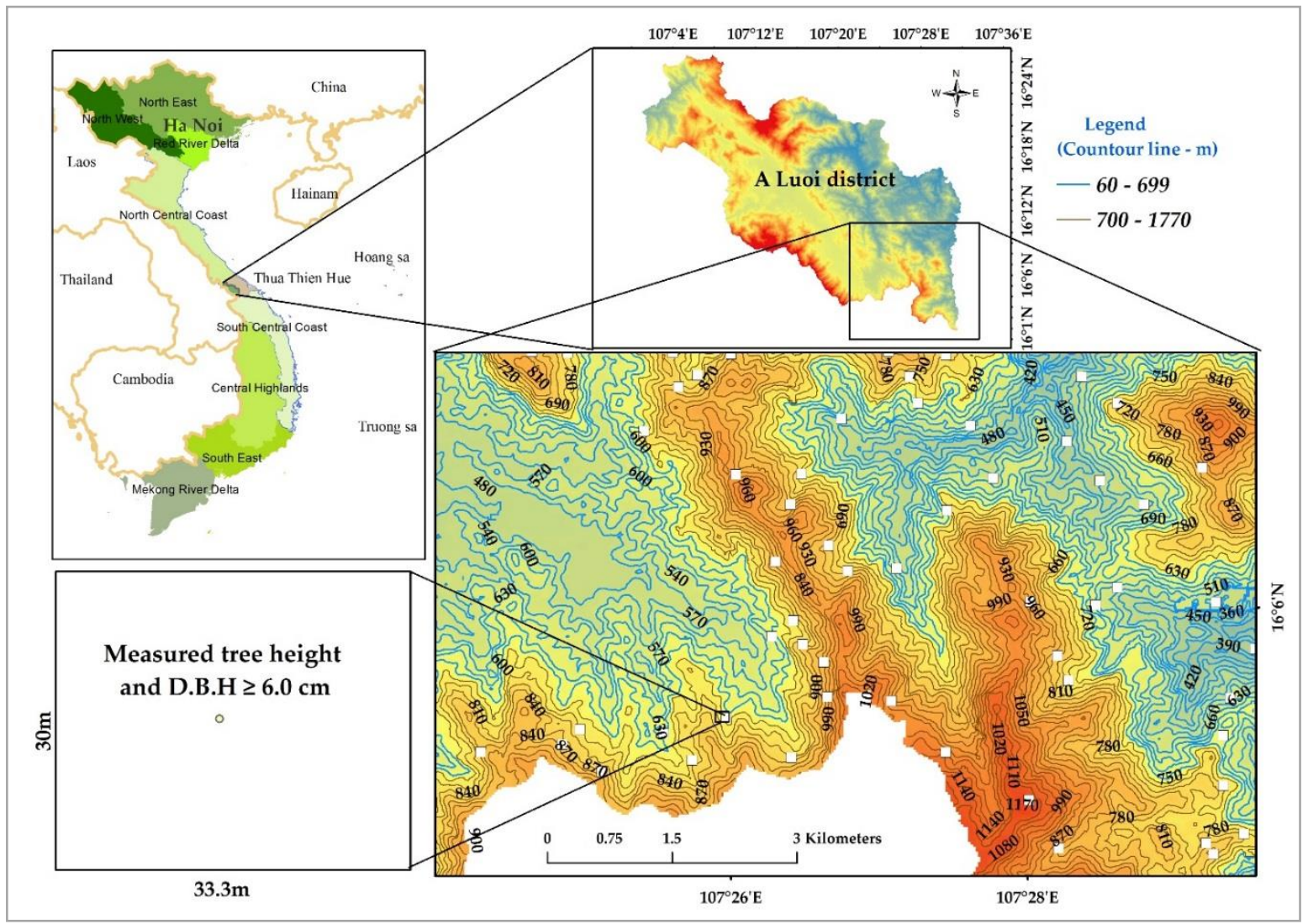

Figure 3.1. Study area and sample plot arrangement.

The primary and secondary lowland evergreen forests are consisted in the current study area [25]. The most dominant genera of Dipterocarpus, Hopea, Parashorea of Dipterocarpceae and Lithocarpus and Castanopsis of Fagaceae and followed by Syzygium of Myrtaceae; as well as the genera of Lauraceae, namely Machilus, Litsea and Cinamomum, and of the Cannabaceae was Gironniera, Aphananthe. Forests in the study area are under management of Sao La Nature Reserve and Management Board of Watershed Forests. Four soil types are present within the research area: Ferralic Acrisols (75\%), Arenic Acrisols (14\%), Humic Acrisols (6\%), and Hyperdystrict Acrisols (5\%) [26]. 


\subsection{Materials and Methods}

3.2.1. Vegetation sampling and Topographic attribute classification

A total of 90 plots $(30 \times 33.3 \mathrm{~m})$ were randomly sampled in the natural forests of the study area. The top height (Ht) in meters and the diameter at breast height (DBH) of all living trees with $\mathrm{DBH} \geq 6.0 \mathrm{~cm}$ were recorded for the calculation of the mean stand parameters $[27,28]$. The tree species were recorded in the field in the Vietnamese language and later translated to their scientific names. The names of all tree species were checked to avoid synonyms in The Plantlist [29]. Coordinates, elevations and slopes of all sample plots were recorded on-site with GPS and calibrated with a Global Digital Elevation Model (DEM) resolution (30 x $30 \mathrm{~m})$ in ArcGIS 10.5. The minimum interval distance between plots was approximately $200 \mathrm{~m}$.

As forests in Vietnam were ecologically classified, we divided the topographic elevation into two levels, H1 (150-696 m a.s.1.) and H2 (700-1162 m a.s.1.). For slope classification, we took into account of studies of $[24,30,31]$ and we decide to divide slopes into two levels, lower slope (S1) ranged from 5 to 20 degrees, and steeper slope (S2) ranged from 20 to 48 degrees.

\subsubsection{Species richness and species diversity distribution}

In general, higher values of biodiversity indices such as species diversity and species dominance indicate large species richness [32]. The Shannon Index $(\mathrm{H})$ of species was calculated as [33]:

$$
\text { Shannon Index }(H)=-\sum_{i=1}^{s} p_{i} \ln \left(p_{i}\right)
$$

where $\mathrm{p}^{\mathrm{i}}$ is the proportion of $\mathrm{S}$ made up of the $\mathrm{i}^{\text {th }}$ species, and the Evenness (Eq) was calculated based [34] as:

$$
E q=\frac{H}{\ln (S)}
$$

where $\mathrm{H}$ is Shannon Index and $\ln (\mathrm{S})$ is the natural logarithm of the total number of species in the attribute.

We calculated the mean number of species, number of families, stem density, and basal area of all sampled plots for each topographic attribute to assess the species richness, stem 
density, dominance, correlation between elevations, and slope and species distribution under different topography.

Statistica 13.3 was used to test for significant differences between the mean numbers of species, number of families and stem density; and the basal area, dominance and abundance of species. In order to present multiple regressions between topographic attributes and forest stand variables, the Scatter Plot Matrices (SPLOMS) with pairs. panels package in R (RStudio Team, 2015) was used [35]. We then compared the means of species, individuals among topographic attributes and stand parameters [36]. The forest parameters of the current study are presented in Table 3.1.

\subsubsection{Species composition}

Along with assessing the species composition for all topographic attributes, we also compared the contributions of dominance and abundance of the most ten species that were present in the representative plots to those of the entire attribute. The species composition of tree species as of species abundance as number of individuals (N/ha), absolute dominance as basal area $\left(\mathrm{m}^{2} / \mathrm{ha}\right)$, frequency in percent $(\%)$, and IVI of each species where consists of relative density, relative frequency and relative dominance of the attribute were calculated $[20,37]$. The comparison of species composition aimed at accessing the contribution of the ten most dominant species which appeared in the representative plots of each topographic attribute with those of the entire attribute with the hope to differentiate different forest ecology habitats where different species were compositionally found in different topographic attribute (Table 3.2).

\subsection{Results}

\subsubsection{Vegetation distribution over topography}

A total of 4297 individual trees were recorded, representing 122 species from 47 families from the total area $(9.0 \mathrm{ha})$. The ten most abundant species at lower elevations (H1), out of 121 species present, were: Syzygium lanceolatum (Lam.) Wight \& Arn, Lithocarpus ducampii (Hickel \& A.Camus), Lithocarpus dealbatus (Hook.f. \& Thomson ex Miq.) Rehder, Gironniera subaequalis Planch, Syzygium zeylanicum (L.) DC, Alangium ridleyi King, Scaphium 
macropodum (Miq) Beumee ex K.Heyne, Bursera tonkinensis Guillaum, Lithocarpus tubulosus (Hickel \& A.Camus) and Symplocos glauca (Thunb.) Koidz. Of these, the three most dominant species were L. dealbatus, L. ducampii and B. tonkinensis Guillaum (Table 3.2).

The ten most dominant species at higher elevations (H2), out of 109 species present, were: Lithocarpus ducampii (Hickel \& A.Camus), Gironniera subaequalis Planch, Lithocarpus tubulosus (Hickel \& A.Camus), Syzygium zeylanicum (L.) DC, Lithocarpus dealbatus (Hook.f. \& Thomson ex Miq.) Rehder, Syzygium zeylanicum (L.) DC, Aphanamixis grandiflora, Scaphium macropodum (Miq) Beumee ex K.Heyne, Alangium ridleyi King and Engelhardtia roxburghiana Lindl. But the most dominant species in $\mathrm{H} 2$ were L. ducampii, Shorea roxburghii G.Don, Dipterocarpus grandiflorus Blanco, Bursera tonkinensis Guillaum (Table 3.2).

The ten most abundant species at shallower slopes (S1), out of 116 species present, were: Syzygium lanceolatum (Lam.) Wight \& Arn, Lithocarpus dealbatus (Hook.f. \& Thomson ex Miq.) Rehder, Alangium ridleyi King, Gironniera subaequalis Planch, Lithocarpus ducampii (Hickel \& A.Camus), Syzygium zeylanicum (L.) DC, Scaphium macropodum (Miq) Beumee ex K.Heyne, Aphanamixis grandiflora, Bursera tonkinensis Guillaum and Symplocos glauca (Thunb.) Koidz. But the most dominant species were L. dealbatus, B. tonkinensis, $S$. lanceolatum and Shorea roxburghii G.Don (Table 3.2).

At the steeper slopes (S2), the ten most dominant species, out of the 117 present, were: Lithocarpus ducampii (Hickel \& A.Camus), Syzygium lanceolatum (Lam.) Wight \& Arn, Gironniera subaequalis Planch, Lithocarpus tubulosus (Hickel \& A.Camus), Syzygium zeylanicum (L.) DC, Aphanamixis grandiflora, Scaphium macropodum (Miq) Beumee ex K.Heyne, Engelhardtia roxburghiana Lindl, Lithocarpus dealbatus (Hook.f. \& Thomson ex Miq.) and Aphananthe cuspidata (Blume) Planch but the most dominant species were $L$. ducampii, Bursera tonkinensis Guillaum, Dipterocarpus grandiflorus Blanco and Shorea roxburghii G.Don (Table 3.2). 
Table 3.2. Species composition of the representative plots and of the entire topographic attribute.

\begin{tabular}{|c|c|c|c|c|c|c|c|c|}
\hline \multirow[b]{2}{*}{ Species } & \multirow[b]{2}{*}{ Family } & \multicolumn{3}{|c|}{ Representative Plots } & \multicolumn{4}{|c|}{ Topographic Attributes } \\
\hline & & 冚 & 节 & $\Sigma$ & 惫 & 䒿 & $\underbrace{d e}_{E}$ & $\Sigma$ \\
\hline Syzygium zeylanicum (L.) DC. (5:63) & Myrtaceae & 1.00 & 0.06 & 24.62 & 12.60 & 0.71 & 66 & 6.07 \\
\hline Bursera tonkinensis Guillaum (4:57) & Burseraceae & 0.80 & 0.12 & 33.82 & 11.40 & 0.89 & 46 & 6.21 \\
\hline Dipterocarpus grandiflorus Blanco (3:46) & Dipterocarpaceae & 0.60 & 0.02 & 13.06 & 9.20 & 0.33 & 42 & 4.21 \\
\hline Shorea roxburghii G.Don (2:26) & Dipterocarpaceae & 0.40 & 0.04 & 14.35 & 5.20 & 0.37 & 34 & 3.54 \\
\hline Alangium ridleyi King (2:63) & Cornaceae & 0.40 & 0.03 & 13.34 & 12.60 & 0.49 & 60 & 5.54 \\
\hline Wrightia annamensis Eberh. \& Dubard (2:36) & Apocynaceae & 0.40 & 0.02 & 10.46 & 7.20 & 0.18 & 44 & 3.42 \\
\hline Artocarpus rigidus Blume (1:14) & Moraceae & 0.20 & 0.07 & 18.49 & 2.80 & 0.16 & 14 & 2.46 \\
\hline Amesiodeuchon chinense (Merr.) Hu (1:19) & Sapindaceae & 0.20 & 0.05 & 13.70 & 3.80 & 0.31 & 28 & 3.07 \\
\hline Artocarpus tonkinensis A.Chev. ex Gagnep. (1:20) & Moraceae & 0.20 & 0.02 & 9.58 & 4.00 & 0.21 & 24 & 2.67 \\
\hline Engelhardtia roxburghiana Lindl (1:46) & Juglandaceae & 0.20 & 0.02 & 8.14 & 9.20 & 0.63 & 46 & 5.08 \\
\hline H1: Other $(\mathbf{3 4 : 3 9 0 )}$ & & 4.40 & 0.12 & 140.44 & 449.00 & 17.53 & - & 231.00 \\
\hline H1: Total (44:2635) & & 8.80 & 0.55 & 300.00 & 527.00 & 21.80 & - & 300.00 \\
\hline Elaeocarpus sylvestris (Lour.) Poir. (7:23) & Elaeocarpaceae & 1.75 & 0.13 & 37.41 & 5.75 & 0.40 & 20 & 3.85 \\
\hline Gironniera subaequalis Planch (4:69) & Cannabaceae & 1.00 & 0.08 & 24.22 & 17.25 & 0.80 & 58 & 8.02 \\
\hline Lithocarpus ducampii (Hickel \& A.Camus) (4:110) & Fagaceae & 1.00 & 0.08 & 23.92 & 27.50 & 2.02 & 60 & 12.06 \\
\hline Scaphium macropodum (Miq) Beumee ex K.Heyne (3:52) & Malvaceae & 0.75 & 0.05 & 17.51 & 13.00 & 0.51 & 68 & 7.02 \\
\hline Helicia cochinchinensis Lour. (3:30) & Proteaceae & 0.75 & 0.01 & 13.08 & 7.50 & 0.29 & 33 & 4.07 \\
\hline Macaranga denticulata (Blume) (2:18) & Euphorbiaceae & 0.50 & 0.04 & 14.07 & 4.50 & 0.12 & 25 & 2.66 \\
\hline Knema elegans Warb (2:23) & Myristicaceae & 0.50 & 0.02 & 12.05 & 5.75 & 0.30 & 23 & 3.47 \\
\hline Vitex quinata (Lour.) F.N.Williams (2:7) & Lamiaceae & 0.50 & 0.01 & 11.28 & 1.75 & 0.05 & 15 & 1.41 \\
\hline Canarium album (Lour.) DC. (2:26) & Burseraceae & 0.50 & 0.01 & 11.10 & 6.50 & 0.35 & 43 & 4.27 \\
\hline Cinnamomum verum J.Presl (2:5) & Lauraceae & 0.50 & 0.01 & 11.09 & 1.25 & 0.03 & 10 & 0.99 \\
\hline $\mathrm{H} 2$ : Other (33:363) & & 3.00 & 0.35 & 124.28 & 324.75 & 21.38 & - & 252.16 \\
\hline
\end{tabular}




\begin{tabular}{|c|c|c|c|c|c|c|c|c|}
\hline H2: Total (43:1662) & & 10.75 & 0.79 & 300.00 & 415.50 & 26.25 & - & 300.00 \\
\hline Lithocarpus tubulosus (Hickel \& A.Camus) (11:37) & Fagaceae & 2.89 & 0.02 & 30.11 & 9.74 & 0.51 & 34 & 5.03 \\
\hline Artocarpus tonkinensis A.Chev. ex Gagnep. (3:18) & Moraceae & 0.79 & 0.00 & 18.23 & 4.74 & 0.28 & 24 & 3.26 \\
\hline Aphanamixis grandiflora $\mathbf{( 3 : 4 2 )}$ & Euphorbiaceae & 0.79 & 0.01 & 14.69 & 11.05 & 0.41 & 58 & 5.19 \\
\hline Endospermun sinensis Benth. (3:21) & Euphorbiaceae & 0.79 & 0.01 & 13.38 & 5.53 & 0.16 & 29 & 2.82 \\
\hline Symplocos glauca (Thunb.) Koidz. (3:41) & Symplocaceae & 0.79 & 0.01 & 10.66 & 10.79 & 0.39 & 47 & 4.89 \\
\hline Nephelium melliferum Gagnep. (2:39) & Sapindaceae & 0.53 & 0.00 & 9.79 & 10.26 & 0.65 & 58 & 5.54 \\
\hline Prunus arborea (Blume) Kalkman (2:23) & Rosaceae & 0.53 & 0.02 & 9.42 & 6.05 & 0.19 & 34 & 3.15 \\
\hline Syzygium lanceolatum (Lam.) Wight \& Arn (2:73) & Myrtaceae & 0.53 & 0.01 & 8.07 & 19.21 & 0.82 & 79 & 7.98 \\
\hline Adina pilulifra $(\mathbf{1 : 1 1})$ & Rubiaceae & 0.26 & 0.01 & 9.72 & 2.89 & 0.06 & 24 & 1.78 \\
\hline Alphonsea monogyna Merr.\&Chun (1:6) & Annonaceae & 0.26 & 0.02 & 7.94 & 1.58 & 0.04 & 11 & 1.18 \\
\hline S1: Other (36:311) & & 3.95 & 0.70 & 167.99 & 426.32 & 17.99 & - & 259.17 \\
\hline S1: Total (46:1931) & & 12.11 & 0.80 & 300.00 & 508.16 & 21.50 & - & 300.00 \\
\hline Lithocarpus ducampii (Hickel \& A.Camus) (5:128) & Fagaceae & 0.96 & 0.09 & 31.99 & 24.62 & 1.86 & 67 & 10.55 \\
\hline Engelhardtia roxburghiana Lindl (3:51) & Juglandaceae & 0.58 & 0.04 & 16.75 & 9.81 & 0.83 & 46 & 5.61 \\
\hline Ormosia pinnata (Lour.) Merr (3:29) & leguminosae & 0.58 & 0.03 & 15.66 & 5.58 & 0.28 & 40 & 3.51 \\
\hline Sapium discolor (3:11) & Euphorbiaceae & 0.58 & 0.03 & 14.39 & 2.12 & 0.10 & 13 & 1.67 \\
\hline Gironniera subaequalis Planch (3:79) & Cannabaceae & 0.58 & 0.01 & 10.98 & 15.19 & 0.62 & 60 & 6.72 \\
\hline Archidendron clypearia (Jack) I.C.Nielsen (3:10) & Leguminosae & 0.58 & 0.01 & 10.29 & 1.92 & 0.07 & 12 & 1.39 \\
\hline Canarium album (Lour.) DC. (3:39) & Burseraceae & 0.58 & 0.01 & 9.83 & 7.50 & 0.27 & 42 & 3.98 \\
\hline Aphananthe cuspidata (Blume) Planch (2:49) & Cannabaceae & 0.38 & 0.04 & 15.55 & 9.42 & 0.52 & 38 & 4.81 \\
\hline Diospyros sylvatica Roxb (2:24) & Ebenaceae & 0.38 & 0.01 & 8.71 & 4.62 & 0.33 & 23 & 3.16 \\
\hline Aphanamixis grandiflora (2:64) & Meliaceae & 0.38 & 0.00 & 7.14 & 12.31 & 0.44 & 60 & 5.84 \\
\hline S2: Other (50:484) & & 5.96 & 0.15 & 158.73 & 361.92 & 20.12 & - & 252.76 \\
\hline S2: Total (60:2366) & & 11.54 & 0.42 & 300.00 & 455.00 & 25.44 & - & 300.00 \\
\hline
\end{tabular}

(Species presented in bracket i.e: (60:2366) indicating number of individual stems in the representative plot and the individual stems in the topographic attribute; $\mathrm{N}=$ number of stems of a species per ha; F = Frequency; IVI = Importance Value Index of the representing plot). 
Table 3.3. The abundant and dominant species in different topographic attributes.

\begin{tabular}{|c|c|c|c|c|c|}
\hline Att & Species & Family & $\mathbf{N}$ & $\begin{array}{l}\text { Abu } \\
\text { (N/ha) }\end{array}$ & $\begin{array}{l}\text { Dom } \\
\left(\mathbf{m}^{2} / \mathbf{h a}\right)\end{array}$ \\
\hline \multirow{12}{*}{$\mathrm{H} 1$} & Syzygium lanceolatum (Lam.) Wight \& Arn & Myrtaceae & 102 & 20.4 & 0.8 \\
\hline & Lithocarpus ducampii (Hickel \& A.Camus) & Fagaceae & 73 & 14.6 & 0.9 \\
\hline & $\begin{array}{l}\text { Lithocarpus dealbatus (Hook.f. \& Thomson ex Miq.) } \\
\text { Rehder }\end{array}$ & Fagaceae & 65 & 13.0 & 1.0 \\
\hline & Gironniera subaequalis Planch & Cannabaceae & 65 & 13.0 & 0.4 \\
\hline & Syzygium zeylanicum (L.) DC. & Myrtaceae & 63 & 12.6 & 0.7 \\
\hline & Alangium ridleyi $\mathrm{King}$ & Cornaceae & 63 & 12.6 & 0.5 \\
\hline & Scaphium macropodum (Miq) Beumee ex K.Heyne & Malvaceae & 58 & 11.6 & 0.4 \\
\hline & Bursera tonkinensis Guillaum & Burseraceae & 57 & 11.4 & 0.9 \\
\hline & Lithocarpus tubulosus (Hickel \& A.Camus) & Fagaceae & 55 & 11.0 & 0.5 \\
\hline & Symplocos glauca (Thunb.) Koidz. & Symplocaeae & 55 & 11.0 & 0.5 \\
\hline & Total (10) & & 656 & 131.2 & 6.7 \\
\hline & Other (111) & & 1979 & 395.8 & 15.1 \\
\hline \multirow{14}{*}{$\mathrm{H} 2$} & Lithocarpus ducampii (Hickel \& A.Camus) & Fagaceae & 110 & 27.5 & 2.0 \\
\hline & Shorea roxburghii G.Don & Dipterocarpaceae & 69 & 17.3 & 0.8 \\
\hline & Dipterocarpus grandiflorus Blanco & Dipterocarpaceae & 61 & 15.3 & 0.8 \\
\hline & Bursera tonkinensis Guillaum & Burseraceae & 60 & 15.0 & 0.6 \\
\hline & Engelhardtia roxburghiana Lindl & Juglandaceae & 58 & 14.5 & 0.6 \\
\hline & Lithocarpus tubulosus (Hickel \& A.Camus) & Fagaceae & 58 & 14.5 & 0.6 \\
\hline & Gironniera subaequalis Planch & Cannabaceae & 54 & 13.5 & 0.6 \\
\hline & Syzygium zeylanicum (L.) DC. & Myrtaceae & 37 & 9.3 & 0.8 \\
\hline & $\begin{array}{l}\text { Lithocarpus dealbatus (Hook.f. \& Thomson ex Miq.) } \\
\text { Rehder }\end{array}$ & Fagaceae & 35 & 8.8 & 0.5 \\
\hline & Aphanamixis grandiflora & Meliaceae & 35 & 8.8 & 0.5 \\
\hline & Alangium ridleyi King & Cornaceae & 21 & 5.3 & 0.6 \\
\hline & Scaphium macropodum (Miq) Beumee ex K.Heyne & Malvaceae & 12 & 3.0 & 0.6 \\
\hline & Total (12) & & 610 & 152.5 & 9.2 \\
\hline & Other (97) & & 1052 & 263.0 & 17.0 \\
\hline \multirow{13}{*}{ S1 } & $\begin{array}{l}\text { Lithocarpus dealbatus (Hook.f. \& Thomson ex Miq.) } \\
\text { Rehder }\end{array}$ & Fagaceae & 72 & 18.9 & 1.1 \\
\hline & Syzygium lanceolatum (Lam.) Wight \& Arn & Myrtaceae & 73 & 19.2 & 0.8 \\
\hline & Shorea roxburghii G.Don & Dipterocarpaceae & 21 & 5.5 & 0.8 \\
\hline & Lithocarpus ducampii (Hickel \& A.Camus) & Fagaceae & 55 & 14.5 & 0.8 \\
\hline & Syzygium zeylanicum (L.) DC. & Myrtaceae & 49 & 12.9 & 0.8 \\
\hline & Gironniera subaequalis Planch & Cannabaceae & 55 & 14.5 & 0.6 \\
\hline & Alangium ridleyi King & Cornaceae & 55 & 14.5 & 0.6 \\
\hline & Engelhardtia roxburghiana Lindl & Juglandaceae & 32 & 8.4 & 0.6 \\
\hline & Scaphium macropodum (Miq) Beumee ex K.Heyne & Malvaceae & 48 & 12.6 & 0.5 \\
\hline & Aphanamixis grandiflora & Meliaceae & 42 & 11.1 & 0.4 \\
\hline & Symplocos glauca (Thunb.) Koidz. & Symplocaeae & 41 & 10.8 & 0.4 \\
\hline & Total (11) & & 543 & 142.9 & 7.3 \\
\hline & Other (106) & & 1388 & 365.3 & 14.2 \\
\hline
\end{tabular}




\begin{tabular}{llccc}
\hline Lithocarpus ducampii (Hickel \& A.Camus) & Fagaceae & 128 & 24.6 & 1.9 \\
Bursera tonkinensis Guillaum & Burseraceae & 28 & 5.4 & 1.1 \\
Dipterocarpus grandiflorus Blanco & Dipterocarpaceae & 41 & 7.9 & 0.9 \\
Shorea roxburghii G.Don & Dipterocarpaceae & 30 & 5.8 & 0.9 \\
Engelhardtia roxburghiana Lindl & Juglandaceae & 51 & 9.8 & 0.8 \\
Lithocarpus tubulosus (Hickel \& A.Camus) & Fagaceae & 79 & 15.2 & 0.8 \\
Lithocarpus dealbatus (Hook.f. \& Thomson ex Miq.) & & 51 & 9.8 & 0.6 \\
Rehder & Fagaceae & 79 & 15.2 & 0.6 \\
Gironniera subaequalis Planch & Cannabaceae & 72 & 13.8 & 0.6 \\
Syzygium zeylanicum (L.) DC. & Myrtaceae & 89 & 17.1 & 0.6 \\
Syzygium lanceolatum (Lam.) Wight \& Arn & Myrtaceae & 49 & 9.4 & 0.5 \\
Aphananthe cuspidata (Blume) Planch & Cannabaceae & 64 & 12.3 & 0.4 \\
Aphanamixis grandiflora & Meliaceae & 62 & 11.9 & 0.4 \\
Scaphium macropodum (Miq) Beumee ex K.Heyne & Malvaceae & 823 & 158.3 & 10.3 \\
Total (13) & & 1543 & 296.7 & 15.2 \\
Other (104) & & & \\
\hline
\end{tabular}

(Att = attribute; $\mathrm{N}=$ number of stems of a species in the attribute; $\mathrm{Abu}=$ Abundance; Dom $=$ Dominance)

\subsubsection{Species diversity and Species distribution}

Table 3.1 shows significant differences $(\mathrm{p}<0.05)$ for mean number of tree species, number of families, tree density and basal area (BA) per hectare between $\mathrm{H} 1$ and $\mathrm{H} 2$. The sample results show that the higher elevation zone had lower species diversity, families, and stem density; but higher BA. Meanwhile, there are no significant differences $(\mathrm{p}<0.05)$ in mean family richness and Evenness (Eq) between S1 and S2. The mean values of number of species, family plot $^{-1}$, and tree density per hectare at the lower elevation and slope were higher than those of the higher elevation and slope, except for number of families in S1 and S2. 
Table 3.1. Species richness, diversity, density over respective topographic attributes

\begin{tabular}{lcccc}
\hline & \multicolumn{2}{c}{ Elevations (m) a.s.l. } & \multicolumn{2}{c}{ Slopes (degree) } \\
\cline { 2 - 5 } \multicolumn{1}{c}{ Attributes/Parameters } & $\mathbf{H 1}$ & $\mathbf{H 2}$ & $\mathbf{S 1}$ & $\mathbf{S 2}$ \\
& $\mathbf{( 1 5 0 - 6 9 9 )}$ & $\mathbf{( 7 0 0 - 1 1 6 2 )}$ & $\mathbf{( 5 - 2 0 )}$ & $\mathbf{( 2 0 - 4 8 )}$ \\
\hline No. of Plots $\left(1000 \mathrm{~m}^{2}\right)$ & 50 & 40 & 38 & 52 \\
Mean topographic attribute $( \pm$ SD/attr) & $527 \pm 146 \mathrm{a}$ & $808 \pm 92 \mathrm{~b}$ & $14.3 \pm 4.7 \mathrm{a}$ & $28.1 \pm 5.8 \mathrm{~b}$ \\
Species richness $( \pm \mathrm{SD})(\mathrm{species} / \mathrm{plot})$ & $29.7 \pm 3.4 \mathrm{a}$ & $20.2 \pm 3.6 \mathrm{~b}$ & $27.1 \pm 5.5 \mathrm{a}$ & $23.8 \pm 5.8 \mathrm{~b}$ \\
Families $( \pm \mathrm{SD})(\mathrm{family} / \mathrm{plot})$ & $21.3 \pm 2.9 \mathrm{a}$ & $15.8 \pm 2.8 \mathrm{~b}$ & $19.6 \pm 3.9 \mathrm{a}$ & $18.0 \pm 3.8 \mathrm{a}$ \\
Stand density $( \pm \mathrm{SD})(\mathrm{stem} / \mathrm{ha})$ & $527 \pm 8.9 \mathrm{a}$ & $415 \pm 13.2 \mathrm{~b}$ & $508 \pm 10.6 \mathrm{a}$ & $455 \pm 13.7 \mathrm{~b}$ \\
Basal Area $( \pm \mathrm{SD})\left(\mathrm{m}^{2} / \mathrm{ha}\right)$ & $21.8 \pm 0.6 \mathrm{~b}$ & $26.2 \pm 1.0 \mathrm{a}$ & $21.5 \pm 0.8 \mathrm{a}$ & $25.4 \pm 0.8 \mathrm{~b}$ \\
Shannon Index $(\mathrm{H})$ & $3.2 \pm 0.14 \mathrm{a}$ & $2.7 \pm 0.20 \mathrm{~b}$ & $3.1 \pm 0.29 \mathrm{a}$ & $2.9 \pm 0.26 \mathrm{~b}$ \\
Equality $(\mathrm{Eq})$ & $94 \pm 0.02 \mathrm{a}$ & $93 \pm 0.03 \mathrm{~b}$ & $98 \pm 0.31 \mathrm{a}$ & $93 \pm 0.05 \mathrm{a}$ \\
\hline
\end{tabular}

(Within column, the values followed by the same letter $(a, b)$ are not significantly different $(p<0.05)$ between $\mathrm{H} 1$ and $\mathrm{H} 2$ of each parameter and values followed by the same letter $(\mathrm{a}, \mathrm{b})$ are not significantly different $(\mathrm{p}<0.05)$ between $\mathrm{S} 1$ and $\mathrm{S} 2$ of each parameter).

The diversity of tree species, family, Shannon Index $(\mathrm{H})$ and Evenness (Eq) of each topographic attribute presented in Table 3.1 indicating the species diversity in Shannon Index and its Evenness amongst attributes were different and showed the same trend of Shannon Index between elevation and slope. Even though, the mean Evenness between S1 and S2 was not significantly different at $(\mathrm{p}<0.05)$. 


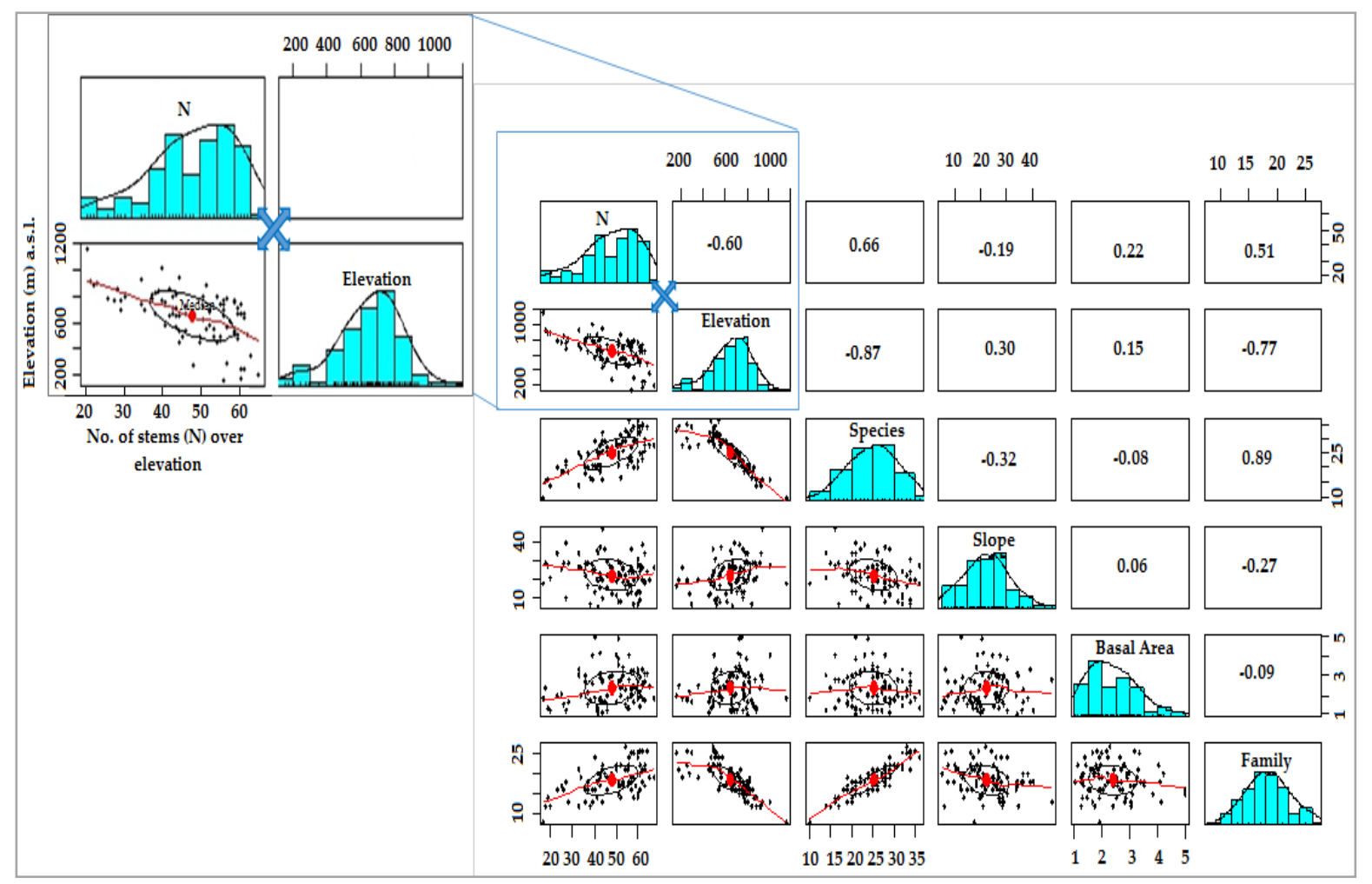

Figure 3.2. Paired correlation between elevation, slope with species, stem density $(\mathrm{N})$, basal area, family

The results presented in Figure 3.2 show negative correlation of the number of species with elevation at -0.87 , with stem density at -0.60 , and with number of families at -0.77 . A weak positive correlation of 0.15 exists between BA and elevation. The results show weak negative correlation of slope with species, stem density and family at $-0.32,-0.19$ and -0.27 , respectively. Slope exhibits a very week positive correlation with BA (0.06).

\subsubsection{Species composition}

The most ten dominant species of each topographic attribute were ranked (Table 3.2) according to species abundance as number of individuals (N/ha), absolute dominance as basal area $\left(\mathrm{m}^{2} / \mathrm{ha}\right)$, frequency in percent $(\%)$, and IVI of each species. The most dominant species at different elevations are mapped in Figure 3.3 in which the ten most dominant species of the representative in $\mathrm{H} 1$ and $\mathrm{H} 2$ were presented based on the elevation levels (m a.s.1.). The species composition provides information on the vegetation formation and contribution of each species through its abundance, dominance, and frequency, which help to explain the ecological habitat status in the 
study area (Table 3.2). The IVI is the combination of relative density, relative dominance and relative frequency in percentage, and helps rank the importance of a species in each attribute.

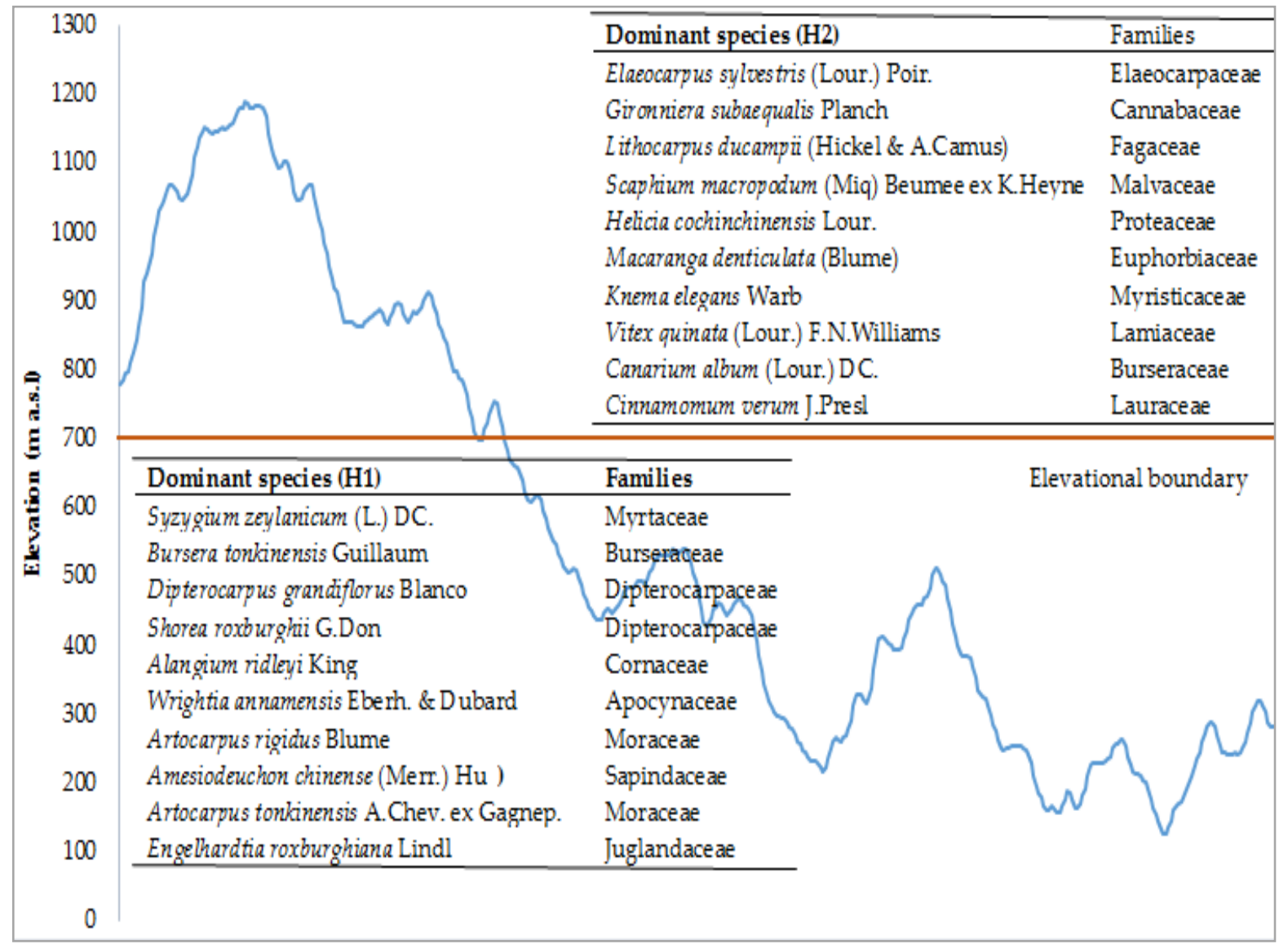

Figure 3.3. Most dominant species accounted in the representative plots of elevation levels (H1 and $\mathrm{H} 2$ ).

\subsection{Discussions}

\subsubsection{Topographic vegetation distribution}

Obtaining knowledge on species richness, species diversity and the species distribution among different elevations and slopes is a powerful tool in plant ecology to determine species composition [38]. The most abundant and dominant species in $\mathrm{H} 1, \mathrm{H} 2, \mathrm{~S} 1$ and $\mathrm{S} 2$ are presented in Table 3.3. The main species present in each attribute were determined, in primarily evergreen and semi- evergreen forests [21]. The number of species and number of families found in the current study, presented in Table 3.3, further emphasize the results of [38] and [39]. The above listed dominant families and species found in the current study were naturally distributed in central Truong Son Mountain range, and were reported by many researchers [39-41]. At the lower 
elevation (H1), the most abundant species presented in Table 3.3 were_S. lanceolatum, L. ducampii, L. dealbatus, G. subaequalis, S. zeylanicum, A. ridleyi, S. macropodum, B. tonkinensis, L. tubulosus and S. glauca. Of those species, L. dealbatus, B. tonkinensis and L. ducampii were the most dominant.

In the higher elevation (H2), the most abundant species present were_L. ducampii, $S$. roxburghii, D. grandifloras, B. tonkinensis, E. roxburghiana, L. tubulosus, G. subaequalis, S. zeylanicum, L. dealbatus, A. grandiflora, A. ridleyi, S. macropodum. Of these species, L. ducampii, S. roxburghii, D. grandifloras and S. zeylanicum were the most dominant and especially in the higher elevation, there were more endemic species from genera of Dipterocarpus, Shorea, Engelhardtia and Scaphium which are important and endemic of the northern Truong Son Mountain Range [11,40].

The abundant and dominant species in both shallower slope (S1) and steeper slope (S2) were not much different among themselves and with $\mathrm{H} 1$ and $\mathrm{H} 2$ presenting in Table 3.3. But it is good to note that the steeper slope had more endemic species than those in shallower slope (i.e, three endemic species were found in S1 as Shorea, Engelhardtia and Scaphium but four endemic species found in S2 were B. tonkinensis, Dipterocarpus, Shorea, Engelhardtia and Scaphium. These patterns help explain that forests in both lower elevation and shallower slope could have more influences by humans than those in the higher elevation and steeper slope $[42,43]$. The endemic species were found more dominant and abundant in the higher elevation and steeper slope where has low disturbance and better management and protection [44-46]. The aim of establishment of protected in Vietnam is to protect, research on the main ecosystem, threatened and endemic species of flora and fauna including their habitats $[11,47]$.

\subsubsection{Species diversity and Species distribution}

In the tropical area, the species richness, diversity and composition at the higher elevation were lower than at the lower elevation, meaning that the species richness, diversity decreased with an increase of elevation [48]. This relationship explains that forests at the lower elevation could be more environmentally shaped than those at the higher elevation. The lower elevation forests may be less productive due to competition or disturbance from humans and management [49]. The 
species richness between $\mathrm{H} 1$ and $\mathrm{H} 2$ was significantly different $(\mathrm{p}<0.05)$. Species richness declined with increasing elevation, which is in agreement with Sharma [31] and Gairola [50]. The species richness was also significantly different $(\mathrm{p}<0.05)$ between $\mathrm{S} 1$ and $\mathrm{S} 2$, where $\mathrm{S} 2$ had lower species richness than $\mathrm{S} 1$. This indicates that the lower elevation and slope had more species richness, and that elevation had more influence than slope on species richness and diversity [51,52]. The species richness, diversity and composition in the study area could have been influenced significantly by the gradients [53], not only with the number of species but also the number of families $(\mathrm{p}<0.05)$. At the lower elevation and lower slope, (which are more influenced by disturbances), forests could be more fragmented since radiation can reach the forest floor, so more pioneer species can become dominant during succession [54]. The tree density between the different elevations and slopes was significantly different $(p<0.05)$, this result corresponds to the findings of others [55-58]. The BA was significantly different between $\mathrm{H} 1$ and $\mathrm{H} 2$, as well as between S1 and S2 (p < 0.05). Since the basal area $(B A)$ is one of the elements contributing to species dominance in the forest stand and over topographic attributes. This finding is in line with the findings of some studies where the BA increased with an increase of elevation $[59,60]$.

Shannon Index (H) and Evenness (Eq) ranged from 2.7 to 3.2 and from 93 to 98 in all topographic attributes, respectively. The species diversity and Evenness at the lower elevation and slope were higher than for the higher elevation and steeper slope $(\mathrm{p}<0.05)$, which corresponds to the species richness. The Shannon Index between $\mathrm{H} 1$ and $\mathrm{H} 2$ is similar to the findings of Sinha $[61]_{2}$ and significantly different (95\%). While the trend of Evenness (Eq) at the steeper slope (S2) is higher than those in S1, it is not significantly different. The different consistence may show that the Evenness correlates to the disturbance, which is stronger in less steep topography [49]. Species diversity, basal area and species distribution presented in the current study can be differed from other studies such as [51] within the tropical rain forest of Costa Rica [31] in the moist temperate forest of Garhwal Himalaya, and [52] in Sierra Nevada, Mexico due to the different temperature and rainfall and different range of elevations of tropical forests in the southeast Asia. Especially in Latin America where the deciduous forests accounted for $47 \%$ of forest area [62]. 


\subsubsection{Species composition}

The most dominant species which contribute to the species composition of the representative plots for $\mathrm{H} 1$ and $\mathrm{H} 2$ was different. However, the $S$. zeylanicum species was the most abundant, numbering five individuals in the representative plot out of 63 individuals (5:63) in the entire topographic attribute $(\mathrm{H} 1)$, the $B$. tonkinensis was not as dominant as $S$. zeylanicum in the presentative plot of $\mathrm{H} 1$ but it is more dominant than $S$. zeylanicum in the entire topographic attribute. As four out of the ten dominant species at the lower elevation (H1) occupied $0.19 \mathrm{~m}^{2}$ out of $8.80 \mathrm{~m}^{2}$ per ha in representative plot, and $2.22 \mathrm{~m}^{2}$ out of $17.53 \mathrm{~m}^{2}$ per ha in the whole attribute, consisting of the Burseraceae, Diptercarpaceae and Juglandaceae families [63]. According to Thai [64], the dominant species below $1000 \mathrm{~m}$ a.s.l. (in the south) and $700 \mathrm{~m}$ a.s.l. (in the north) are of Fagaceae, Myrtaceae, Lauraceae, Cannabaceae, Meliaceae, Malvaceae, Leguminosae; and Dipterocarpaceae, Burseraceae, Sapotaceae, Magnoliaceae, and Meliaceae; respectively.

The dominance of these species confirms the stated forest type of moist and evergreen forests (where the annual rainfall is above $2500 \mathrm{~mm}$ and the moisture content is greater than 85\%) [65]. Some of the predominant species, such as S. zeylanicum, A. ridleyi, W. annamensis, A. rigidus, A. chinense and A. tonkinensis, were dominant and light demanding at this elevation range, representing a type of secondary forest [21]. These ten species occupied $160 \%$ out of $300 \%$ of IVI in the representative plot and $42.27 \%$ out $300 \%$ of IVI of the entire topographic attribute. The comparison of the Important Value Index of the dominant species in the representative plots with those in the entire topography gave a modest explanation of species composition in the entire topographic attribute. The values for dominance and abundance of both the representative plots and the topographic attribute is an indicator of species diversity, as lower dominance and abundance values result in high diversity. At the higher elevation $(\mathrm{H} 2)$, the dominant species were E. sylvestri, G. subaequalis and L. ducampii, which occupied $37.41 \%, 24.22 \%$ and $23.92 \%$ out of $175.72 \%$ in representative plot and occupied $50.5 \%$ out of $90.75 \%$ abundance and $3.22 \mathrm{~m}^{2}$ out of $4.87 \mathrm{~m}^{2}$ per ha of the ten most dominant species in this range of elevation. In this plot, there were three S.macropodum individuals out of 52, this species is the multiple-use propose of this area [66]. 
The composition of C. album, C. verum, L. ducampii, E. sylvestris, G. subaequalis indicates complex vegetation cover, where approximately 80 to 90 species can be commonly found in the fallow soil type or after being selectively-logged or fragmented. The dominant species in two representative plots of S1 and S2 could explain vegetation cover occurring in the lowland forests below $700 \mathrm{~m}$ (in the north) and $1000 \mathrm{~m}$ a.s.l. (in the south), especially in the humid region of both the Northern and Southern Truong Son Mountain Range where a combination of Lauraceae, Fagaceae, Moraceae, Anacardiaceae families were commonly found [39,40].

At steeper slope (S2), Lithocarpus ducampii are the most abundant and dominant, accounting for $32 \%$ in the representative plot and $10.55 \%$ in the topographic attribute. In this ecological range, Engelhardtia roxburghiana accounted for $16.75 \%$, followed by Ormosia pinnata (15.66\%), Sapium discolor (14.39\%), and Gironniera subaequalis (10.98\%) in the representative plot. On the other hand, G. subaequalis had the second highest abundance in the whole attribute with 15.19 individuals per ha, followed by Aphanamixis grandiflora (12.31 individuals) and Engelhardtia roxburghiana (9.81 individuals).

\subsection{Conclusions}

The species richness, species diversity, stand density and basal area were significantly different between lower and higher elevations, as well as between shallower and steeper slopes. The lower elevation and shallower slope had more species richness and diversity than the higher elevation and steeper slope did. The species diversity Evenness (Eq) presented in both the lower elevation (H1) and slope (S1) was higher than those of higher elevation (H2) and slope (S2). The higher elevation and steeper slope had a larger mean basal area, but less individuals per ha, this could result from forest disturbance and successional processes. Elevation had more influence on species, stand density, species diversity, basal area and family distribution than those of the slope. Slope had a weak correlation with the species richness, stand density and basal area in the study area. Elevation was the key factor influencing species richness, stem density and species dominance in the study area.

Species composition between elevations and slopes was significantly different in term of species dominance and abundance. Difference of species composition could have been subjected 
to disturbance or successional processes of forest ecosystem in the current study area. The species composition between slopes was not clearly distinguishable, this could help to confirm that slopes do not contribute to species distribution over topographic attributes. The species composition of the most abundant and dominant species in the representative plots did not fully represent the species which were dominant and abundant at the entire topographic attribute in the study area. It could result from the low variation of topographic elevation or can be that the location of the representative plots favors for a certain microsite or aspects. The current study can only report some major parameters of the forests; therefore, further efforts are needed for more information on endemic species and the most dominant species, which would contribute to appropriate conservation, restoration and management strategies in the area.

Acknowledgements: The authors would like to thank: the German Academic Exchange Service (DAAD); We acknowledge support of the German Research Foundation and the Open Access Publication Funds of the Göttingen University; the Department of Climate Change under the Ministry of Natural Resource and Environment of Vietnam; the University of Hue Agriculture and Forestry for their help in arranging administrative permission to access the research areas; the experts of Sub- Forest Inventory and Forest Planning in Thua Thien Hue province; We would like to express our sincere thanks to Prof. Dr. Ralph Mitlöhner for his valuable advice and to the forest experts of Forest Management Board of the A Luoi and Rangers of Sao La Nature Reserve for their during different phases of fieldwork; the botanists for tree species identification; and local authorities and local people in the A Luoi district. We thank Department of Cartography, GIS and Remote Sensing, Göttingen University for providing the ArcGIS software in the framework of research. We specially thank editors and reviewers for constructive comments for publication assistance.

\subsection{References}

1. Ashton, P.S.; Hall, P. Comparisons of Structure Among Mixed Dipterocarp Forests of NorthWestern Borneo. Journal of Ecology 1992, 80, 459.

2. Whitmore, T.C. An introduction to tropical rain forests; Clarendon Press: Oxford, 1990. 
3. McIntosh, R.P. An Index of Diversity and the Relation of Certain Concepts to Diversity. Journal of Ecology 1967, 48, 392-404.

4. Hall, J.B.; Swaine, M.D. Classification and Ecology of Closed-Canopy Forest in Ghana. Journal of Ecology 1976, 64, 913.

5. Huang, W.; Pohjonen, V.; Johansson, S.; Nashanda, M.; Katigula, M.; Luukkanen, O. Species diversity, forest structure and species composition in Tanzanian tropical forests. Forest Ecology and Management 2003, 173, 11-24.

6. Anbarashan, M.; Parthasarathy, N. Tree diversity of tropical dry evergreen forests dominated by single or mixed species on the Coromandel coast of India. Journal of Tropical Ecology 2013, 54, 179-190.

7. Brown, R.; Frederichsen, T. Topographic Factors Affecting the Tree Species Composition of Forests in the Upper Piedmont of Virginia. Virginia Journal of Science 2008, 59, 1-9.

8. Bunyavejchewin, S.; LaFrankie, J.V.; Baker, P.J.; Kanzaki, M.; Ashton, P.S.; Yamakura, T. Spatial distribution patterns of the dominant canopy dipterocarp species in a seasonal dry evergreen forest in western Thailand. Forest Ecology and Management 2003, 175, 87-101.

9. Kacholi, D.S. Edge-Interior Disparities in Tree Species and Structural Composition of the Kilengwe Forest in Morogoro Region, Tanzania. International Scholarly Research Notices 2014, 2014, 1-8.

10. Thomas, E.; Vandebroek, I.; van Damme, P. Valuation of Forests and Plant Species in Indigenous Territory and National Park Isiboro-Sécure, Bolivia. Economic Botany 2009, 63, 229-241.

11. Chien, P.D. Demography of threatened tree species in Vietnam. PhD Thesis; Utrecht University: Utrecht, 2006, 132.

12. Jong, W. de; van Hung, T. Forest Rehabilitation in Vietnam: Histories, Realities, and Future: Histories, Realities, and Future; CIFOR, 2006.

13. Olson, D.M.; Dinerstein, E.; Wikramanayake, E.D.; Burgess, N.D.; Powell, G.V.N.; Underwood, E.C.; D'amico, J.A.; Itoua, I.; Strand, H.E.; Morrison, J.C.; et al. Terrestrial Ecoregions of the World: A New Map of Life on Earth. BioScience 2001, 51, 933.

14. Clark, D.A.; Clark, D.B. Assessing the Growth of Tropical Rain Forest Trees: Issues for Forest Modelling and Management. Journal of Applied Ecology 1999, 9, 981-997.

15. Trejo, I.; Dirzo, R. Deforestation of seasonally dry tropical forest. Biological Conservation 2000, 94, 133-142.

16. María, C.-J.; Aide, T.M. Vegetation structure, species diversity, and ecosystem processes as measures of restoration success. Forest Ecology and Management 2005, 218, 159-173.

17. Chazdon, R.L.; Letcher, S.G.; van Breugel, M.; Martínez-Ramos, M.; Bongers, F.; Finegan, B. Rates of change in tree communities of secondary Neotropical forests following major 
disturbances. Philosophical Transactions of the Royal Society B: Biological Sciences 2007, $362,273-289$.

18. Desta, F.; Colbert, J.J.; Rentch, J.S.; Gottschalk, K.W. Aspect Induced Differences in Vegetation, Soil, and Microclimatic Characteristics of an Appalachian Watershed. Southern Appalachian Botanical Society 2004, 69, 92-108.

19. Jucker, T.; Boris B; David F. R. P. Burslem; Reuben N; Simon L. Lewis; Michele D; Phillips O.L; Lan Q; David A. C. Topography shapes the structure, composition and function of tropical forest landscapes. Ecology letter 2018, 21, 989-1000.

20. Nguyen, H.; David, L.; John, H.; Jenifer, F. Designing Mixed Species Tree Plantations for the Tropics: Balancing Ecological Attributes of Species with Landholder Preferences in the Philippines. PLoS ONE 2014, 9.

21. Nguyen, H.; Diez, J.; Kerstin, W. Spatial distribution and association patterns in a tropical evergreen broad-leaved forest of north-central Vietnam. Journal of Vegetation Science 2016, $27,318-327$.

22. Do, H.T.T.; Grant, J.C.; Trinh, B.N.; Zimmer, H.C.; Nichols, J.D. Diversity depends on scale in the forests of the Central Highlands of Vietnam. Journal of Asia-Pacific Biodiversity 2017, $10,472-488$.

23. Le Ba Thao. Vietnam. The Country and Its Geographical Regions 1997.

24. Nguyen, T.L.; Florimond, D.S. Analysis and Mapping of Rainfall-Induced Landslide Susceptibility in A Luoi District, Thua Thien Hue Province, Vietnam. Water 2019, 11, 5166.

25. Le, N. Adding some vascular plants to the list of plants in Thua Thien Hue Province. Journal of Research and Development 2016, 4, 96-107.

26. Pham, T.G.; Nguyen, H.T.; Kappas, M. Assessment of soil quality indicators under different agricultural land uses and topographic aspects in Central Vietnam. International Soil and Water Conservation Research 2018, 6, 280-288.

27. Tran, H.; Shigeru IIDA; Inoue S. Species Composition, Diversity and Structure of Secondary Tropical Forests Following Selective Logging in Huong Son, Ha Tinh Province, Vietnam. Journal of the Faculty of Agriculture - Kyushu University 2005, 50, 551-571.

28. van Laar, A.; Akça, A. Forest mensuration; Springer Netherlands: Dordrecht, 2007, 377.

29. Kalwij, J.M. Review of 'The Plant List, a working list of all plant species'. Journal of Vegetation Science 2012, 23, 998-1002.

30. Mazier D, Baumgartner F, Lepitre C. Terrain classification for tropical logging: Application in the case of Gabon 1975, 162.

31. Sharma, C.; Suyal S; Gairola S; Ghildiyal S.K. Species richness and diversity along an altitudinal gradient in moisttemperate forest of Garhwal Himalaya. American Journal of Science 2009, 5, 119-128. 
32. Adekunle, V.; Olagoke, A.; Akinele, S. Tree species diversity and structure of a Nigerian strict nature reserve. Journal of Tropical Ecology 2013, 54, 275-289.

33. Claude E. Shannon. The Mathematical Theory of Communication. In A Mathematical Theory of Communication; Claude E.Shannon, Warren Weaver, Eds.: University of Illinois Press: Urbana, 1964, pp. 29-125.

34. Pielou, E.C. The measurement of diversity in different types of biological collections. Journal of Theoretical Biology 1966, 13, 131-144.

35. William, R. Procedures for Psychological, Psychometric, and Personality Research; Northwestern University: Evanston, Illinois, 2013.

36. Meireles, L.D.; Shepherd, G.J. Structure and floristic similarities of upper montane forests in Serra Fina mountain range, southeastern Brazil. Acta Botanica Brasilica 2015, 29, 58-72.

37. Curtis, J.T.; McIntosh, R.P. The Interrelations of Certain Analytic and Synthetic Phytosociological Characters. Ecology 1950, 31, 434-455.

38. Naidu, M.T.; Kumar, O.A. Tree diversity, stand structure, and community composition of tropical forests in Eastern Ghats of Andhra Pradesh, India. Journal of Asia-Pacific Biodiversity 2016, 9, 328-334.

39. Van, Y.T.; Cochard, R. Tree species diversity and utilities in a contracting lowland hillside rainforest fragment in Central Vietnam. Forest Ecosystems 2017, 4, 115.

40. Le, N.T.T. Adding some vascular plants to the list of plants in Thua Thien Hue province. 2016, 4.

41. Soejima, A.; Tagane, S.; Nguyen Van, N.; Duy, C.N.; Huong, N.T.T.; Yahara, T. Callicarpa bachmaensis Soejima \& Tagane (Lamiaceae), a new species from Bach Ma National Park in Thua Thien Hue Province, Central Vietnam. PhytoKeys 2016, 62, 33-39.

42. Hadley, K.S. The Role of Disturbance, Topography, and Forest Structure in the Development of a Montane Forest Landscape. Bulletin of the Torrey Botanical Club 1994, 121, 47-61.

43. Sébastien, L.; John, D. Thompson, Eric G; Max D. The Biology and Ecology of Narrow Endemic and Widespread Plants: A Comparative Study of Trait Variation in 20 Congeneric Pairs. OIKOS 2004, 107, 505-518.

44. Noss, R.F.; Cooperrider, A.Y. Saving nature's legacy: protecting and restoring biodiversity; Island Press: Washington, D.C., 1994.

45. Yocom, L.; Fulé, P.Z. Human and climate influences on frequent fire in a high-elevation tropical forest. Journal of Applied Ecology 2012, 49, 1356-1364.

46. Fabrucius, C.; Burger, M.; Hockey, P.A.R. Comparing biodiversity between protected areas and adjacent rangeland in xeric succulent thicket, South Africa: arthropods and reptiles. Journal of Applied Ecology 2003, 40, 392-403. 
47. An, L.; Markowski, J.; Bartos, M. The comparative analyses of selected aspects of conservation and management of Vietnam's national parks. Journal for Nature Conservation 2018, 25, 1-30.

48. Sabatini, F.M.; Borja, J.A, Sabina, B.; Andrea, L.; Milan, C. Beta-diversity of central European forests decreases along an elevational gradient due to the variation in local community assembly processes. Ecography 2018, 41, 1038-1048.

49.Zhang, J.T.; Xu, B.; Li, M. Vegetation Patterns and Species Diversity Along Elevational and Disturbance Gradients in the Baihua Mountain Reserve, Beijing, China. Mountain Research and Development 2013, 33.

50. Gairola, S.; Sharma, C.M.; Ghildiyal, S.K.; Suyal, S. Tree species composition and diversity along an altitudinal gradient in moist tropical montane valley slopes of the Garhwal Himalaya, India. Forest Science and Technology 2011, 7, 91-102.

51. Clark, D.B.; Hurtado, J.; Saatchi, S.S. Tropical rain forest structure, tree growth and dynamics along a 2700-m elevational transect in Costa Rica. PLOS ONE 2015, 10, e0122905.

52. Sánchez A. G; López L. M. Plant species richness and diversity along an altitudinal gradient in the Sierra Nevada, Mexico 2005, 11, 567-575.

53. Dorji, T.; Stein, R.M.; Julia, A.K.; Totland, Ø. Plant Species Richness, Evenness, and Composition along Environmental Gradients in an Alpine Meadow Grazing Ecosystem in Central Tibet, China. Arctic Antarctic and Alpine Research 2014, 46, 308-326.

54. Emery, S. Succession: A Closer Look. Nature Education Knowledge Project 2010, 3, 45.

55. Dossa, G.G.O.; Ekananda, P.; Junichi, F.; Yu, H.; Wanlop, C.; Zhang, Y.; Paz, P.; Harrison, R. Factors Determining Forest Diversity and Biomass on a Tropical Volcano, Mt. Rinjani, Lombok, Indonesia. PLOS ONE 2013, 8.

56. Ifo, S.A.; Moutsambote, J.-M.; Koubouana, F.; Yoka, J.; Ndzai, S.F.; Bouetou-Kadilamio, L.N.O.; Mampouya, H.; Jourdain, C.; Bocko, Y.; Mantota, A.B.; et al. Tree Species Diversity, Richness, and Similarity in Intact and Degraded Forest in the Tropical Rainforest of the Congo Basin: Case of the Forest of Likouala in the Republic of Congo. International Journal of Forestry Research 2016, 2016, 1-12.

57. Sahu, S.; Dhal, N.; Rama, R. Tree species diversity, distribution and population structure in a tropical dry deciduous forest of Malyagiri hill ranges, Eastern Ghats, India. Tropical Ecology 2012, 53, 163-168.

58. Campbell, D.G.; Stone, J.L.; Rosas, A., JR. A comparison of the phytosociology and dynamics of three floodplain (Várzea) forests of known ages, Rio Juruá, western Brazilian Amazon. Botanical Journal of the Linnean Society 1992, 108, 213-237.

59. Whitmore, T.C.; Sidiyasa, K. Composition and Structure of a Lowland Rain Forest at Toraut, Northern Sulawesi. Kew Bulletin 1986, 41, 747-757. 
60. Chris, C. The environmental control of plant species density on Himalayan elevation gradient. Journal of Biogeography 2005, 32, 999-1018.

61. Sinha, S.; Badola, H.; Bijoy, C.; Gaira, K.; Lepcha, J.; Pitamber, P. Effect of altitude and climate in shaping the forest compositions of Singalila National Park in Khangchendzonga Landscape, Eastern Himalaya, India. Journal of Asia-Pacific Biodiversity 2018, 11, 267-275.

62. Toledo, T.A.; García, F.O. Effects of forest-pasture edge on C, N and P associated with Caesalpinia eriostachys, a dominant tree species in a tropical deciduous forest in Mexico. Ecological Research 2008, 23, 271-280.

63. Lin, L.; Huang, Z.; Ye, W.; Cao, H.; Wei, S.; Wang, Z.; Lian, J.; Sun, I.F.; Ma, K.; He, F. Spatial distributions of tree species in a subtropical forest of China. OIKOS 2009, 118, 495502.

64. Thai, V. Forest vegetation cover of Vietnam, 2nd ed; Science and Technics Publishing House: Ha Noi, 1978.

65. Schmid, M., Ed. Some considerations on the edaphic conditions in the tropical forest areas and their implications to land management, 1977.

66. Le, Q.H. Growth, demography and stand structure of Scaphium macropodum in differently managed forests in Vietnam; Utrecht University, Forest Science Institute of Vietnam: Netherlands, 2012. 


\title{
Chapter 4. Land Cover and Forest Type Classification by Values of Vegetation Indices and Forest Structure of Tropical Lowland Forests in Central Vietnam
}

\author{
Hung Nguyen Trong ${ }^{1,2}$, The Dung Nguyen ${ }^{1,3}$, Martin Kappas ${ }^{1}$ \\ ${ }^{1}$ Department of Cartography, GIS and Remote Sensing, Georg-August-Universität Göttingen, \\ 37077 Göttingen, Germany; tronghung2128@gmail.com (H.N.T); tnguyen4@gwdg.de \\ (N.T.D); mkappas@gwdg.de (M.K) \\ ${ }^{2}$ Ministry of Natural Resources and Environment, Hanoi, Vietnam. \\ ${ }^{3}$ Vietnam National University of Forestry, Xuan Mai, Ha Noi, Vietnam; \\ *Correspondence: tronghung2128@ gmail.com; \\ Academic Editor: Anna Źróbek-Sokolnik
}

\section{Abstract:}

This paper aims to (i) optimize the application of multiple bands of satellite images for land cover classification by using random forest algorithms and (ii) assess correlations and regression of vegetation indices of a better-performed land cover classification image with vertical and horizontal structures of tropical lowland forests in Central Vietnam. In this study, we used Sentinel-2 and Landsat-8 to classify seven land cover classes of which three forest types were sub-stratified as undisturbed, low disturbed and disturbed forests where forest inventory of 90 plots, as ground truth, was randomly sampled to measure forest tree parameters. A total of 3226 training points was sampled on seven land cover types. The performance of Landsat-8 showed out-of-bag error of $31.6 \%$, overall accuracy of $68 \%$, kappa of $67.5 \%$ while Sentinel-2 showed out-of-bag error of $14.3 \%$ and overall accuracy of $85.7 \%$, kappa of $83 \%$. Ten vegetation indices of the better-performed image were extracted to find out (i) the correlation and regression of horizontal and vertical structures of trees, (ii) assess the variation values between groundtruthing plots and training sample plots in three forest types. The result of the t-test on vegetation indices showed that six out of ten vegetation indices were significant at $p<0.05$. Seven vegetation indices had a correlation with the horizontal structure, but four vegetation indices namely Enhanced Vegetation Index, Perpendicular Vegetation Index, Difference Vegetation Index, and Transformed Normalized Difference Vegetation Index had better correlations $r=0.66,0.65$, $0.65,0.63$ and regression results were of $\mathrm{R}^{2}=0.44,0.43,0,43$ and 0,40 respectively. The correlations of tree height were $r=0.46,0.43,0.43,0.49$ and its regressions were of $R^{2}=0.21$, $0.19,0.18$ and 0.24 respectively. The results show the possibility of using random forest algorithm with Sentinel-2 in forest type classification in line with vegetation indices application.

Keywords: Sentinel-2, Landsat-8, Random Forest, Vegetation Indices, Dominant Species. 


\section{Citation:}

Hung Nguyen Trong*, The Dung Nguyen, Martin Kappas, "Land Cover and Forest Type Classification by Values of Vegetation Indices and Forest Structure of Tropical Lowland Forests in Central Vietnam", International Journal of Forestry Research, vol. 2020, Article ID 8896310, 18 pages, 2020. https://doi.org/10.1155/2020/8896310

* Correspondent author.

\subsection{Introduction}

Forests, at a nationwide scale, need a monitoring system as fundamental tools to support the management of landscapes, land use, ecosystem, biodiversity for multiple production purposes including national forest inventory (NFI) and international conventions [1-4]. It is clearly stated that land cover and land use mapping classification, derived from remote sensing data, for natural resource management, monitoring and development strategies are still open as big demand of the society and can be expressed as discrete classes or continuous land cover attributes [5]. Many studies have made land cover maps from different data sources such as multispectral, hyperspectral, radar aperture [6-9] and efforted to generating information from remote sensing (RS) by using machine learning algorithms to classify land cover [10-12]. Machine learning algorithms such as support vector machine, k-Nearest Neighbor and Random Forest are non-parametric classifiers caused huge attention for remote sensing in the last decades. The Random Forest (RF) is one of the most optimal artificial methodologies used for land cover classification with non-parametric classification algorithms that can run on large data sets $[13,14]$. Furthermore, RF is an optimal algorithm which is suitable for an excellent number of remote sensing applications and compared to other conventional techniques [15-17].

Remote sensing images provide potential information on tropical landscape forests and land use types [18] where the landscape is defined as a heterogeneous land area from a set of a cluster of interacting ecosystems that repeat in similar shape throughout and as an area that is spatially heterogeneous in at least one factor of interests $[19,20]$. The structure of forest has a relation to spatial distribution and as an important factor of forest ecological processes which supports to give more patterns of some taxa and even the disturbance status [21,22]. Forest structure provides important additional information to improve the estimation of forest stand variables [23]. High-resolution remote sensing images with the support of promising technique is potential for capturing the status but may not obtain forest productivity, which can partially reflect forest structure [23]. The outstanding method for evaluating land cover classification is a ground-based assessment derived from remote sensing [24]. Different sensors and methodology may give different results of application and information [25-27]. Vegetation indices (VIs) are 
essential for vegetation cover classification captured from the radiometric biophysical derivation and, vegetation structure. These indices contribute to land use planning and manage natural resources management and provide to policy making [28-31]. Sentinel-2 and Landsat-8 were developed to support vegetation, land cover, land use, environmental monitoring and others such as biophysical and geographical resources [32,33]. The Sentinel-2 measures reflected radiance within 13 spectral bands, whereas Landsat- 8 has eleven bands. Multi-spectral bands help to map the vegetation types of the regional scale $[34,35]$. Some studies have tried to classify land cover and vegetation cover in tropical life form using vegetation indices and texture but mapping different land cover and forest types in the tropic is a big challenge due to its heterogeneity of landscape, availability of optical satellite images with low cloud ratio [36,37]. The spatial resolution is dependent on the particular spectral bands but $10 \mathrm{~m}$ resolution of Sentinel-2 can provide feasible phenological values for different landscapes [38]. Several studies applied multispectral bands of Landsat- 8 with a resolution of $30 \mathrm{~m}$ to assess vegetation dynamic [39]. The key process of the research workflow is presented in Figure 4.1.

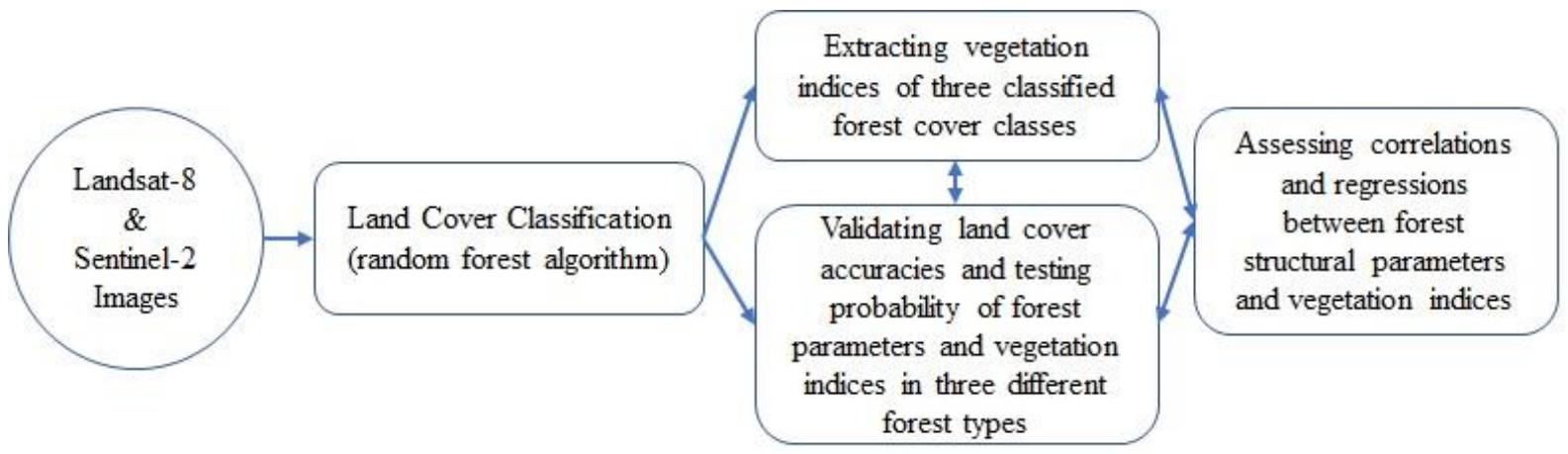

Figure 4.1. A key process on land cover classification, vegetation indices extraction and verification of research workflow

No studies have been conducted applying RF for land cover classification in combination with extracted vegetation indices to stratify forest structures and to compare the values of vegetation indices between the ground truth and training sample plots of VIs from the bestperformed satellite images in the tropical lowland forests in Vietnam. This paper aims to (i) compare the application of multiple band Sentinel-2 and Landsat-8 images for land cover classification by applying RF and (ii) evaluate the correlation and regression of vegetation indices forest vertical and horizontal structures with the above -mentioned two sensors in the tropical lowland forests in Central Vietnam.

\subsection{Study area}

The study area is located between $107^{\circ} .22^{\prime} \mathrm{E}$ to $107.30^{\prime} \mathrm{E}$ and $16^{\circ} .02^{\prime} \mathrm{N}$ to $16^{\circ} 10^{\prime} \mathrm{N}$ in the Western part of Thua Thien Hue province (Figure 4.2). The average annual temperature is 
$21.9^{\circ} \mathrm{C}$, the average high temperature is $25.3^{\circ} \mathrm{C}$, and the average low temperature is $17^{\circ} \mathrm{C}$. Moisture content varies from $81 \%$ to $94 \%$, and it is normally influenced by an inter-tropical convergence zone that typically causes tropical low pressures, monsoons, and typhoons leading to annual rainfall of about $3500 \mathrm{~mm}$ with an average of 200 rainy days annually, most of which accumulates between September and December [40,41].

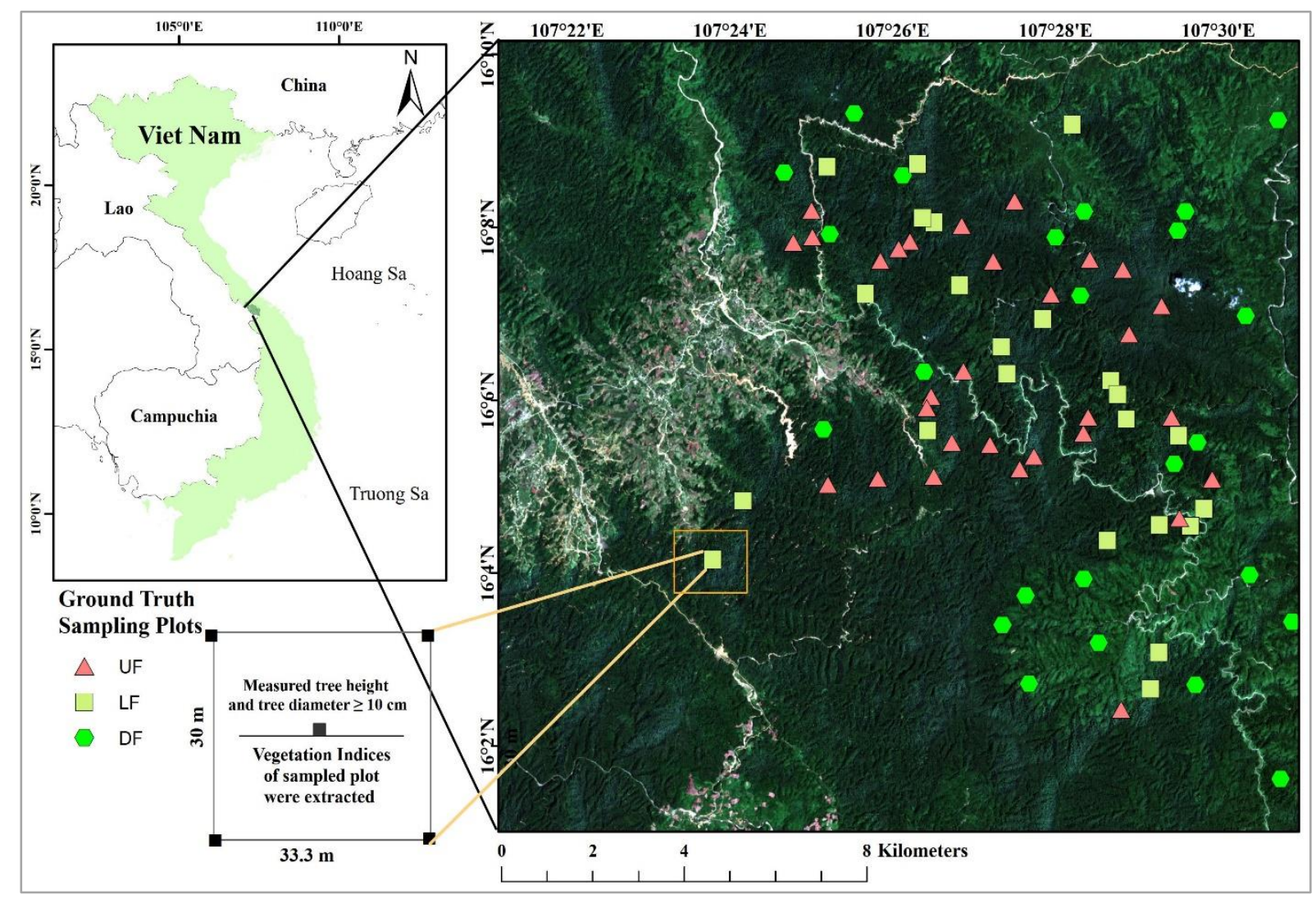

Figure 4.2. Research Area. The ground truth sampling plots were conducted at three forest types: $\mathrm{UF}=$ undisturbed forest; $\mathrm{LF}=$ less disturbed forest; $\mathrm{DF}=$ disturbed forest.

This study area located in a mountainous region consisting of primary and secondary closed evergreen broadleaved lowland forests [42]. The dominant species in the study area are of families: Fagaceae, Myrtaceae, Lauraceae, Cannabaceae, Leguminosae, Dipterocarpaceae, Malvaceae, Meliaceae, Myristacaeae, Burseraceae and Annonaceae [42,43]. There are four main land-use types grass, natural forest, plantation forest and agricultural land in A Luoi district. The predominant soil types are of Humic Acrisols, Hyperdystrict Acrisols, Arenic Acrisols, and Ferralic Acrisols [44]. According to Thai [45], the study area consists of mainly lowland evergreen broadleaf forests. The classification system of forest-based ecosystem enclosing five main stories namely (i) upper storey where tree with height of about 40 to $50 \mathrm{~m}$; (ii) Ecological dominance where most of trees belong to Fagaceae, Lauraceae, Magnoliaceae, Burseraceae, Meliaceae; (iii) Lower storey where tree height is from 8 to $15 \mathrm{~m}$ belonging to Annonaceae, Ulmaceaeand, Myristicaceae and Clusiaseae; (iv) Under storey where trees are from 2 to $8 \mathrm{~m}$ 
high and (v) Climbers with the height of less than two meters. Four forest types of the lowland forest consist of evergreen closed, semi-deciduous closed, deciduous closed and closed, hard leaved that echoed the development of lowland tropical forests in Vietnam since 1960s. The four forest types classification method of Germany introduced by Loeschau to Vietnam in 1959 has been widely applied $[46,47]$. The rich forest distributes in the very remote, and high terrain area where forests are protected and forest structure is well-preserved, called undisturbed forest (UF) which had the basal area of about $30 \mathrm{~m}^{2} \mathrm{ha}^{-1}$ [48]. The UF is dominated by Fagaceae, Lauraceae, Dipterocarpaceae, Leguminosae and Meliaceae. The second forest type is classified as a medium forest where the forest has been somehow slightly logged and disturbed, canopy fragmentation exists, and its structure is somehow maintained with the basal area ranging from $21-26 \mathrm{~m}^{2}$ ha ${ }^{1}$ [49]. This forest type is classified as less disturbed forest (LF), which is dominated by Fagaceae, Lauraceae, Euphorbiaceae, and Sapidaceae. The third type is secondary forest, where forest is heavily disturbed (DF), is dominated with Myristicaceae, Clusiaceae, Annonaceae, Euphorbiaceae and Myrtaceae [45,50] with the basal area from $10-21 \mathrm{~m}^{2} \mathrm{ha}^{-1}$ [49].

\subsection{Materials and Methods}

\subsubsection{Ground truth samples}

In order to gather the ground truth data for (1) forest types classification and (2) assess the correlation between vegetation indices and forest vertical and horizontal structures, we based on the local forest status map to randomly layout 90 sampled plots $(30 \times 33.3 \mathrm{~m})$ in three different forest classes hereafter referred to as forest types of UF, LF and DF to measure the height $(\mathrm{H})$ in meter and the diameter at breast height $(\mathrm{DBH}) \geq 10$ in a centimeter of all living trees. Forest stand parameters were collected using conventional forest inventory techniques [51]. The tree species were first recorded in Vietnamese nomenclature and then to scientific names [52]. Names of all tree species were then checked to avoid synonym [53,54]. The mean stand parameters were then calculated, analyzed and conducted t-test $[55,56]$. The dominance of tree species in basal area $\left(\mathrm{m}^{2} / \mathrm{ha}^{-1}\right)$, abundance of tree species occurring as number stem of a tree species $\left(\mathrm{N} / \mathrm{ha}^{-1}\right)$, frequency (\%) and Importance Value Index (IVI) of the most dominant and abundant species were calculated $[57,58]$. The in-stored random samples in GPS were used to guide the field team to the sampled site. The minimum interval distance among plots is around 200 meters. Reference dataset has been created by a field survey where ground truth values have been recorded using the Global Positioning System (GPS). The ground-truth sampling was conducted $3^{\text {rd }}$ April to the $28^{\text {th }}$ of May 2017. 


\subsubsection{Remote sensing data}

Both Sentinel-2-Level 1C (ID: L1C_T48PYC_A009124_20170322T033236) acquired on 22 March 2017 and Landsat-8 (ID: LC08_L1TP_125049_20170809_20170823_01_T1, acquired on 09 August 2017) were downloaded from the website of the United States Geological Survey [59]. The imagery was atmospherically corrected by using the Sen2Cor tool incompatibility in the platform of the Sentinel Application Platform (SNAP) toolbox [60]. All band, except band 10 of Sentinel-2, were converted to radiance, TOA reflectance, and surface reflectance and resampled to $10 \mathrm{~m}$ x $10 \mathrm{~m}$ resolution with the Shuttle Radar Topography Mission (SRTM) Digital Elevation Model referencing before compositing and extracting by mask to the study area. The Sentinel - Cirrus band was neither used for land cover classification nor vegetation calculation [61]. The composited $10 \mathrm{~m}$ band imageries were used for classification and extraction of vegetation indices in this study. The Landsat- 8 provides 11 multispectral bands, nine bands except for band 8 and band 9 (Panchromatic and Cirrus) were not used for classification. All selected bands were resampled to $10 \mathrm{~m} \times 10 \mathrm{~m}$ resolution for sampling and classification. The flow of remote sensing data collection and process is presented in Figure 4.3.

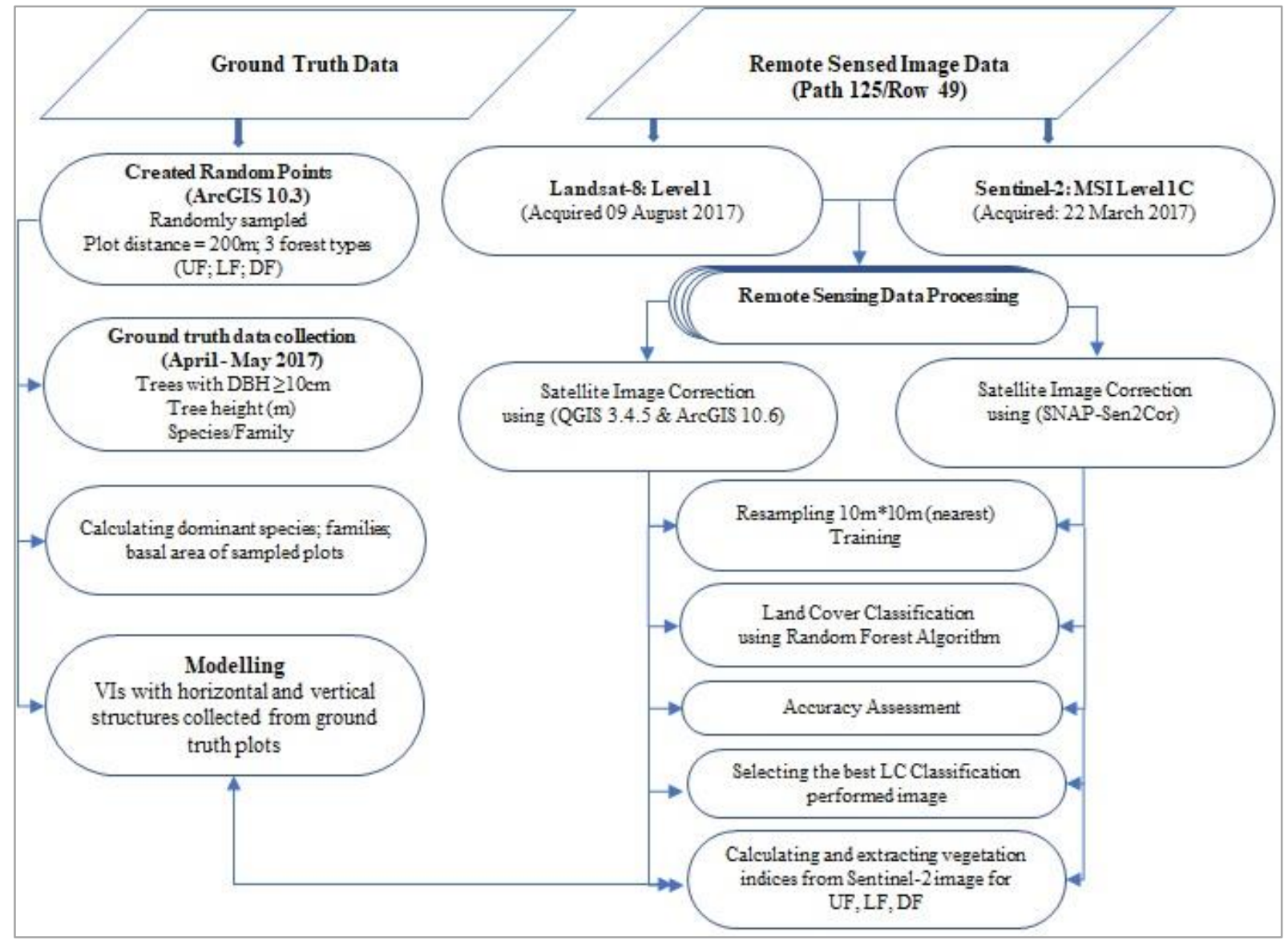

Figure 4.3. Flowchart of satellite data and ground truth data processing methods 


\subsubsection{Land Cover Classification Training and Testing Samples}

\subsubsection{Training dataset classification and testing}

A set of polygons was created to collect training sample data by using ArcGIS 10.6.1 toolbox. The training data were manually sampled in composited RGB imagery of Sentinel-2. To enhance the accuracy of training sample, the up-to-date imagery of Google Earth was also used as a reference. Different sizes of polygons may differ the number of pixels per land cover class. The training and test samples are presented in Table 4.1.

Table 4.1. Land cover training and testing samples

\begin{tabular}{lcccc}
\hline \multicolumn{1}{c}{ Land cover } & $\begin{array}{c}\text { No. } \\
\text { Classes }\end{array}$ & $\begin{array}{c}\text { Class } \\
\text { training } \\
\text { pixels }\end{array}$ & $\begin{array}{c}\text { Training/ } \\
\text { Testing } \\
\text { pixel of } \\
\text { Landsat-8 }\end{array}$ & $\begin{array}{c}\text { Training/ } \\
\text { Testing } \\
\text { pixel of } \\
\text { Sentinel-2 }\end{array}$ \\
\hline Residential and Constructions (RC) & 1 & 435 & $290 / 145$ & $308 / 127$ \\
Water and River (WR) & 2 & 270 & $187 / 83$ & $180 / 90$ \\
Agriculture (Agr) & 3 & 500 & $384 / 149$ & $351 / 147$ \\
Slash and Burnt (SB) & 4 & 323 & $226 / 97$ & $229 / 94$ \\
Disturbed Forest (DF) & 5 & 600 & $445 / 155$ & $414 / 186$ \\
Low Disturbed Forest (LF) & 6 & 487 & $341 / 146$ & $335 / 152$ \\
Undisturbed Forest (UF) & 7 & 611 & $421 / 189$ & $441 / 170$ \\
\hline
\end{tabular}

The Land Use/Land Cover (LULC) of the selected area is divided into seven classes. In accordance with Land Law 2013 of Vietnam, the three main land-use types are agricultural, nonagricultural, and unused lands. Of the seven land cover classes in table 4.1, RC and WR belong to non-agricultural land. The Agr, SB, DF, LF, and UF are of agricultural land. Forest lands are the most dominant in the current study area [62]. Land cover and land use were classified into four land-use types arable land, plantation forest, natural forest for production, and bare land [44]. Thus the seven land cover classes are the most representative of the natural land in this area. The residential and construction areas illustrated in this study consist of civil constructions such as houses, roads, irrigation, schools, clinics. Water area includes river which, at the imagery acquired data, was partly shallow. The agricultural area is of rice, maize, vegetable production. Slash and Burnt is either upland land which is considered as land for woodlots, exotic tree species plantation such as Acacia auriculiformis, Acacia mangium, Acacia hybrid, Hevea brasiliensis, Anacardium occidentale and Hopea ordorata or periodically being burnt after harvesting. This type of land exists in all mountainous areas of Vietnam. The three forest cover classes classified into disturbed forests were (i) forests were heavily degraded or deforested (DF), (ii) forests were 
somehow degraded but its structure is maintained (LF), and (iii) forests where minor disturbances by nature or human have occurred and its structure are well-preserved (UF) $[47,63]$.

\subsubsection{Random Forest Classification}

The two most important parameters in RF land cover classification are ntree and mtry which effect to the results of land cover classification where the random classifier vector generates from different pixels and each tree cast is a unit vote for the most class to rank the input vector [14,64]. Twelve bands of the Sentinel-2 as 12 input variables and the nine bands of the Landsat- 8 as nine bands as input variables were used for classification. The composition of RF classification is basically from sub-samples of ntree, which are trained and fit best to the most popular class. A total of 2236 pixels for seven classes as seven land-use types used unbalanced random sampling. To support the $\mathrm{RF}$ algorithm, a ratio of $70 \%$ training pixels (2258 training samples) was used to run the RF algorithm, and 30\% of the total training pixels (964 training samples) was used for testing. The remaining samples are used, by RF, to obtain the class error estimates indicating via the score of out of bag (OOB). According to some researchers, ntree parameters applied in RF classifier can be default $[65,66]$, and other studies state that increase of ntree will produce the better performance of accuracy estimates [65]. The number of ntree in this study was defined as a list of nine levels continuously ranging from 100, 200, 300, 400, 500, $600,700,800$, and 900. The feature in each split called mtry which is controlled by user in the sub-samples and feeds the RF classifier [6]. The default mtry for $\mathrm{p}$ features is $m$ try $=\sqrt{p}$ where $\mathrm{p}$ is the number of variable predictors; thus, increasing mtry may improve performance [67]. The mtry in this study was defined (1, variables) to run the classifier with the same defined ntree $(100,200,300,400,500,600,700,800$ and 900). Therefore, the highest accuracy of mtry and ntree result was selected. Random forest classification analysis was done in R studio.

\subsubsection{Accuracy Assessment and Validation}

Three forest classes are based on the field sample plots. The idea is to estimate the accuracy of quantification of mapping from using remote sensing data to the ground truth conditions and compare the performance of different satellite images in terms of its bands as variables. We can then determine the level of error of users and producers that might be contributed by the land use or land cover in further analyses in which it is incorporated. Accuracy assessment of each defined class drives from an error matrix that compares map information with reference data and the sampled area/points, these types of errors are driven by the producer's and user's accuracies respectively $[68,69]$. The accuracy is generated from an error of matrix for the final classification consisting of different multivariate statistical analyses in which the overall accuracy and kappa 
indicate the accuracy of different classified classes [69-71]. The performance of RF classifier in each land-use class of two selected satellite images proves the optimal choice of further processes.

\subsubsection{Vegetation indices extraction}

The values of ten VIs were calculated from different combinations of spectral bands, mostly from NIR and red bands, derived from the better-performed images [72-74]. Nine out of ten VIs are broadband greenness that help to understand canopy leaf area, canopy formation, vegetation productivity.

These VIs provide and compare the reflectance peak in the range of near-infrared to red band. While selection of Atmospherically Resistant Vegetation Index (ARVI) was as a test to measure the reflectance of the narrow and steep slope of vegetation structure change comparing to broadband greenness with the hope that it can help to differentiate different vegetation canopy structures.

The VIs were extracted from both ground truth plots and training sample points. The Normalized Difference Vegetation Index (NDVI) is a simple, and effective index that helps to quantify the green vegetation, ranging from -1 to 1 and the indicated green healthy and dense vegetation is between 0.2 to 0.8 [75,76]. The Infrared Percentage Vegetation Index (IPVI) is a non-negative vegetation index that helps to measure the percentage of the radiance of both nearinfrared and red bands [77,78].

Similar to NDVI, the Green Normalized Difference Vegetation Index (GNDVI) is more sensitive to chlorophyll concentration than NDVI and used for measuring the green spectrum from 540 to $570 \mathrm{~nm}$ instead of the red spectrum [79]. The Atmospherically Resistant Vegetation Index (ARVI) resists to atmospheric effects compared to NDVI and is supported by a selfcorrected process on the red band [80]. The range of ARVI is dynamically similar to NDVI, but it is four times less sensitive to atmospheric as NDVI. The Enhanced Vegetation Index (EVI) values range from -1 to 1 , of which the healthy vegetation denotes from 0.2 to $0.8[31,81]$. The Normalized Difference Index (DVI) is sensitive to vegetation and more distinguishing with soil and is more linear and of use for vegetation cover monitoring [82,83]. The Normalized Difference Index (NDI45) with less saturation at higher values than the NDVI is the ratio between the Red Edge (band 5) and the red band (Band 4) [84]. The value of the Ratio Vegetation Index (RVI) ranges from 0 to 30 in which value between 2 to 8 indicates health vegetation. The RVI reduces the effects of atmosphere and topography [85-87]. This effect which occurs in the natural surface in the mountainous area. The Perpendicular Vegetation Index (PVI) is a generation of DVI differentiating soil lines of different slopes and near-infrared (NIR) axis in 
degree, is to some extend sensitive to atmospheric variations [88]. The algorithm of Transformed Normalized Difference Vegetation Index (TNDVI) is the square root of NDVI and indicates a relationship between green biomass that is found in a pixel [89].

In this study, we calculated ten VIs from the best performed image in Table 4.2 from 90 ground truth randomly sampled plots (GTVIs) and 1303 training sample points of three substratified forest types (CLVIs) in Table 4.8. T-tests of the mean were done among three forest types of both GTVIs and LCVIs and ran the correlation among VIs of the GTVIs and horizontal and vertical forest structure [90] to test the significant difference among forest types and groundtruth and training sample plots. All t-tests of forest parameters and vegetation indices were tested by using Statistica 13.5 .

Table 4.2. Vegetation Radiometric Indices

\begin{tabular}{|c|c|c|}
\hline $\begin{array}{l}\text { Vegetation } \\
\text { Indices }\end{array}$ & Formula & References \\
\hline NDVI & $(\mathrm{B} 8-\mathrm{B} 4) /(\mathrm{B} 8+\mathrm{B} 4)$ & [91] \\
\hline IPVI & $I P V I=\frac{\mathrm{B} 8}{\mathrm{~B} 8+\mathrm{B} 4}$ & [79] \\
\hline GNDVI & $G N D V I=\frac{\mathrm{B} 8-\mathrm{B} 3}{\mathrm{~B} 8+\mathrm{B} 3}$ & {$[92]$} \\
\hline ARVI & $\begin{aligned} \mathrm{B} 8-[\mathrm{B} 4-\gamma(\mathrm{B} 4-\mathrm{B} 2)] / \mathrm{B} 8+[\mathrm{B} 4-\gamma(\mathrm{B} 4-\mathrm{B} 2)] \\
\gamma=\mathrm{gamma}=1 \\
(\mathrm{~B} 8-\mathrm{B} 4)\end{aligned}$ & {$[80]$} \\
\hline EVI & $\begin{array}{c}\mathrm{G} * \overline{(\mathrm{B} 8+\mathrm{C} 1 * \mathrm{~B} 4-\mathrm{C} 2 * \mathrm{~B} 2+\mathrm{L})} \\
\text { where: }(\mathrm{G}=2.5 ; \mathrm{C} 1=6 ; \mathrm{C} 2=7.5 ; \mathrm{L}=1)\end{array}$ & [93] \\
\hline NDI45 & $(\mathrm{B} 5-\mathrm{B} 4) /(\mathrm{B} 5+\mathrm{B} 4)$ & {$[84]$} \\
\hline RVI & B8/B4 & {$[85]$} \\
\hline DVI & B8-B4 & {$[82]$} \\
\hline PVI & $\begin{array}{l}\qquad(a \rho * B 8-\beta \rho * B 4) \\
\text { where } \rho \text { is reflectance in NIR or Red band. } a \text { and } \\
\beta \text { are soil line parameters }\end{array}$ & {$[88]$} \\
\hline TNDVI & $\sqrt{(B 3-B 4) /(B 3+B 4)+0.5}$ & {$[82]$} \\
\hline
\end{tabular}

4.4. Results

\subsubsection{Ground Truth Input}

The forest sampled parameters of three forest types UF, LF, and DF are not uniquely different. The mean of height as a vertical structure of forest stands LF and DF is significant different from UF at $\mathrm{p}<0.05$ but not between LF and DF. The mean basal area and of volume as 
a horizontal structure of forest stand is significantly different among UF, LF and DF while tree stems per plot were not significantly different among forest types in Table 4.3.

Table 4.3. Parameters of different forest types

\begin{tabular}{lccc}
\hline \multirow{2}{*}{\multicolumn{1}{c}{ Parameters }} & \multicolumn{3}{c}{ Forest types } \\
\cline { 2 - 4 } & UF & LF & DF \\
\hline No. Plots $\left(1000 \mathrm{~m}^{2}\right)$ & 30 & 30 & 30 \\
Mean height $(\mathrm{H})$ in meter & $16.4 \pm 1.2 \mathrm{a}$ & $14.7 \pm 1.2 \mathrm{~b}$ & $14.3 \pm 0.9 \mathrm{bc}$ \\
Basal area (BA) ha ${ }^{-1}$ & $33.1 \pm 0.6 \mathrm{a}$ & $21.3 \pm 0.3 \mathrm{~b}$ & $15.6 \pm 0.4 \mathrm{c}$ \\
Volume (V) ha $^{-1}$ & $361 \pm 8.8 \mathrm{a}$ & $211 \pm 4.0 \mathrm{~b}$ & $147 \pm 4.7 \mathrm{c}$ \\
Tree stem ha $^{-1}$ & $445 \pm 9.4 \mathrm{a}$ & $466 \pm 13.5 \mathrm{a}$ & $400 \pm 12.0 \mathrm{a}$ \\
\hline
\end{tabular}

(The letter same $a, b$ or $c$ indicates not significantly different at $(p<0.05)$ )

The composition of species and families in different forest types illustrated in mean height, dominance $\left(\mathrm{m}^{2} / \mathrm{ha}\right)$, abundance $(\mathrm{N} / \mathrm{ha})$, frequency $(\%)$ and Importance Value Index (IVI) of each forest type in Table 4.4; Table 4.5. Table 4.4 shows the most dominant, abundant species in each forest type with its frequency and IVI in which L. ducampii, A. grandiflora, T. myriocarpa and S. roxburghii in UF where L. ducampii was found 59 stems over 20 plots occupying 19.67 trees per ha while 39 stems of $S$. roxburghii was found in 21 plots and were the most dominant with $2.31 \mathrm{~m}^{2} / \mathrm{ha}$. This species is also dominant in the height of $21.98 \mathrm{~m}$ with $70 \%$ frequency. In $\mathrm{LF}, B$. tonkinensis was found most dominant, but $L$. ducampii was also found most abundant. While $S$. macropodum and M. mediocris are at the lower height stratum comparing to $L$. ducampii and $B$. tonkinensis. L. ducampii is more abundant but less dominant than B. tonkinensis. In DF, $G$. oliveri, $K$. furfuracea, E. petelotii and S. lanceolatum are the four most dominant and abundant species. Of those four species, G. oliveri and $K$. furfuracea are the two most dominant and abundant species. 
Table 4.4. Dominance and Abundance Species of Horizontal Structure in different forest types

\begin{tabular}{|c|c|c|c|c|c|c|}
\hline Types & Species & $\begin{array}{l}\text { Mean } \\
\mathbf{H}(\mathbf{m})\end{array}$ & 泀 & 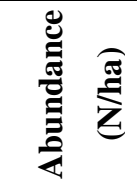 & 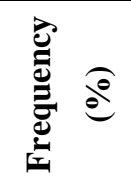 & IVI \\
\hline \multirow{5}{*}{ UF } & Lithocarpus ducampii (Hickel \& A.Camus) (59:20) & 16.97 & 1.51 & 19.67 & 66.67 & 7.58 \\
\hline & Aphanamixis grandiflora $(50: 19)$ & 15.67 & 0.98 & 16.67 & 63.33 & 6.70 \\
\hline & Terminalia myriocarpa Van Heurck \& Müll. Arg(41:19) & 20.23 & 1.58 & 13.67 & 63.33 & 7.49 \\
\hline & Shorea roxburghii G.Don (39:21) & 21.98 & 2.31 & 13.00 & 70.00 & 8.74 \\
\hline & Others $(1148: 96)$ & & 26.69 & 382.67 & & 269.49 \\
\hline \multirow{5}{*}{ LF } & Lithocarpus ducampii (Hickel \& A.Camus) (54:16) & 16.44 & 1.06 & 18.00 & 53.33 & 6.51 \\
\hline & $\begin{array}{l}\text { Scaphium macropodum (Miq) Beumee ex K.Heyne } \\
(41: 21)\end{array}$ & 14.03 & 0.39 & 13.67 & 70.00 & 6.07 \\
\hline & Magnolia mediocris (Dandy) Figlar (41:18) & 14.14 & 0.63 & 13.67 & 60.00 & 5.91 \\
\hline & Bursera tonkinensis Guillaum (40:19) & 18.53 & 1.61 & 13.33 & 63.33 & 7.95 \\
\hline & Others $(1221: 107)$ & & 17.70 & 407.00 & & 273.56 \\
\hline \multirow{5}{*}{$\mathrm{DF}$} & Garcinia oliveri Pierre (66:25) & 12.49 & 0.49 & 22.00 & 83.33 & 8.01 \\
\hline & Knema furfuracea (Hook. f. \& Thomson) Warb (48:21) & 14.76 & 0.54 & 16.00 & 70.00 & 7.12 \\
\hline & Enicosanthellum petelotii (Merr.) Ban (46:17) & 12.25 & 0.30 & 15.33 & 56.67 & 5.64 \\
\hline & Syzygium lanceolatum (Lam.) Wight \& Arn (45:22) & 13.00 & 0.42 & 15.00 & 73.33 & 7.12 \\
\hline & Others $(997: 105)$ & & 13.84 & 332.33 & & 272.12 \\
\hline
\end{tabular}

(Species presented in bracket i.e: (59:20) indicating number of individual stems $(N)$ representing in the number of corresponding plots where the species are dominated and abundant with its occurrence frequency; IVI = Importance Value Index of the species in the study area)

Table 4.5 describes the species which prevail higher canopy stratum of which D. kerrii has the mean height of $27.98 \mathrm{~m}$ following by $T$. bellirica with $26.70 \mathrm{~m}$ while $S$. roxburghii and $D$. grandiflorus are most dominant and abundant in UF where the three out of four dominant and abundant species are of Dipterocarpaceae and one species is of Combretaceae. Furthermore, $S$. roxburghii and D. grandiflorus were found most frequent with 39 stems over 21 sampled plots and 17 out of 30 sampled plots with 34 stems respectively. The number of species in LF, the dominance and abundance of four species $F$. lacor, S. roxburghii, C. indica and T. myriocarpa are not so much varied. F. lacor, the highest vertical stratum, has four stems distributing in four out of 30 sampled plots followed $S$. roxburghii which is $21.27 \mathrm{~m}$ in height with eight stems distributing in six sampled plots. The other two species $C$. indica and T. myriocarpa are more abundant than two other species mentioned above. The vertical stratum in DF is even more scattered than the species in LF and UF. P. ellipticum, one single stem distributing on one sampled plot, was found to be the highest in this forest type with $34.50 \mathrm{~m}$. The height of three species A. chinense, L. verticillata and A. pilosa ranges from $18.06 \mathrm{~m}$ to $19.17 \mathrm{~m}$. 
Table 4.5. Dominance and Abundance Species of Vertical Structure in different forest types

\begin{tabular}{|c|c|c|c|c|c|c|}
\hline Types & Species & $\begin{array}{l}\text { Mean } \\
\mathbf{H}(\mathrm{m})\end{array}$ & हี & 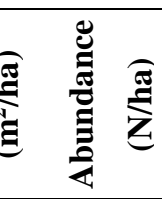 & 总 & IVI \\
\hline \multirow{5}{*}{ UF } & Dipterocarpus kerrii King (6:3) & 27.98 & 0.51 & 2.00 & 10.00 & 5.19 \\
\hline & Terminalia bellirica (Gaertn.) Roxb. (4:4) & 26.70 & 0.29 & 1.33 & 13.33 & 2.97 \\
\hline & Shorea roxburghii G.Don (39:21) & 21.98 & 2.31 & 13.00 & 70.00 & 8.74 \\
\hline & Dipterocarpus grandiflorus Blanco (34:17) & 21.04 & 1.81 & 11.33 & 56.67 & 7.51 \\
\hline & Others (1254:96) & & 28.15 & 418.00 & & 275.60 \\
\hline \multirow{5}{*}{$\mathrm{LF}$} & Ficus lacor Buch. Ham. (4:4) & 24.50 & 0.33 & 1.33 & 13.33 & 3.97 \\
\hline & Shorea roxburghii G.Don (8:6) & 21.27 & 0.47 & 2.67 & 20.00 & 4.39 \\
\hline & Castanopsis indica (Roxb. ex Lindl.) A.DC (11:6) & 20.12 & 0.34 & 3.67 & 20.00 & 3.59 \\
\hline & Terminalia myriocarpa Van Heurck \& Müll. Arg (10:5) & 19.42 & 0.26 & 3.33 & 16.67 & 3.19 \\
\hline & Others (1364:107) & & 19.98 & 454.67 & & 284.87 \\
\hline \multirow{5}{*}{ DF } & Placolobium ellipticum N.D.Khoi \& Yakovlev (1:1) & 34.50 & 0.12 & 0.33 & 3.33 & 5.40 \\
\hline & Alangium chinense (Lour.) Harms (3:2) & 19.17 & 0.10 & 1.00 & 6.67 & 2.67 \\
\hline & Litsea verticillata Hance (6:3) & 18.07 & 0.11 & 2.00 & 10.00 & 2.42 \\
\hline & Actinodaphne pilosa $(7: 5)$ & 18.06 & 0.23 & 2.33 & 16.67 & 3.40 \\
\hline & Others (1185:105) & & 15.02 & 395.00 & & 286.10 \\
\hline
\end{tabular}

(Species presented in bracket i.e: (6:3) indicating number of individual stems $(N)$ representing in the number of corresponding plots where the species are dominated and abundant with its occurrence frequency; IVI = Importance Value Index of the species in the study area)

The four most horizontal dominant and abundant families are Fagaceae, Lauraceae, Leguminosae and Dipterocarceae. Of those, Fagaceae and Lauraceae are more abundant with 52.7 stems and 33.3 stems per hectare while Diperocarpaceae is the most dominant with 93 stems recorded in 29 out of 30 sampled plots. Fagaceae is more dominant and abundant than those in LF, but a shift is with Lauraceae which is more dominant and abundant in LF. Euphorbiaceae and Myrtaceae were not found dominant and abundant in UF but in LF and DF. It is obvious that the Myristicaceae and Clusiaceae are only found dominant and abundant in DF. The vertical tree families in UF are Leguminosae and Dipterocarpaceae of which Dipterocarpaceae is pre-height dominant and abundant. The dominance and abundance of Combretaceae are more than Moraceae. Compare to the horizontal family structure, the dominant and abundant families belong to Dipterocarpaceae, Combretaceae, Moraceae, Leguminosae, Burseraceae, and Polygalaceae. Of those, Dipterocarpaceae and Leguminosae were found in both vertical and horizontal family structures of species composition in the study area. 


\subsubsection{Performance of RF classifier}

The best-produced results from mtry and ntree combined-datasets showed the highest accuracy presented in Figure 4.4. Tuning results of two RF classifiers illustrated that repeated cross-validation accuracy where mtry $=2$, at ntree $=500$ in Landsat and mtry $=5$ at ntree $=700$ in Sentinel-2.

\section{Landsat-8}

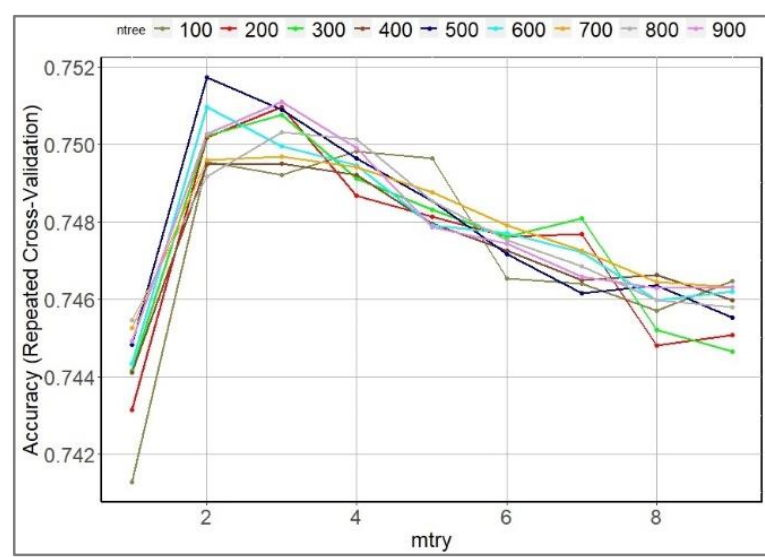

Sentinel-2

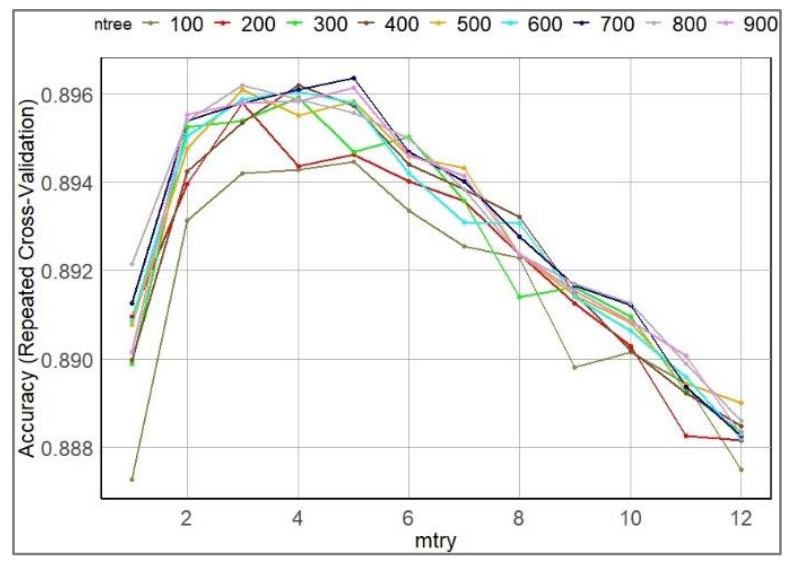

Figure 4.4. The number of trees and random split number of variables at each node of RF classifiers in Landsat- 8 and Sentinel-2 using the same training sample data.

The same mtry and training sampled dataset which were used to assess the error of each land-use type in Figure 4.5. The results showed the OOB in Landsat- 8 of $31.6 \%$ in Landsat, and the OOB is of $14.3 \%$ in Sentinel-2.

Landsat-8

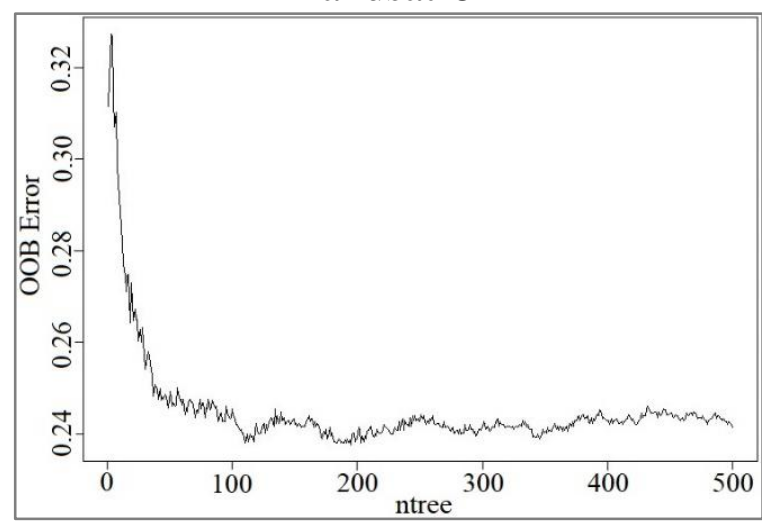

Sentinel-2

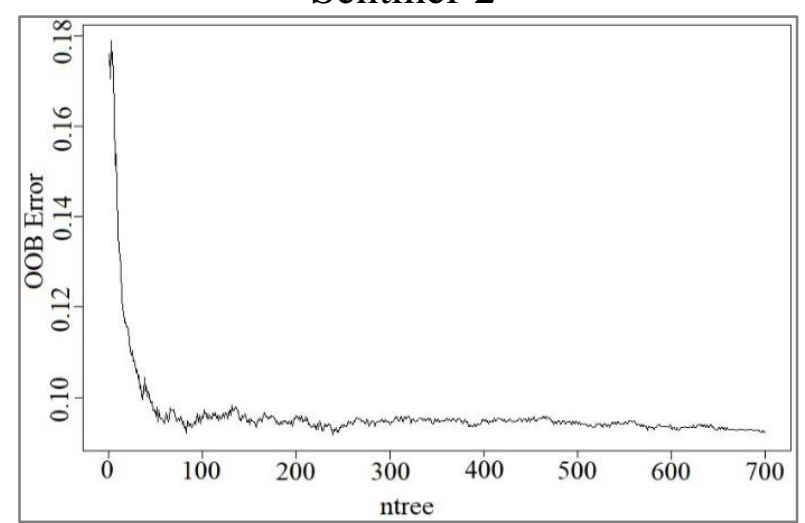

Figure 4.5. The OOB error (y-axis) and ntree in (x-axis) of RF classifier of Landsat- 8 and Sentinel-2 using the same training sample data.

\subsubsection{Comparison of sensors over class validation and assessment}

The agreement of the RF classification including the overall accuracy and the kappa statistic is presented in Table 4.6 and Table 4.7. The Accuracy assessment of land cover RF classifiers in Landsat- 8 showed the overall accuracy of $68 \%$ and Kappa of $67.5 \%$. The results 
showed that producer accuracy of Water and River (WR), Slash and Burnt (SB), which are presented in Table 4.6, having the lowest accuracy with $20 \%, 1 \%$, respectively.

Table 4.6. Accuracy assessment of land cover classes of Landsat-8

\begin{tabular}{ccccccccc}
\hline LC/LU & RC & WR & Agr & SB & DF & LF & UF & $\begin{array}{c}\text { User } \\
\text { Accuracy }\end{array}$ \\
\hline RC & 104 & 19 & 13 & 30 & 7 & 5 & 2 & 58 \\
WR & 8 & 17 & 5 & 1 & 0 & 1 & 0 & 53 \\
Agr & 30 & 37 & 112 & 48 & 3 & 3 & 1 & 48 \\
SB & 0 & 0 & 0 & 1 & 0 & 0 & 0 & 100 \\
DF & 0 & 2 & 13 & 9 & 134 & 5 & 0 & 82 \\
LF & 0 & 7 & 2 & 4 & 10 & 118 & 16 & 75 \\
UF & 3 & 1 & 4 & 4 & 1 & 14 & 170 & 86 \\
\hline Producer & 72 & 20 & 75 & 01 & 86 & 81 & 90 & \\
Accuracy & & & & & & & 68 \\
\hline Overall accuracy & & & & & & & \\
Kappa & & & & & & & & \\
\hline
\end{tabular}

The overall accuracy of the RF classifier in Sentinel-2 in Table 4.7 was $86 \%$ and kappa of $83 \%$. The producer's error and user's error of water and river class in Sentinel-2 are the highest compared to other classes.

Table 4.7. Accuracy assessment of land cover classes of Sentinel-2

\begin{tabular}{ccccccccc}
\hline LC/LU & RC & WR & Agr & SB & DF & LF & UF & $\begin{array}{c}\text { User } \\
\text { Accuracy }\end{array}$ \\
\hline RC & 108 & 13 & 6 & 4 & 0 & 0 & 0 & 82 \\
WR & 2 & 52 & 5 & 3 & 0 & 0 & 0 & 84 \\
Agr & 11 & 11 & 123 & 8 & 6 & 0 & 4 & 75 \\
SB & 6 & 9 & 6 & 79 & 0 & 0 & 0 & 79 \\
DF & 0 & 0 & 4 & 0 & 180 & 9 & 0 & 93 \\
LF & 0 & 1 & 1 & 0 & 0 & 128 & 8 & 93 \\
UF & 0 & 4 & 2 & 0 & 0 & 15 & 158 & 88 \\
\hline Producer & 85 & 58 & 84 & 84 & 97 & 84 & 93 & \\
Accuracy & & & & & & & 0.86 \\
\hline Overall accuracy & & & & & & & 0.83 \\
Kappa & & &
\end{tabular}

Figure 4.6 showed pairwise matrix of 7 land cover classes in which the most misinterpreted training samples are of water and river (WR), slash and burst (SB) classes in Landsat-8 and WR in Sentinel-2. Interpretation of training samples in Sentinel-2 is more constant. In Figure 4.7, the water body and slash and burnt ratio are more visualized in Landsat- 8 than those in Sentinel-2. 
Landsat-8

\begin{tabular}{|c|c|c|c|c|c|c|c|}
\hline \multirow{4}{*}{ 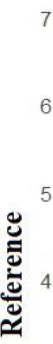 } & 0.5 & 0 & 0.3 & 0 & 0 & 4.1 & 44.1 \\
\hline & 1.7 & 0.3 & 1 & 0 & 1.7 & 39.6 & 4.7 \\
\hline & 2.2 & 0 & 0.9 & 0 & 42.4 & 3.2 & 0.3 \\
\hline & 15.2 & 0.5 & 24.2 & 0.5 & 4.5 & 2 & 2 \\
\hline 3 & 4.3 & 1.6 & 36.8 & 0 & 4.3 & 0.7 & 1.3 \\
\hline 2 & 11.2 & 9.4 & 22.4 & 0 & 1.2 & 4.1 & 0.6 \\
\hline 1 & 35.1 & 2.7 & 10.1 & 0 & 0 & 0 & 1 \\
\hline & 1 & 2 & Pr & ${ }^{4}$ & 5 & 6 & 7 \\
\hline & & & rate & $10 \quad 20$ & $0 \quad 40$ & & \\
\hline
\end{tabular}

Sentinel-2

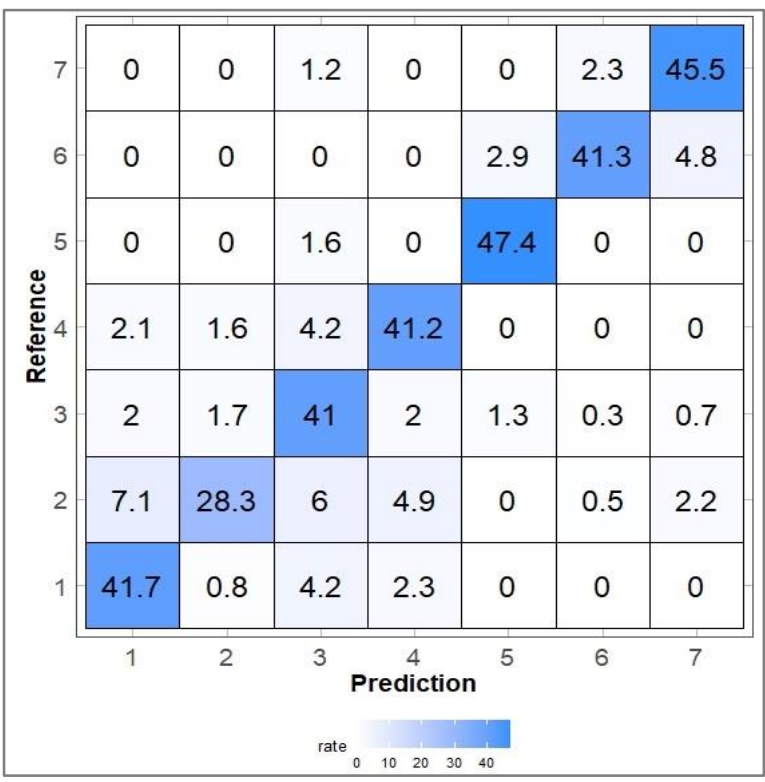

Figure 4.6. Explanation of each class prediction of Landsat- 8 and Sentinel-2 using square matrix. The higher result of reference and prediction, the better accuracy of classification (Classes are: $1=R C ; 2=W R ; 3=A g r ; 4=S B ; 5=D F ; 6=L F$ and $7=U F)$.

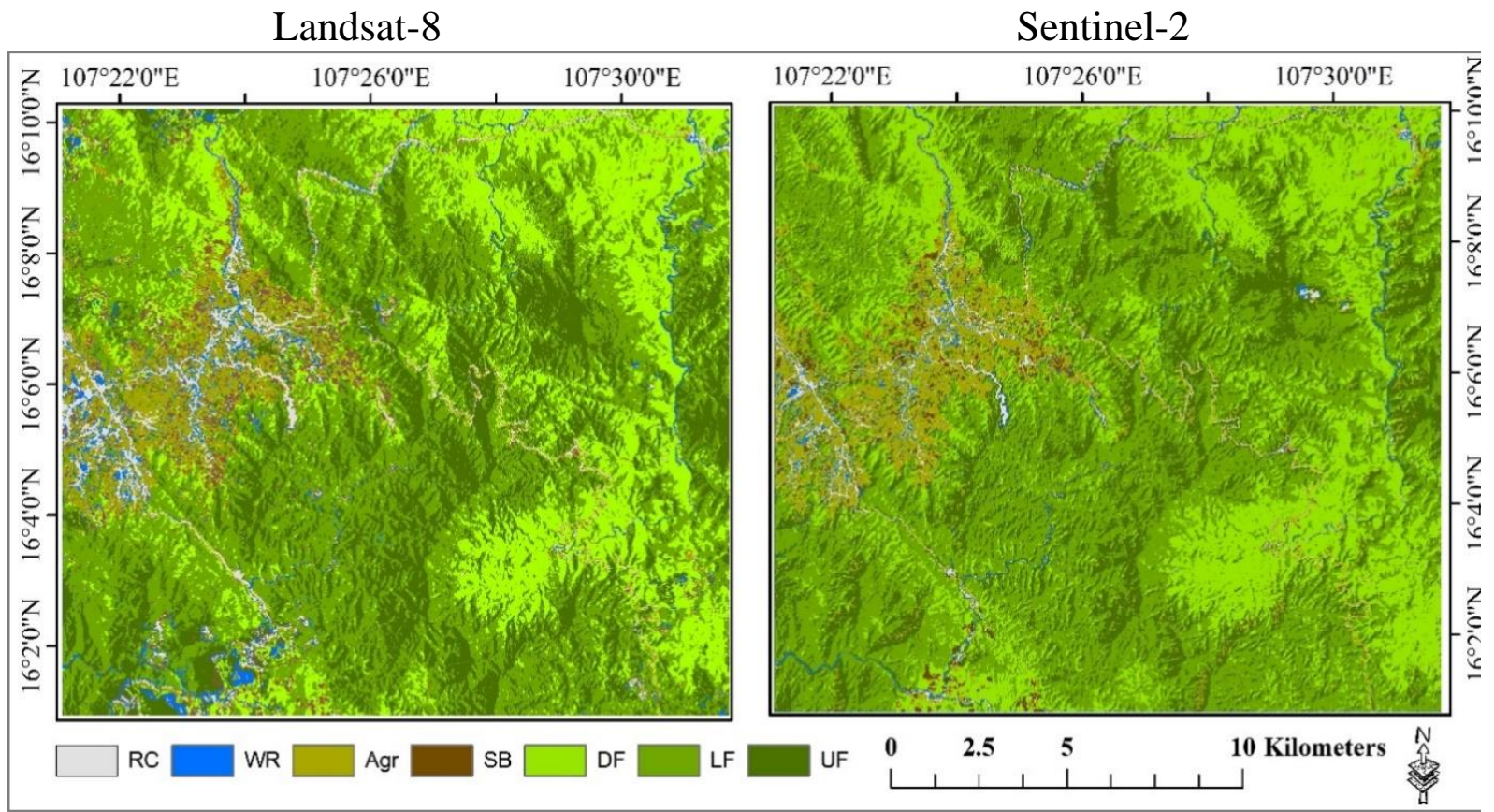

Figure 4.7. Classification map by random forest presenting results of the best accuracy of classifiers in Landsat- 8 and Sentinel-2

Forest area is most dominant in the study area with $88 \%$ of the total natural land [62].

\subsubsection{Difference of vegetation indices}

Ten extracted Vegetation Indices from three forest cover classes of the best-performed image are presented in Table 4.2 which consists of VIs values of GTVIs and CLVIs. T-tests of the mean were done among three forest types of both GTVIs, and LCVIs in Table 4.8. The NDVI, 
IPVI, EVI, DVI, PVI, and TNDVI in different forest types of both GTVIs and LCVIs showed significant difference at $\mathrm{p}<0.05$. While GNDVI, ARVI, NDI45 and RVI of different forest types of GTVIs were not significantly different. Not all vegetation indices of each corresponding forest type in GTVIs and LCVIs are significant different. The vegetation indices of EVI, DVI and TNDVI of GTVIs and LCVIs in each corresponding forest type are significantly different at $\mathrm{p}<0.05$.

Table 4.8. Mean vegetation indices of forest types in ground truth and training sample plots extracted from Sentinel-2 imagery dated on 22 March 2017

\begin{tabular}{cccc|ccc}
\hline $\begin{array}{c}\text { Vegetation } \\
\text { Indices }\end{array}$ & \multicolumn{2}{c}{ Ground Truth Plots (GTVIs) } & \multicolumn{3}{c}{ Training Sample Plots (LCVIs) } \\
\hline & UF $(\mathrm{N}=30)$ & LF $(\mathrm{N}=30)$ & $\mathrm{DF}(\mathrm{N}=30)$ & UF $(\mathrm{N}=611)$ & $\mathrm{LF}(\mathrm{N}=487)$ & $\mathrm{DF}(\mathrm{N}=600)$ \\
\hline NDVI & $0.84 \pm 0.02^{\mathrm{aA}}$ & $0.85 \pm 0.01^{\mathrm{bA}}$ & $0.86 \pm 0.02^{\mathrm{cA}}$ & $0.83 \pm 0.02^{\mathrm{aA}}$ & $0.85 \pm 0.02^{\mathrm{bB}}$ & $0.87 \pm 0.01^{\mathrm{cB}}$ \\
IPVI & $0.92 \pm 0.01^{\mathrm{aA}}$ & $0.93 \pm 0.01^{\mathrm{bA}}$ & $0.93 \pm 0.01^{\mathrm{cA}}$ & $0.91 \pm 0.01^{\mathrm{aA}}$ & $0.92 \pm 0.01^{\mathrm{bB}}$ & $0.94 \pm 0.01^{\mathrm{cB}}$ \\
GNDVI & $0.73 \pm 0.03^{\mathrm{aA}}$ & $0.74 \pm 0.02^{\mathrm{aA}}$ & $0.74 \pm 0.02^{\mathrm{aA}}$ & $0.72 \pm 0.03^{\mathrm{aB}}$ & $0.73 \pm 0.02^{\mathrm{bB}}$ & $0.74 \pm 0.02^{\mathrm{cA}}$ \\
ARVI & $0.85 \pm 0.03^{\mathrm{aA}}$ & $0.84 \pm 0.02^{\mathrm{aA}}$ & $0.85 \pm 0.02^{\mathrm{aA}}$ & $0.83 \pm 0.03^{\mathrm{aA}}$ & $0.84 \pm 0.03^{\mathrm{abB}}$ & $0.85 \pm 0.02^{\mathrm{cB}}$ \\
EVI & $0.22 \pm 0.04^{\mathrm{aA}}$ & $0.33 \pm 0.05^{\mathrm{bA}}$ & $0.40 \pm 0.08^{\mathrm{cA}}$ & $0.21 \pm 0.04^{\mathrm{aA}}$ & $0.32 \pm 0.04^{\mathrm{bB}}$ & $0.49 \pm 0.07^{\mathrm{cB}}$ \\
NDI45 & $0.54 \pm 0.07^{\mathrm{aA}}$ & $0.53 \pm 0.04^{\mathrm{aA}}$ & $0.55 \pm 0.05^{\mathrm{aA}}$ & $0.49 \pm 0.06^{\mathrm{aA}}$ & $0.53 \pm 0.04^{\mathrm{bA}}$ & $0.59 \pm 0.03^{\mathrm{cB}}$ \\
RVI & $12.1 \pm 1.9^{\mathrm{aA}}$ & $12.8 \pm 1.2^{\mathrm{abA}}$ & $13.7 \pm 1.9^{\mathrm{cA}}$ & $11.1 \pm 1.7^{\mathrm{aA}}$ & $12.2 \pm 1.5^{\mathrm{bB}}$ & $15.1 \pm 1.9^{\mathrm{cB}}$ \\
DVI & $0.07 \pm 0.02^{\mathrm{aA}}$ & $0.11 \pm 0.02^{\mathrm{bA}}$ & $0.15 \pm 0.04^{\mathrm{cA}}$ & $0.12 \pm 0.02^{\mathrm{aB}}$ & $0.19 \pm 0.03^{\mathrm{bB}}$ & $0.33 \pm 0.06^{\mathrm{cB}}$ \\
PVI & $0.12 \pm 0.03^{\mathrm{aA}}$ & $0.20 \pm 0.03^{\mathrm{bA}}$ & $0.25 \pm 0.06^{\mathrm{cA}}$ & $0.07 \pm 0.01^{\mathrm{aB}}$ & $0.12 \pm 0.02^{\mathrm{bB}}$ & $0.19 \pm 0.04^{\mathrm{cA}}$ \\
TNDVI & $1.07 \pm 0.02^{\mathrm{aA}}$ & $1.10 \pm 0.01^{\mathrm{bA}}$ & $1.11 \pm 0.02^{\mathrm{cA}}$ & $1.06 \pm 0.02^{\mathrm{aB}}$ & $1.10 \pm 0.01^{\mathrm{bB}}$ & $1.17 \pm 0.01^{\mathrm{cB}}$ \\
\hline
\end{tabular}

(Within rows, values followed by the same lowercase letter $(a, b)$ are not significantly different $(p<0.05)$ between forest types; Within rows, values followed by the same capital letter $(A, B)$ are not significantly different $(p<0.05)$ of forest types between ground truth and training sample plots).

4.4.5. Correlation of vegetation indices

The correlation and regression among VIs of the GTVIs and horizontal and vertical forest structure are presented in Table 4.9 and Figure 4.8. The figures presented in Table 4.9 do not only describe the correlation between Height and BA with ten vegetation indices but also among themselves for further understandings. In this study, we decided to choose the correlations more than $50 \%$ with BA and above $40 \%$ with height thus focused on the correlation between BA, and height with EVI, PVI, DVI and TNDVI. The correlation of these four VIs with BA ranges from 0.63 to 0.66 while the correlation of height with these four VIs ranges from 0.43 to 0.49 . Three VIs showed the lowest correlation with BA, and height were GNDVI, ARVI and NDI45. 
Table 4.9. Correlation of Vegetation Indices with BA and height in ground-truth plots

\begin{tabular}{|c|c|c|c|c|c|c|c|c|c|c|c|c|}
\hline & $B A\left(m^{2}\right)$ & $H(m)$ & $N D V I$ & $I P V I$ & GNDVI & $A R V I$ & $E V I$ & NDI45 & $R V I$ & $P V I$ & $D V I$ & $T N D V I$ \\
\hline $\mathrm{BA}\left(\mathrm{m}^{2}\right)$ & 1.00 & & & & & & & & & & & \\
\hline $\mathrm{H}(\mathrm{m})$ & $0.73^{*}$ & 1.00 & & & & & & & & & & \\
\hline NDVI & $-0.34 *$ & $-0.32 *$ & 1.00 & & & & & & & & & \\
\hline IPVI & $-0.34 *$ & $-0.32 *$ & $1.00^{*}$ & 1.00 & & & & & & & & \\
\hline GNDVI & -0.08 & -0.19 & $0.69^{*}$ & $0.69^{*}$ & 1.00 & & & & & & & \\
\hline ARVI & -0.02 & -0.12 & $0.81^{*}$ & $0.81 *$ & $0.49^{*}$ & 1.00 & & & & & & \\
\hline EVI & $-0.66^{*}$ & $-0.46^{*}$ & $0.60^{*}$ & $0.60^{*}$ & $0.30^{*}$ & 0.19 & 1.00 & & & & & \\
\hline NDI45 & -0.12 & -0.13 & $0.52^{*}$ & $0.52 *$ & $0.27^{*}$ & $0.49^{*}$ & 0.13 & 1.00 & & & & \\
\hline RVI & $-0.36^{*}$ & $-0.30^{*}$ & $0.97^{*}$ & $0.97^{*}$ & $0.63^{*}$ & $0.80^{*}$ & $0.61 *$ & $0.54^{*}$ & 1.00 & & & \\
\hline PVI & $-0.65^{*}$ & $-0.43^{*}$ & $0.59 *$ & $0.59^{*}$ & $0.29 *$ & 0.19 & $0.99 *$ & 0.14 & $0.61 *$ & 1.00 & & \\
\hline DVI & $-0.65^{*}$ & $-0.43^{*}$ & $0.59 *$ & $0.59^{*}$ & $0.29 *$ & 0.19 & $0.99 *$ & 0.14 & $0.61^{*}$ & $1.00^{*}$ & 1.00 & \\
\hline TNDVI & $-0.63^{*}$ & $-0.49^{*}$ & $0.73 *$ & $0.73^{*}$ & $0.44 *$ & $0.32 *$ & $0.96 *$ & 0.17 & $0.71 *$ & $0.94 *$ & $0.94 *$ & 1.00 \\
\hline
\end{tabular}

$\left(\mathrm{BA}=\right.$ Basal Area $=\left(\left(\mathrm{DBH}^{2} \mathrm{x} \pi\right) / 4\right)$ is the cross-sectional area in $\mathrm{m} 2$ of a tree measured at breast height and expressed as per unit of land area. BA in Table 4.3 is the mean cross-sectional area in ground truth sample plot; $*=$ correlations are significant at $\mathrm{p}<0.05$ ).

4.4.6. Relationship of VIs with horizontal and vertical structure of dominance species

Species that are mostly and horizontally dominant and abundant showed correlation with VIs in UF of Terminalia myriocarpa with 41 stems distributing in 19 sampled plots as presented in Table 4.4 followed by Lithocarpus ducampii. This species is most abundant in UF and LF but its horizontal parameter was not as correlative as this in UF but Bursera tonkinensis showed most correlation with VIs and followed by Magnolia mediocris. In DF, Enicosanthellum petelotii showed more correlation with VIs then Garcinia oliveri, Syzygium lanceolatum and Knema furfuracea in Table 4.10. 
Table 4.10. Correlation of VIs with dominance species in horizontal structure

\begin{tabular}{|c|c|c|c|c|c|c|c|c|}
\hline \multirow{2}{*}{ UF } & \multicolumn{2}{|c|}{ L. ducampii } & \multicolumn{2}{|c|}{ A.grandiflora } & \multicolumn{2}{|c|}{ T. myriocarpa } & \multicolumn{2}{|c|}{ S. roxburghii } \\
\hline & $\mathrm{H}$ & $\mathrm{BA}$ & $\mathrm{H}$ & $\mathrm{BA}$ & $\mathrm{H}$ & $\mathrm{BA}$ & $\mathrm{H}$ & $\mathrm{BA}$ \\
\hline EVI & 0.11 & -0.25 & 0.02 & -0.28 & -0.58 & -0.43 & -0.13 & 0.01 \\
\hline PVI & -0.04 & -0.26 & 0.03 & -0.29 & -0.48 & -0.35 & -0.17 & -0.01 \\
\hline DVI & -0.03 & -0.27 & 0.03 & -0.29 & -0.48 & -0.35 & -0.18 & -0.02 \\
\hline TNDVI & 0.10 & -0.20 & 0.16 & -0.12 & -0.75 & -0.46 & -0.01 & 0.11 \\
\hline \multirow{2}{*}{$\mathrm{LF}$} & \multicolumn{2}{|c|}{ L. ducampii } & \multicolumn{2}{|c|}{ S. macropodum } & \multicolumn{2}{|c|}{ M. mediocris } & \multicolumn{2}{|c|}{ B. tonkinensis } \\
\hline & $\mathrm{H}$ & BA & $\mathrm{H}$ & $\mathrm{BA}$ & $\mathrm{H}$ & $\mathrm{BA}$ & $\mathrm{H}$ & $\mathrm{BA}$ \\
\hline EVI & 0.10 & -0.01 & -0.01 & 0.09 & -0.56 & -0.15 & 0.02 & 0.30 \\
\hline PVI & 0.15 & -0.02 & 0.00 & 0.04 & -0.58 & -0.16 & 0.18 & 0.30 \\
\hline DVI & 0.15 & -0.01 & 0.01 & 0.05 & -0.59 & -0.16 & 0.18 & 0.30 \\
\hline TNDVI & 0.02 & 0.00 & -0.08 & 0.07 & -0.50 & -0.05 & -0.06 & 0.21 \\
\hline \multirow{2}{*}{ DF } & \multicolumn{2}{|c|}{ G. oliveri } & \multicolumn{2}{|c|}{ K. furfuracea } & \multicolumn{2}{|c|}{ E. petelotii } & \multicolumn{2}{|c|}{ S. lanceolatum } \\
\hline & $\mathrm{H}$ & $\mathrm{BA}$ & $\mathrm{H}$ & $\mathrm{BA}$ & $\mathrm{H}$ & $\mathrm{BA}$ & $\mathrm{H}$ & $\mathrm{BA}$ \\
\hline EVI & 0.15 & -0.18 & -0.09 & -0.07 & -0.08 & -0.42 & -0.25 & 0.09 \\
\hline PVI & 0.12 & -0.19 & -0.07 & -0.02 & -0.01 & -0.37 & -0.26 & 0.10 \\
\hline DVI & 0.12 & -0.18 & -0.08 & -0.03 & -0.01 & -0.38 & -0.26 & 0.09 \\
\hline TNDVI & 0.22 & -0.15 & -0.16 & -0.23 & -0.11 & -0.44 & -0.27 & 0.08 \\
\hline
\end{tabular}

In the vertical structure of most dominant and abundant tree species presented in Table 4.5 which showed a strong correlation with VIs. Of which, in UF, Dipterocarpus kerrii followed by Terminalia bellirica, Dipterocarpus grandiflorus and Shorea roxburghii. In LF, Shorea roxburghii showed a relatively higher correlation with VIs than Ficus lacor, Castanopsis indica and Terminalia myriocarpa. While in DF, those four species Placolobium ellipticum, Alangium chinense, Litsea verticillata and Actinodaphne pilosa showed a strong correlation with VIs presented in Table 4.11 . 
Table 4.11. Correlation of VIs with dominance species in vertical structure

\begin{tabular}{|c|c|c|c|c|c|c|c|c|}
\hline \multirow{2}{*}{$\mathrm{UF}$} & \multicolumn{2}{|c|}{ D. kerrii } & \multicolumn{2}{|c|}{ T. bellirica } & \multicolumn{2}{|c|}{ S. roxburghii } & \multicolumn{2}{|c|}{ D. grandiflorus } \\
\hline & $\mathrm{H}$ & BA & $\mathrm{H}$ & $\mathrm{BA}$ & $\mathrm{H}$ & BA & $\mathrm{H}$ & BA \\
\hline EVI & -0.96 & -0.53 & 0.42 & 0.73 & -0.18 & -0.01 & 0.30 & 0.16 \\
\hline PVI & -0.96 & -0.52 & 0.41 & 0.73 & -0.23 & -0.03 & 0.25 & 0.04 \\
\hline DVI & -0.96 & -0.52 & 0.42 & 0.73 & -0.23 & -0.04 & 0.26 & 0.05 \\
\hline TNDVI & -0.99 & -0.64 & 0.40 & 0.71 & -0.05 & -0.09 & 0.29 & 0.21 \\
\hline \multirow{2}{*}{$\mathrm{LF}$} & \multicolumn{2}{|c|}{ Ficus lacor } & \multicolumn{2}{|c|}{ S. roxburghii } & \multicolumn{2}{|c|}{ C. indica } & \multicolumn{2}{|c|}{ T. myriocarpa } \\
\hline & $\mathrm{H}$ & BA & $\mathrm{H}$ & BA & $\mathrm{H}$ & $\mathrm{BA}$ & $\mathrm{H}$ & BA \\
\hline EVI & -0.17 & -0.53 & 0.50 & 0.50 & -0.25 & -0.84 & -0.34 & 0.48 \\
\hline PVI & -0.20 & -0.55 & 0.51 & 0.51 & -0.21 & -0.82 & 0.16 & 0.62 \\
\hline DVI & -0.17 & -0.53 & 0.52 & 0.51 & -0.23 & -0.83 & 0.18 & 0.59 \\
\hline TNDVI & 0.08 & -0.30 & 0.40 & 0.44 & -0.48 & -0.88 & -0.31 & 0.52 \\
\hline \multirow{2}{*}{$\mathrm{DF}$} & \multicolumn{2}{|c|}{ P. ellipticum } & \multicolumn{2}{|c|}{ A. chinense } & \multicolumn{2}{|c|}{ L. verticillata } & \multicolumn{2}{|c|}{ A. pilosa } \\
\hline & $\mathrm{H}$ & BA & $\mathrm{H}$ & $\mathrm{BA}$ & $\mathrm{H}$ & BA & $\mathrm{H}$ & $\mathrm{BA}$ \\
\hline EVI & - & - & -0.98 & -0.99 & 0.99 & 0.98 & 0.67 & 0.18 \\
\hline PVI & - & - & -0.97 & -0.99 & 0.98 & 0.98 & 0.81 & 0.21 \\
\hline DVI & - & - & -0.97 & -0.99 & 0.98 & 0.97 & 0.80 & 0.19 \\
\hline TNDVI & - & - & -1.00 & -0.96 & 1.00 & 0.99 & 0.60 & 0.25 \\
\hline
\end{tabular}

4.4.7. VIs regression with horizontal and vertical structures

Negative linear regression of four vegetation indices with the mean basal area and height of the ground truth sample plots in the study area are presented in Figure 4.8. As presented above, we focused on the regression of BA and Height with EVI, PVI, DVI, and TNDVI. As a result, the regression of these four VIs is better with the horizontal structure of forest stand than those with vertical ones. The results showed that EVI had more negative linear regression with the basal area than DVI, PVI, and TNDVI with $\mathrm{R}^{2}$ of $0.44 ; 0.43 ; 0.43$ and 0.40 , respectively. On the other hand, the TNDVI had more negative linear regression with the mean height of forest stand than EVI, PVI, and DVI with $\mathrm{R}^{2}$ of $0.24 ; 0.21 ; 0.19$ and 0.18 respectively. 

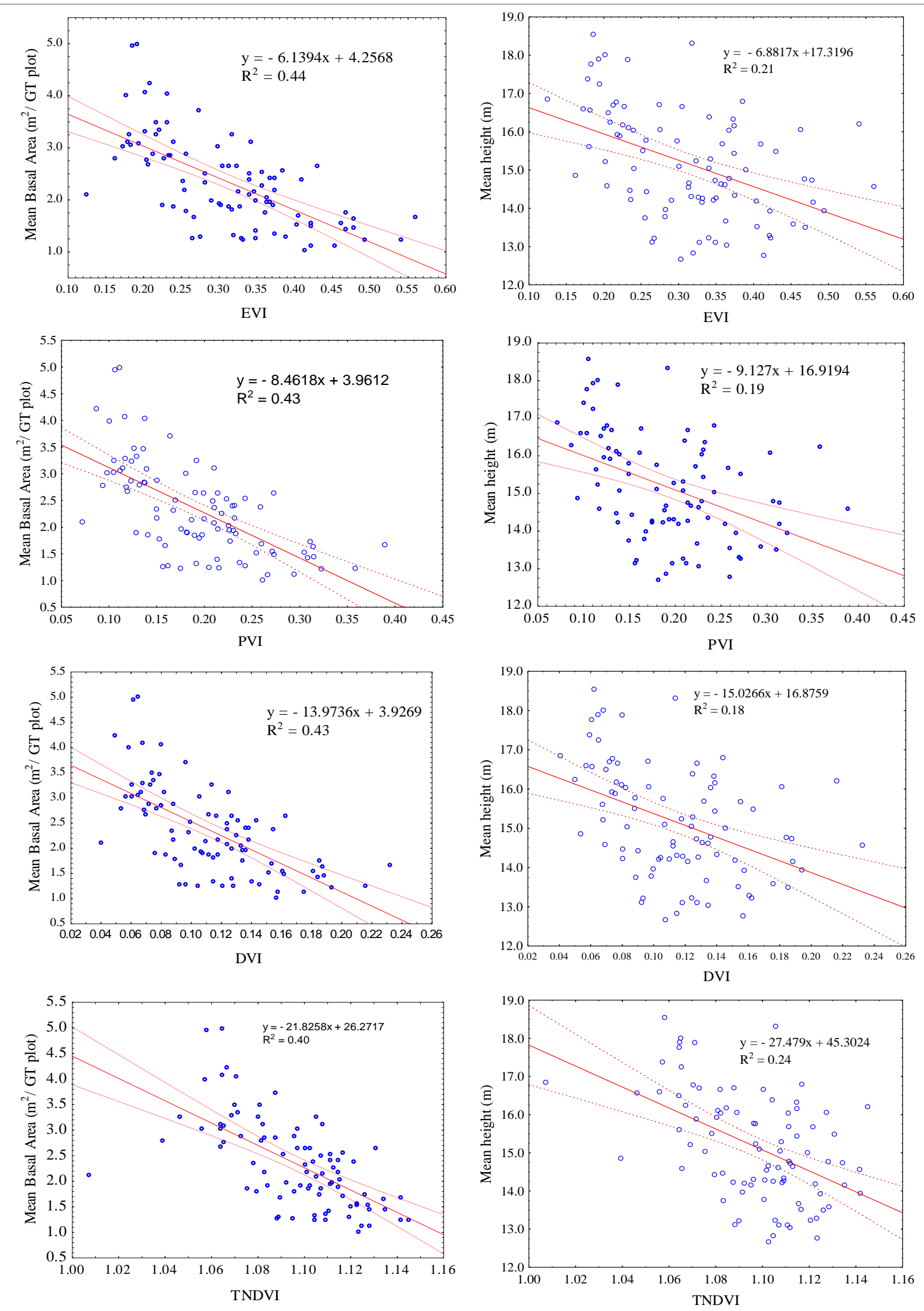

Figure 4.8. The negative linear regression results of EVI, PVI, DVI and TNDVI extracting from Sentinel-2 with basal area, and height 


\subsection{Discussions}

\subsubsection{Species vertical and horizontal structure of different forest types}

Referencing the local forest status maps before setting up random sample plots could hint for a significant difference in the horizontal structure of different forest types. The difference shows the reliability of the pre-existing forest status map. The vertical stratum of forest types in Table 4.3 is not unique due to either human disturbances or geographical factors such as elevations, slopes, and species distribution $[43,54,94]$. The forest type (UF) composed of more D. kerrii, T. bellirica, S. roxburghii, D. grandiflorus species that belong to Dipterocarpaceae, Leguminosea, Combretaceae, Moraceae and Burseraceae families. These families usually distribute in the evergreen or semi-evergreen forests $[43,50,95,96]$. These species are more vertical dominant than those in LF that consists of either the same species or families. Species and families, classified as a high vertical stratum, in DF are less dominant and abundant than those in UF and LF. The mix of forest species distribution and forest destruction in LF and DF causes no significant difference in the mean of vertical stratum $[46,97,98]$ in Table 4.5 . The mixture of forest types based dominant species between UF and LF are of evergreen and semievergreen forests, these dominant and abundant species and families distribute at the elevation of less than $900 \mathrm{~m}$ above sea level where the mean annual rainfall more than $2500 \mathrm{~mm}[45,99]$. In contrast, the similarity of the number of stems, species and families in three different forest types could be due to the inter-mixed location of sample plots and disturbances in forest type respectively at where the mean of those three parameters shows no significant difference [100 102]. On the other hands, the species and families contributing to the horizontal structure of forest stands in the tropic of Malesia - Indonesia and India regions are more light - demanding species of L. ducampii, A. grandiflora, T. myriocarpa, S. roxburghii, S. macropodum, M. mediocris, B. tonkinensis, G. oliveri, K. furfuracea, E. petelotii, S.lanceolatum belonging to Fagaceae, Lauraceae, Leguminosae, Dipterocarpaceae, Euphorbiaceae, Myrtaceae and Clusiaceae $[42,45,54,63,103-105]$.

\subsubsection{Performance of RF classifier}

There have been contradictions on the performance of RF classifier on various training sample sizes with different satellite images in many studies [64]. The proportion of the land cover types of different land uses in the mountainous region is imbalanced and sometimes fragmented into small scale areas that led to a non-unique number of training pixels in classes in Table 4.1. The smaller number of pixels in each training dataset of each class outputted the smaller ratio of producer accuracy resulting to the precision of user's accuracy but the best 
random split and selection of sub-dataset of attribute at each node from sampled points by RF introduced by [14] is a successful ensembled approach. Also, it was due to the mixed cultivation of crops in the agricultural (Agr) area as well as the cultivation period in slash and burnt (SB); the accuracy of producer and user was lower than those of other forest cover classes in Table 4.6 and Table 4.7. Furthermore, the misinterpreted training dataset of WR and SB class in Landsat8 is much higher than those of other classes and in Sentinel-2 in Figure 4.6. On the other hand, when the training sample size was unique and big enough, the classifier is less sensitive. As mentioned above, different cultivation periods plus different times of image capture result in the performance of classification [106]. The results of forest types (DF, LF and UF) classification by RF classifier presented in Table 4.7, and illustrated in Figure 4.6 of Sentinel-2 showed the producer's accuracy between $84 \%$ and $97 \%$, and the user's accuracy was from $88 \%$ to $93 \%$. The user's class error was from $7 \%$ to $13 \%$, and the producer's error ranged from $3 \%$ to $16 \%$. It is clear that the accuracy does not only depend on the number of training samples but also depends on the size of the class $[64,107,108]$.

\subsubsection{Comparison VIs of ground-truth forest cover with those of training sampled points}

The detection accuracy of vegetation cover using satellite images depends on the quality of ground-truth samplings, ten vegetation indices used in this study are to determine the difference between ground truth plots, and the training sample plots. Ghebrezgabher $[108,109]$ used multi-spectral of Landsat-1, Landsat-3, Landsat-5 and Landsat-7 ETM to extract NDVI, VCP, SAVI, CVA, and MNDWI. Gerstmann [110] used multi-spectral RapidEye imagery to extract seven vegetation indices. Kobayashi [111] used spectral indices of multi-bands of the Sentinel-2A image to improve the classification accuracy of crops. The significant difference of VIs in different forest types and each type of both GTVIs and LCVIs presented in Table 4.8. The values of seven VIs namely NDVI, IPVI, EVI, RVI, DVI, PVI and TNDVI derived from groundtruthing sample plots and from training sampled points were significantly different at $(p<0.05)$. It meant that these vegetation indices derived from UF, LF, and DF were significantly different at $(\mathrm{p}<0.05)$. This significant difference firstly supports to confirm that the classified forest types of the ground-truthing sample plots correspond with training sample points and its classified accuracies. Only three VIs, namely GRVI, ARVI, and DNI45 did not show any difference among different defined and classified forest types. In contrast, most of the t-test results of the same value of each vegetation index (VI) from ground-truth and training sample plots of three forest types showed significant differences. This can be explained of the imbalanced number of samples in ground-truth and training sample data causing the different mean values of VI respectively. 
4.5.4. Relationship of VIs with vertical and horizontal forest structure

Seven out of ten VIs showed negative-significant differences with basal area of forest sample plots as horizontal structure and height as vertical structure of the forest sample plots in Table 4.11. The study of dos Reis [112] used Landsat-5 TM to estimate basal area and volume of Eucalyptus camaldulensis Dehn plantation forest, the correlation of basal area and volume of the E. camaldulensis is 0.91 and -0.52 respectively. Chrysafis [113] assessed growing stock volume in Rhodopes of Greece by using Landsat-8 (OLI and Sentinel-2 to extract NDVI, DVI, CTVI, PVI, EVI, TSAVI. Their results of the correlation of DVI, EVI, PVI, and NDVI with growing stock volume were $r=-0.55, r=-0.56, r=-0.56, r=-0.36$ respectively. The study of Gamon [114] showed both negative and positive correlation between NDVI and moisture vegetation indices with parameters of forests in dry and humid seasons. Vegetation indices showed strong correlations with the content of leaf chlorophyll, the correlation ratio depends on species with similar color [115]. The dominant and abundant species in Table 4.10 and Table 4.11 showed different correlations with BA and height of species and even the same species in different forest stratums since the horizontal structure, species composition, diameter, and height class distribution in unique forest types are different [116]. For the whole forest stand where the basal area increased, the vegetation decreased. This trend defined the relationship between biomass productivity of mature forest and chlorophyll contents in the immature forest types.

\subsection{Conclusions}

The multiple spectral bands for land cover and land use classification by using random forest algorithm in Sentinel-2 showed higher accuracy than those of Landsat-8. Sentinel-2 images showed high potential for landscapes and forest type classification for conservation and management purposes in tropical lowland forests. A time series classification by using Sentinel2 with ground-truth samples is seen as a bright hint to distinguish natural forest areas where the Sentinel-2 is available. This contributes to forest land cover mapping since the random forest classifier showed more consistent among land cover classes in Sentinel-2.

Seven vegetation indices extracted from Sentinel-2 showed significant differences between different classified forest types of ground truth and training sample plots. The four defined vegetation indices namely EVI, DVI, PVI and TNDVI derived from the reflectance of the forest canopy by red and near-infrared bands which are considered as useful and possible indicators to assess canopy horizontal structure of lowland forest but further studies are in need for vertical structure assessment of lowland forest canopy. 
The correlation between chlorophyll content of different dominant and abundant species in different forest types suggests further studies to trait the tree species distribution, composition and to assess growth productivities of natural forest landscapes on the targeted forest tree species. The EVI, PVI, DVI, and TNDVI extracted from Sentinel-2 could help predict the better correlation with the horizontal structure but not with the vertical forest structure of forest stands.

Further research consists of more ground truth sample plots that need to affirm the correlation and regressions between vegetation indices-based forest type with its horizontal and vertical structures.

\section{Data Availability}

The ground truth data and satellite images are available upon request from the corresponding author.

\section{Conflicts of Interest}

The authors declare that there are no conflicts of interest in publishing this article.

\section{Funding Statement}

The funding for doing this research is from the German Academic Exchange Service (DAAD) and the German Research Foundation and Open Access Fund of Göttingen University for publication.

\section{Acknowledgement}

We would like to express our thanks to the German Academic Exchange Service (DAAD); The German Research Foundation and the Open Access Fund of the Göttingen University for funding this research and publication; the Department of Climate Change under the Ministry of Natural Resource and Environment of Vietnam; the University of Hue Agriculture and Forestry for their help in arranging administrative permission to access the research areas; the experts of Sub-Forest Inventory and Forest Planning in Thua Thien Hue province; We thank the forest experts of Forest Management Board of the A Luoi and Rangers of Sao La Nature Reserve for their assistance during different phases of fieldwork; the botanists for tree species identification; and local authorities and local people in the A Luoi district. We thank the Department of Cartography, GIS, and Remote Sensing, Göttingen University for providing the ArcGIS software in the framework of research. We especially thank editors and reviewers for constructive comments for publication. 
1. Toranza, C.; Lucas, C.; Ceroni, M. Distribución espacial y cobertura arbórea del bosque serrano y de quebrada en Uruguay Los desafíos de mapear ecosistemas parchosos. Agrociencia Uruguay 2019, 23.

2. Mitchell, A.L.; Rosenqvist, A.; Mora, B. Current remote sensing approaches to monitoring forest degradation in support of countries measurement, reporting and verification (MRV) systems for REDD. Carbon balance and management 2017, 12, 9.

3. Mori, A.S.; Lertzman, K.P.; Gustafsson, L. Biodiversity and ecosystem services in forest ecosystems: a research agenda for applied forest ecology. J Appl Ecol 2017, 54, 12-27.

4. Lefsky, M.A.; Cohen, W.B.; Spies, T.A. An evaluation of alternate remote sensing products for forest inventory, monitoring, and mapping of Douglas-fir forests in western Oregon. Can. J. For. Res. 2001, 31, 78-87.

5. Colditz, R.R.; Schmidt, M.; Conrad, C.; Hansen, M.C.; Dech, S. Land cover classification with coarse spatial resolution data to derive continuous and discrete maps for complex regions. Remote Sensing of Environment 2011, 115, 3264-3275.

6. Zafari, A.; Zurita-Milla, R.; Izquierdo-Verdiguier, E. Evaluating the Performance of a Random Forest Kernel for Land Cover Classification. Remote Sensing 2019, 11, 575.

7. Carrão, H.; Gonçalves, P.; Caetano, M. Contribution of multispectral and multitemporal information from MODIS images to land cover classification. Remote Sensing of Environment 2008, 112, 986-997.

8. Craig Dobson, M.; Ulaby, F.T.; Pierce, L.E. Land-cover classification and estimation of terrain attributes using synthetic aperture radar. Remote Sensing of Environment 1995, 51, 199-214.

9. Pal, M.; Foody, G.M. Feature Selection for Classification of Hyperspectral Data by SVM. IEEE Trans. Geosci. Remote Sensing 2010, 48, 2297-2307.

10. Patenaude, G.; Milne, R.; Dawson, T.P. Synthesis of remote sensing approaches for forest carbon estimation: reporting to the Kyoto Protocol. Environmental Science \& Policy 2005, 8, 161-178.

11. Rosenqvist, Å.; Milne, A.; Lucas, R.; Imhoff, M.; Dobson, C. A review of remote sensing technology in support of the Kyoto Protocol. Environmental Science \& Policy 2003, 6, 441-455.

12. Wulder, M.A.; Coops, N.C.; Roy, D.P.; White, J.C.; Hermosilla, T. Land cover 2.0. International Journal of Remote Sensing 2018, 39, 4254-4284.

13. Raczko, E.; Zagajewski, B. Comparison of support vector machine, random forest and neural network classifiers for tree species classification on airborne hyperspectral APEX images. European Journal of Remote Sensing 2017, 50, 144-154.

14. Breiman, L. Random Forests. Machine Learning 2001, 45, 5-32.

15. Sonobe, R.; Yamaya, Y.; Tani, H.; Wang, X.; Kobayashi, N.; Mochizuki, K. Assessing the suitability of data from Sentinel-1A and 2A for crop classification. GIScience \& Remote Sensing 2017, 54, 918-938.

16. Chen, J.; Li, M.; Wang, W. Statistical Uncertainty Estimation Using Random Forests and Its Application to Drought Forecast. Mathematical Problems in Engineering 2012, 2012, 112. 
17. Hawryło, P.; Wężyk, P. Predicting Growing Stock Volume of Scots Pine Stands Using Sentinel-2 Satellite Imagery and Airborne Image-Derived Point Clouds. Forests 2018, 9 , 274.

18. Butt, M.J.; Waqas, A.; Iqbal, M.F.; Muhammad, G.; Lodhi, M.A.K. Assessment of Urban Sprawl of Islamabad Metropolitan Area Using Multi-Sensor and Multi-Temporal Satellite Data. Arab J Sci Eng 2012, 37, 101-114.

19. Turner, M.G. Landscape Ecology: What Is the State of the Science? Annu. Rev. Ecol. Evol. Syst. 2005, 36, 319-344.

20. Forman, R.T.T.; Godron, M. Landscape ecology; Wiley: New York, Chichester, 1986.

21. Finke, D.L.; Snyder, W.E. Conserving the benefits of predator biodiversity. Biological Conservation 2010, 143, 2260-2269.

22. Schall, P.; Gossner, M.M.; Heinrichs, S.; Fischer, M.; Boch, S.; Prati, D.; Jung, K.; Baumgartner, V.; Blaser, S.; Böhm, S.; et al. The impact of even-aged and uneven-aged forest management on regional biodiversity of multiple taxa in European beech forests. Journal of Applied Ecology 2018, 55, 267-278.

23. Fischer, R.; Knapp, N.; Bohn, F.; Shugart, H.H.; Huth, A. The Relevance of Forest Structure for Biomass and Productivity in Temperate Forests: New Perspectives for Remote Sensing. Surv Geophys 2019, 40, 709-734.

24. Huang, C.; Goward, S.N.; Masek, J.G.; Thomas, N.; Zhu, Z.; Vogelmann, J.E. An automated approach for reconstructing recent forest disturbance history using dense Landsat time series stacks. Remote Sensing of Environment 2010, 114, 183-198.

25. Chakraborty, A.; Sachdeva, K.; Joshi, P.K. A Reflection on Image Classifications for Forest Ecology Management: Towards Landscape Mapping and Monitoring. In Handbook of Neural Computation: Elsevier, 2017, pp. 67-85.

26. Liu, H.; Zhou, Q. Accuracy analysis of remote sensing change detection by rule-based rationality evaluation with post-classification comparison. International Journal of Remote Sensing 2004, 25, 1037-1050.

27. Elmore, A.J.; Mustard, J.F.; Manning, S.J.; Lobell, D.B. Quantifying Vegetation Change in Semiarid Environments. Remote Sensing of Environment 2000, 73, 87-102.

28. Bounoua, L.; DeFries, R.; Collatz, G.J.; Sellers, P.; Khan, H. Effects of Land Cover Conversion on Surface Climate. Climatic Change 2002, 52, 29-64.

29. White, J.C.; Wulder, M.A.; Hobart, G.W.; Luther, J.E.; Hermosilla, T.; Griffiths, P.; Coops, N.C.; Hall, R.J.; Hostert, P.; Dyk, A.; et al. Pixel-Based Image Compositing for Large-Area Dense Time Series Applications and Science. Canadian Journal of Remote Sensing 2014, 40, 192-212.

30. Brown, M.E.; Pinzon, J.E.; Didan, K.; Morisette, J.T.; Tucker, C.J. Evaluation of the consistency of long-term NDVI time series derived from AVHRR,SPOT-vegetation, SeaWiFS, MODIS, and Landsat ETM+ sensors. IEEE Trans. Geosci. Remote Sensing 2006, 44, 1787-1793.

31. Matsushita, B.; Yang, W.; Chen, J.; Onda, Y.; Qiu, G. Sensitivity of the Enhanced Vegetation Index (EVI) and Normalized Difference Vegetation Index (NDVI) to Topographic Effects: A Case Study in High-density Cypress Forest. Sensors (Basel, Switzerland) 2007, 7, 2636-2651.

32. Hansen, M.C.; Loveland, T.R. A review of large area monitoring of land cover change using Landsat data. Remote Sensing of Environment 2012, 122, 66-74. 
33. Roy, D.P.; Wulder, M.A.; Loveland, T.R.; C.E., W.; Allen, R.G.; Anderson, M.C.; Helder, D.; Irons, J.R.; Johnson, D.M.; Kennedy, R.; et al. Landsat-8: Science and product vision for terrestrial global change research. Remote Sensing of Environment 2014, 145, 154-172.

34. Xie, Y.; Sha, Z.; Yu, M. Remote sensing imagery in vegetation mapping: a review. Journal of Plant Ecology 2008, 1, 9-23.

35. Jones, H.G.; Vaughan, R.A. Remote sensing of vegetation: Principles, techniques, and applications; Oxford University Press: Oxford, 2010.

36. Asner, G.P. Cloud cover in Landsat observations of the Brazilian Amazon. International Journal of Remote Sensing 2001, 22, 3855-3862.

37. Erinjery, J.J.; Singh, M.; Kent, R. Mapping and assessment of vegetation types in the tropical rainforests of the Western Ghats using multispectral Sentinel-2 and SAR Sentinel-1 satellite imagery. Remote Sensing of Environment 2018, 216, 345-354.

38. Vrieling, A.; Meroni, M.; Darvishzadeh, R.; Skidmore, A.K.; Wang, T.; Zurita-Milla, R.; Oosterbeek, K.; O'Connor, B.; Paganini, M. Vegetation phenology from Sentinel-2 and field cameras for a Dutch barrier island. Remote Sensing of Environment 2018, 215, $517-$ 529.

39. Frost, G.V.; Epstein, H.E.; Walker, D.A. Regional and landscape-scale variability of Landsat-observed vegetation dynamics in northwest Siberian tundra. Environ. Res. Lett. 2014, 9, 25004.

40. Mai, D.T.; Thanh, N.T. Precipitation extremes over Vietnam: 5th International Scientific Conference on the Global Energy and Water Cycle: Orange County, USA, 2005.

41. Nguyen, H.; Diez, J.; Kerstin, W. Spatial distribution and association patterns in a tropical evergreen broad-leaved forest of north-central Vietnam. Journal of Vegetation Science 2016, 27, 318-327.

42. Averyanov, L.; Phan, L.; Nguyen, H.; Nguyen, V.; Pham, T.; Do, D.; Thao, V.; Tran, M.; Ngo, T.; Duong, V.; et al. Lowland flora and vegetation preliminary survey, Part 1: Green Corridor Project in Thua Thien Hue Province, 2005.

43. Le, N. Adding some vascular plants to the list of plants in Thua Thien Hue Province. Journal of Research and Development 2016, 4, 96-107.

44. Pham, T.G.; Nguyen, H.T.; Kappas, M. Assessment of soil quality indicators under different agricultural land uses and topographic aspects in Central Vietnam. International Soil and Water Conservation Research 2018, 6, 280-288.

45. Thai, V. Ecosystems of tropical forests in Vietnam; Science and Technics Publishing House: Ha Noi, 1998.

46. Phuong, V.T.; Anh, H.V.; Lung, N.N.; Sam, D.D.; Ky, N.D.; Lien, T.V. Forest ecological stratification in Vietnam. Techniques and Science Publishing House, Hanoi, Vietnam 2012, 139.

47. Hung, N.T. Dynamics and Management of the Natural Forests in Quang Ngai, Southern Coastal Centre, Vietnam, Msc, Goettingen. Dissertation: Göttingen, 2010.

48. Lamprecht, H. Silviculture in the tropics: Tropical forest ecosystems and their tree species: possibilities and methods for their long-term utilization; Deutsche Gesellschaft für Technische Zusammenarbeit GTZ: Eschborn, 1989.

49. Bui, M.H. Structure and restoration of natural secondary forests in the Central Highlands, Vietnam,. Ph.D Dissertation: TU Dresend, 2016. 
50. Thai, V. Forest vegetation cover of Vietnam, 2nd ed; Science and Technics Publishing House: Ha Noi, 1978.

51. Sader, S.A.; Waide, R.B.; Lawrence, W.T.; Joyce, A.T. Tropical forest biomass and successional age class relationships to a vegetation index derived from landsat TM data. Remote Sensing of Environment 1989, 28, 143-198.

52. Nguyen, T.; Tran, H. Namina Vernacula plantarum silvaticarum Vietnamicarum: Tên cây rù̀ng Việt Nam; Agriculture Publishing House: Hanoi., 1971.

53. Kalwij, J.M. Review of 'The Plant List, a working list of all plant species'. Journal of Vegetation Science 2012, 23, 998-1002.

54. Trong, H.N.; Gia, T.P.; Kappas, M. Evaluating the Influence of Topography on Species Diversity, Distribution and Composition of Forests in Central Vietnam. Indian Journal of Science and Technology 2019, 12, 1-7.

55. Laar, V.A.; Akça, A. Forest Mensuration; Springer: Dordrecht, 2007.

56. Tran, H.; Shigeru IIDA; Inoue S. Species Composition, Diversity and Structure of Secondary Tropical Forests Following Selective Logging in Huong Son, Ha Tinh Province, Vietnam. Journal of the Faculty of Agriculture - Kyushu University 2005, 50, 551-571.

57. Curtis, J.T.; McIntosh, R.P. The Interrelations of Certain Analytic and Synthetic Phytosociological Characters. Ecology 1950, 31, 434-455.

58. Nguyen, H.; David, L.; John, H.; Jenifer, F. Designing Mixed Species Tree Plantations for the Tropics: Balancing Ecological Attributes of Species with Landholder Preferences in the Philippines. PLOS ONE 2014, 9.

59. United States Geological Survey. USGS. Available online: https://earthexplorer.usgs.gov/ (accessed on Accessed 22 September, 2019).

60. Clevers, J.; Kooistra, L.; van den Brande, M. Using Sentinel-2 Data for Retrieving LAI and Leaf and Canopy Chlorophyll Content of a Potato Crop. Remote Sensing 2017, 9, 405.

61. Zhang, H.K.; Roy, D.P.; Yan, L.; Li, Z.; Huang, H.; Vermote, E.; Skakun, S.; Roger, J.-C. Characterization of Sentinel-2A and Landsat-8 top of atmosphere, surface, and nadir BRDF adjusted reflectance and NDVI differences. Remote Sensing of Environment 2018, 215, 482-494.

62. Thua Thien Hue People's Committee, Ed. Land Use Planning Report of A Luoi District; People's Committee: Thua Thien Hue, 2016.

63. Ngoc Le, D.T.; van Thinh, N.; The Dung, N.; Mitlöhner, R. Effect of Disturbance Regimes on Spatial Patterns of Tree Species in Three Sites in a Tropical Evergreen Forest in Vietnam. International Journal of Forestry Research 2016, 2016, 1-16.

64. Thanh Noi, P.; Kappas, M. Comparison of Random Forest, k-Nearest Neighbor, and Support Vector Machine Classifiers for Land Cover Classification Using Sentinel-2 Imagery. Sensors (Basel, Switzerland) 2017, 18.

65. Liaw, A.; Wiener, M. Classification and Regression by randomForest 2002, 2/3, 18-22.

66. Zhang, H.K.; Roy, D.P. Using the $500 \mathrm{~m}$ MODIS land cover product to derive a consistent continental scale $30 \mathrm{~m}$ Landsat land cover classification. Remote Sensing of Environment 2017, 197, 15-34.

67. Strobl, C.; Boulesteix, A.-L.; Kneib, T.; Augustin, T.; Zeileis, A. Conditional variable importance for random forests. BMC bioinformatics 2008, 9, 307.

68. Congalton, R.G. Assessing the accuracy of remotely sensed data; CRC Press: U.S.A., 1997. 
69. Foody, G.M. Status of land cover classification accuracy assessment. Remote Sensing of Environment 2002, 80, 185-201.

70. Gumma, M.K.; Thenkabail, P.S.; Teluguntla, P.; Whitbread, A.M. Indo-Ganges River Basin Land Use/Land Cover (LULC) and Irrigated Area Mapping. In Indus River Basin: Elsevier, 2019, pp. 203-228.

71. Congalton, R.G. Assessing Landsat Classification Accuracy Using Discrete Multivariate Analysis Statistical Techniques, 1983.

72. Steven, M.D.; Malthus, T.J.; Baret, F.; Xu, H.; Chopping, M.J. Intercalibration of vegetation indices from different sensor systems. Remote Sensing of Environment 2003, 88, $412-422$.

73. Deepak, M.; Keski-Saari, S.; Fauch, L.; Granlund, L.; Oksanen, E.; Keinänen, M. Leaf Canopy Layers Affect Spectral Reflectance in Silver Birch. Remote Sensing 2019, 11, 2884.

74. Glenn, E.P.; Huete, A.R.; Nagler, P.L.; Nelson, S.G. Relationship Between Remotelysensed Vegetation Indices, Canopy Attributes and Plant Physiological Processes: What Vegetation Indices Can and Cannot Tell Us About the Landscape. Sensors (Basel, Switzerland) 2008, 8, 2136-2160.

75. Gandhi, G.M.; Parthiban, S.; Thummalu, N.; Christy, A. Ndvi: Vegetation Change Detection Using Remote Sensing and Gis - A Case Study of Vellore District. Procedia Computer Science 2015, 57, 1199-1210.

76. Calvet, J.-C. Vegetation. In Extreme Hydroclimatic Events and Multivariate Hazards in a Changing Environment; Calvet, J.-C., Ed.: Elsevier, 2019, pp. 145-159.

77. Grippen, R. Calculating the vegetation index faster. Remote Sensing of Environment 1990, $34,71-73$.

78. Sripada, R.P.; Farrer, D.C.; Weisz, R.; Heiniger, R.W.; White, J.G. Aerial Color Infrared Photography to Optimize In-Season Nitrogen Fertilizer Recommendations in Winter Wheat. Agronomy Journal 2007, 99, 1424.

79. Gitelson, A.A.; Merzlyak, M.N. Remote sensing of chlorophyll concentration in higher plant leaves. Advances in Space Research 1998, 22, 689-692.

80. Kaufman, Y.J.; Tanre, D. Atmospherically resistant vegetation index (ARVI) for EOSMODIS. IEEE Trans. Geosci. Remote Sensing 1992, 30, 261-270.

81. Loranty, M.; Davydov, S.; Kropp, H.; Alexander, H.; Mack, M.; Natali, S.; Zimov, N. Vegetation Indices Do Not Capture Forest Cover Variation in Upland Siberian Larch Forests. Remote Sensing 2018, 10, 1686.

82. Tucker, C.J. Red and photographic infrared linear combinations for monitoring vegetation. Remote Sensing of Environment 1979, 8, 127-150.

83. Humagain, K.; Portillo-Quintero, C.; Cox, R.; Cain, J. Mapping Tree Density in Forests of the Southwestern USA Using Landsat 8 Data. Forests 2017, 8, 287.

84. Delegido, J.; Verrelst, J.; Alonso, L.; Moreno, J. Evaluation of Sentinel-2 red-edge bands for empirical estimation of green LAI and chlorophyll content. Sensors (Basel, Switzerland) 2011, 11, 7063-7081.

85. Birth, G.S.; McVey, G.R. Measuring the Color of Growing Turf with a Reflectance Spectrophotometer1. Agronomy Journal 1968, 60, 640.

86. Chen, J.M. Evaluation of Vegetation Indices and a Modified Simple Ratio for Boreal Applications. Canadian Journal of Remote Sensing 1996, 22, 229-242. 
87. Stenberg, P.; Rautiainen, M.; Manninen, T.; Voipio, P.; Smolander, H. Reduced simple ratio better than NDVI for estimating LAI in Finnish pine and spruce stands. Silva Fenn. 2004, 38 .

88. Qi, J.; Chehbouni, A.; Huete, A.R.; Kerr, Y.H.; Sorooshian, S. A modified soil adjusted vegetation index. Remote Sensing of Environment 1994, 48, 119-126.

89. Senseman, G.M.; Bagley, C.F.; Tweddale, S.A. Correlation of rangeland cover measures to satellite-imagery-derived vegetation indices. Geocarto International 1996, 11, 29-38.

90. Gałecki, A.; Burzykowski, T. Linear Mixed-Effects Models Using R: A Step-by-Step Approach; Springer New York; Imprint; Springer: New York, NY, 2013.

91. Tucker, C.J.; Slayback, D.A.; Pinzon, J.E.; Los, S.O.; Myneni, R.B.; Taylor, M.G. Higher northern latitude normalized difference vegetation index and growing season trends from 1982 to 1999. International journal of biometeorology 2001, 45, 184-190.

92. Gitelson, A.A.; Kaufman, Y.J.; Merzlyak, M.N. Use of a green channel in remote sensing of global vegetation from EOS-MODIS. Remote Sensing of Environment 1996, 58, 289298.

93. Huete, A.; Didan, K.; Miura, T.; Rodriguez, E.; Gao, X.; Ferreira, L. Overview of the radiometric and biophysical performance of the MODIS vegetation indices. Remote Sensing of Environment 2002, 83, 195-213.

94. Yocom, L.; Fulé, P.Z. Human and climate influences on frequent fire in a high-elevation tropical forest. Journal of Applied Ecology 2012, 49, 1356-1364.

95. Soejima, A.; Tagane, S.; Nguyen Van, N.; Duy, C.N.; Huong, N.T.T.; Yahara, T. Callicarpa bachmaensis Soejima \& Tagane (Lamiaceae), a new species from Bach Ma National Park in Thua Thien Hue Province, Central Vietnam. PhytoKeys 2016, 62, 33-39.

96. Nguyen, T.T.; Baker, P.J. Structure and composition of deciduous dipterocarp forest in Central Vietnam: patterns of species dominance and regeneration failure. Plant Ecology \& Diversity 2016, 9, 589-601.

97. Van, Y.T.; Cochard, R. Tree species diversity and utilities in a contracting lowland hillside rainforest fragment in Central Vietnam. Forest Ecosystems 2017, 4, 115.

98. Luong, T.H. Forest resources and forestry in Vietnam. 171-177 Pages / Journal of Vietnamese Environment, Vol 6 No 2 (2014) / Journal of Vietnamese Environment, Vol 6 No 2 (2014) 2014.

99. Champion, H.H. A Preliminary survey of forest types of India and Burma, 1st ed; Indian For Rec N S Silvic: New Delhi, 1936.

100. Allaby, M.; Day, T.; Moore, P.D. Biomes of the Earth; Chelsea House: New York, 2006.

101. Stork, N.E. Living in a dynamic tropical forest landscape (9781405156431) SDJQ/90021; Blackwell Pub, 2008.

102. Robinson, J.G.; Bennett, E.L., Eds. Hunting for sustainability in tropical forests; Columbia University Press: New York, op. 2000.

103. Hung, P.Q. Structure and light factor in differently logged moist forests in Vu QuangHuong Son, Vietnam, 1st ed; Cuvillier Verlag: Göttingen, 2008.

104. Ngo, T.L.; Hölscher, D. The Fate of Five Rare Tree Species after Logging in a Tropical Limestone Forest (Xuan Son National Park, northern Vietnam). Tropical Conservation Science 2014, 7, 326-341.

105. Huy, L. Growth, demography and stand structure of Scapium macropodum in differently managed forests in Vietnam; s.n.]: [S.1., 2012. 
106. Macintyre, P.; van Niekerk, A.; Mucina, L. Efficacy of multi-season Sentinel-2 imagery for compositional vegetation classification. International Journal of Applied Earth Observation and Geoinformation 2020, 85, 101980.

107. Sung, W.-P.; Kao, J.C.M.; Chen, R. Frontiers of energy and environmental engineering: Proceedings of the 2012 International Conference on Frontiers of Energy and Environmental Engineering (ICFEEE 2012), Hong Kong, China, 11-13 December 2012 / editors, Wen-Pei Sung, Jimmy C.M. Kao, Ran Chen; CRC Press/Balkema: Leiden, Netherlands, 2013.

108. Ghebrezgabher, M.G.; Yang, T.; Yang, X.; Wang, X.; Khan, M. Extracting and analyzing forest and woodland cover change in Eritrea based on landsat data using supervised classification. The Egyptian Journal of Remote Sensing and Space Science 2016, 19, 37-47.

109. Haque, M.I.; Basak, R. Land cover change detection using GIS and remote sensing techniques: A spatio-temporal study on Tanguar Haor, Sunamganj, Bangladesh. The Egyptian Journal of Remote Sensing and Space Science 2017, 20, 251-263.

110. Gerstmann, H.; Möller, M.; Gläßer, C. Optimization of spectral indices and long-term separability analysis for classification of cereal crops using multi-spectral RapidEye imagery. International Journal of Applied Earth Observation and Geoinformation 2016, $52,115-125$.

111. Kobayashi, N.; Tani, H.; Wang, X.; Sonobe, R. Crop classification using spectral indices derived from Sentinel-2A imagery. Journal of Information and Telecommunication 2020, 4, 67-90.

112. dos Reis, A.A.; Carvalho, M.C.; Mello, J.M. de; Gomide, L.R.; Ferraz Filho, A.C.; Acerbi Junior, F.W. Spatial prediction of basal area and volume in Eucalyptus stands using Landsat TM data: an assessment of prediction methods. N.Z. j. of For. Sci. 2018, 48.

113. Chrysafis, I.; Mallinis, G.; Siachalou, S.; Patias, P. Assessing the relationships between growing stock volume and Sentinel-2 imagery in a Mediterranean forest ecosystem. Remote Sensing Letters 2017, 8, 508-517.

114. GAMON, J.A.; Field, C.B.; Goulden, M.L.; Griffin, K.L.; Hartley, A.E.; Joel, G.; PENUELAS, J.; Valentini, R. Relationships Between NDVI, Canopy Structure, and Photosynthesis in Three Californian Vegetation Types. Ecological Applications 1995, 5, $28-41$.

115. Lu, S.; Lu, F.; You, W.; Wang, Z.; Liu, Y.; Omasa, K. A robust vegetation index for remotely assessing chlorophyll content of dorsiventral leaves across several species in different seasons. Plant methods 2018, 14, 15.

116. Merschel, A.G.; Heyerdahl, E.K.; Spies, T.A.; Loehman, R.A. Influence of landscape structure, topography, and forest type on spatial variation in historical fire regimes, Central Oregon, USA. Landscape Ecol 2018, 33, 1195-1209. 


\title{
Chapter 5. Assessment of soil quality indicators under different agricultural land uses and topographic aspects in Central Vietnam
}

\begin{abstract}
Soil quality assessment is valuable for agricultural production. In this research, 155 soil samples at two soil depths were collected from four land use types in an agricultural area of the A Luoi District in the Central Vietnam. Differences of soil organic carbon, total nitrogen in soil and soil $\mathrm{pH}$ under different land use types and topographic aspects were compared. Soil organic carbon contents in arable land and plantation forest are higher than those in natural forest and grassland $(\mathrm{p}<0.05)$. Conversely, the total nitrogen in natural forest was significantly lesser in comparison to other land use types. Meanwhile there were no significant differences of the total nitrogen content $(\mathrm{p}<0.05)$ among arable land, plantation forest, and grassland. The soil of grassland, natural and plantation forests land use types were more significantly acidic than those of the soils of the arable land use type. Soil organic carbon and total nitrogen showed a decreasing trend while soil depth increased in all land use types. The soil $\mathrm{pH}$ in plantation forest and arable land use types showed no significant change in relation to soil depth. Significant differences were not found in topographic aspects and soil organic carbon content; however, the different changing trends of soil organic carbon content between land use types and aspects were found. The impact of slope, elevation, farming system or soil texture accounted for the differences in these soil indicators under different land use types in the A Luoi District.
\end{abstract}

Keywords: Central Vietnam; Land use type; Hilly area; Soil quality; Topographic aspects

\section{Citation:}

Tung Gia Pham*, Hung Trong Nguyen, Martin Kappas (2018). Assessment of Soil Quality Indicators under Different Agricultural Land Uses and Topographic Aspect in Central Vietnam. International Soil and Water Conservation Research; Vol 6; Issue 4; Pages 280-288. DOI: https://doi.org/10.1016/j.iswcr.2018.08.001

* Corresponding author 


\subsection{Introduction}

According to the first Revised World Soil Charter, endorsed by The Food and Agriculture Organization (FAO) of the United Nations, "soils are a key enabling resource, central to the creation of a host of goods and services integral to ecosystems and human well-being" [1]. In general, soil quality is the ability of soil to provide nutrients to plants, maintain and improve water and air within the soil, and support human needs [2]. Unfortunately, soil quality is rapidly decreasing in many regions around the world [3]. Many reasons leading to soil quality deterioration, including changes in land use types from forest to arable land [4] and the consequences of intensive land use [5]. Improvement of soil quality because of different land use types or crop rotation can be measured by changes in soil indicators and other parameters $[6,7]$.

Various studies have been conducted to evaluate the soil quality indicators under different land use types [8-10]. The most popular indicators used to assess soil quality are soil organic carbon (SOC), soil total nitrogen (STN) and soil acidity (pH). SOC is fundamental to soil fertility and is a reliable indicator of a soil's biological health [11] as well as its chemical, biological, and physical processes. STN is the primary nutrient used for vegetation growth and is also used as a critical soil quality assessment [12]. Soil $\mathrm{pH}$ is one of the most essential soil parameters and essential for agricultural production. Most crops develop best in soil with a $\mathrm{pH}$ from 5.5 to 6.5 [13]. In the warm and humid environments of Central Vietnam, soil acidification occurs over time as the products of weathering are leached by water moving laterally or downwards through the soil.

Although the effects of different land use types on SOC, STN, and $\mathrm{pH}$ have been widely studied, the results remain inconclusive. Abbasi et al. (2007) [8], Dengiz et al. (2015) [14], and Kalu et al. (2015) [10] found that SOC content in forested land is higher compared to other land use types. Conversely, Jonczak (2013) [15] argued that fallow land has the highest SOC content, whereas Shi et al. (2010) [16] stated that paddy rice has the highest SOC content. Similar to SOC, Chen et al. (2016) [17] reported that STN in croplands was significantly lower than in forested land; however, Moges et al. (2013) [18] argued that STN did not show any significant variation across all land use types. Soil $\mathrm{pH}$ also is affected by different land use types $[19,20]$.

In general, the total organic carbon (OC) is the amount of carbon in the soil related to living organisms or derived from them. In Vietnamese soils, total OC usually differs remarkably depending on soil type and topography, typically ranging from $1.0-1.5 \%$ of total soil weight. Under rainfed farming systems, it is typically $1 \%$ [21]. Increasing the quantity of OC stored in 
soil may be one option for decreasing the atmospheric concentration of carbon dioxide $\left(\mathrm{CO}_{2}\right)$, a major greenhouse gas. This function of $\mathrm{OC}$ is also considered in the Vietnamese National Adaptation Strategy to Climate Change.

Increasing the amount of OC stored in soil may also improve soil quality as OC contributes to many beneficial physical, chemical, and biological processes in the soil ecosystem (Figure 5.1). When OC in soil is below $1 \%$, soil health is low, and yield potential (based on rainfall) may be constrained [22].

The quantity of OC stored in soil is the difference between all OC inputs and losses from soil. The primary inputs of OC in rainfed farming systems are from crop residues, plant roots, and animal manure. Inputs of plant material are generally higher when plant growth is denser.

Losses of OC from soil occur through decomposition by microorganisms, erosion of the surface soil, and withdrawal in plant and animal production. During decomposition, microorganisms convert about half of the $\mathrm{OC}$ to $\mathrm{CO}_{2}$. This process is continuous; thus without a steady supply of OC, the quantity stored in the soil will decrease over time.

Losses by erosion may profoundly influence the quantity of OC storage due to the heavy concentration of OC as small particles in the surface soil layer that are easily eroded. In Vietnamese agriculture, erosion can cause the annual loss of less than $5 \mathrm{t} / \mathrm{ha}$ of soil under crop production [23-25] and up to 150-200 t/ha from soil under bare fallow [26]. Withdrawal of OC in plant and animal production is also an important loss of OC from the soil. Harvested materials such as grain, hay, feed, and forage, all represent the loss of OC for plant and animal production. Soil quality is simply defined as "the capacity of a specific kind of soil to function" [27], i.e., mainly to provide nutrition to plants and absorb and drain water. The different properties of soil are - texture, moisture, fertility (level of nitrogen, phosphorus, and potassium) and $\mathrm{pH}$ level, where the $\mathrm{pH}$ is the measure of a soil's acidity or alkalinity. 


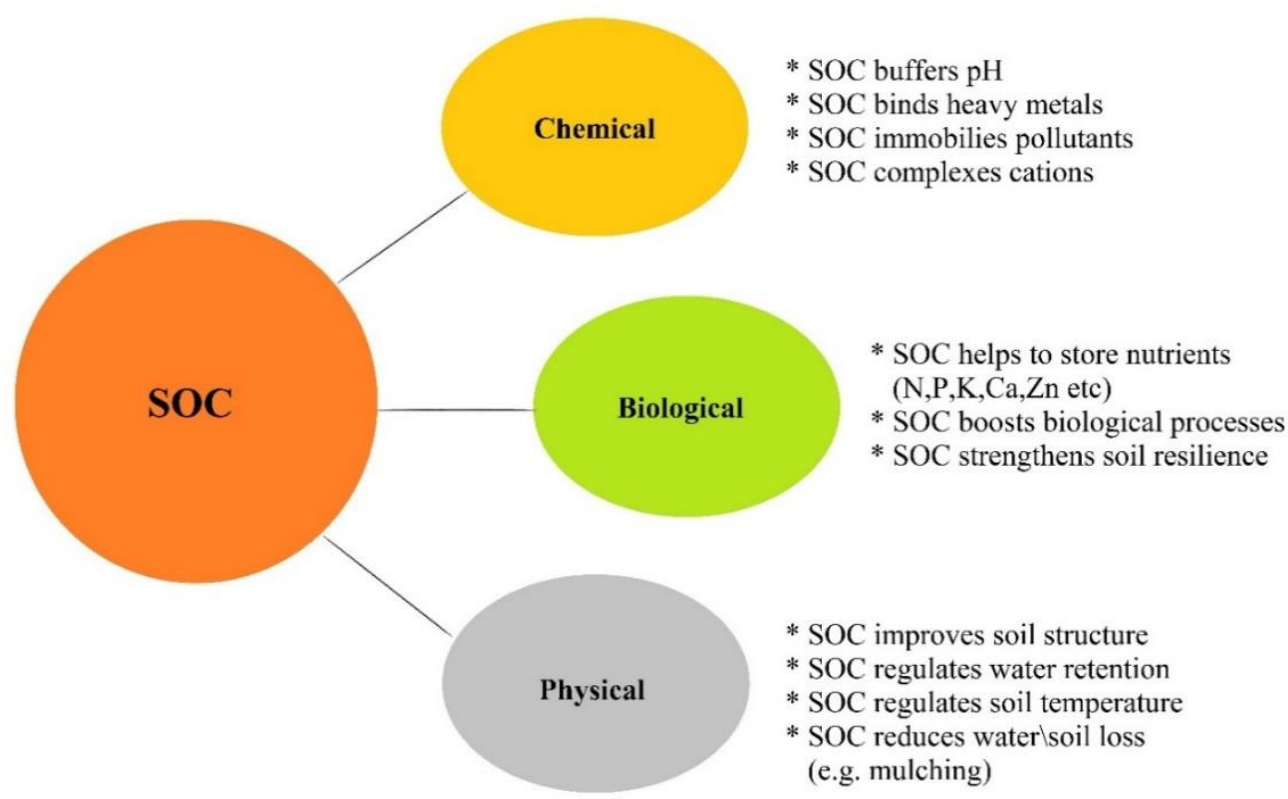

Figure 5.1. Chemical, biological, and physical benefits in soil to which soil organic carbon (SOC) contributes [28].

Hydrology, in terms of surface runoff and soil erosion, has a high impact on current and future OC contents in topsoil in Central Vietnam. The specific hydrological situation of the A Luoi study area has investigated by some authors [29-31].

Soil properties are significantly influenced by spatial factors such as topographic aspect, positions, and climatic conditions. The variations in soil properties and topographic positions are strongly related [32]. According to Pausas et al. (2007) [33], climatic and topographic conditions result in changes of SOC, and changes in OC depend on related topographic position (aspects and slope). In this study, the concept of paired correlation of SOC of land use types and aspects was analyzed.

Among the three macro regions of Vietnam, the Central region is the least developed [34]. The agricultural and forested land areas of the Central region account for $78 \%$ total area [35]. Concerning the impact of different land use types on the ecological systems in Vietnam, the researchers focused on soil erosion, carbon emissions, and climate changes [36-38]. In this area, no soil quality studies have been carried out to date for different types of land use and topographic aspects.

Therefore, the primary objectives of this study, conducted in A Luoi district, are to (i) determine the content of SOC, STN, and $\mathrm{pH}$ values for four land use types and (ii) study the differences in SOC, STN, and pH under different land use types, soil depths, and topographic aspects. 


\subsection{Material and methods}

\subsubsection{Research area}

The study area is located between $107^{\circ}$ to $107^{\circ} 30^{\prime} \mathrm{E}$ and $16^{\circ}$ to $16^{\circ} 30^{\prime} \mathrm{N}$ at around $60 \mathrm{~km}$ west of Hue city, in Central Vietnam. The area is home to the ethnic majority Kinh and four minority ethnic groups: Ta Oi, Co Tu, Van Kieu, and Pa Ko. By 2015, the population was about 47,115 inhabitants. Agricultural production and collection of forest products are the main livelihoods of most local peoples. The lack of basic resources such as finance and knowledge is one of the main obstacles to sustainable livelihood development, especially in agricultural cultivation [39].

The climate at the research site shows tropical monsoon characteristics with an annual rainy season from September to December. According to statistics from 2005 to 2015, the average yearly precipitation is about $3180 \mathrm{~mm}$. The average temperature reaches the highest in May and the lowest in January at $25^{\circ} \mathrm{C}$ and $17^{\circ} \mathrm{C}$, respectively [40]. The research site has mountainous topography, with a minimum and maximum height from $60 \mathrm{~m}$ to $1760 \mathrm{~m}$ above sea level, decreasing from West to East. The slope of the terrain is complex and steep with an average of more than 10 degrees. Based on the international classification systems [41], there are four soil types within the research area; including acrisols (ferralic) (75\%), acrisols (arenic) (14\%), acrisols (humic) (6\%), and acrisols (hyperdystric) (5\%).

The natural area of A Luoi District is 122,415 hectares (ha) comprising 60,105 ha (49\%) of protection forests; 57,492 ha (47\%) of agricultural land; 2,318 ha (2\%) of water body and 2,500 ha $(2 \%)$ of residential and infrastructural areas [42]. Sample locations are presented in Figure 5.2 and 5.3. 


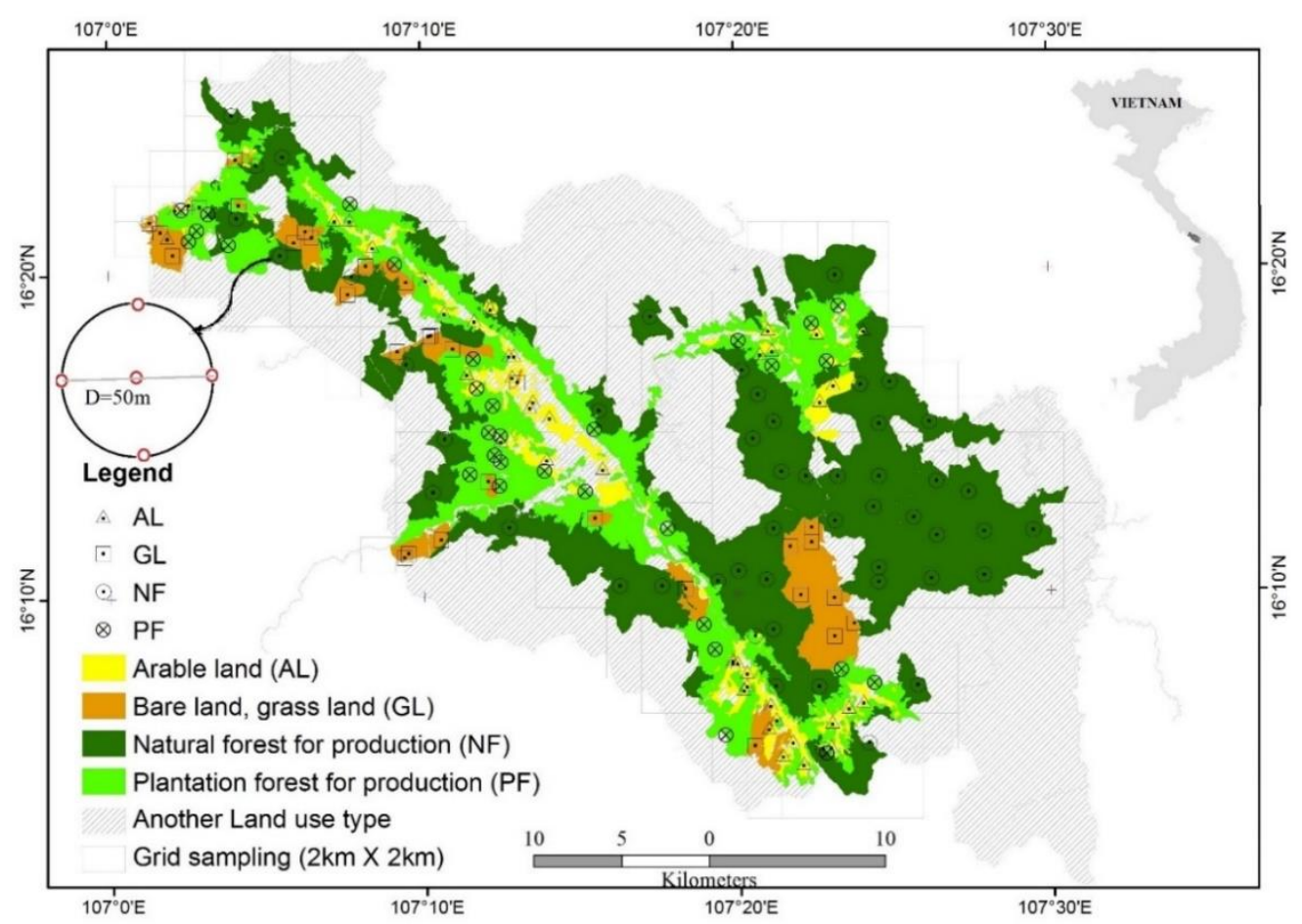

Figure 5.2. Agricultural land use map in 2015 and showing soil sampling position

Regarding agricultural lands, there are 32,653 ha of natural forests (NF) for production; 15,804 ha of plantation forests (PF) for production; 5,252 ha of grasslands (GL), and 3,783 ha of arable lands (AL) [42] presented in Table 5.1.

Table 5.1. Agricultural land use

\begin{tabular}{lclr}
\hline Land use type & Symbol & Dominant crops & Area (ha) \\
\hline Bare land, grass land & GL & Bare land, grass, shrub & 5,252 \\
Natural forest for production & NF & Mixed forest, shrub, acacia & 32,653 \\
Plantation forest for production & PF & Acacia, rubber & 15,804 \\
Arable land & AL & Cassava, rice & 3,783 \\
\hline
\end{tabular}

\subsubsection{Methods}

\subsubsection{Soil sampling}

The soil samples were collected in 2015 and 2016 relying on a soil unit map and a grid sampling method. Soil units in Vietnam result from overlapping a soil type map, land use map, and slope map. In total, there are 78 soil units within the research site. A grid sampling of $2 \mathrm{~km}$ x $2 \mathrm{~km}$ size for general cases and $4 \mathrm{~km} \mathrm{x} 4 \mathrm{~km}$ for large areas and highly homogeneous areas was carried out. The guideline for sampling follows two basic principles: 1) if only one soil unit exists in the grid cell, the sample will be taken at the center of the cell, or 2) if more than one soil unit exists, the sample will be taken at the center for each unit that covers an area larger than 30 hectares in that grid. For each sample, soil material in the layer at $0-30 \mathrm{~cm}$ and the layer at 
30-60 cm was collected from five points (North, South, East, West, and Center) inside a circle with a radius of $25 \mathrm{~m}$ then mixed as a soil sample. In total, 155 samples at these two depths were collected, air-dried, and passed through a $2 \mathrm{~mm}$ sieve to remove stones, grass, forest litter, and any material on the soil surface.

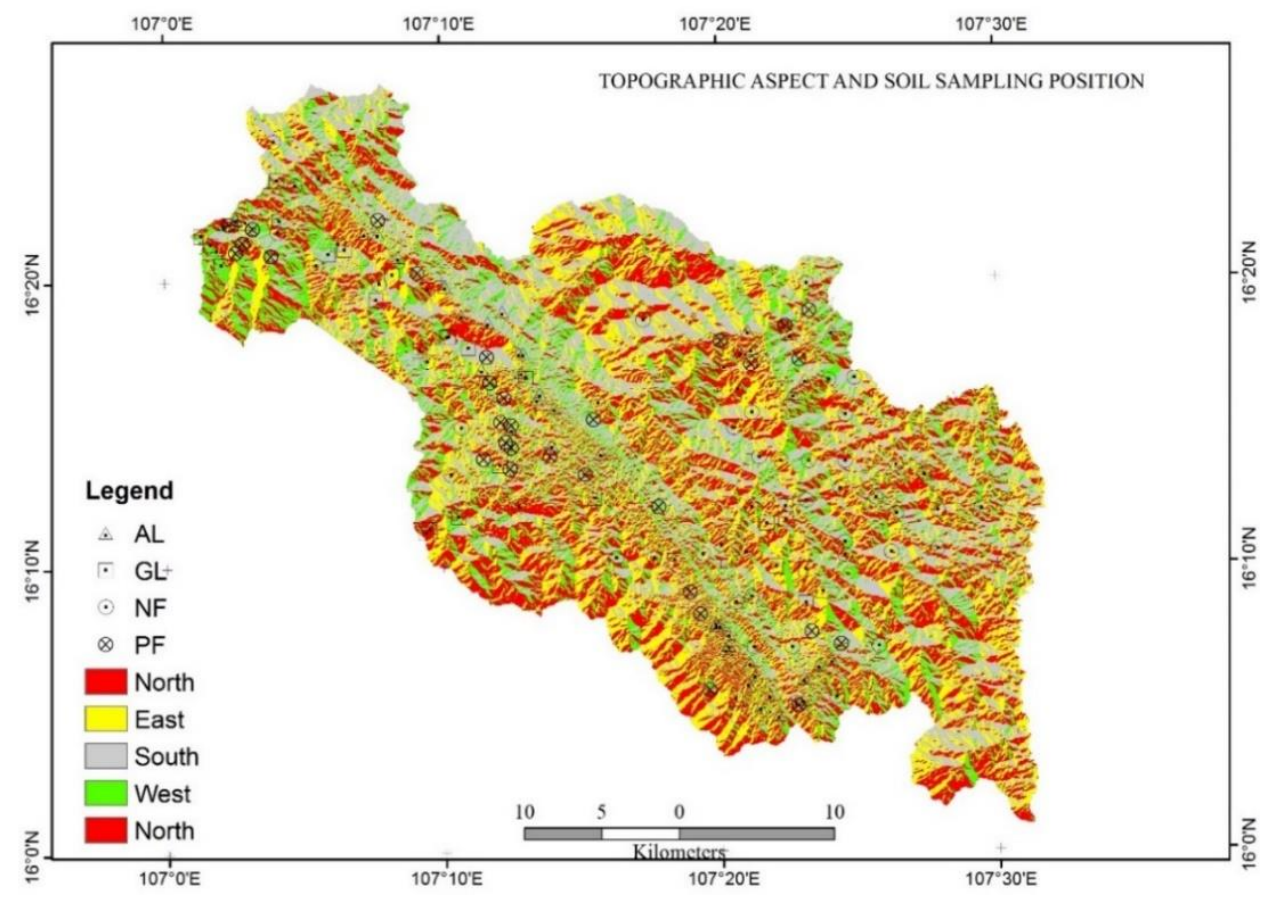

Figure 5.3. Location of sampling sites on a slope aspect map

\subsubsection{Laboratory analysis}

The soil samples were analyzed to determine SOC, STN, and soil $\mathrm{pH}$. All samples were analyzed at the Laboratory of the Soil Science Department of Hue University of Agriculture and Forestry, Vietnam. SOC was determined by the Walkley-Black method [43], TN was determined by Kjeldahl's digestion [44], and $\mathrm{pH}$ was calculated using a portable $\mathrm{pH}$ meter with $\mathrm{KCl} 1 \mathrm{M}$ [45].

\subsubsection{Statistical analysis}

All statistical analyses were carried out in SPSS 16.0. An analysis of the variance test technique (ANOVA) and the post hoc multiple comparisons test was used to evaluate the differences in soil indicators between different land use types, tested with a confidence interval of $95 \%$. A Paired-samples T-test function was used to evaluate the difference of SOC, TN, and $\mathrm{pH}$ between the two soil depths layers [46].

We extracted aspects of land use types at the sample points by using the ASTER Global Digital Elevation Model (DEM) with $30 \mathrm{~m}$ resolution, and created a matrix between SOC and land use types. The SOC per aspect of land use type was averaged and the paired-correlation 
between land use types and aspects were analyzed by using the pairs. panels function in the psych package in R studio Version 0.99.903 - (c) 2009-2016.

\subsection{Results}

\subsubsection{Soil quality characteristics}

Table 5.2 shows the location characteristics of the soil samples for the land use types. GL is located in the steepest terrain with an average slope of 20 degrees, followed by NF (17 degrees), PF (12 degrees), and AL (8 degrees). The trend in elevation is the same for the slope. GL has the highest elevation, whereas PF and AL have the lowest, respectively.

The results of the analysis for the 155 soil samples are presented in Table 5.3. The percent of SOC content was greater in the topsoil layer compared to the deeper layer: $1.30 \%$ compared to $0.83 \%$, respectively. Our results are similar to previous studies [47] and showed that SOC is low compared to average levels from a SOC classification by Le and Ton, cited in Nguyen \& Klinnert (2001) [21].

Table 5.2. Distribution of the soil samples by slope and elevation

\begin{tabular}{cccccccc}
\hline \multirow{2}{*}{ Land use type } & \multirow{2}{*}{ N } & \multicolumn{3}{c}{ Slope (Degrees) } & \multicolumn{3}{c}{ Elevation (m) } \\
\cline { 3 - 8 } & & Max & Mean & Min & Max & Mean & Min \\
\hline GL & 31 & 52 & 20 & 0 & 1184 & 618 & 185 \\
NF & 50 & 34 & 17 & 1 & 945 & 524 & 137 \\
PF & 31 & 26 & 12 & 3 & 755 & 496 & 111 \\
AL & 43 & 21 & 8 & 0 & 780 & 496 & 58 \\
\hline
\end{tabular}

$N$ : number of soil samples

The soils for agricultural purposes in A Luoi District shows light acidity with a pH ranging from 3.60 to 4.68 for the topsoil and 3.60 to 4.90 for the deeper layers, which are consistent with values from other researchers [48-50]. The soil total nitrogen amount varies from $0.05-0.21 \%$ for topsoil layers and 0.04-0.15\% for deeper layers. The average quality of STN in agricultural land in A Luoi belongs to the medium level group as Do Dinh Sam and Nguyen Ngoc Binh suggestion for Vietnamese soil (less than $0.1 \%$ is poor, from 0.1 to 0.2 is medium, and more than $0.2 \%$ is rich) [51]. 
Table 5.3. Soil quality characteristic of soil samples

\begin{tabular}{cccccccc}
\hline Soil properties & $\begin{array}{c}\text { Soil Depth } \\
(\mathbf{c m})\end{array}$ & $\mathbf{N}$ & Min & Max & Mean & SD & Skewness \\
& $0-30$ & 155 & 0.42 & 3.02 & 1.30 & 0.44 & 0.90 \\
SOC & $30-60$ & 155 & 0.05 & 2.61 & 0.83 & 0.39 & 0.94 \\
\hline \multirow{2}{*}{ STN } & $0-30$ & 155 & 0.05 & 0.21 & 0.10 & 0.03 & 0.87 \\
& $30-60$ & 155 & 0.04 & 0.15 & 0.08 & 0.02 & 0.47 \\
\hline \multirow{2}{*}{ pH } & $0-30$ & 155 & 3.60 & 4.68 & 4.11 & 0.20 & 0.11 \\
& $30-60$ & 155 & 3.60 & 4.90 & 4.11 & 0.21 & 0.35 \\
\hline
\end{tabular}

$N$ : number of soil sample, SD: standard deviation

5.3.2. Soil quality indicator under different land use types

\subsubsection{Soil organic carbon}

The SOC content of the soils in the research site varied from $0.42 \%$ to $3.02 \%$ for the $0-30$ cm soil depth layer and 0.05 to $2.61 \%$ for $30-60 \mathrm{~cm}$ soil depth layer.

There were significant differences $(\mathrm{p}<0.05)$ between the AL and PF groups and the NF and GL groups in both soil depths levels. The highest SOC content rate is found in AL $(1.50 \pm 0.44$ for 0-30 cm depth and $1.06 \pm 0.45$ for 30-60 cm depth), which is not significantly higher than the SOC content of PF. The SOC content of the NF and GL groups were not different at the significance level of $95 \%$ in both soil depths, even though the average SOC in NF is higher than GL in the topsoil: $1.18 \pm 0.36$ compared to $1.10 \pm 0.40$. However, SOC in NF is lower than GL in the deeper slayer: $0.66 \pm 0.25$ compared to $0.70 \pm 0.28$. For the soil depths, there were significant differences in all of land use types between the two soil depths. The SOC content of all land use types in the $0-30 \mathrm{~cm}$ layer is higher than the SOC content in the $30-60 \mathrm{~cm}$. The SOC content is presented in Table 5.4. 
Table 5.4. Mean value of SOC (\%) under different land use types at two soil depths

\begin{tabular}{cccc}
\hline Land use type & $\mathbf{N}$ & $\mathbf{0 - 3 0} \mathbf{~ c m}$ & $\mathbf{3 0 - 6 0} \mathbf{~ c m}$ \\
\hline GL & 31 & $1.10 \pm 0.40^{\mathrm{aA}}$ & $0.70 \pm 0.28^{\mathrm{aB}}$ \\
NF & 50 & $1.18 \pm 0.36^{\mathrm{aA}}$ & $0.66 \pm 0.25^{\mathrm{aB}}$ \\
PF & 31 & $1.43 \pm 0.44^{\mathrm{bA}}$ & $0.93 \pm 0.41^{\mathrm{bB}}$ \\
AL & 43 & $1.50 \pm 0.44^{\mathrm{bA}}$ & $1.06 \pm 0.45^{\mathrm{bB}}$ \\
\hline
\end{tabular}

$N$ : Number of samples; within columns, values followed by the same lowercase letter $(a$, $b)$ are not significantly different $(p<0.05)$ between land use types; within rows, values followed by the same capital letter $(A, B)$ are not significantly different $(p<0.05)$ between soil depths.

\subsubsection{Soil total nitrogen}

Table 5.5 shows the STN content of the land use types. There was a significant difference $(\mathrm{p}<0.05)$ of STN content between NF and the remaining land use types in both of soil layers. On the contrary, the STN content in GL, PF and AL show no significant differences at the significance level of 0.05 , even though the average value of STN in PF $(0.115 \pm 0.030)$ appears to be higher than in GL $(0.107 \pm 0.030)$ and $\operatorname{AL}(0.104 \pm 0.025)$ for the topsoil layer. The STN concentrations in all land use types of the deeper layer show the same trend as the topsoil layer. The STN content of all land use types change significantly by the depth of soil, with the topsoil, STN content greater than the deeper layer.

Table 5.5. Mean value of STN (\%) under different land use types at two soil depths

\begin{tabular}{cccc}
\hline Land use type & $\mathbf{N}$ & $\mathbf{0 - 3 0} \mathbf{~ c m}$ & $\mathbf{3 0 - 6 0} \mathbf{~ c m}$ \\
\hline GL & 31 & $0.107 \pm 0.030^{\mathrm{aA}}$ & $0.082 \pm 0.021^{\mathrm{aB}}$ \\
NF & 50 & $0.090 \pm 0.029^{\mathrm{bA}}$ & $0.070 \pm 0.022^{\mathrm{bB}}$ \\
PF & 31 & $0.115 \pm 0.030^{\mathrm{aA}}$ & $0.084 \pm 0.017^{\mathrm{aB}}$ \\
AL & 43 & $0.104 \pm 0.025^{\mathrm{aA}}$ & $0.082 \pm 0.018^{\mathrm{aB}}$ \\
\hline
\end{tabular}

$N$ : Number of samples; within columns, values followed by the same lowercase letter ( $a$, $b)$ are not significantly different $(p<0.05)$ between land use types; within rows, values followed by the same capital letter $(A, B)$ are not significantly different $(p<0.05)$ between soil depths. 


\subsubsection{Soil pH}

Table 5.6. Mean value of soil $\mathrm{pH}$ under different land use types at two soil depths

\begin{tabular}{cccc}
\hline Land use type & $\mathbf{N}$ & $\mathbf{0 - 3 0} \mathbf{~ c m}$ & $\mathbf{3 0 - 6 0} \mathbf{~ c m}$ \\
\hline GL & 31 & $4.05 \pm 0.19^{\mathrm{aA}}$ & $4.00 \pm 0.18^{\mathrm{aB}}$ \\
NF & 50 & $4.05 \pm 0.16^{\mathrm{aA}}$ & $4.07 \pm 0.17^{\mathrm{aB}}$ \\
PF & 31 & $4.05 \pm 0.17^{\mathrm{aA}}$ & $4.06 \pm 0.19^{\mathrm{aA}}$ \\
AL & 43 & $4.24 \pm 0.18^{\mathrm{bA}}$ & $4.26 \pm 0.23^{\mathrm{bA}}$ \\
\hline
\end{tabular}

$N$ : Number of samples; within columns, values followed by the same lowercase letter $(a, b)$ are not significantly different $(p<0.05)$ between land use types; within rows, values followed by the same capital letter $(A, B)$ are not significantly different $(p<0.05)$ between soil depths.

Table 5.6 presents the soil $\mathrm{pH}$ value of the land use types. The $\mathrm{pH}$ for AL was significantly different and higher than the other land use types in both soil depth levels: $4.24 \pm 0.18$ for topsoil and $4.26 \pm 0.23$ for deeper soil. There were no significant differences in the $\mathrm{pH}$ values between the remaining land use types together in both soil layers, even though the average value of $\mathrm{pH}$ for GL in the deeper layer is slightly lower.

Soil $\mathrm{pH}$ was not significantly different with soil depth in PF and AL; however, the $\mathrm{pH}$ value in GL and NF change significantly by soil depth.

\subsubsection{Soil organic carbon under different aspects}

For the topographic aspects, the study focuses only on the topsoil layer and the SOC content. There are 154 soil samples in the North (49), East (39), South (33), and West (33), and one sample plot is in a flat position and not representative of any aspect. The SOC content of aspects in the research varies from $0.95 \%$ to $1.58 \%$. The data depicts that the mean of SOC values were $1.38 \%, 1.23 \%, 1.33 \%$, and $1.26 \%$ on the North, East, South, and West aspect, respectively (Table 5.7). 


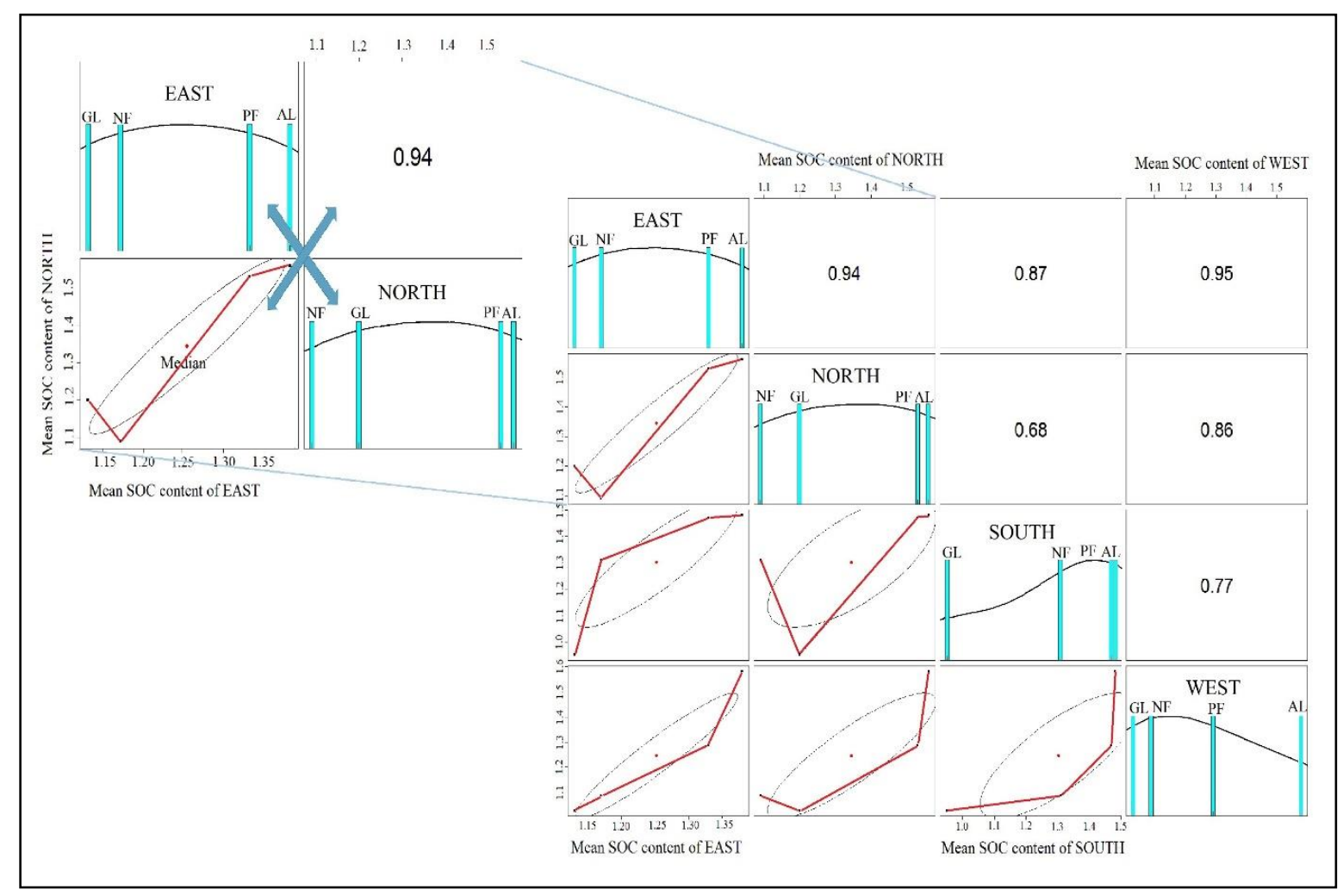

Figure 5.4. Correlation of SOC content changed by land use type between topographic aspects

The results did not show any significant differences in the mean SOC concentration by topographic aspects using a 95\% confidence level. A correlation of SOC content change by land use type between topographic aspects in the topsoil was found (Figure 5.4). The results indicated that the correlation between the East and North aspects is 0.94, the East and South is 0.87, and North and West is 0.86 . The highest correlation was found in East and West (0.95), whereas the lowest correlations were found for the South and West (0.77) and North and South (0.68).

Table 5.7. Mean value of SOC content of the topsoil layer under different topographic aspects

\begin{tabular}{cccccc}
\hline & $\begin{array}{c}\text { North } \\
(\mathbf{N}=49)\end{array}$ & $\begin{array}{c}\text { East } \\
(\mathbf{N}=39)\end{array}$ & $\begin{array}{c}\text { South } \\
(\mathbf{N}=33)\end{array}$ & $\begin{array}{c}\text { West } \\
(\mathbf{N}=33)\end{array}$ & $\begin{array}{c}\text { Mean } \\
(\mathbf{N}=\mathbf{1 5 4})\end{array}$ \\
\hline GL (N=30) & $1.20 \pm 0.55^{\mathrm{abA}}$ & $1.13 \pm 0.27^{\mathrm{aA}}$ & $0.95 \pm 0.52^{\mathrm{aA}}$ & $1.03 \pm 0.42^{\mathrm{aA}}$ & $1.10 \pm 0.41^{\mathrm{a}}$ \\
$\mathbf{N F}(\mathbf{N}=\mathbf{5 0})$ & $1.09 \pm 0.36^{\mathrm{aA}}$ & $1.17 \pm 0.22^{\mathrm{aA}}$ & $1.31 \pm 0.48^{\mathrm{aA}}$ & $1.09 \pm 0.26^{\mathrm{aA}}$ & $1.18 \pm 0.36^{\mathrm{a}}$ \\
$\mathbf{P F}(\mathbf{N}=\mathbf{3 1})$ & $1.53 \pm 0.40^{\mathrm{bA}}$ & $1.33 \pm 0.29^{\mathrm{aA}}$ & $1.47 \pm 0.53^{\mathrm{aA}}$ & $1.29 \pm 0.50^{\mathrm{abA}}$ & $1.43 \pm 0.45^{\mathrm{b}}$ \\
$\mathbf{A L}(\mathbf{N}=\mathbf{4 3})$ & $1.56 \pm 0.51^{\mathrm{bA}}$ & $1.38 \pm 0.42^{\mathrm{aA}}$ & $1.48 \pm 0.33^{\mathrm{aA}}$ & $1.58 \pm 0.42^{\mathrm{bA}}$ & $1.50 \pm 0.44^{\mathrm{b}}$ \\
$\mathbf{M e a n}$ & & & & & \\
$(\mathbf{N = 1 5 4})$ & $1.38 \pm 0.49^{\mathrm{A}}$ & $1.23 \pm 0.32^{\mathrm{A}}$ & $1.33 \pm 0.49^{\mathrm{A}}$ & $1.26 \pm 0.44^{\mathrm{A}}$ & \\
\hline
\end{tabular}

$N$ : Number of samples; within columns, values followed by the same lowercase letter $(a, b)$ are not significantly different $(p<0.05)$ between land use types; within rows, values followed by the same capital letter $(A, B)$ are not significantly different $(p<0.05)$ between topographic aspects. 


\subsection{Discussions}

5.4.1. Soil organic carbon and soil total nitrogen under different land use types

The results differ from other studies on the SOC and STN content in different land use types [52,53], in which the SOC content in forests and grasslands was higher than in cultivated lands in regions of Spain and North China. Conversely, the results from this research indicate that these soil quality indicators are higher in arable land than in forested land with a confidence level of $95 \%$ in both soil depths. Therefore, the results of this research further confirmed the findings of Li et al. (2014) [54] and Liu et al. (2011) [55], who found that SOC content in croplands is higher than forested land and grasslands.

The highest STN average occurred for AL and the lowest for NF. These results, therefore, differed somewhat from those in other studies $[56,57]$ in which the forested land had the highest STN storage and croplands had the lowest.

In the A Luoi District, GL and NF reside in of steep terrain, high elevations, whereas AL is located in lower landscape areas (Table 3.2). The study results are consistent with Mu et al. (2015) [58] who determined that the slope factor has a negative effect on the SOC content. A steeper slope might result in more soil erosion, which leads to a decline in SOC. Wei et al. (2010) [59] indicated that for hilly land areas of China, the SOC and STN increased at lower slopes and decreased at the higher slopes. This finding can be used to explain the SOC and STN of AL and PF resulting in higher than NF and GL.

AL is affected by humans via cultivation activities, in which farmers apply fertilizer to provide and improve SOC concentration. On the other hand, management practices that can increase SOC storage due to the increase in carbon inputs, such as fertilizer applications [6062]. For instance, Aula et al. (2016) [63] stated that nitrogen application significantly increased SOC content when nitrogen rates exceeded $90 \mathrm{~kg}$ per hectare. During the cassava cultivation in the hilly areas of the Thua Thien Hue province, farmers often add 1.5 tons of organic fertilizer and $100 \mathrm{~kg}$ of nitrogenous per hectare [64]. For rice production in the same areas, farmers applied around 4-6 tons of manure fertilizer and $200 \mathrm{~kg}$ of nitrogenous fertilizer per hectare per season (2 seasons per year).

Moreover, after the harvesting season, the belowground residue (e.g., root biomasses) is directly input into the soil system and acting as a major contributor to SOC [65]. Zhang et al. (2016) [66] reported that when the rate of crop residue incorporation was increased from 15\%, $50 \%$, and $90 \%$, the average annual SOC increased from 78, 489, and $1005 \mathrm{~kg} \mathrm{C}$ per ha/year, 
respectively. In addition, irrigation may increase total crop biomass production and the amount of crop residues returned to the soil which could contribute to the increase of SOC and STN [67].

SOC and STN showed a decreasing trend with increasing soil depth in all land use types which correlates to previous studies [17,68,69]. Plant cycling and carbon inputs from plant roots as well as plant residues could explain the higher levels of SOC and STN in the topsoil [70].

\subsubsection{Soil $\mathrm{pH}$ under different land use types}

In the research site, the average soil $\mathrm{pH}$ value was low and belongs to the "Extremely Acid" group as suggested by Smith in Agyare (2004) [71] or "Acid Soil" group as suggestion by local researchers for upland soil in Vietnam [21]. Unlike other studies, Rokunuzzaman et al. (2016) [72] and Moges et al. (2013) [18] reported that soil pH is not significantly different among the land use types, and Chen et al. (2016) [17] claimed that soil pH in croplands is lower than in forested land. Our research found that the highest $\mathrm{pH}$ value in both soil depths belongs to the $\mathrm{AL}$ group. The results were in agreement with Kiflu \& Beyene, (2013) [73] and Liao, et al., (2015) [74], who reported that $\mathrm{pH}$ of banana and maize land use areas are higher than grassland, and Abbasi, et al., (2007) [8], who found that the soil $\mathrm{pH}$ for forest, grassland, and arable lands was significantly different at $6.95,7.64$ and 7.84 respectively.

The significantly high $\mathrm{pH}$ of AL might be attributed to the ameliorating effect of the farming system, namely, lime application. Liming is a regular agronomic practice to improve acidic soils for crop production [75,76]. For cultivated land in Central Vietnam, the farmers usually add $500 \mathrm{~kg}$ lime per hectare during tillage [77,78].

\subsubsection{Soil organic carbon of different aspects}

Even though there are no significant differences at the $95 \%$ confidence level, the absolute mean value of SOC concentration for the North and South aspect appears higher than the East and West aspects (Table 5.7). According to the map from World Bank (2017) [79], the North and South of A Luoi District have lower solar radiation in comparison to the East and West part. This may result from cooler temperatures may decreased decomposition rates causing turnover and loss of $\mathrm{C}$ to $\mathrm{CO}_{2}$ is much lower, retaining more $\mathrm{C}$. These results were similar to findings by Lemenih \& Itanna, (2004) [80], who reported a negative correlation between SOC content and temperature, and Yimer, et al., (2006) [81], who stated that the SOC content rises up with a decrease in temperature. 
Table 5.8. Number of soil samples by topographic aspects and soil texture

\begin{tabular}{ccccc}
\hline & Silt loam & Loam & Clay loam & Total \\
\hline North & 15 & 25 & 9 & 49 \\
East & 11 & 24 & 4 & 39 \\
South & 9 & 23 & 1 & 33 \\
West & 10 & 20 & 3 & 33 \\
\hline
\end{tabular}

Moreover, we found that there is strong similarity in the change in SOC content in the East and West or East and North aspects in terms of land use types. This may be the consequence of soil texture, the number of samples with clay loam soil texture in the North and East was higher than the other two directions (Table 5.8). Krull et al. (2001) [82] and Plante et al. (2006) [83] have also shown that the soil texture influences SOC content. However, in Central Vietnam, similar studies are needed to confirm the initial observations in this paper.

\subsection{Conclusions}

The SOC and STN content in all land use types belong to the group "poor" to "medium" in comparison with other regions in Vietnam. The soil is acidic. Most of the soil quality indicators were significantly influenced by different land use systems. The SOC content AL and PF were higher and had significant differences compared to GL and NF at $\mathrm{p}<0.05$. STN content in GL, $\mathrm{PF}$, and AL show no significant differences compared together; however, they are significantly higher than NF. Furthermore, all soil indicators decreased by soil depth with significant differences at $\mathrm{p}<0.05$, which may result from fertilizer applications and terrain. Meanwhile, $\mathrm{pH}$ values in AL are highest and show significant differences with all remaining land use types. The reason for this difference is lime application during cultivation that could improve the soil acidity. The differences in $\mathrm{pH}$ values between two soil depths were observed in GL and NF. The significant differences of SOC and topographic aspects did not show at $p<0.05$, however, the correlation in the changing trend of SOC content for land use types between East and West was highest with a value 0.95 .

\subsection{References}

1. Food and Agriculture Organization of the United Nations. Revised World Soil Charter: Rome, Italy, 2015.

2. Doran, J.W.; Parkin, T.B. Defining and Assessing Soil Quality. In Defining Soil Quality for a Sustainable Environment; Doran, J.W., Coleman, D.C., Bezdicek, D.F., Stewart, B.A., Eds.: Soil Science Society of America and American Society of Agronomy: Madison, WI, USA, 1994, pp. 1-21. 
3. Vitousek, P.M. Human Domination of Earth's Ecosystems. Science 1997, 277, 494-499.

4. Oguike, P.C.; Mbagwu, J. Variations in Some Physical Properties and Organic Matter Content of Soils of Coastal Plain Sand under Different Land Use Types. World Journal of Agricultural Sciences 2009, 5, 63-69.

5. Jamala, G.Y.; Oke, D.O. Soil Profile Characteristics as affected by Land Use Systems in The Southeastern Adamawa State, Nigeria. Journal of Agriculture and Veterinary Science 2013, 6, 4-11.

6. Müller, D.; Manfred, Z. Land use dynamics in the central highlands of Vietnam: a spatial model combining village survey data with satellite imagery interpretation. Agricultural Economics 2002, 27, 333-354.

7. Reynolds, W.D.; Drury, C.F.; Yang, X.M.; Fox, C.A.; Tan, C.S.; Zhang, T.Q. Land management effects on the near-surface physical quality of a clay loam soil. Soil and Tillage Research 2007, 96, 316-330.

8. Abbasi, M.K.; Zafar, M.; Khan, S.R. Influence of different land-cover types on the changes of selected soil properties in the mountain region of Rawalakot Azad Jammu and Kashmir. Nutr Cycl Agroecosyst 2007, 78, 97-110.

9. Ishaq, S.; Begum, F.; Ali, K.; Ahmed, S.; Ali, S.; Karim, R.; Ali, H.; Durrani, S.A. Assessment of soil quality under different land use practices in Altit Valley, Hunza Nagar, Gilgit-Baltistan. Journal of Biodiversity and Environmental Sciences 2015, 6, 454-459.

10. Kalu, S.; Koirala, M.; Khadka, U.R.; Anup, K.C. Soil Quality Assessment for Different Land Use in the Panchase Area of Western Nepal. International Journal of Environmental Protection 2015, 5, 38-43.

11. Chan, K.Y.; Oates, A.; Liu, D.L.; Prangnell, R.; Poile, G.; Conyers, M.K. A farmer's guide to increasing soil organic carbon under pastures; Industry \& Investment NSW: Wagga Wagga, N.S.W., 2010.

12. Ren, T.; Wang, J.; Chen, Q.; Zhang, F.; Lu, S. The effects of manure and nitrogen fertilizer applications on soil organic carbon and nitrogen in a high-input cropping system. PLoS ONE 2014, 9, e97732.

13. Havlin, J.; Beaton, J.D.; Tisdale, S.L.; Nelson, W.L. Soil fertility and fertilizers: An introduction to nutrient management, 7th ed; Prentice Hall: Upper Saddle River, N.J., London, 2008.

14. Dengiz, O.; Sağlam, M.; Türkmen, F. Effects of soil types and land use - land cover on soil organic carbon density at Madendere watershed. Eurasian Journal of Soil Science 2015, 4, 82-87.

15. Jonczak, J. Soil Organic Matter Properties in Stagnic Luvisols under Different Land Use Types. Acta Agrophysica Journal 2013, 20, 565-576.

16. Shi, L.; Zheng, L.B.; Mei, X.Y.; Yu, L.Z.; Jia, Z.C. Characteristics of soil organic carbon and total nitrogen under different land use types in Shanghai. The Chinese journal of applied ecology 2010, 21, 2279-2287.

17. Chen, C.-P.; Juang, K.-W.; Cheng, C.-H.; Pai, C.-W. Effects of adjacent land-use types on the distribution of soil organic carbon stocks in the montane area of central Taiwan.

Botanical studies 2016, 57, 32. 
18. Moges, A.; Dagnachew, M.; Yimer, F. Land Use Effects on Soil Quality Indicators: A Case Study of Abo-Wonsho Southern Ethiopia. Applied and Environmental Soil Science 2013, 2013, 1-9.

19. Fayissa, A.; Ababaew, A.; Chimdi, A. Effects of Different Land Uses (Forest, Grazing and Cultivated) on the Fertility Status of Acidic Soils of Dano District, West Shoa Zone, Oromia Region, Ethiopia. American-Eurasian Journal of Scientific Research 2015, 10, 235-242.

20. Khormali, F.; Shamsi, S. Effect of Land Use on the Carbon Stock and Soil Quality Attributes in Loess Derived Soils in Agh-Su Watershed, Golestan Province, Iran. Environmental Resources Research Journal 2, 2, 107-121.

21. Nguyen, T.D.; Klinnert, C. Problems with and local solutions for organic matter management in Vietnam. Nutrient Cycling in Agroecosystems Journal 2001, 61, 89-97.

22. Kay. B.D; Angers D.A. Soil Structure. In Handbook of soil science, 1st ed; Malcolm E. Sumner, Ed.: CRC Press/Taylor \& Francis Group; Replika Press Pvt. Ltd: Boca Raton [etc.], 2010, pp. 229-264.

23. Andersson, J. Possible strategies for sustainable land use in the hilly area of northern Vietnam; Institutionen för markvetenskap, avdelningen för lantbrukets hydroteknik: Uppsala, 2002.

24. Maglinao, A.R.; Agus, F.; Ilao, R.O.; Toan T.D.; Penning, D. Soil Erosion Management in Catchments: Identifying Best Bet Options with Farmers' Participation. In The 12th International Soil Conservation Organization Conference, Sustainable Utilization of Global Soil and Water Resources; Jiao Juren, Ed.: Beijing, China, 2012, pp. 374-381.

25. Pham, T.G.; Degener, J.; Kappas, M. Integrated universal soil loss equation (USLE) and Geographical Information System (GIS) for soil erosion estimation in A Sap basin: Central Vietnam. International Soil and Water Conservation Research 2018, 6, 99-110.

26. Douglas, I. Control of Soil Erosion, Sedimentation and Flash Flood Hazards (Basin-Wide) Review and Assessment Report for Phase 1 (1990-1996), 1997.

27. Karlen, D.L.; Mausbach, M.J.; Doran, J.W.; Cline, R.G.; Harris, R.F.; Schuman, G.E. Soil Quality: A Concept, Definition, and Framework for Evaluation (A Guest Editorial). Soil Science Society of America Journal 1997, 61, 4.

28. Carson, J. How much carbon can soil store?: NSW, 2013.

29. Hong Quang Nguyen; Thi Thu Hang Le; Thi Thanh Nga Pham; Martin Kappas. Modelling surface runoff and soil erosion for Yen Bai Province, Vietnam, using the Soil and Water Assessment Tool (SWAT). Journal of Vietnamese Environment 2016, 8, 71-79.

30. Rafiei Emam, A.; Kappas, M.; Linh, N.; Renchin, T. Hydrological Modeling and Runoff Mitigation in an Ungauged Basin of Central Vietnam Using SWAT Model. Hydrology 2017, 4, 16.

31. Rafiei Emam, A.; Kappas, M.; Fassnacht, S.; Linh, N.H.K. Uncertainty analysis of hydrological modeling in a tropical area using different algorithms. Front. Earth Sci. 2018, 12, 661-671.

32. Ovalles, F.A.; Collins, M.E. Soil-landscape Relationships and Soil Variability in North Central Florida1. Soil Science Society of America Journal 1986, 50, 401. 
33. Garcia-Pausas, J.; Casals, P.; Camarero, L.; Huguet, C.; Sebastià, M.-T.; Thompson, R.; Romanyà, J. Soil organic carbon storage in mountain grasslands of the Pyrenees: effects of climate and topography. Biogeochemistry 2007, 82, 279-289.

34. Bautista, R.M. Agriculture-based Development: a SAM perspective on Central Viet Nam, 1999.

35. Vietnam General Statistics Office. Statistical yearbook of Vietnam; Statistical publisher of Vietnam: Hanoi, Vietnam, 2014.

36. Avitabile, V.; Schultz, M.; Herold, N.; Bruin, S. de; Pratihast, A.K.; Manh, C.P.; Quang, H.V.; Herold, M. Carbon emissions from land cover change in Central Vietnam. Carbon Management 2016, 7, 333-346.

37. Tran, T.P.; Chau, V.; Nguyen, B.N.; Huynh, V.C. Modeling Soil Erosion within Small Mountainous Watershed in Central Vietnam Using GIS and SWAT. Resources and Environment 2014, 4, 139-147.

38. Laux, P.; Nguyen, P.; Cullmann, J.; Kunstmann, H. Impacts of Land-Use/Land-Cover Change and Climate Change on the Regional Climate in the Central Vietnam. In Land Use and Climate Change Interactions in Central Vietnam: LUCCi; Nauditt, A., Ribbe, L., Eds.: Springer: Singapore, 2017, pp. 143-151.

39. National Institute of Agricultural Planning and Projection of Vietnam. Soil map of Thua Thien Hue province (1/100000); National Institute of Agricultural Planning and Projection of Vietnam: Ha Noi, 2005.

40. People's Committee of A Luoi district. Statistical year book: 2005-2015.

41. Food and Agriculture Organization of the United Nations. World reference base for soil resources 2014: International soil classification system for naming soils and creating legends for soil maps; FAO: Rome, 2014.

42. Natural Resources and Environment Department of A Luoi district. Land Use Map of A Luoi district, Thua Thien Hue province, (1/50000); Natural Resources and Environment Department of A Luoi district: Thua Thien Hue, Vietnam, 2015.

43. Wakley, A.; Black, I.A. An Examination of the Degtjareff Method for Determining Soil Organic Matter, and a Proposed Modification of the Chromic Acid Titration Method. Soil Science 1934, 37, 29-38.

44. Bremner, J.M. Determination of nitrogen in soil by the Kjeldahl method. J. Agric. Sci. 1960, 55, 11.

45. Food and Agriculture Organization of the United Nations. Guidelines for soil description, 4th ed; FAO: Rome, 2006.

46. Landau, S.; Everitt, B.S. A handbook of statistical analyses using SPSS; CRC Press: Boca Raton, FL, 2004.

47. van Nguyen, L. Use of GIS modelling in Assessment of Forestry Land's Potential in Thua Thien Hue province of Central Vietnam. Ph.D: Goettingen, 2008.

48. Pham, H.Q. Carbon in Vietnamese Soils and Experiences to Improve Carbon Stock in Soil. In Evaluation and Sustainable Management of Soil Carbon Sequestration in Asian Countries; Zueng-Sang Chen, Fahmuddin Agus, Eds.: ISRI, FFTC, and NIAES: Bogor, Indonesia, 2010, pp. 175-186. 
49. Thai, P.; Nguyen, C.V. Soil Organic Matter management for Sustainable Cassava production in Vietnam. In Cassava Research and Development in Asia: Exploring New Opportunities for an Ancient Crop.; Howeler, R., Ed.: Bangkok, Thailand, 2002, pp. 234250.

50. Dong, T.L.; Doyle, R.; Beadle, C.L.; Corkrey, R.; Quat, N.X. Impact of short-rotation Acacia hybrid plantations on soil properties of degraded lands in Central Vietnam. Soil Res. 2014, 52, 271.

51. Do Dinh Sam, Nguyen Ngoc Binh. Assessment of productivity of forest land in Vietnam; Vietnam Statistical Pubshing House: Hanoi, Vietnam, 2001.

52. Liu, M.-Y.; Chang, Q.-R.; Qi, Y.-B.; Liu, J.; Chen, T. Aggregation and soil organic carbon fractions under different land uses on the tableland of the Loess Plateau of China. CATENA 2014, 115, 19-28.

53. Rodríguez-Murillo, J.C. Organic carbon content under different types of land use and soil in peninsular Spain. Biology and Fertility of Soils 2001, 33, 53-61.

54. Li, Y.; Han, J.; Wang, S.; Brandle, J.; Lian, J.; Luo, Y.; Zhang, F. Soil organic carbon and total nitrogen storage under different land uses in the Naiman Banner, a semiarid degraded region of northern China. Can. J. Soil. Sci. 2014, 94, 9-20.

55. Liu, Z.; Shao, M.; Wang, Y. Effect of environmental factors on regional soil organic carbon stocks across the Loess Plateau region, China. Agriculture, Ecosystems \& Environment 2011, 142, 184-194.

56. Emiru, N.; Gebrekidan, H. Effect of land use changes and soil depth on soil organic matter, total nitrogen and available phosphorus contents of soils in Senbat watershed, western Ethiopia. ARPN Journal of Agricultural and Biological Science 2013, 8, 206-212.

57. Li, C.; Zhao, L.; Sun, P.; Zhao, F.; Di Kang; Yang, G.; Han, X.; Feng, Y.; Ren, G. Deep Soil C, N, and P Stocks and Stoichiometry in Response to Land Use Patterns in the Loess Hilly Region of China. PLoS ONE 2016, 11, e0159075.

58. Mu, W.; Yu, F.; Li, C.; Xie, Y.; Tian, J.; Liu, J.; Zhao, N. Effects of Rainfall Intensity and Slope Gradient on Runoff and Soil Moisture Content on Different Growing Stages of Spring Maize. Water 2015, 7, 2990-3008.

59. Wei, X.; Shao, M.; Fu, X.; Horton, R. Changes in soil organic carbon and total nitrogen after 28 years grassland afforestation: effects of tree species, slope position, and soil order. Plant Soil 2010, 331, 165-179.

60. Angelova, V.R.; Akova, V.I.; Artinova N.S.; Ivanov K.I. The effect of Organic amendments on Soil Chemical Characteristics. Bulgarian Journal of Agricultural Science 2013, 19, 958-971.

61. Singh, B.R.; Lal, R. The Potential of Soil Carbon Sequestration Through Improved Management Practices in Norway. Environ Dev Sustain 2005, 7, 161-184.

62. Yang, R.; Su, Y.; Wang, T.; Yang, Q. Effect of chemical and organic fertilization on soil carbon and nitrogen accumulation in a newly cultivated farmland. Journal of Integrative Agriculture 2016, 15, 658-666.

63. Aula, L.; Macnack, N.; Omara, P.; Mullock, J.; Raun, W. Effect of Fertilizer Nitrogen (N) on Soil Organic Carbon, Total N, and Soil pH in Long-Term Continuous Winter Wheat 
(Triticum Aestivum L.). Communications in Soil Science and Plant Analysis 2016, 47, 863-874.

64. Nguyen, V.T.; Nguyen, D.T. Effects of fertilizer rate, planting density on two cassava varieties namely KM444 and KM21-12 at hilly areas of Thua Thien Hue province. HUAF Journal of Agricultural Science and Technology 2017, 1, 383-394.

65. Jobbágy, E.G.; Jackson, R.B. The vertical distribution of soil organic carbon and its relation to climate and vegetation. Ecological Applications Journal 2000, 10, 423-436.

66. Zhang, L.; Zhuang, Q.; He, Y.; Liu, Y.; Yu, D.; Zhao, Q.; Shi, X.; Xing, S.; Wang, G. Toward optimal soil organic carbon sequestration with effects of agricultural management practices and climate change in Tai-Lake paddy soils of China. Geoderma 2016, 275, 2839.

67. Halvorson, A.D.; Schlegel, A.J. Crop Rotation Effect on Soil Carbon and Nitrogen Stocks under Limited Irrigation. Agronomy Journal 2012, 104, 1265.

68. Guan, F.; Tang, X.; Fan, S.; Zhao, J.; Peng, C. Changes in soil carbon and nitrogen stocks followed the conversion from secondary forest to Chinese fir and Moso bamboo plantations. CATENA 2015, 133, 455-460.

69. Iqbal, A.; Hossen, S.; Islam, N. Soil organic carbon dynamics for different land uses and soil management practices in Mymensingh. In Proceedings of 5th International Conference on Environmental Aspects of Bangladesh; Atiqur, R.A., Hiroyuki Miyake, Eds.: University of Dhaka: Dhaka, 2014.

70. Jobbágy, E.G.; Jackson, R.B. The distribution of soil nutrients with depth: Global patterns and the imprint of plants. Biogeochemistry Journal 2001, 53, 51-77.

71. Agyare, W.A. Soil characterization and modeling of spatial distribution of saturated hydraulic conductivity at two sites in the Volta Basin of Ghana, 1st ed; Cuvillier:

Gottingen, 2004.

72. Rokunuzzaman, M.; Ueda, Y.; Chen, L.; Tanaka, S.; Ohnishi, K. Effects of Land Use Changes from Paddy Fields on Soil Bacterial Communities in a Hilly and Mountainous Area. Microbes and environments 2016, 31, 160-164.

73. Kiflu, A.; Beyene, S. Effects of different land use systems on selected soil properties in South Ethiopia. Journal of Soil Science and Environmental Management 2013, 4, 100-107.

74. Liao, W.; Tang, D.; Wang, X.; Cheng, X. Soil Quality Status of Different Land-Use Types in Shiqu County, China. In Proceedings of the 2015 International Symposium on Energy Science and Chemical Engineering; Yunqiu, H., Ed.: Atlantis Press, 2015, pp. 135-140.

75. Nduwumuremyi, A.; Ruganzu, V.; Mugwe, J.N.; Cyamweshi Rusanganwa, A. Effects of Unburned Lime on Soil pH and Base Cations in Acidic Soil. ISRN Soil Science 2013, 2013, $1-7$.

76. Rengel, Z. Handbook of soil acidity; Marcel Dekker: New York, 2005, 2003.

77. Hoang, T.T.H.; Le, H.L. Effects of Nitrogen and Potassium rates on peanut yield in coastal sandy soil of Binh Dinh province. Journal of Science of Hue University 2012, 71, 133-144.

78. Tran, T.T.H. Effect of Phosphorus Fertilizer on Groundnut Yield in Poor Alluvial and Sandy Soils of Thua Thien Hue. Better Crops International Journal 2003, 17, 16-17.

79. World Bank. Solar resource data: SolarGIS, 2017. 
80. Lemenih, M.; Itanna, F. Soil carbon stocks and turnovers in various vegetation types and arable lands along an elevation gradient in southern Ethiopia. Geoderma 2004, 123, 177188.

81. Yimer, F.; Ledin, S.; Abdelkadir, A. Soil organic carbon and total nitrogen stocks as affected by topographic aspect and vegetation in the Bale Mountains, Ethiopia. Geoderma 2006, 135, 335-344.

82. Krull, E.; Baldock, J.; Skjemstad, J. Soil Texture Effects on Decomposition and Soil Carbon Storage. In Net ecosystem exchange, Workshop proceedings, CRC for Greenhouse Accounting, April 2001; Kirschbaum, M.U.F., Mueller, R., Eds.: CRC for Greenhouse Accounting: Canberra, 2001.

83. Plante, A.F.; Conant, R.T.; Stewart, C.E.; Paustian, K.; Six, J. Impact of Soil Texture on the Distribution of Soil Organic Matter in Physical and Chemical Fractions. Soil Science Society of America Journal 2006, 70, 287. 


\title{
Chapter 6. Non-Timber Forest Products as Potential Ecosystem Provisioning Services for Local People in a Mountainous Region, Central Vietnam
}

\author{
Hung Nguyen Trong ${ }^{\mathrm{a}^{*}}$, Renate Bürger-Arndt ${ }^{b}$ and Martin Kappas ${ }^{\mathrm{a}}$
}

a Institute of Geography, Cartography, GIS \& Remote Sensing Department, Georg-August University Goettingen, Goldschmidtstr. 5, 37077 Göttingen, Germany.

${ }^{a}$ Institute of Geography, Cartography, GIS \& Remote Sensing Department, Georg-August University Goettingen, Goldschmidtstr. 5, 37077 Göttingen, Germany.

b Faculty of Forest Sciences and Forest Ecology, Georg-August University Goettingen, Büsgenweg 3, 37077, Germany.

* Corresponding author at: Institute of Geography, Cartography, GIS \& Remote Sensing Department, Georg-August University Goettingen, Goldschmidtstr. 5, 37077 Göttingen, Germany. Email: tronghung2128@gmail.com (Hung Nguyen Trong).

\begin{abstract}
Non-timber forest products (NTFPs) from natural forests are important to local people living in mountainous areas. Increasing the supply and ensuring their sustainable use could improve living conditions of the local people. This study, conducted in A Luoi District, Central Vietnam, demonstrates necessary information to start such natural forest management approach. Since our approach based on the needs, understanding, agreement, implementation and responsibility of the local community, we did not just consider the current potential supply from the forests but also the respective demand. The supply was assessed by using classical forest inventory data, adding traditional and scientific knowledge about tree species with NTFP potential and their use options. Those NTFP species were mainly medicinal use, followed by food and resin or oil. The assessment of the demand was based on household interviews, considering people's rankings of the natural forests with respect to the importance and satisfaction they associated with NTFP supply. It also comprised their personal involvement in NTFP extraction and the relevance they attributed to different land use practices. All data were stratified considering gender, age, education and income. The results revealed considerable but insufficient supply for profitable NTFP use which should be increased by appropriate silviculture. People's awareness of negative land-use consequences, and their acceptance for restoration measures were verified.
\end{abstract}

Keywords: Ecosystem Provisioning Services; Potential NTFPs; Demand Assessments; Landscape Restoration 


\subsection{Introduction}

Primary forests originate from indigenous tree species that once immigrated naturally and formed indigenous vegetation without any direct human impact but driven by natural site conditions, disturbances and species competition. This vegetation may be vertically stratified in different ways, with different layers of trees, shrubs, herbs and mosses each with different and characteristic species composition [1-3]. Starting with the advent of farming, these primary forests have always been considerably deforested and destroyed by human activities. During recent decades, massive deforestation has taken place particularly in developing countries $[4,5]$. Wherever forests are not completely affected for the for the benefit of grasslands, arable land, settlements or industrial areas, but were used as woodland pastures or as forests for timber or firewood, their structures, species composition and indigenous species could persist to a certain extent. This resulted either in a less impacted or in a heavily disturbed managed forest status. And wherever forests could regrow and regenerate naturally without any kind of forest management, they grew up as so-called secondary forests, which - after long time of recovery might finally resemble the original natural forest.

In our study area, like in entire Vietnam, all these forest types are considered as natural forests, in contrast to plantations where young individuals of a single tree species which might also be exotic are all planted. Forest cover in Vietnam was $43 \%$ in 1943 but it decreased to $27 \%$ in 1990, due to two wars against French colonialism and the United States of America, forest fires, illegal logging activities and land-use conversion, as well as poor management practices. The forest cover increased again from $28 \%$ in 1995 [6] to $41.2 \%$ in 2017 [7]. However, the quality of those rehabilitated natural forests is still a big concern for improvement $[8,9]$. The national forest development strategy of Vietnam targeted a nationwide forest cover of 16.2 million ha (45 to $47 \%$ ) by the year 2020 [10]. This target reached nearly $41.9 \%$ by 2019 [11]. The strategy defined its goals to rehabilitate degraded natural forests and expand forest plantations on unused hilly land for forest plantations. This included regions in the Northwest, Northeast, North Central, Central Coastal, and Central Highlands. The goal was to improve the quality of forests, mitigate the disaster risks from landslides in the mountainous areas, and meet the forestry economy targets stipulated in the strategy.

Nonetheless, deforestation and forest degradation still do happen today [12,13], notably in the North Central, Northeast and Central Highlands, and Northwest areas. This deforestation is due to the conversion into other land uses, of which agricultural land purposes have been recorded the most. However, traditional practices such as shifting cultivation and the expansion of fast-growing species have also caused a decline of forest use options [14-16]. 
The local people in the remote mountain areas of Vietnam used to rely on the natural forests that surrounded them. Their use of natural forest resources for purposes such as fuelwood, NonTimber Forest Products (NTFPs), pasturing, and animal fodders have been granted by national regulations. However, there are some important exceptions such as timber logging, shifting cultivation, hunting, trapping, and over-extraction of goods [17-19]. Many of these activities and products are banned nowadays, due to the aforementioned regulations, which restrict their availability and uses for the sake of natural forest rehabilitation. However, the tropical forests are rich in tree species, which still provide a multitude of essential NTFPs as very significant sources for food, medicine, and resins. Their use is still permitted and may improve living conditions and improve the livelihoods of local communities.

At present, the assessment of forest resources as potential provisioning services is an urgent and essential task to contribute to better management practices and policies [20,21]. Such types of human benefits from ecosystems started to be conceptualized and defined as ecosystem services towards the end of the $20^{\text {th }}$ century [22-24]. The approach originated in economics and tried to estimate the economic value of nature. However, the major intention was to demonstrate humans' essential dependency on nature and biodiversity and to foster appropriate appreciation, care, and political awareness. The idea gained great scientific resonance and provoked intensive discussions about ecosystem conditions and functions, their relevance for human welfare, the claiming of benefits by different stakeholders, and changes to ecosystems and their services that result from human impacts.

Considering the multiple benefits, that nature generates for human well-being, ecosystem services were not restricted to tangible goods but classified into four categories presented in the Millennium Ecosystem Assessment [25]. Those are (1) provisioning services (tangible goods like food, wood and fiber, fuel or freshwater), (2) regulating services (concerning climate, floods, soil or water quality), (3) cultural services (with respect to aesthetic, spiritual, educational or recreational relevance) and (4) supporting services (by soil formation, nutrient cycling or primary production). The latter is to conform to the intrinsic ecological functioning of ecosystems which may generate ecosystem services wherever their functioning is beneficial and accessible for humans.

This emphasizes that ecosystem services are not just a matter of nature but likewise of human society. They get realized at the natural-societal interface, where human needs and demands - better to say stakeholder demands - meet ecosystem services supply [26]. In this respect, we rely on Albert et al., [27], who followed the definition of ecosystem services from "The Economics of Ecosystems and Biodiversity" (TEEB-Initiative) as "the direct and indirect 
contributions of nature to human well-being”. Inside TEEB, they contrasted themselves to the human inputs as "anthropogenic contributions to ecosystem services generation", which may optimize or maximize certain required services and their beneficial outcomes.

Knowing and assessing human demand is essential for political decision-making and appropriate management. Demands of people for specific ecosystem services in a particular time or space do differ depending on gender, age, education, profession, and income. Furthermore, these demands may change over time. They are also not necessarily fulfilled due to limited or restricted access and often they are higher than what the ecosystem can provide [27]. This is particularly true in degraded ecosystems where the ecosystem services potential or capacity has been impaired, therefore decreasing the possible flow of benefits [28].

Such degradation of ecosystem services jeopardizes the achievement of the Millennium Ecosystem Assessment [25], which is why ecosystem services are considered as key elements for policies and decision-making at various scales from global to local [29]. In this context, the Participatory Rural Appraisal (PRA) became a basic prerequisite and was thoroughly promoted as an outstanding tool for successful practices of local community in terms of problem analysis, awareness-raising, and mutual learning in landscape planning [30-32]. Meanwhile, the process of making decisions in landscape management includes the consensus of the local people in the communities to achieve the prioritized objectives and choices [33,34].

Wherever natural forest areas decreased or got degraded, the benefits from forest ecosystem services to the local people living nearby can be severely affected [35]. Therefore, the restoration of such forests has been conceptualized to meet both, human needs and ecological priorities [36]. The timber production in the natural forests of Vietnam is not an option for the people, because the use is currently restricted by law [17]. Therefore, the study focuses on the supply and demand of certain important NTFPs, namely food, medicine and resin/oil as the most important alternative provisioning services from natural forests for human well-being [37], taking the natural forests in the A Luoi District in the Central Vietnam as an example. A sustainable use of NTFPs contribute to successful forest management and social development because they can offer goods and income without degrading the structure, biodiversity, and integrity of the forest ecosystems. Insofar, tropical forests may provide substantial values in a unit of area [38]. However, the restoration of deforested areas and degraded forests in order to gain back the functionality of the natural forest ecosystems and enhance the benefits for local human well-being is a long-term process [39]. 
To achieve the goals of natural forest restoration and enrichment of natural resources (including NTFPs) as alternative ecosystem provisioning services, an efficient forest management and development plan for the natural forests in the area is required. The development of such a plan covers the assessment of potential natural resources of opportunities and environmental risks concerning their use and of the needs for restoration of the natural forests on the one hand. On the other hand, it needs to consider local people's needs and demands for ecosystem services from these forests, their satisfaction with the recent supply, their awareness of natural risks and their acceptance concerning forest restoration measures in order to develop and provide reasonable, constructive and realizable forest management measures which are comprehended, accepted and supported by the local people.

Accordingly, (i) we evaluated the demands of local people for non-timber forest products (NTFPs) as provisioning services in the A Luoi District, Central Vietnam, by considering the respective importance and satisfaction ranking of different target groups; (ii) we assessed the forest resources with respect to their potential provisioning services concerning non-timber forest products that can be used as foods, medicine, resins, or oil; (iii) we assessed local people's perceptions of natural risks and shortages to evaluate their awareness and readiness for restoring the natural forest landscapes; (iv) we give recommendations for basic implications for restoration of natural forest landscapes in the remote mountainous regions in Vietnam. The overall methodological approach of the study is presented in Figure 6.1.

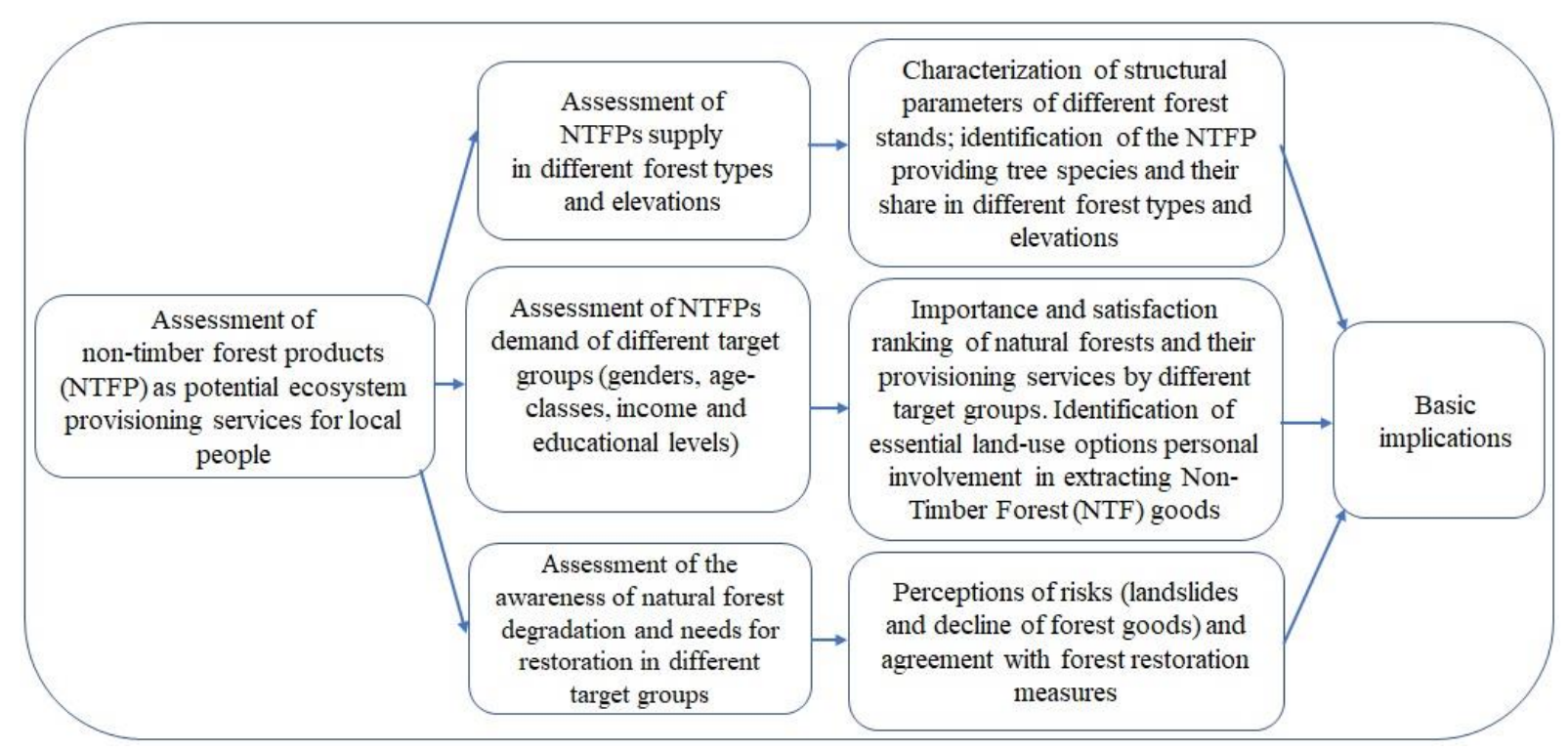

Figure 6.1. Overview of methodological approach used in this study (UF: Undisturbed forest, LF: Less disturbed forest, DF: Disturbed forest, H1: 150-699m, H2: 700-1162m above sea level) 


\subsection{Study area}

In Vietnam, the Truong Son mountain range stretches from the north to the south along the border with Laos and Cambodia for almost $1200 \mathrm{~km}$, forming hilly to steep mountainous areas, which occupy three-quarters of the entire land's territory. Especially in the North Central Coast (NCC) where the coastline is close with appropriate $50 \mathrm{~km}$ to the study area, this area is relatively steep and highly affected by heavy rainfalls which occur as typical tropical events, often causing landslides $[40,41]$.

The study area is situated in such a tropical mountainous area between $107^{\circ} .22^{\prime} \mathrm{E}$ to $107^{\circ} .30^{\prime} \mathrm{E}$ and $16^{\circ} .02^{\prime} \mathrm{N}$ to $16^{\circ} .10^{\prime} \mathrm{N}$ bordering to Laos. It belongs to the A Roang Commune of A Luoi District in the Southwestern part of Thua Thien Hue Province (Figure 6.2) where forest inventory and interviews were conducted. The topography is very steep with 5 to 48 degrees and the highest peak reaching around $1800 \mathrm{~m}$ above sea level (a.s.l). The data collection area ranged from $150 \mathrm{~m}$ to $1162 \mathrm{~m}$ a.s.l. The climate in the A Luoi District shows tropical monsoon characteristics with two distinguished seasons. The dry one is short and lasts from February to March with a monthly rainfall of only around $60 \mathrm{~mm}$. Most of the total annual rainfall of 3502 $\mathrm{mm}$, falls during the long rainy season between April and December with a mean of 200 rainy days per year. The rainfall occurs most heavily from August to December and particularly in October with an average of almost $1000 \mathrm{~mm}$ [42]. Under these topographic and temperature conditions, landslides happen occasionally. The mean temperature year-round is $21.9^{\circ} \mathrm{C}$. The mean high temperature of $25.3^{\circ} \mathrm{C}$ occurs in May and June while the coldest month is January with a mean temperature of $16.9^{\circ} \mathrm{C}$. The air humidity ranges from $81 \%$ to $94 \%$ [43]. 


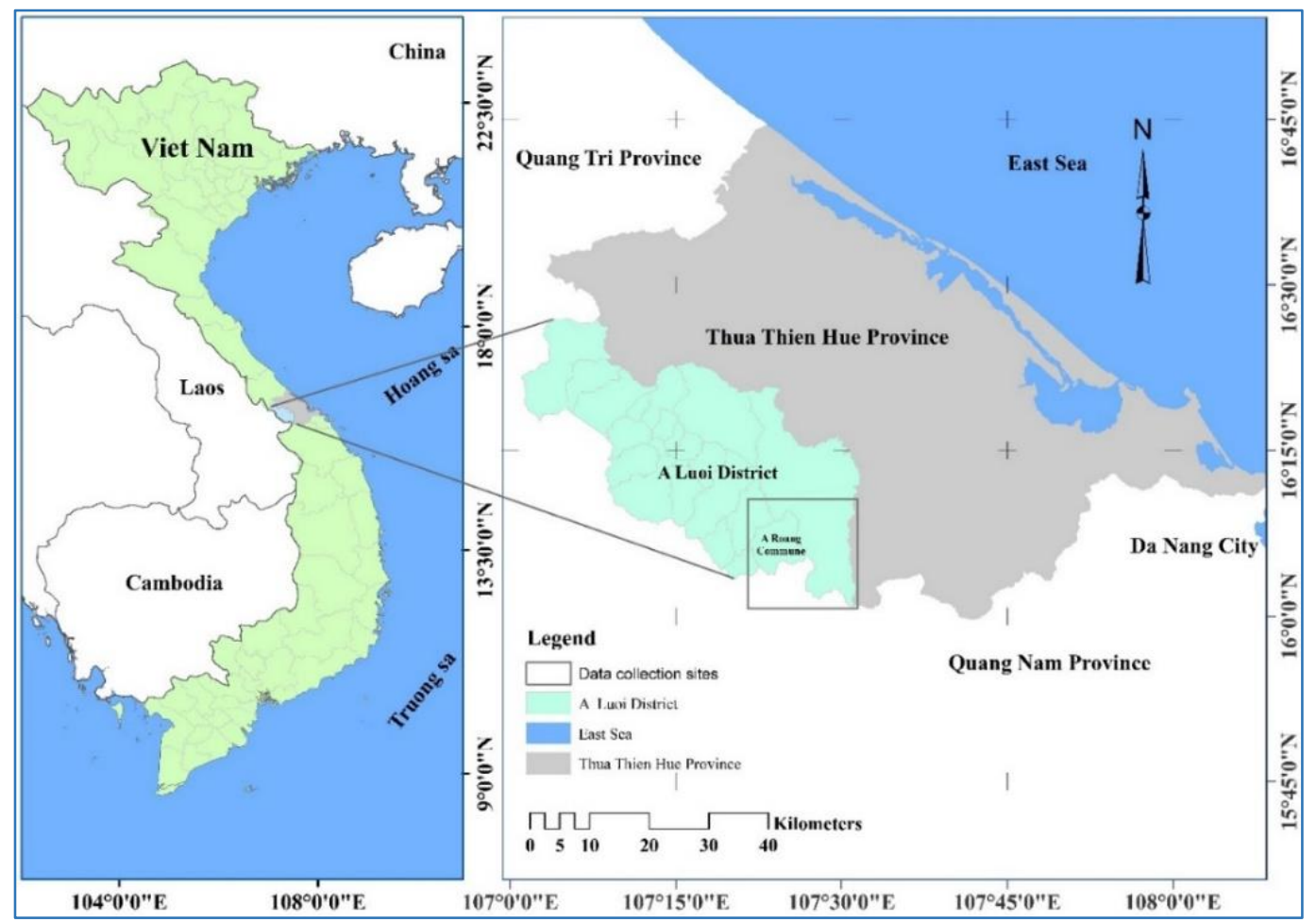

Figure 6.2. Relative location of the study area in the A Roang Commune of A Luoi District in Thua Thien Hue Province, Central Vietnam

Figure 6.3 illustrates the different land use types which were classified by using Sentinel2 satellite imagery in the area [43]. Although rain-fed rice production is the main crop in the study area, the respective agricultural land is rather small (around 1\%). However, the home gardens in the residential households can also be considered as a productive area for crops such as vegetables, cassava, and fruit trees such as Mango, Orange, Longan and Litchi. Meanwhile, the slash-and-burn areas $(2.2 \%)$ with their rotating seasonal production, are used for fast-growing species plantations such as Acacia spp. and Hevea brasiliensis, Cassava plantations, upland rice cultivation. The cultivation is very scattered and fragmented due to limitation of land availability. Water surface areas (8.4\%) are not equally distributed, thus aquaculture production is not a major income for local people.

With $77.1 \%$ coverage, natural forests occupy the largest proportion of the land area. Most of them are primary and secondary closed evergreen broadleaved lowland forests with dominant genera from the following botanical families: Fagaceae with Castanopsis and Lithocarpus; Lauraceae with Litsea, Cinnamomum, Actinodaphne, Diospyros, Cryptocarya, Machilus; Myrtaceae with Syzygium, Cannabaceae of Gironniera, Aphananthe and Trema; Leguminosae with Peltophorum, Archidendron, Placolobium and Ormosia; Dipterocarpaceae with Dipterocarpus, Parashorea and Shorea; Malvaceae with Scaphium, Pterospermum and Sterculia; Meliaceae with Aphanamixis, Aglaia and Chukrasia; Myristacaeae with Knema; Burseraceae with Canarium and Bursera; Annonaceae with Enicosanthellum, Polyalthia and 
Alphonsea $[1,44,45]$. The forest classification method, introduced by Loeschau in 1961, has been applied in Vietnam. This method was applied in studies of Phuong et al., 2012 [46] and Bui 2016 [47]. According to the classification of Nguyen Trong et al., [43], there are three types of natural forests due to different intensities of human impact. Undisturbed forest (UF) with no apparent evidence of human interventions is distributed in very remote and difficult terrain where forests have persisted and the natural forest structure is preserved. The UF has a basal area of around $30 \mathrm{~m}^{2} \mathrm{ha}^{-1}$. The dominant genera are Lithocarpus, Litsea, Cinnamomum, Dipterocarpus, Shorea, Peltophorum, Archidendron, Ormosia, Aphanamixis, Aglaia. Less disturbed (LF) forest occurs where the stands have been slightly logged and disturbed but their natural structure is still noticeable. This type of forest, is dominated by Lithocarpus, Machilus, Litsea, Cinnamomum, Sapium, Hancea, Endospermun, Macaranga, Nephelium, Mischocarpus, Amesiodeuchon and Mischocarpus, has a basal area ranging 21-26 $\mathrm{m}^{2} \mathrm{ha}^{-1}$. Finally, the secondary forest occurs where the forest is seriously disturbed (DF) with a basal area between 10-21 $\mathrm{m}^{2} \mathrm{ha}^{-1}$. This forest type is dominated by genera of Knema, Garcinia, Enicosanthellum, Polyalthia, Microdesmis and Syzygium $[1,2]$. The natural vegetation originates mostly from natural lowland forests and has been managed by local communities and forest management boards of A Luoi District. Most of the forest areas in the A Roang Commune are for production purposes and managed by the local communities under guidelines from local authorities. The remaining forest areas are for protection purposes.

A Roang Commune comprises seven villages with a total population of 2,732 persons from 627 families. Apart from very few Kinh people, there are three dominant ethnic groups, namely Van Kieu, Ta Oi, and Co Tu living close to forests and depending on income from agricultural cultivation and forestry activities. 


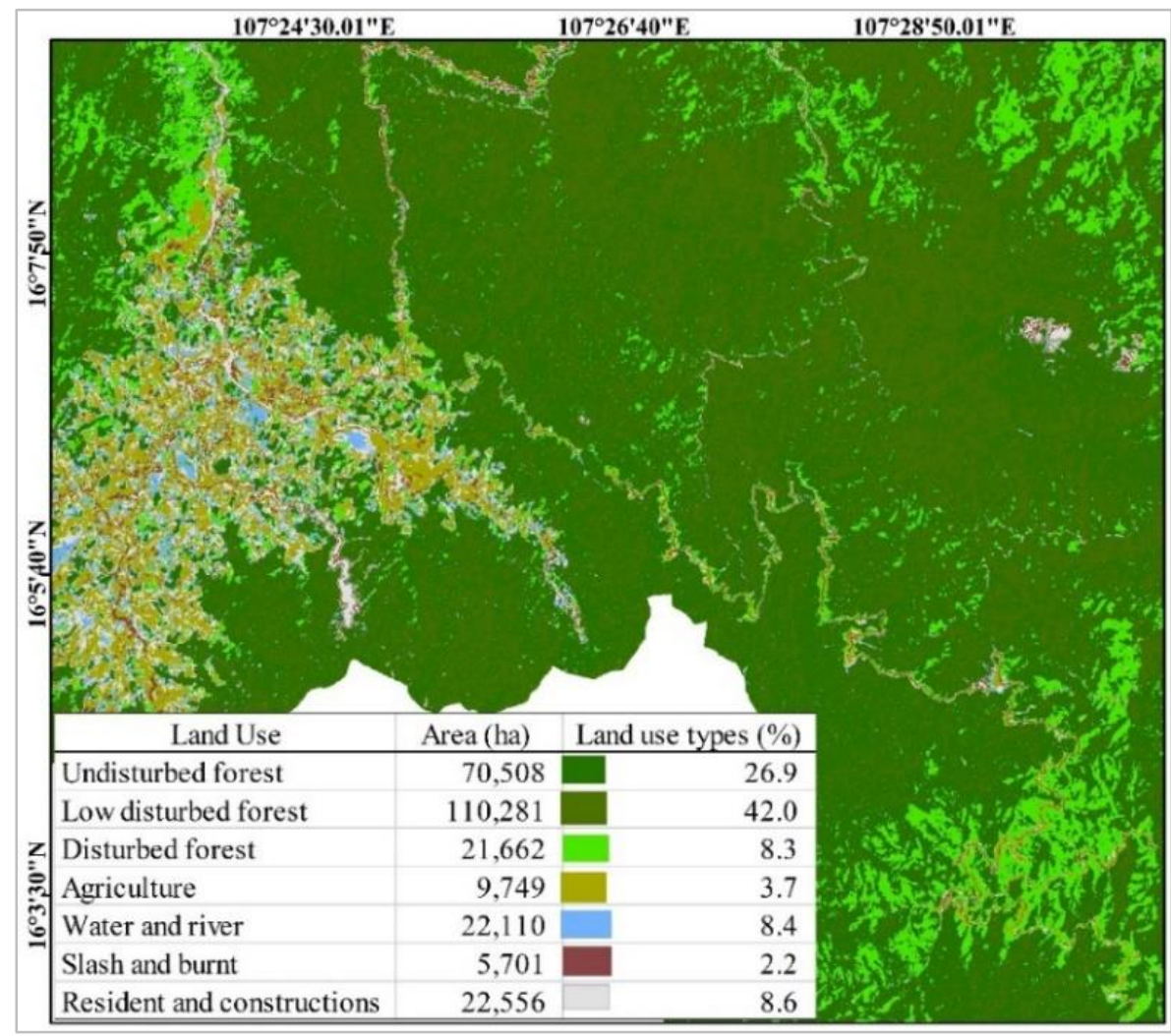

Figure 6.3. Land use types in the study site in A Roang Commune as described in Figure 6.2

The non-agricultural and the unused lands occupy a small percentage of $4 \%$ and $1 \%$ of the total natural area of A Luoi District and A Roang Commune respectively. The area used for rice cultivation per person in A Roang Commune is about $1450 \mathrm{~m}^{2}$ but only $578 \mathrm{~m}^{2}$ of these lands can be used for rice cultivation year-round. Education system from primary to high schools in the area is covered by the public school system which consists of a primary school with 229 students and a secondary school with 209 students [48]. The students who pass secondary school, an estimated 44\%, are sent to high school in A Luoi District [49]. The high school is about 40 $\mathrm{km}$ away from A Roang Commune. There are $46.26 \%$ of the people who are classified as poor (compared to $37.40 \%$ in the entire district), having less than 700.000 Viet Nam Dong (35 USD) per month at their disposal [50].

\subsection{Data sampling and Methods}

\subsubsection{Forest inventory}

To document the structural forest characteristics and the proportion of NTFP tree species as potential ecosystem services supply, we conducted a classical forest inventory, as it has been developed for the assessment of timber resources [51,52]. However, in the context of current natural forest management in Vietnam, timber exploitation for construction by communities or households is banned while other management goals like rehabilitation have gained relevance. 
Thus, we used data from a forest inventory, which was conducted in accordance with forest inventory guideline. A total of 90 plots with a size of $30 \times 33.3 \mathrm{~m}$ were randomly sampled in the natural forests of the three aforementioned forest types (Figure 6.4) from April to May 2017. Each forest type was represented by 30 sample plots [43] and for elevations: H1 = 50 sample plots, $\mathrm{H} 2=40$ sample plots, the classification of elevations was based on study of Trong et al.[53]. In each plot, the top height $(\mathrm{H})$ in meters and the diameter at breast height (DBH) in centimeters of all living trees (including NTFP tree species) with a DBH $\geq 6.0 \mathrm{~cm}$ were measured in accordance with conventional forest inventory techniques [54]. The names of tree species were recorded in the Vietnamese language by local dendrologists and translated later to their scientific names [55]. To avoid synonyms, we checked the names of all recorded tree species in The Plant List [56].

Then, the means of forest stand parameters such as the number of stems, total species numbers per forest types and elevation, the basal area $\left(B A\right.$ in $\left.\mathrm{m}^{2}\right)$ and the volume $\left(\mathrm{G}\right.$ in $\left.\mathrm{m}^{3}\right)$ per ha, the mean of diameter at breast height $(\mathrm{DBH}$ in $\mathrm{cm})$ and top height $(\mathrm{H} \mathrm{in} \mathrm{m})$ of the trees, and the number of tree species per plot were calculated and analyzed [57-59]. The form factor 0.5 was commonly used [60] and tested by the t-test among forest types and elevations. Finally, the relations between DBH and top height for the different forest types and elevations to identify structural gaps concerning the stands of all forest tree species as well as those with NTFPs potential.

The sample plots had been pre-sampled by sub-stratified forest status based on the forest status maps as feature classes to create random points in ArcGIS. These sample points were transferred to the Global Positioning System (GPS) for tracking during the fieldwork. Coordinates, elevations, and slopes of all sample plots were recorded on-site with GPS referencing the Shuttle Radar Topography Mission - Digital Elevation Model (SRTM - DEM) after fieldwork. The interval distance among plots was minimally around 200 meters. 


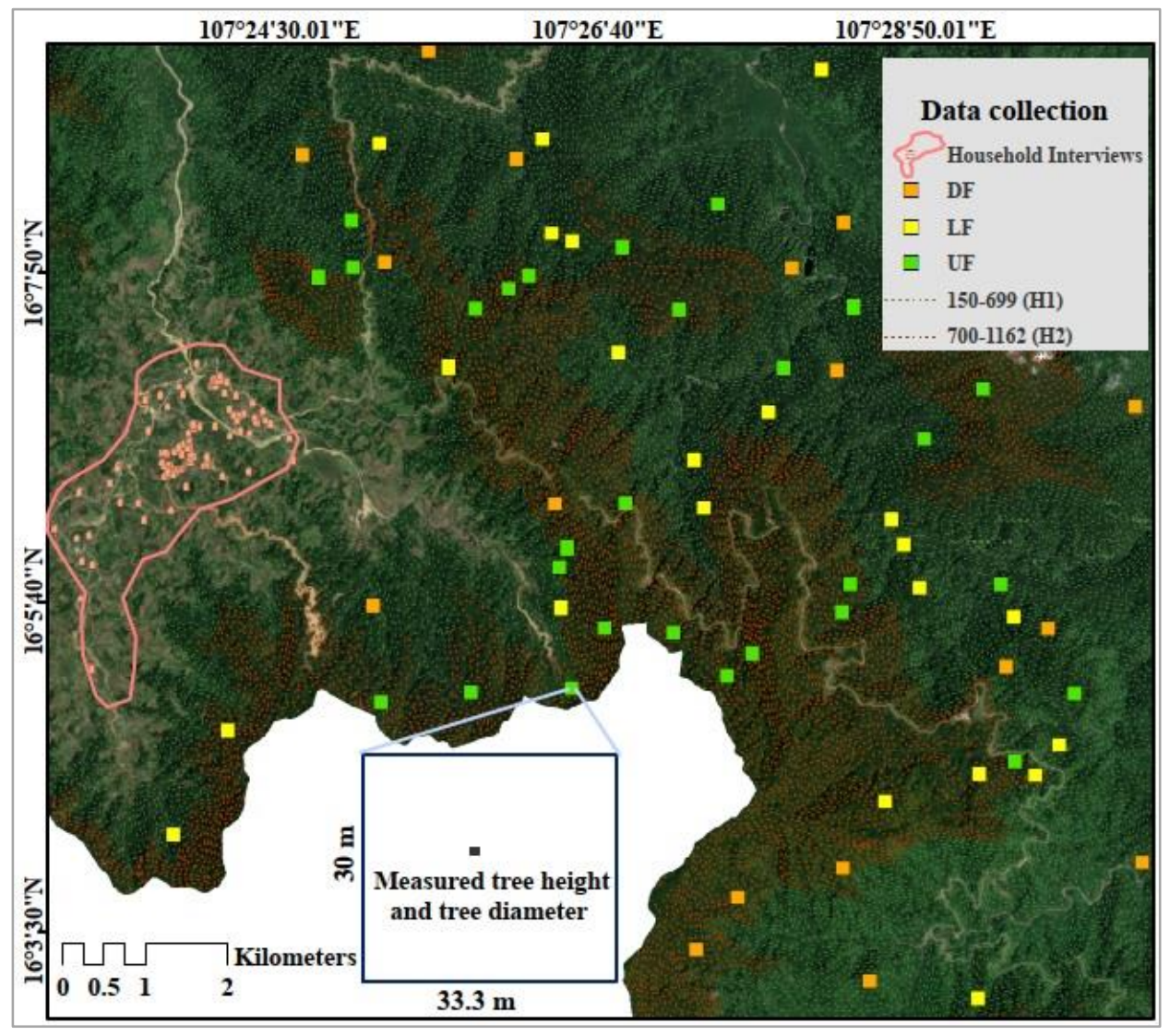

Figure 6.4. Data sample arrangement for the forest types: (UF = Undisturbed forest (green), LF $=$ Less disturbed forest (yellow), DF = Disturbed forest (orange); For elevations above sea level: $\mathrm{H} 1=150-699 \mathrm{~m}$ indicated by the light-blue dotted line, and $\mathrm{H} 2=700-1162 \mathrm{~m}$ indicated by the dark-brown dotted lines and the area for household interviews in the light-orange circle where local people have been inhabited. Each rectangle of the forest samples has a size of $30 \times 33.3 \mathrm{~m}$ ).

\subsubsection{Identification of use options for NTFP tree species}

Today timber is not reachable because the government issued a policy to cease timber logging from natural forests in 2017 [17]. At least, NTFPs are mostly accessible by local people for domestic uses and some are for sale. However, the inventory of NTFP tree species has not been considered much, so far [61]. Hence, we conducted forest inventory based on indigenous knowledge of the local forest inventory teams and literature reviews in both Vietnamese and Scientific terminologies $[62,63]$. The use options of NTFPs for different purposes were further reviewed in 49 publications. These NTFP species were once again short-listed into what parts of the species are traditionally and pharmaceutically used for foods, medicine, and resin/oil.

\subsubsection{Assessment of NTFPs supply}

These data were converted into the entire mean of the measured parameters such as number of species per plot, basal area, volume and stems per ha in the different investigated forest types and elevations in order to assess the potential supply of foods, medicine and resin/oil. 
Furthermore, they were related to the respective parameters of the entire stands (forest types and elevations) to provide better information about their specific supply.

\subsubsection{Interviews}

To assess the views, awareness and perspectives of local people concerning existing natural forests and help to avoid risks of inappropriate management implementation and support method-based for conservation research [64-67], we interviewed people from 120 households in a commune close to the existing natural forests, where the forest inventory was conducted. The households were chosen from a list of all 627 households from seven villages of the commune. Around 150 monthly salaried households of workers from non-agroforestry local factories, teachers at schools, and army veterans were excluded because these households have permanent income and do not depend on extra income from natural forests. Then, one out of every five of the remaining households was selected for the interview. The necessary sample size of the interviewed households was calculated based on Slovin's formula $[68,69]$. The size represented $26 \%$ of the total households with a confidence interval of $95 \%$ and an error margin of $5 \%$. Conducting more interviews was not affordable because funding for the study was inadequate to allow for complete survey of all communities within in the study area. In addition, the remoteness of some households presented a challenge for accessibility.

The interviews were conducted (i) to assess the specific importance and satisfaction that local people attributes to the natural forest and its supply of NTFPs as provisioning services; (ii) to get to know about individual involvement of local people in extracting natural forest goods and (iii) to let them specify their most relevant land use practices. We also wanted (iv) to know about their awareness of the consequences of human impact like landslides or the decline of forest goods as well as (v) about their acceptance concerning necessary forest restoration initiatives. All interview aspects were documented in questionnaires for further analysis.

In order to capture specific views of different people, eleven target groups of local people were stratified according to gender, income, educational levels, and age-classes. The group sizes ranged between 21 and 73 people. Distinguishing their specific qualitative as well as quantitative judgement profile (what do they choose and how many of them) might help to address the right people for specific forest management measures.

\subsubsection{Assessment of NTFPs demand}

The assessment of the local demand for NTFPs as forest provisioning services followed a semi-quantitative approach considering the following aspects: The qualitative ranking of the importance of the natural forests and their NTFP supply by different target groups, and of their 
satisfaction with this supply; their present factual involvement in extracting the respective forest goods; and their specification of their most essential common land use practices. While ranking the importance of NTFPs from natural forests and considering the personal involvement in their extraction were chosen as appropriate indication of the specific demand, ranking the satisfaction with the existing supply tells about the degree of demand fulfilment. The identification of the significance of different land use options demonstrates what people actually do.

3.6. Assessment of different perceptions concerning natural risks and the necessity of forest restoration

Increasing the awareness of local people concerning the conditions and necessities for good ecological functioning and essential ecosystem services would promote better management of natural forests while balancing the supply and demand of the natural resources [65]. Therefore, the local people were asked to confirm $(\mathrm{Y})$ or negate $(\mathrm{N})$ their perception of landslides and declines of forest goods from natural forests as well as their agreement with forest restoration measures.

The respective data were likewise analyzed quantitatively, considering different genders, age-groups, education and income levels, to find out about their specific awareness of problems, and their acceptance for improvement. Insofar, the results of the perception analysis provide valuable information to identify practicable solutions for natural forest restoration. The process of data collection and initial interview results were consulted with different local authorities like local forest protection and forest development units and communal representatives to briefly inform them about the initial assessment [70].

6.4. Results

6.4.1. Characteristics of local forest stand structure

The mean parameters of all forest stand in the different forest types (UF, LF, DF) and elevations $(\mathrm{H} 1, \mathrm{H} 2)$ in the study area are presented in Table 6.1 . 
Table 6.1. The mean parameters and standard deviations of the forest stand in different forest types: (UF=undisturbed forest, $\mathrm{LF}=$ less disturbed forest, $\mathrm{DF}=$ disturbed forest) and elevations above sea level $(\mathrm{H} 1=150-699 \mathrm{~m}$ and $\mathrm{H} 2=700-1162 \mathrm{~m})$. The same letter in the same row indicates no significant difference at $\mathrm{p}<0.05$.

\begin{tabular}{lccccc}
\hline \multirow{2}{*}{ Stand parameters } & \multicolumn{3}{c}{ Forest types } & \multicolumn{3}{c}{ Elevations } \\
\cline { 2 - 6 } & UF & LF & DF & H1 & H2 \\
\hline No. of plots $\left(1000 \mathrm{~m}^{2}\right)$ & 30 & 30 & 30 & 50 & 40 \\
No. of stems $\mathrm{ha}^{-1}$ & $483.7 \pm 9.0 \mathrm{a}$ & $500.3 \pm 14.2 \mathrm{~b}$ & $493.7 \pm 12.8 \mathrm{ab}$ & $527.4 \pm 9.0 \mathrm{a}$ & $415 \pm 13.2 \mathrm{~b}$ \\
Basal area $\mathrm{m}^{2} \mathrm{ha}^{-1}$ & $33.3 \pm 0.6 \mathrm{a}$ & $21.6 \pm 0.3 \mathrm{~b}$ & $15.9 \pm 0.4 \mathrm{c}$ & $21.8 \pm 0.6 \mathrm{a}$ & $26.2 \pm 1.0 \mathrm{~b}$ \\
Volume $\mathrm{m}^{3} \mathrm{ha}^{-1}$ & $362.7 \pm 8.8 \mathrm{a}$ & $212.6 \pm 4.0 \mathrm{~b}$ & $150 \pm 4.7 \mathrm{c}$ & $208.6 \pm 7.4 \mathrm{a}$ & $283.3 \pm 13.0 \mathrm{~b}$ \\
Species/plot & $25.1 \pm 4.9 \mathrm{a}$ & $27.4 \pm 6.4 \mathrm{~b}$ & $25.3 \pm 5.3 \mathrm{ab}$ & $29.7 \pm 3.4 \mathrm{a}$ & $20.2 \pm 3.6 \mathrm{~b}$ \\
Total species per & & & & & \\
forest type and & 102 & 113 & 112 & & 121 \\
elevation level & & & & & 109 \\
\hline
\end{tabular}

The number of stems per hectare in the disturbed forests (LF and DF) were slightly higher than those in the undisturbed forests (UF), however with significant differences only for LF. A significant increase of stems could also be shown for lower elevations (H1) compared to the higher ones $(\mathrm{H} 2)$, where their numbers remained even below the mean values of undisturbed forests.

In contrast, the basal areas and volumes differed significantly between forest types and elevations: the highest values were found in the undisturbed forests (UF) and decreased with increasing human impact from LF to DF. Significantly bigger volumes and basal areas occurred also at the higher and less accessible altitudes (H2) compared to the lower ones (H1), but did not reach the high mean values of undisturbed forests.

Those differences in wood supply are also reflected by the distribution of diameters at breast height $(\mathrm{DBH})$ and top heights in the respective stands. As illustrated in Figure 6.5, both values are mostly considerably smaller in stands which presumably have been exposed to bigger human impact (i.e LF, DF and H1) than in the less impacted (UF and H2). The relationship between DBH and top height of trees indicated further that the more deforested and degraded forest types showed lower correlations with $\mathrm{R}^{2}=0.58$ in $\mathrm{DF}, 0.61 \mathrm{in} \mathrm{LF}$, and 0.69 in UF. The same could be considered with respect to the altitude of the forest sites with lower correlation in $\mathrm{H} 1\left(\mathrm{R}^{2}=0.58\right)$ than in $\mathrm{H} 2\left(\mathrm{R}^{2}=0.72\right)$. 


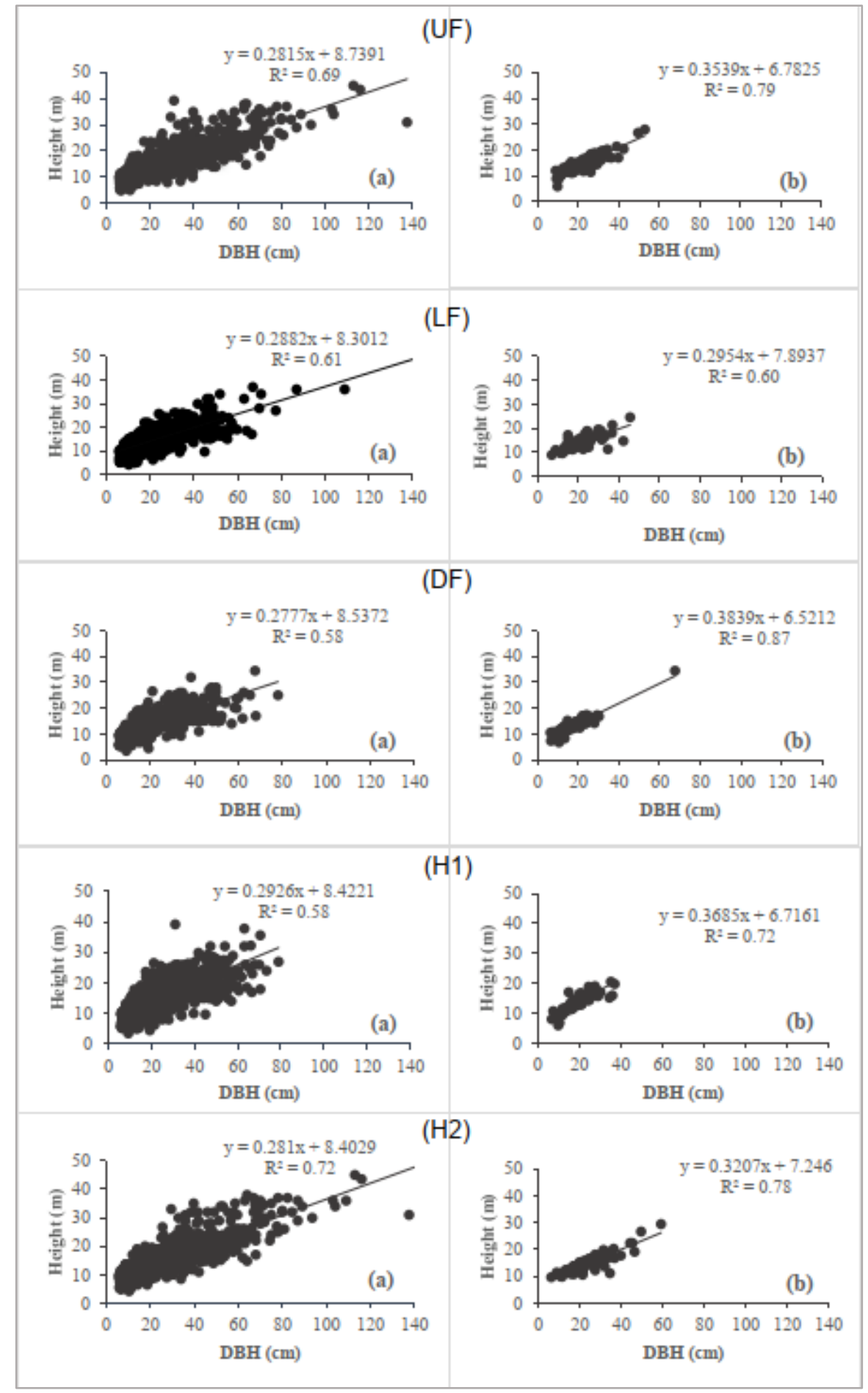

Figure 6.5. The relationship between diameter at breast height (DBH) and top height in different forest types and elevations:

(a) shows the relations of DBH and height of each tree, represented as a dot in the whole forest stand, (b) shows the relationship of DBH and height of only NTFP species in the forest stand.

The total number of registered tree species was 122. The species numbers per plot did not differ significantly in the different forest types with 20 - 33 species. Only the mean species numbers in LF were slightly but significantly higher than in UF. However, there were significant 
differences in the number of species between different altitudes (H1 and H2) with higher species numbers to be found at lower altitudes and smaller species numbers at higher elevations. It seems difficult to conclude whether this is due to natural site conditions or to human impact.

6.4.2. Use options and potential supply of NTFPs tree species as potential forest provisioning services

The results of our literature review are compiled in Table 6.2. 39 out of the inventoried 122 tree species (32\%) were mentioned in 49 publications as providers of medicine, food or resin and edible oil. They belong to 28 families. The dominant medical species belong to the families of Malvaceae, Magnoliaceae, Juglandaceae, Lauraceae, Araliaceae, Clusiaceae, and Leguminosae; species used as food sources belong to Fagaceae, Burseraceae, Sapindaceaem and Anacardiaceae; and dominant species for resin/oil production were members of Dipterocarpaceae, Proteaceae, Lauraceae, and Anacardiaceae.

Adding up to 26 different species (21\%), the medical species were found to be the most numerous. Nine species (7\%) were known to provide food, and five species (4\%) were categorized for resin or oil tapping. Different parts of these tree species such as leaves, fruits, nuts, seeds, bark, roots or trunks are collected and used by local people to be eaten or as traditional medical treatment.

Table 6.2. Use options of NTFP species

\begin{tabular}{|c|c|c|c|c|c|c|}
\hline \multirow[b]{2}{*}{ No } & \multicolumn{2}{|l|}{ Species } & \multirow{2}{*}{ 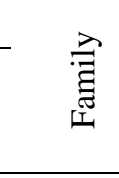 } & \multirow[b]{2}{*}{$\stackrel{\otimes}{\infty}$} & \multirow[b]{2}{*}{ Descriptions } & \multirow{2}{*}{ 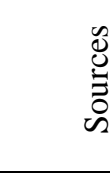 } \\
\hline & Scientific names & $\begin{array}{l}\text { Local } \\
\text { names }\end{array}$ & & & & \\
\hline 1 & $\begin{array}{l}\text { Syzygium lanceolatum (Lam.) } \\
\text { Wight \& Arn }\end{array}$ & Trâm trắng & Myr & $\mathrm{F}$ & Fruits are edible & [71] \\
\hline 2 & $\begin{array}{l}\text { Lithocarpus tubulosus (Hickel } \\
\text { \& A.Camus) }\end{array}$ & Dẻ & Fag & $\mathrm{F}$ & Nuts are edible & {$[72,73]$} \\
\hline 3 & Nephelium melliferum Gagnep & Bồ hòn & Sapi & $\mathrm{F}$ & Fruits are edible & {$[74]$} \\
\hline 4 & Canarium album (Lour.) DC. & Trám trắng & Bur & $\mathrm{F}$ & Fruits are edible & {$[74,75]$} \\
\hline 5 & Mangifera minutifolia Evrard & Xoài rừng & Ana & $\mathrm{F}$ & $\begin{array}{l}\text { Young leaves and fruits are } \\
\text { edible }\end{array}$ & {$[74]$} \\
\hline 6 & $\begin{array}{l}\text { Syzygium chanlos (Gagnep.) } \\
\text { Merr. \& L.M.Perry }\end{array}$ & Trâm sừng & Myr & $\mathrm{F}$ & Fruits are edible & {$[76]$} \\
\hline 7 & Saurauia napaulensis & Dương đào & Act & $\mathrm{F}$ & Fruits are edible. & {$[77]$} \\
\hline 8 & Sterculia lanceolata Cav. & Trôm & Mal & $\mathrm{F}$ & Seeds are edible. & {$[78]$} \\
\hline 9 & Canarium pimela K.D.Koenig & Trám đen & Bur & $\mathrm{F}$ & Fruits are edible & [79] \\
\hline 10 & $\begin{array}{l}\text { Scaphium macropodum (Miq) } \\
\text { Beumee ex K.Heyne }\end{array}$ & U’ơi & Mal & M & $\begin{array}{l}\text { Nuts and seeds are used to treat } \\
\text { diarrhea, dysentery and }\end{array}$ & {$[74]$} \\
\hline
\end{tabular}


asthmatic complaints and

against fevers

\begin{tabular}{|c|c|c|c|c|c|c|}
\hline 11 & Garcinia oliveri Pierre & Bứa & Clu & $\mathrm{M}$ & $\begin{array}{l}\text { Fruits used for mitigating } \\
\text { sprains }\end{array}$ & [80] \\
\hline 12 & $\begin{array}{l}\text { Magnolia mediocris (Dandy) } \\
\text { Figlar }\end{array}$ & Giổi & Mag & M & $\begin{array}{l}\text { Seeds are used as spices. Seeds } \\
\text { and bark are used to treat colic } \\
\text { and fever. }\end{array}$ & [81] \\
\hline 13 & $\begin{array}{l}\text { Engelhardtia roxburghiana } \\
\text { Lindl }\end{array}$ & Chẹo tía & Jug & M & $\begin{array}{l}\text { Bark, roots and leaves are used } \\
\text { as antiseptic }\end{array}$ & [82] \\
\hline 14 & $\begin{array}{l}\text { Schefflera heptaphylla }(\mathrm{L} .) \\
\text { Frodin }\end{array}$ & $\begin{array}{l}\text { Chân chim } \\
\text { rừng }\end{array}$ & Ara & M & $\begin{array}{l}\text { Leaves and bark are used for } \\
\text { treating rheumatism, joint pain } \\
\text { and to help digestion }\end{array}$ & {$[80]$} \\
\hline 15 & $\begin{array}{l}\text { Knema globularia (Lam.) } \\
\text { Warb }\end{array}$ & $\begin{array}{l}\text { Máu chó lá } \\
\text { nhỏ }\end{array}$ & Myri & M & $\begin{array}{l}\text { Bark and wood are used to cure } \\
\text { scabies, backache, skin } \\
\text { diseases }\end{array}$ & [83] \\
\hline 16 & $\begin{array}{l}\text { Litsea glutinosa (Lour.) } \\
\text { C.B.Rob. }\end{array}$ & Bời lời nhớt & Lau & M & $\begin{array}{l}\text { Roots used for treatment of } \\
\text { diarrhea, enteritis, diabetes } \\
\text { mellitus, bruising injuries. Bark } \\
\text { and leaves used to treat } \\
\text { inflammation of the parotid } \\
\text { glands, boils, mastitis, swelling } \\
\text { of the calf, and to stop } \\
\text { bleeding. }\end{array}$ & {$[82,84,85]$} \\
\hline 17 & Machilus bonii Lecomte & Kháo vàng & Lau & M & $\begin{array}{l}\text { Bark and leaves used for } \\
\text { treating burns and toothache }\end{array}$ & {$[80,86]$} \\
\hline 18 & $\begin{array}{l}\text { Glycosmis citrifolia (Willd.) } \\
\text { Lindl. }\end{array}$ & Bưởi bung & Rut & $\mathrm{M}$ & $\begin{array}{l}\text { Roots and leaves are used to } \\
\text { treat flu, cough, stomach ache }\end{array}$ & {$[87,88]$} \\
\hline 19 & $\begin{array}{l}\text { Wrightia annamensis Eberh. \& } \\
\text { Dubard }\end{array}$ & Lòng mức & Apo & M & $\begin{array}{l}\text { Trunk, leaves, and roots are } \\
\text { used to treat pharyngitis, } \\
\text { typhoid, and malaria. These } \\
\text { can also be used to treat } \\
\text { rheumatoid arthritis and } \\
\text { hepatitis jaundice }\end{array}$ & {$[85]$} \\
\hline 20 & Litsea verticillata Hance & Bời lời vòng & Lau & M & $\begin{array}{l}\text { Bark and leaves are used to } \\
\text { treat swelling caused by injury } \\
\text { or by snake bites. Extract to } \\
\text { natural anti-HIV agents }\end{array}$ & {$[89,90]$} \\
\hline
\end{tabular}

Bark is used to treat several ailments like stomatitis, insomnia, skin troubles, constipation, ringworm, insomnia, dysentery, muscular pains, sores, and skin disorders and is the source of diverse

21 (DC.) K.Heyne Lim xẹt Leg M kinds of chemical constituents such as aliphatic alcohols, fatty acids, amino acids, terpenoids, phenolics, flavonoids, alkaloids, steroids 


\begin{tabular}{|c|c|c|c|c|c|c|}
\hline 22 & Nauclea orientalis (L.) L. & Gáo vàng & Rub & M & $\begin{array}{l}\text { Bark is used to treat fever, } \\
\text { cirrhosis of ascites, abdominal } \\
\text { pain, animal bites and wounds. } \\
\text { Leaves are applied externally } \\
\text { to boils and tumors, A bark } \\
\text { decoction is used for the } \\
\text { treatment of diarrhea and } \\
\text { toothaches }\end{array}$ & {$[81,92]$} \\
\hline 23 & Syzygium jambos (L.) Alston & Trâm mốc & Myr & M & $\begin{array}{l}\text { Bark and young leaves are used } \\
\text { for anti-thermal and antiseptic } \\
\text { properties }\end{array}$ & {$[82,93]$} \\
\hline 24 & $\begin{array}{l}\text { Macaranga denticulata } \\
\text { (Blume) }\end{array}$ & Lá nến & Eup & M & $\begin{array}{l}\text { Leaves used for postpartum } \\
\text { treatment and as antiseptic }\end{array}$ & {$[94]$} \\
\hline 25 & $\begin{array}{l}\text { Vitex quinata (Lour.) } \\
\text { F.N.Williams }\end{array}$ & Đẻn năm lá & Lam & $\mathrm{M}$ & $\begin{array}{l}\text { Bark is used as a tonic, as a } \\
\text { stomachic (an infusion to } \\
\text { stimulate the appetite), and } \\
\text { against cancer. }\end{array}$ & {$[95,96]$} \\
\hline 26 & $\begin{array}{l}\text { Polyalthia cerasoides (Roxb.) } \\
\text { Bedd. }\end{array}$ & Nhọc & Ann & M & $\begin{array}{l}\text { Consumption of the water of } \\
\text { boiled roots is used to treat } \\
\text { hives. }\end{array}$ & {$[97,98]$} \\
\hline 27 & $\begin{array}{l}\text { Symplocos cochinchinensis var. } \\
\text { laurina (Retz.) Noot. }\end{array}$ & Dung nam bộ & Sym & M & $\begin{array}{l}\text { Shoots are used to treat burns. } \\
\text { Bark is used to treat fever, } \\
\text { dysentery, diarrhea, and } \\
\text { common colds. }\end{array}$ & {$[80,99]$} \\
\hline 28 & $\begin{array}{l}\text { Peltophorum dasyrrhachis } \\
\text { (Miq.) Kurz }\end{array}$ & Lim vang & Leg & M & $\begin{array}{l}\text { Bark gives tannin and cures } \\
\text { cough }\end{array}$ & {$[100,101]$} \\
\hline 29 & $\begin{array}{l}\text { Alangium chinense (Lour) } \\
\text { Harms }\end{array}$ & Thôi ba & Cor & M & $\begin{array}{l}\text { Roots used to treat rheumatism, } \\
\text { treat snakebite, bone pain, joint } \\
\text { pain, and swelling pain. Fruits } \\
\text { used with other species to treat } \\
\text { kidney disease. Leaves used for } \\
\text { animals' fodder. }\end{array}$ & {$[80,102]$} \\
\hline 30 & $\begin{array}{l}\text { Terminalia bellirica (Gaertn.) } \\
\text { Roxb. }\end{array}$ & Chiêu liêu & Com & M & $\begin{array}{l}\text { Seeds are used to treat diarrhea } \\
\text { and dysentery of livestock }\end{array}$ & 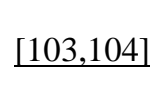 \\
\hline 31 & Trema orientalis (L.) Blume & Hu đay & Can & M & $\begin{array}{l}\text { Leaves used for treating } \\
\text { epilepsy, laxative effect, } \\
\text { hypoglycemic, diuretic and } \\
\text { analgesic and anti-arthritic } \\
\text { activities }\end{array}$ & {$[105,106]$} \\
\hline 32 & Gironniera nervosa Planch & Ngát lông & Can & M & $\begin{array}{l}\text { Seeds are edible and used to } \\
\text { treat rheumatism and cardiac } \\
\text { diseases }\end{array}$ & {$[107,108]$} \\
\hline 33 & $\begin{array}{l}\text { Madhuca pasquieri (Dubard) } \\
\text { H.J.Lam }\end{array}$ & Sến mật & Sap & M & $\begin{array}{l}\text { Shoots are used to treat burns. } \\
\text { Bark is used to treat fever, } \\
\text { dysentery, diarrhea, and } \\
\text { common colds. It also tannin } \\
\text { extracts }\end{array}$ & $\begin{array}{l}{[80,100,} \\
101,109]\end{array}$ \\
\hline 34 & Nageia fleuryi (hickel) de Laub & Kim giao & Pod & M & $\begin{array}{l}\text { Leaves are used in medicine to } \\
\text { cure cough and antidote }\end{array}$ & {$[110,111]$} \\
\hline
\end{tabular}


35

36

37

Cinnamomum verum J.Presl

Dầu đọt tím

Dip

$\mathrm{R}$

Resin tapping

$[112]$

Helicia cochinchinensis Lour. Quắn trung bộ Pro

$\mathrm{R} / \mathrm{F} \quad$ Resin tapping. Seeds are edible

$[113,114]$

Used as oil and treats digestive complaints, such as dyspepsia,

flatulency, mild spasms,

[115-117] cramps, diarrhea, and vomiting

38 Melanorrhoea laccifera Sơn huyết Ana $\mathrm{R} \quad$ Resin production for art

39 Dipterocarpus baudii Korth Dầu lông $\quad$ Dip $\quad \mathrm{R} \quad$ Resin production $\quad$ [119,120]

$(\mathrm{M}=$ Medicine; $\mathrm{F}=$ Foods; $\mathrm{RO}=$ resin/oil. The abbreviation of families were as: Dipterocarpaceae $=$ Dip; Lauraceae $=$ Lau; Anacardiaceae $=$ Ana; Proteaceae $=$ Pro; Podocarpaceae $=$ Pod $;$ Sapotaceae $=$ Sap Cannabaceae $=$ Can Combretaceae $=$ Com $;$ Cornaceae $=$ Cor $;$ Leguminosae $=$ Leg; Symplicaceae $=$ Sym; Annocaceae $=$ Ann; Lamiaceae $=$ Lam; Euphorbiaceae $=$ Eup $;$ Myrtaceae $=$ Myr; Rubiaceae $=$ Rub; Apocynaceae $=$ Apo , Rutaceae $=$ Rut Myristicacea $=$ Myri; Araliaceae = Ara; Juglandaceae = Jug; Magnoliaceae = Mag; Clusiaceae $=\mathrm{Clu} ;$ Malvaceae $=$ Mal $;$ Burseraceae $=$ Bur; Actinnidiaceae $=$ Act $;$ Fagaceae $=$ Fag $;$ Sapindaceae $=$ Sapi $)$.

Table 6.3 shows the total amount of NTFP tree species and selected quantitative forest parameters concerning their potential supply of food, medicine, and resin/oil in the different forest types and at different elevations, revealing significant differences. NTFP tree species for medicinal use were the most numerous (3-6 species per plot) and showed the highest quantities for all forest types and elevations, while the use potential for resin or oil was usually the lowest apart from their volume in undisturbed forests (UF) and at higher elevations (H2). At the same time, the number of the respective tree species was the lowest (1-2 species per plot). NTFP tree species with use potential for food reached always intermediate values from 2-3 species per plot.

Table 6.4 relates these data to those of the entire stands, giving percentages of the respective amount for each parameter. It reaffirms the previous results, indicating that the absolute quantities of NTFP tree species in the stands correspond to their share in the forest structure presented in Table 6.1. In other words, this made some additional remarks that tree species for medicinal use have always the biggest share in all stand types, followed by food providing species in most cases, while resin and oil providing species do usually reach the smallest share. The respective graphs in Figure 6.5 illustrates further that DBH and top height of the NTFP trees always remained at the lower range of the stand, particularly in those stands where human impact has to be considered. The linear regressions between their DBHs and heights (Figure 6.5) showed the same trend like for the other trees (apart from those in DF in which the correlation was $\left.\mathrm{R}^{2}=0.87\right)$. 
The comparatively high potential supply of NTFP tree species for medicinal use in all explored forest types and elevations goes along with raised percentages (20 - 26\%) of medicinal species and their share in the numbers of stems, basal area and volume (15 - 24\%) (Table 6.4). It further reveals that the disturbed forests (DF) do provide the highest quantitative share of medicinal plants (around 24\%), followed by the less disturbed forest stands (LF with 17-18\%), while their share in the undisturbed forests (UF) is obviously smaller (around 15\%). This differences between the forest types did not result in differences between altitudes, apart from an elevated share of species numbers at higher elevations.

Table 6.3. The stand parameters and standard deviations of NTFP species in different forest types and elevations: (UF=undisturbed forest, $\mathrm{LF}=$ less disturbed forest, $\mathrm{DF}=$ disturbed forest) and elevations $(\mathrm{H} 1=150-699 \mathrm{~m}$ and $\mathrm{H} 2=700-1162 \mathrm{~m}$ above sea level). The same letter in the same row indicates no significant difference at $p<0.05$; highest, lowest and intermediate values are shaded respectively.

\begin{tabular}{|c|c|c|c|c|c|}
\hline Stand parameters & \multicolumn{3}{|c|}{ Forest types } & \multicolumn{2}{|c|}{ Elevations } \\
\hline Medicinal trees & UF & $\mathrm{LF}$ & $\mathrm{DF}$ & $\mathrm{H} 1$ & $\mathrm{H} 2$ \\
\hline No. plots $\left(1000 \mathrm{~m}^{2}\right)$ & 30 & 30 & 30 & 50 & 40 \\
\hline No. stems ha ${ }^{-1}$ & $92 \pm 4.4 a$ & $122.3 \pm 6.3 b$ & $117.7 \pm 4.9 b c$ & $120.2 \pm 4.8 \mathrm{a}$ & $98.7 \pm 5.8 \mathrm{a}$ \\
\hline Basal area $\mathrm{m}^{2} \mathrm{ha}^{-1}$ & $5.2 \pm 0.3 \mathrm{a}$ & $3.9 \pm 0.2 b$ & $3.8 \pm 0.2 b c$ & $4.0 \pm 0.2 \mathrm{a}$ & $4.7 \pm 0.2 \mathrm{a}$ \\
\hline Volume $\mathrm{m}^{3} \mathrm{ha}^{-1}$ & $54.2 \pm 2.8 \mathrm{a}$ & $35.6 \pm 2.2 b$ & $35.4 \pm 1.9 b c$ & $37.2 \pm 2.1 \mathrm{a}$ & $47.4 \pm 0.2 \mathrm{a}$ \\
\hline Species/plot & $4.9 \pm 1.7 \mathrm{a}$ & $6.6 \pm 2.3 b$ & $6.5 \pm 2.1 b c$ & $6.4 \pm 2.1 \mathrm{a}$ & $5.4 \pm 2.1 b$ \\
\hline Food providing trees & UF & LF & DF & $\mathrm{H} 1$ & $\mathrm{H} 2$ \\
\hline No. plots $\left(1000 \mathrm{~m}^{2}\right)$ & 29 & 30 & 29 & 49 & 39 \\
\hline No. stems ha ${ }^{-1}$ & $43.5 \pm 2.9 \mathrm{a}$ & $49.7 \pm 2.7 \mathrm{a}$ & $52.0 \pm 2.9 \mathrm{a}$ & $50.4 \pm 2.4 a$ & $44.5 \pm 3.1 \mathrm{a}$ \\
\hline Basal area $\mathrm{m}^{2} \mathrm{ha}^{-1}$ & $2.0 \pm 0.2 \mathrm{a}$ & $1.9 \pm 0.1 \mathrm{a}$ & $2.0 \pm 0.1 \mathrm{a}$ & $1.9 \pm 0.1 \mathrm{a}$ & $2.1 \pm 0.2 \mathrm{a}$ \\
\hline Volume $\mathrm{m}^{3} \mathrm{ha}^{-1}$ & $20.4 \pm 1.9 a$ & $17.8 \pm 1.3 \mathrm{a}$ & $18.8 \pm 1.5 \mathrm{a}$ & $17.3 \pm 1.3 \mathrm{a}$ & $21.0 \pm 1.9 \mathrm{a}$ \\
\hline Species/plot & $2.6 \pm 0.98 \mathrm{a}$ & $2.5 \pm 1.1 \mathrm{a}$ & $2.6 \pm 1.0 \mathrm{a}$ & $2.7 \pm 1.1 \mathrm{a}$ & $2.3 \pm 0.8 \mathrm{a}$ \\
\hline $\begin{array}{l}\text { Resin/oil providing } \\
\text { trees }\end{array}$ & UF & $\mathrm{LF}$ & $\mathrm{DF}$ & $\mathrm{H} 1$ & $\mathrm{H} 2$ \\
\hline No. plots $\left(1000 \mathrm{~m}^{2}\right)$ & 26 & 17 & 20 & 30 & 29 \\
\hline No. stems ha ${ }^{-1}$ & $30.4 \pm 1.3 a$ & $24.7 \pm 1.2 \mathrm{ab}$ & $19.5 \pm 1.2 b c$ & $27.7 \pm 1.4 \mathrm{a}$ & $26.5 \pm 1.3 \mathrm{a}$ \\
\hline Basal area $\mathrm{m}^{2} \mathrm{ha}^{-1}$ & $2.9 \pm 0.3 \mathrm{a}$ & $1.0 \pm 0.1 b$ & $0.6 \pm 0.1 b c$ & $1.1 \pm 0.1 \mathrm{a}$ & $2.4 \pm 0.3 b$ \\
\hline Volume $\mathrm{m}^{3} \mathrm{ha}^{-1}$ & $35.5 \pm 4.5 \mathrm{a}$ & $10.1 \pm 1.4 \mathrm{ab}$ & $5.4 \pm 0.7 b c$ & $11.4 \pm 1.5 \mathrm{a}$ & $29.7 \pm 4.3 b$ \\
\hline Species/plot & $1.5 \pm 0.7 \mathrm{a}$ & $1.5 \pm 0.6 \mathrm{a}$ & $1.6 \pm 0.6 \mathrm{a}$ & $1.5 \pm 0.6 \mathrm{a}$ & $1.6 \pm 0.6 \mathrm{a}$ \\
\hline
\end{tabular}


The potential supply of food from NTFP tree species which was found to be considerably smaller, did also concern their share. Their basal areas ranged between $6-12,6 \%$ of the entire stand while the volume of wood reached 5.6 $-12.5 \%$, both in ascending order $\mathrm{UF}<\mathrm{LF}<\mathrm{DF}$. However, the share of stems and species numbers did not differ (both around 10\%); neither could there be identified any substantial differences concerning the share of parameters at different altitudes. Similar coherences were also found with respect to the relatively low supply of resin or oil where the respective species contributed less than $10 \%$ to most of the measured stand parameters provided by 1-2 species per plot only which represented just around $6 \%$ of the species composition of the respective stands. For example: $19.5 \%$, the relative share between medical tree species in UF (Table 6.3) with the means of tree species per plot in UF (Table 6.1).

Table 6.4. The relative share $(\%)$ between NTFP tree species in different forest types and elevations with the means of those the entire forest stand: (UF=undisturbed forest, LF = less disturbed forest, $\mathrm{DF}=$ disturbed forest $)$ and elevations $(\mathrm{H} 1=150-699 \mathrm{~m}$ and $\mathrm{H} 2=700-1162 \mathrm{~m}$ above sea level).

\begin{tabular}{|c|c|c|c|c|c|}
\hline \multirow{2}{*}{$\begin{array}{l}\text { Stand parameters } \\
\text { Medicinal trees }\end{array}$} & \multicolumn{3}{|c|}{ Forest types } & \multicolumn{2}{|c|}{ Elevations } \\
\hline & UF & $\mathrm{LF}$ & DF & H1 & $\mathrm{H} 2$ \\
\hline No. plots $\left(1000 \mathrm{~m}^{2}\right)$ & 30 & 30 & 30 & 50 & 40 \\
\hline No. stems ha ${ }^{-1}(\%)$ & 19.0 & 24.4 & 23.8 & 22.8 & 23.8 \\
\hline Basal area $\mathrm{m}^{2} \mathrm{ha}^{-1}(\%)$ & 15.6 & 18.1 & 23.9 & 18.3 & 17.9 \\
\hline Volume $\mathrm{m}^{3} \mathrm{ha}^{-1}(\%)$ & 14.9 & 16.7 & 23.6 & 17.8 & 16.7 \\
\hline Species/plot (\%) & 19.5 & 24.1 & 25.7 & 21.5 & 26.7 \\
\hline Food providing trees & UF & $\mathrm{LF}$ & DF & H1 & $\mathrm{H} 2$ \\
\hline No. plots $\left(1000 \mathrm{~m}^{2}\right)$ & 29 & 30 & 29 & 49 & 39 \\
\hline No. stems ha-1(\%) & 9.0 & 10.4 & 10.5 & 9.6 & 10.7 \\
\hline Basal area $\mathrm{m}^{2} \mathrm{ha}^{-1}(\%)$ & 6.0 & 9.3 & 12.6 & 8.7 & 8.0 \\
\hline Volume $\mathrm{m}^{3} \mathrm{ha}^{-1}(\%)$ & 5.6 & 8.8 & 12.5 & 8.3 & 7.4 \\
\hline Species/plot (\%) & 10.4 & 9.5 & 10.3 & 9.1 & 11.4 \\
\hline Resin/oil providing trees & UF & $\mathrm{LF}$ & DF & H1 & $\mathrm{H} 2$ \\
\hline No. plots $\left(1000 \mathrm{~m}^{2}\right)$ & 26 & 17 & 20 & 30 & 29 \\
\hline No. stems ha-1(\%) & 6.3 & 4.9 & 3.9 & 5.3 & 6.4 \\
\hline Basal area $\mathrm{m}^{2} \mathrm{ha}^{-1}(\%)$ & 8.7 & 4.6 & 3.8 & 5.0 & 9.2 \\
\hline Volume $\mathrm{m}^{3} \mathrm{ha}^{-1}(\%)$ & 9.8 & 4.8 & 3.6 & 5.5 & 10.5 \\
\hline Species/plot (\%) & 6.0 & 5.5 & 6.3 & 5.1 & 7.9 \\
\hline
\end{tabular}


6.4.3. Importance and satisfaction ranking for natural forests and their provisioning services

The original data of the importance and satisfaction ranking are documented in the following Table 6.5.

Table 6.5. Ranking of the importance of natural forests and their provisioning services and of the satisfaction

with these services by the numbers of people in the different target groups.

\begin{tabular}{cccccccccccc}
\hline \multirow{2}{*}{$\begin{array}{c}\text { Target } \\
\text { groups }\end{array}$} & No. & \multicolumn{1}{c}{ Importance levels } & \multicolumn{7}{c}{ Satisfaction levels } \\
\cline { 2 - 12 } F & 73 & 1 & 3 & 6 & 7 & 56 & 8 & 19 & 15 & 17 & 14 \\
M & 47 & 0 & 1 & 4 & 8 & 34 & 4 & 14 & 8 & 3 & 18 \\
\hline In1 & 38 & 1 & 5 & 7 & 7 & 18 & 4 & 9 & 13 & 4 & 8 \\
In2 & 43 & 0 & 0 & 6 & 15 & 22 & 4 & 16 & 4 & 6 & 13 \\
In3 & 39 & 0 & 5 & 4 & 13 & 17 & 4 & 10 & 6 & 10 & 9 \\
\hline E1 & 60 & 0 & 7 & 12 & 17 & 24 & 6 & 19 & 15 & 10 & 10 \\
E2 & 39 & 1 & 2 & 6 & 7 & 23 & 4 & 11 & 6 & 7 & 11 \\
E3 & 21 & 0 & 1 & 3 & 7 & 10 & 4 & 4 & 3 & 4 & 6 \\
\hline A1 & 31 & 0 & 4 & 2 & 5 & 20 & 3 & 10 & 5 & 6 & 7 \\
A2 & 43 & 0 & 3 & 6 & 12 & 22 & 4 & 10 & 12 & 7 & 10 \\
A3 & 45 & 0 & 2 & 8 & 16 & 19 & 5 & 13 & 6 & 7 & 14 \\
\hline All (\%) & 120 & 0.6 & 6.9 & 13.64 & 23.8 & 55.3 & 10.4 & 28.2 & 19.4 & 17.0 & 25.0 \\
\hline
\end{tabular}

(No.= number of interviewees, gender: $\mathrm{F}=$ female; $\mathrm{M}=$ male; income levels: $\mathrm{In} 1=$ income level1 (<700.000VND/month), In2=income level2 (700.000-1 million VND/month), In3 = income level3 (1-1.5 million VND/month), education levels: E1=Primary school, E2=Secondary school, E3 = above secondary school, age groups: A1 $=18-29$ years old, $\mathrm{A} 2=30-39$ years old, $\mathrm{A} 3 \geq 40$ years old. Importance levels: 1 = slightly important, $2=$ moderately important, $3=$ rather important, $4=$ highly important, $5=$ essentially important; satisfaction levels: $1=$ slightly satisfied, $2=$ moderately satisfied, $3=$ sufficiently satisfied, $4=$ highly satisfied, 5= completely satisfied).

While the importance level can be taken as an indication for the respective demand, the satisfaction level indicates its fulfillment. In Figure 6.6 we combined the high importance levels 4 and 5 in each target group together. The overall assessment of the importance of the natural forests showed that $79.1 \%$ of all interviewees attributed the top levels (levels 4 and 5) to them, meaning that they considered natural forest as highly to essentially important for their lives. If, on the other hand, we take the highest satisfaction levels 4 and 5 as an indication for ecosystem services fulfillment, we see that those are much lower. Only $42 \%$ of all interviewees indicated that they 
were highly or completely satisfied. In particular people with low income and just basic education noted little satisfaction. Insofar the effective supply (which might also be influenced by accessibility) must be considered as insufficient.

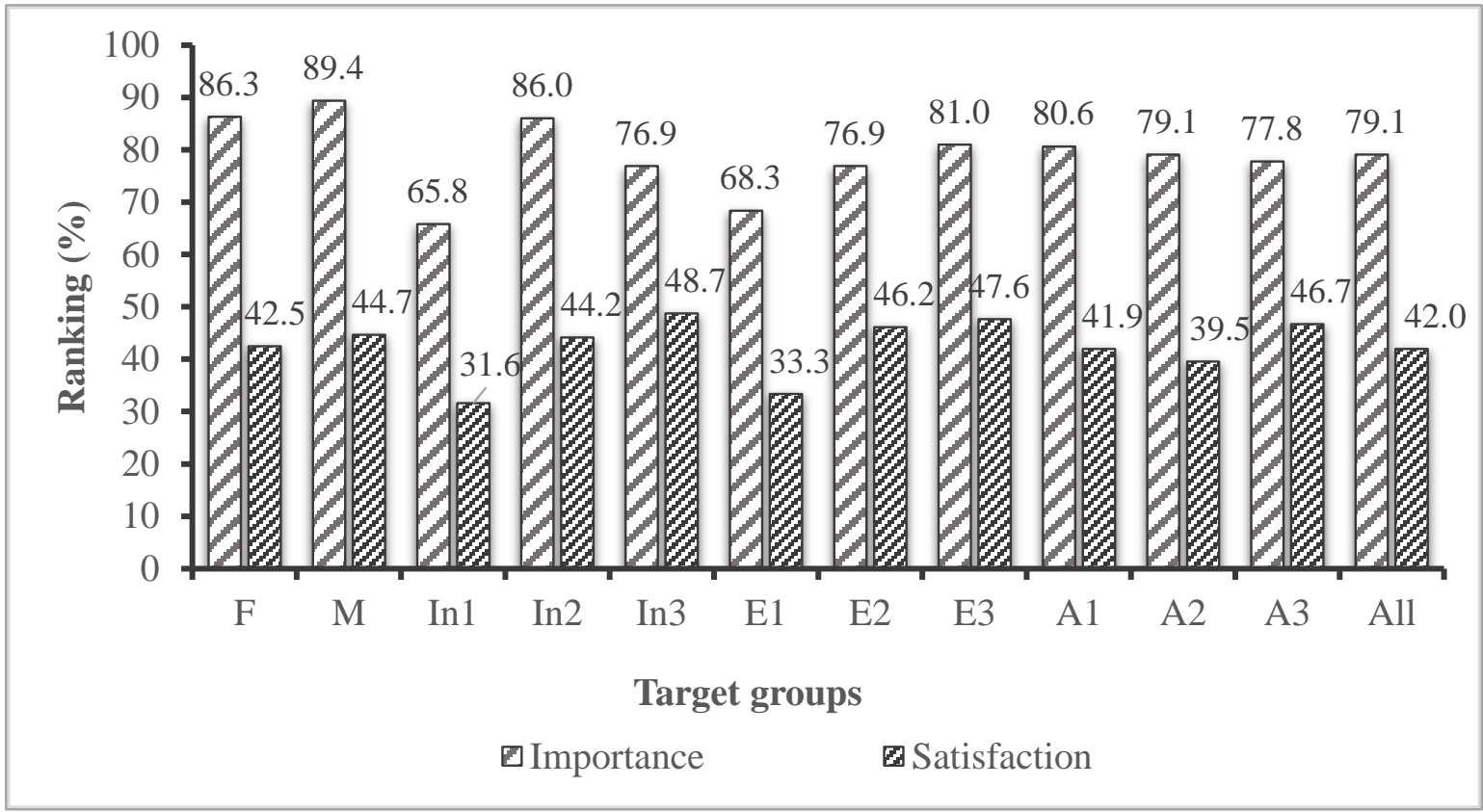

Figure 6.6. Percentages of people who gave high importance and satisfaction ranking (highly to essentially important and satisfied) of natural forests in different target groups: gender: $F=$ female; M=male; income levels: In1=income level1 (<700.000VND/month), In2=income level2 (700.0001 million VND/month), In3 = income level3 (1-1.5 million VND/month), education levels: E1=Primary school, E2=Secondary school, E3 = above secondary school, age groups: A1=1829 years old, $A 2=30-39$ years old, $A 3 \geq 40$ years old .

6.4.4. Identification of essential land-use options

The essential land-use options of different target groups show imbalances among groups and within each group itself (Table 6.6). 
Table 6.6. Identification of essential land use options by the percentage of people in different target groups.

\begin{tabular}{ccccccccc}
\multicolumn{3}{c}{$\begin{array}{c}\text { Percentages of people } \\
\text { in the respective target groups } \\
\text { (indicated by shading) }\end{array}$} & 1-20\% & $21-40 \%$ & $41-60 \%$ & $61-80 \%$ & $81-100 \%$ \\
\hline $\begin{array}{c}\text { Target } \\
\text { groups }\end{array}$ & No. & $\begin{array}{c}\text { Paddy } \\
\text { field }\end{array}$ & $\begin{array}{c}\text { Plantation } \\
\text { forest }\end{array}$ & $\begin{array}{c}\text { Fruit } \\
\text { trees }\end{array}$ & $\begin{array}{c}\text { Natural } \\
\text { forest }\end{array}$ & $\begin{array}{c}\text { Crop } \\
\text { land }\end{array}$ & $\begin{array}{c}\text { Fish } \\
\text { raising }\end{array}$ & $\begin{array}{c}\text { Grass } \\
\text { land }\end{array}$ \\
\hline F & 73 & 100.0 & 74.0 & 49.3 & 31.5 & 28.8 & 19.2 & 0.0 \\
\hline M & 47 & 95.7 & 80.9 & 40.4 & 21.3 & 25.5 & 36.2 & 0.0 \\
\hline In1 & 38 & 100.0 & 65.8 & 42.1 & 39.5 & 39.5 & 15.8 & 0.0 \\
\hline In2 & 43 & 100.0 & 79.1 & 46.5 & 32.6 & 25.6 & 30.2 & 0.0 \\
\hline In3 & 39 & 94.9 & 74.4 & 48.7 & 17.9 & 25.6 & 30.8 & 0.0 \\
\hline E1 & 60 & 100.0 & 78.3 & 50.0 & 41.7 & 36.7 & 23.3 & 0.0 \\
\hline E2 & 39 & 100.0 & 76.9 & 48.7 & 35.9 & 23.1 & 30.8 & 0.0 \\
\hline E3 & 21 & 85.7 & 61.1 & 33.3 & 22.2 & 27.8 & 27.8 & 0.0 \\
\hline A1 & 31 & 100.0 & 80.6 & 29.0 & 16.1 & 9.7 & 12.9 & 0.0 \\
\hline A2 & 43 & 100.0 & 74.4 & 51.2 & 46.5 & 44.2 & 30.2 & 0.0 \\
\hline A3 & 45 & 95.7 & 71.7 & 52.2 & 47.8 & 30.4 & 30.4 & 0.0 \\
\hline
\end{tabular}

(No.= number of interviewees, gender: $\mathrm{F}=$ female; $\mathrm{M}=$ male; income levels: $\mathrm{In} 1=$ income level1 (<700.000VND/month), In2=income level2 (700.000-1 million VND/month), In3 = income level3 (1-1.5 million VND/month), education levels: E1=Primary school, E2=Secondary school, E3 = above secondary school, age groups: $\mathrm{A} 1=18-29$ years old, $\mathrm{A} 2=30-39$ years old, $\mathrm{A} 3 \geq 40$ years old).

The identification of the essential land use practices in different target groups as presented in Table 6.6 provides further information with respect to the socio-economic relevance of the importance and satisfaction concerning natural forests and their provisioning services. It does demonstrate the relatively low ranking of the natural forest by the local people, usually at third and fourth, sometimes even at last position (16-18\% of the younger people and of people with high income respectively) compared to the other land use options. At least, the compliance increased with the age of the interviewees (A2 with 47\%; A3 with 48\%). In contrast, paddy fields were chosen at first position by most of all target groups ( 86 - 100\%, followed by plantation forests (61 
- $81 \%$ ) and fruit tree plantations (29 - 52\%). Cropland and fish raising gained the smallest number of votes from all groups, mostly between 20 and $40 \%$, in case of the younger generation even just 10 and $13 \%$ respectively.

\subsubsection{Personal involvement in extracting NTF goods}

To confirm the results of the importance ranking, another question addressed the factual personal involvement in the extraction of NTFPs as forest goods. Considering the different potential answers (yes $=\mathrm{Y} / \mathrm{no}=\mathrm{N}$ instead of ranking options 1-5) the respective results are integrated in Table 6.7. They reveal the very high personal involvement of 78,3\% of all interviewees in the extraction of forest goods ranging between $71.1 \%$ and $90.5 \%$ in the different target groups. Males and well-educated people were at top level (around 90\%) while people with lower education (E1) were the only who reported less personal involvement $(68.3 \%)$. These results do correspond to those of the importance ranking.

\subsubsection{Awareness of natural forest degradation and needs for restoration}

Local people's perceptions as presented in Table 6.7 consider natural forest degradations by landslides and the decline of goods supply resulting from extractions such as fuelwood and nontimber forest products. It further documents local people's agreement to restore the natural forests in the area to improve ecosystem provisioning services.

The results indicate the widespread and very high awareness of risks and the readiness for restoration measures in natural forests in all different target groups (close to 100\%). Both did slightly increase from elder to younger people. Women, young people, people with higher income and those with secondary school education confirmed a 100\% support for natural forest restoration. 
Table 6.7. Perceptions of human induced risks (landslides and decline of forest goods) and needs for natural forest restoration by different target groups (\%).

\begin{tabular}{|c|c|c|c|c|c|c|c|c|c|}
\hline \multirow{3}{*}{$\begin{array}{l}\text { Target } \\
\text { groups }\end{array}$} & \multicolumn{3}{|c|}{$\begin{array}{l}\text { Percentages of people } \\
\text { he respective target groups } \\
\text { (indicated by shading) }\end{array}$} & \multicolumn{2}{|c|}{$1-20 \%$} & \multicolumn{2}{|l|}{$21-40 \%$} & $61-80 \%$ & $81-100 \%$ \\
\hline & \multirow[t]{2}{*}{ No. } & \multicolumn{2}{|c|}{$\begin{array}{l}\text { Personal } \\
\text { involvement in } \\
\text { extracting forest } \\
\text { goods }\end{array}$} & \multicolumn{2}{|c|}{$\begin{array}{l}\text { Perception of } \\
\text { landslide } \\
\text { observation }\end{array}$} & \multicolumn{2}{|c|}{$\begin{array}{l}\text { Perception of } \\
\text { forest goods } \\
\text { declined }\end{array}$} & \multicolumn{2}{|c|}{$\begin{array}{l}\text { Perception of } \\
\text { needs for natural } \\
\text { forest restoration }\end{array}$} \\
\hline & & $\mathrm{Y}$ & $\mathrm{N}$ & $\mathrm{Y}$ & $\mathrm{N}$ & $\mathrm{Y}$ & $\mathrm{N}$ & $\mathrm{Y}$ & $\mathrm{N}$ \\
\hline $\mathrm{F}$ & 73 & 71.2 & 28.8 & 97.3 & 2.7 & 98.6 & 1.4 & 100.0 & 0.0 \\
\hline M & 47 & 89.4 & 10.6 & 100.0 & 0.0 & 100.0 & 0.0 & 97.9 & 2.1 \\
\hline In 1 & 38 & 71.1 & 28.9 & 100.0 & 0.0 & 97.4 & 2.6 & 94.7 & 5.3 \\
\hline $\operatorname{In} 2$ & 43 & 83.7 & 16.3 & 97.7 & 2.3 & 100.0 & 0.0 & 95.3 & 4.7 \\
\hline In3 & 39 & 79.5 & 20.5 & 97.4 & 2.6 & 100.0 & 0.0 & 100.0 & 0.0 \\
\hline E1 & 60 & 68.3 & 31.7 & 98.3 & 1.7 & 98.3 & 1.7 & 93.3 & 6.7 \\
\hline E2 & 39 & 87.2 & 12.8 & 97.4 & 2.6 & 100.0 & 0.0 & 100.0 & 0.0 \\
\hline E3 & 21 & 90.5 & 9.5 & 90.5 & 9.5 & 100.0 & 4.8 & 100.0 & 4.8 \\
\hline A1 & 31 & 80.6 & 19.4 & 100.0 & 0.0 & 100.0 & 0.0 & 100.0 & 0.0 \\
\hline $\mathrm{A} 2$ & 43 & 79.1 & 20.9 & 97.7 & 2.3 & 100.0 & 0.0 & 97.7 & 2.3 \\
\hline A3 & 45 & 73.9 & 23.9 & 95.7 & 2.2 & 95.7 & 2.2 & 91.3 & 6.5 \\
\hline All & 120 & 78.3 & 21.7 & 98.3 & 1.7 & 99.2 & 0.8 & 96.7 & 3.3 \\
\hline
\end{tabular}

( $\mathrm{Y}=$ yes, $\mathrm{N}=$ no; gender: $\mathrm{F}=$ female; $\mathrm{M}=$ male; income levels: $\mathrm{In} 1=$ income level1 (<700.000VND/month), In2=income level2 (700.000-1 million VND/month), In3 = income level3 (1-1.5 million VND/month), education levels: E1=Primary school, E2=Secondary school, E3 = above secondary school, age groups: A1 $=18-29$ years old, $\mathrm{A} 2=30-39$ years old, A3 $\geq 40$ years old).

\subsection{Discussions}

6.5.1. Characteristics of the natural forest stand structures confirm different intensities of human disturbances

The analysis of the present natural forest stand structure confirmed the initial classification of the forest stands as undisturbed (UF), less disturbed (LF), and disturbed (DF) forests. It revealed a number of indications for former human disturbances and ongoing successional process in the natural forests. Those comprised smaller DBHs and top heights but slightly increased numbers of stems per ha, resulting in respectively lowered stand basal area and stand volume in LF and DF 
compared to UF as well as $\mathrm{H} 1$ compared to $\mathrm{H} 2$. It is obvious that forests in the more disturbed and lower elevations had lower means for basal area and volume $\mathrm{ha}^{-1}$ and that the elevations have more influences on forest parameters (Table 6.1). A cumulation of smaller diameter classes in disturbed stands has been reported repeatedly as a usual successional process where young trees regenerate in gaps of the old stands [121-124]. This may favor light demanding NTFP tree species in the more disturbed stands. Meanwhile, the species numbers per plot did not provide clear evidence of human impact. Differences in species composition might do so but have not been analyzed.

\subsubsection{High demand but insufficient supply of NTFPs}

The final assessment of the supply and demand concerning NTFPs as forest provisioning services should consider all relevant aspects which have been presented in section $5.1-5.2 .2$. The assessment concerning NTFPs as forest provisioning services confirmed that there is high demand of NTFPs but not sufficient provision and do limit benefits for local people. We decided to do this in a narrative and qualitative way rather than to use a formal quantitative aggregation in order to better incorporate group specific considerations which otherwise might have been missed.

\subsubsection{Considerable potential supply from medical tree species}

In addition to firewood, NTFPs were always very important for local people who extracted parts of the respective species for different purposes to improve their well-being [125] especially, many parts of the medical tree species are used as antibiotics, antiseptics, or to stop bleeding while other parts are collected and processed through pharmaceutical steps to produce drugs. Such biological materials may provide an average of $22 \%$ of the total income in developing countries [126]. Identification of tree species which were registered in the inventory and known to provide NTFPs referring to local knowledge and scientific publications was an outstanding measure [51], this was the case for 32\% (39 out of an overall 122 trees species). Most of them (21\%) were known for medicinal use, compared to just $7 \%$ for food and $5 \%$ for resin or oil (Table 6.2). For the quantitative assessment of the potential NTFPs supply, we then used classical structural stand parameters of the respective tree species as indicators. Since the analysis of the specific stand structures confirmed different intensities of human impact and disturbance, the interpretation of the results should take the less and undisturbed stands (UF and H2) as reference. 
All in all, we only found a considerable potential quantitative and qualitative supply of NTFP tree species for medicinal use, going along with raised absolute species numbers and their share in species composition, leaving that one for food and resin/oil clearly behind. This supply was significantly higher in the undisturbed stands (UF) and at higher elevations (H2), where the number of stems was lower but with higher basal area and consequently increased volume of wood. The same trend could be observed with respect to the food providing tree species, but not as clearly as for the medicine providers. Resin and oil provisioning species also reached the highest basal area and volume in the undisturbed forests (UF) and at higher elevations (H2). These results indicate the natural supply of the respective NTFP that can be expected in the undisturbed and unmanaged forest stands. However, the top heights and DBHs of the respective trees were always considerably smaller than those of the rest of the forest stands (Figure 6.5).

Meanwhile, the highest share of medicinal tree species (around 24\% for all considered parameters) was provided in the disturbed forest stands (DF), followed by the less disturbed ones (LF with 17-18\%), while their share in the undisturbed forests (UF) was considerably smaller (around 15\%). The share of food providing tree species had the same gradation (DF $>\mathrm{LF}<\mathrm{UF}$ ) but was found to be clearly smaller (around 10\% and little higher). The lowest quantitative share (less than $10 \%$ ) was offered by resin and oil providing tree species, but in contrast to medicinal and food options, in reversed order (UF $>\mathrm{LF}>\mathrm{DF}$ and $\mathrm{H} 2>\mathrm{H} 1)$. DBH and top height of the NTFP trees always remained at the lower range of the stand, particularly where human impact had to be considered (Table 6.4). So, we may conclude that the share of NTFP trees has been increased due to human impact, but has not reached the quantities that can be reached in the undisturbed forests. However, the results of the demand assessment will demonstrate that the current status quo of supply must be considered as insufficient.

\subsubsection{Unsatisfied demand for NTFP}

This assessment considered four different qualitative aspects based on personal statements of the local people from different target groups (i.e. gender, age, income and education): (i) The importance of the natural forests (and their NTFP supply) for their wellbeing; and (ii) their satisfaction with the respective supply, both given in a five-ary ranking system; as well as (iii) 
their personal involvement in extracting these goods from the forest and (iv) the relevance of seven usual land use practices for them, including the natural forests, both either confirmed or denied.

At least two thirds of the people in all target groups assigned high to very high importance to the natural forests, but only a maximum of $48.7 \%$ did the same concerning their satisfaction with the NTFP supply (Figure 6.6). Insofar the natural forests do not provide enough goods to meet their demands, although more than two third did also confirm their personal involvement in extracting non-timber forest goods, particularly men, well-educated and younger people (Table 6.7). Consequently, the natural forest was mentioned as essential land use practice by less than $40 \%$ of the people in most target groups. Particularly the younger ones and those with higher income who did not have to rely on them did not mention the natural forest to be particularly relevant for them (Table 6.6). Other land use options are obviously more attractive. The paddy fields for rice cultivation in mountainous regions are usually small but provide enough rice to feed local people. Thus, paddy fields gathered most people's first choice. The lowest confirmation of their relevance was given by people with higher income (85.7\%) as presented in Table 6.6. Forest plantations of fast-growing species with Acacia spp, Eucalyptus spp, and Hevea brasiliensis and fruit trees such as oranges, mandarins, and mango are more profitable and may bring quick income. In most target groups their high relevance was attested by more than $70 \%$ and more than $40 \%$ of the respondents respectively.

Cropland was mentioned to be essential by smaller numbers of respondents than the natural forest because this type of land use is lower-ranking in the entire area. Grassland is usually not practiced at all because pasturing in natural forests as well as in plantation forests was always a free habit. Finally, fish raising is not popular since most of the water areas are not suitable for it. The rivers in the area are small and can fall dry during the dry season. If ever, this practice is only cultivated by households whose house locates nearby a river, small irrigation systems, or small artificial dams.

The choice of particularly relevant land-use practices also reflects some group specific land use attitudes: Women in the ethnic groups commonly take the responsibility for food and economic concerns of the households. Apart from plantation forests and fish raising they chose all cultivation 
practices to be essential more often than men did including natural forests. The study of Tyagi [127] found further that women are closer to nature than men; and Byers and Sainju [128] stated that women are more knowledgeable about local plants.

Nonetheless, men spend more time and effort to extract and collect forest goods. They ranked natural forests of slightly higher importance and satisfaction than women did, but they also preferred natural forests less often and plantations more often than women because they think that the latter provide faster income. This is especially the case if they planted fast-growing tree species being aware that the timber from natural forests is currently not reachable due to the logging ban [17].

Although they admitted the high importance of natural forests, the younger people rarely mentioned themselves to be particularly relevant for natural forests (16\%). A very high percentage of them rather mentioned paddy fields and plantation forests (100\% and $81 \%$ respectively), followed by far less who also chose fruit trees (29\%). Cropland and fish raising gained even less reference $(<20 \%)$. In contrast, people of higher age demonstrated their bond and dependence concerning the natural forests the most (around 48\%). These results demonstrate, that their specific socio-economic conditions have to be considered when it comes to choose appropriate partners for cooperation in forest management.

6.5.3. Local people evince high awareness of risks and needs for natural forest restoration

Many studies have been conducted with the aim of assessing the awareness and knowledge of local people to develop optimal management guidelines for users of NTFPs [61]. The perceptions of landslides and of the declination of forest goods availability in the presented study testifies to a very high and widespread awareness of risks (>95\%) which led to respectively high agreement with the needs for natural forest restoration (>90\%) in all target groups. This awareness and agreement indicate that local people do evince the natural risks and accept for natural forest restoration. This should be taken as fortunate precondition and used as a chance for respective forest management measures in collaboration and participation of local people at all stages of planning and decision-making to improve the sustainability of livelihoods of local people as suggested by Wong 2000 [62], Stiglitz 2002 [64] and Carter 1996 [51]. The "getting back process" 
can be assessed at national or sub-national levels, and scopes of perceptions and potentials [39]. Many researchers have also recommended engaging the collaboration and participation of local people at all stages of planning and decision-making to improve the sustainability of their livelihoods $[51,62,64]$. Gathering different views and priorities promotes feasible interventions, including strategies such as constitutional and institutional addresses [129]. Choosing the appropriate options and consistent alternatives for a compromised strategic alignment is challenging; but scientific and technical perspectives can lead to better decision-making by taking into account results of needs assessments [130]. Indigenous and traditional knowledge is very important and contributes to sustainable forest management and the provision of ecosystem services based on awareness [131].

\subsection{Conclusions}

If well managed, these biological resources can also contribute considerably to the household income. Based on indigenous knowledge and beliefs, many parts of medicinal tree species have been used by local people for ages. Still today these species are very important to people while working and living in the forests, where drugs are not always accessible. Insofar, medicinal tree species can diversify the pharmaceutical biological sources in either traditional or non-traditional treatments. Thus, their systematic and sustainable use might be an option to provide income for the local people. As our assessment revealed, the quantitative supply of NTFP in undisturbed forests may be bigger than in managed ones. Hence, the respective tree species could and should be integrated and supported by appropriate measures of silviculture, including the provision of planting material.

The involvement of local people at all stages of inventory, assessment and improvement of NTFP supply can also help to improve the sustainability of local livelihoods. Without this step people would usually not accept the decisions over the long term. The "getting back process" assessment at different scopes of perceptions, and potentials from national or sub-national levels should be considered. With this assessment approach, local people would find "trust" to reveal their witness, involvement, and aspirations toward improvement of natural resources and participation to forest restoration process. 
The involvement of various stakeholders in decision-making based on mutual understanding of opportunities despite differing perspectives is important as fundamental input to the national strategies of forest landscape restoration. The management and recovery of natural forests can be the first-level priority in this process of landscape restoration. It also enforces disaster risk mitigation. The enrichment of non-timber forest products can be the second priority.

However, this restoration will be a long-term process of recalling the functioning of ecosystems and their multiple services from the deforested or degraded forest landscapes while magnifying the benefits and well-being of the local people. It also needs to balance the supply and demand concerning provisioning services in a given population area. The presented evaluation might help to identify the respective opportunities and priorities.

Acknowledgement: We would like to express our thanks to the German Academic Exchange Service (DAAD); The German Research Foundation and the Open Access Fund of the Göttingen University for funding this research and publication; the Department of Climate Change under the Ministry of Natural Resource and Environment of Vietnam; the University of Hue Agriculture and Forestry for their help in arranging administrative permission to access the research areas; the experts of Sub-Forest Inventory and Forest Planning in Thua Thien Hue province; We thank the forest experts of Forest Management Board of the A Luoi and Rangers of Sao La Nature Reserve for their assistance during different phases of fieldwork; the botanists for tree species identification; and local authorities, experts and local people in the A Luoi District. We thank the Department of Cartography, GIS, and Remote Sensing, Göttingen University for providing the ArcGIS software in the framework of research. We especially thank editors and reviewers for constructive comments for publication.

Author Contribution: Conceptualization, data curation; writing original draft the manuscript, methodology and formal analyzed (H.N.T); Supervision, Reviewing and Editing the manuscript; validation; visualization (M.K); Concept and structure editing, Investigation and Visualization (R.B.A). All authors have read and agreed to the published version of the manuscript. 
Funding: The research is funded by German Academic Exchange Service (DAAD - 91612843); The German Research Foundation and the Open Access Fund of the Göttingen University for funding this research and publication.

Declaration of Competing Interest: The authors declare no conflict of interes.

6.7. Reference

1. Thai, V. Forest vegetation cover of Vietnam, 2nd ed; Science and Technics Publishing House: Ha Noi, 1978.

2. Thai, V. Ecosystems of tropical forests in Vietnam; Science and Technics Publishing House: Ha Noi, 1998.

3. Park, C.C. Tropical rainforests; Routledge: New York, 2003.

4. Mertz, O.; Wadley, R.L.; Nielsen, U.; Bruun, T.B.; Colfer, C.J.P.; Neergaard, A. de; Jepsen, M.R.; Martinussen, T.; Zhao, Q.; Noweg, G.T. A fresh look at shifting cultivation: fallow length an uncertain indicator of productivity. Agricultural Systems 2008, 96, 75-84.

5. Lung, T.; Schaab, G. A comparative assessment of land cover dynamics of three protected forest areas in tropical eastern Africa. Environmental monitoring and assessment 2010, 161, 531-548.

6. Jong, W. de; Sam, D.D.; van Hung, T. Forest Rehabilitation in Vietnam: Histories, realities and future; Harapan Prima: Jakarta, Indonesia, 2006.

7. MARD, Ed. Forest area classified based functions of Vietnam; MARD: Hanoi, 2017.

8. Do, D.S. Shifting cultivation in Vietnam: its social, economic and environmental values relative to alternative land use; lied, 1994.

9. Tuynh, V.H.; Phuong, P.X. Impacts and effectiveness of logging bans in natural forests: vietnam. Forests out of bounds 2001, 185.

10. GoV, Ed. National Forest Strategy for the period 2006-2020, 18th ed: Hanoi, 2007.

11. Trieu, V.; Pham, T.; Dao Thi, L. Report on Results of Vietnam's National Forestry Development Strategy 2006-2020 and Proposals for Forest Development 2021-2030 vision to 2050; Center for International Forestry Research (CIFOR), 2020.

12. Khuc, V.Q.; Tran, B.Q.; Meyfroidt, P.; Paschke, M.W. Drivers of deforestation and forest degradation in Vietnam: An exploratory analysis at the national level. Forest Policy and Economics 2018, 90, 128-141.

13. José, J.C.A., Ed. Forests, inclusive and sustainable economic growth and employment, 2019.

14. Nugroho, H.Y.S.H.; van der Veen, A.; Skidmore, A.K.; Hussin, Y.A. Expansion of traditional land-use and deforestation: a case study of an adat forest in the Kandilo Subwatershed, East Kalimantan, Indonesia. J. For. Res. 2018, 29, 495-513. 
15. Angelsen, A. Shifting cultivation and "deforestation": A study from Indonesia. World Development 1995, 23, 1713-1729.

16. Sunderlin, W.D.; Ba, H.T. Poverty alleviation and forests in Vietnam; CIFOR: Jakarta, 2005.

17. GoV, Ed. Announcement on implementing conclusions of Prime Minister at the national conference on increasing forest management, protection and measures for the near future; Government Office: Hanoi, 2017.

18. GoV, Ed. Promulgating the regulation production forest management: Hanoi, 2016.

19. GoV, Ed. On the benefits and obligations of households and individuals assigned, leased or contracted forests and forestry land; Government: Hanoi, 2001.

20. Wetterwald, O.; Zingerli, C.; Sorg, J.-P. Non-timber Forest Products in Nam Dong District, Central Vietnam: Ecological and Economic Prospects. Schweizerische Zeitschrift fur Forstwesen 2004, 155, 45-52.

21. Saha, D.; Sundriyal, R.C. Utilization of non-timber forest products in humid tropics: Implications for management and livelihood. Forest Policy and Economics 2012, 14, 28-40.

22. Costanza, R.; Daly, H.E. Natural capital and sustainable development. Conservation Biology 1992, 6, 37-46.

23. Costanza, R.; d'Arge, R.; Groot, R. de; Farber, S.; Grasso, M.; Hannon, B.; Limburg, K.; Naeem, S.; O'neill, R.V.; Paruelo, J. The value of the world's ecosystem services and natural capital. Nature 1997, 387, 253-260.

24. Daily, G.C. Nature's services: Societal Dependence on Natural Ecosystems; Island Press, Washington, DC, 1997.

25. Millennium Ecosystem Assessment. Ecosystems and human well-being; Island Press: Washington, Covelo, London, 2005.

26. Haines-Young, R.; Potschin, M. The links between biodiversity, ecosystem services and human well-being. Ecosystem Ecology: a new synthesis 2010, 1, 110-139.

27. Albert, C.; Bonn, A.; Burkhard, B.; Daube, S.; Dietrich, K.; Engels, B.; Frommer, J.; Götzl, M.; Grêt-Regamey, A.; Job-Hoben, B.; et al. Towards a national set of ecosystem service indicators: Insights from Germany. Ecological Indicators 2015, 61, 38-48.

28. Maes, J.; Teller, A.; Erhard, M.; Liquete, C.; Braat, L.; Berry, P.; Egoh, B.; Puydarrieux, P.; Fiorina, C.; Santos, F. Mapping and Assessment of Ecosystems and their Services. An analytical framework for ecosystem assessments under action 2013, 5, 1-58.

29. Burkhard, B.; Maes, J. Mapping Ecosystem Services; Pensoft Publishers, 2017.

30. Al-Qubatee, W.; Ritzema, H.; Al-Weshali, A.; van Steenbergen, F.; Hellegers, P.J.G.J. Participatory rural appraisal to assess groundwater resources in Al-Mujaylis, Tihama Coastal Plain, Yemen. Water International 2017, 42, 810-830.

31. Jones, M. The European landscape convention and the question of public participation. Landscape Research 2007, 32, 613-633. 
32. Selman, P.H. Sustainable landscape planning: The reconnection agenda; Routledge: Milton Park, Abingdon, Oxon, 2012.

33. Hartnett, T. Consensus-oriented decision-making: The CODM model for facilitating groups to widespread agreement; New Society; Gazelle: Philadelphia, Pa., Lancaster, 2011.

34. Calderon, C.; Butler, A. Politicising the landscape: a theoretical contribution towards the development of participation in landscape planning. Landscape Research 2019, 36, 1-12.

35. Masozera, M.K.; Alavalapati, J.R.R. Forest Dependency and its Implications for Protected Areas Management: A Case Study from the Nyungwe Forest Reserve, Rwanda. Scandinavian Journal of Forest Research 2004, 19, 85-92.

36. Mansourian, S.; Dudley, N.; Vallauri, D. Forest Landscape Restoration: Progress in the Last Decade and Remaining Challenges. Ecological Rest. 2017, 35, 281-288.

37. Uprety, Y.; Poudel, R.C.; Gurung, J.; Chettri, N.; Chaudhary, R.P. Traditional use and management of NTFPs in Kangchenjunga Landscape: implications for conservation and livelihoods. Journal of ethnobiology and ethnomedicine 2016, 12, 19.

38. Lawrence, A. No forest without timber? int. forest. rev. 2003, 5, 87-96.

39. IUCN and WRI. A guide to the restoration opportunities assessment methodology (ROAM): assessing forest landscape restoration opportunities at the national or sub-national level. IUCN, Gland, Switzerland 2014.

40. Sikor, T.; Truong, D.M. Agricultural policy and land use changes in a Black Thai commune of northern Vietnam, 1952-1997. Mountain Research and Development 2002, 22, 248-255.

41. Averyanov, L.V.; Loc, P.K.; Hiep, N.T.; Harder, D.K. Phytogeographic review of Vietnam and adjacent areas of Eastern Indochina. Komarovia 2003, 3, 1-83.

42. Mai, D.T.; Thanh, N.T. Precipitation extremes over Vietnam: 5th International Scientific Conference on the Global Energy and Water Cycle: Orange County, USA, 2005.

43. Nguyen Trong, H.; Nguyen, T.D.; Kappas, M. Land Cover and Forest Type Classification by Values of Vegetation Indices and Forest Structure of Tropical Lowland Forests in Central Vietnam. International Journal of Forestry Research 2020, 2020, 1-18.

44. Averyanov, L.; Phan, L.; Nguyen, H.; Nguyen, V.; Pham, T.; Do, D.; Thao, V.; Tran, M.; Ngo, T.; Duong, V.; et al. Lowland flora and vegetation preliminary survey, Part 1: Green Corridor Project in Thua Thien Hue Province, 2005.

45. Le, N. Adding some vascular plants to the list of plants in Thua Thien Hue Province. Journal of Research and Development 2016, 4, 96-107.

46. Phuong, V.T.; Anh, H.V.; Lung, N.N.; Sam, D.D.; Ky, N.D.; Lien, T.V. Forest ecological stratification in Vietnam. Techniques and Science Publishing House, Hanoi, Vietnam 2012, 139.

47. Bui, M.H. Structure and restoration of natural secondary forests in the Central Highlands, Vietnam,. Ph.D Dissertation: TU Dresend, 2016. 
48. Thua Thien Hue People's Committee, Ed. Land Use Planning Report of A Luoi District; People's Committee: Thua Thien Hue, 2016.

49. Hue, T.T., Ed. Statistical Yearbook; Thua Thien Hue Statistics Office: Hue, 2015.

50. A Luoi Statistics Office, Ed. Statistical Yearbook 2017; Statistics Office: A Luoi, 2018.

51. Carter, J. Recent approaches to participatory forest resource assessment; Overseas Development Institute (ODI): London, UK, 1996.

52. MARD, Ed. Circular 33/2018/TT-BNNPTNT on Regulation on Forest Inventory and Monitoring; MARD: Hanoi, 2018.

53. Trong, H.N.; Gia, T.P.; Kappas, M. Evaluating the Influence of Topography on Species Diversity, Distribution and Composition of Forests in Central Vietnam. Indian Journal of Science and Technology 2019, 12, 1-7.

54.Sader, S.A.; Waide, R.B.; Lawrence, W.T.; Joyce, A.T. Tropical forest biomass and successional age class relationships to a vegetation index derived from landsat TM data. Remote Sensing of Environment 1989, 28, 143-198.

55. Nguyen, T.; Tran, H. Namina Vernacula plantarum silvaticarum Vietnamicarum: Tên cây rùng Việt Nam; Agriculture Publishing House: Hanoi., 1971.

56. Kalwij, J.M. Review of 'The Plant List, a working list of all plant species'. Journal of Vegetation Science 2012, 23, 998-1002.

57. Laar, V.A.; Akça, A. Forest Mensuration; Springer: Dordrecht, 2007.

58. Tran, H.; Shigeru IIDA; Inoue S. Species Composition, Diversity and Structure of Secondary Tropical Forests Following Selective Logging in Huong Son, Ha Tinh Province, Vietnam. Journal of the Faculty of Agriculture - Kyushu University 2005, 50, 551-571.

59. Kershaw, J.A.; Ducey, M.J.; Beers, T.W.; Husch, B. Forest Mensuration; John Wiley \& Sons, Ltd: Chichester, UK, 2016, 592.

60. Whitmore, T.C.; Burnham, C.P. Tropical rain forests of the Far East, 2nd ed; Clarendon: Oxford, 1984.

61. Bih, F. Assessments Methods for Non-timber Forest Products in Off-reserve Forests: Case Study of Goaso District, Ghana; Citeseer, 2006.

62. Wong, J.L.G. The biometrics of non-timber forest product resource assessment: a review of current methodology; DFID, 2000.

63. Martin, G.J. Ethnobotany; Springer US: Boston, MA, 1995.

64. Stiglitz, J.E. Participation and Development: Perspectives from the Comprehensive Development Paradigm. Rev Development Economics 2002, 6, 163-182.

65. Richards, D.R.; Warren, P.H.; Maltby, L.; Moggridge, H.L. Awareness of greater numbers of ecosystem services affects preferences for floodplain management. Ecosystem Services 2017, $24,138-146$. 
66. Young, J.C.; Rose, D.C.; Mumby, H.S.; Benitez-Capistros, F.; Derrick, C.J.; Finch, T.; Garcia, C.; Home, C.; Marwaha, E.; Morgans, C.; et al. A methodological guide to using and reporting on interviews in conservation science research. Methods Ecol Evol 2018, 9, 10-19.

67. Freya V.; Keane, A.M.; Jones, Julia, P. G.; Milner-Gulland, E.J. Robust study design is as important on the social as it is on the ecological side of applied ecological research. $J$ Appl Ecol 2014, 51, 1479-1485.

68. Ryan, T.P. Sample size determination and power; John Wiley \& Sons, 2013.

69. Asaduzzaman, M.; Salma, U.; Ali, H.S.; Hamid, M.A.; Miah, A.G. Problems and prospects of turkey (Meleagris gallopavo) production in Bangladesh. Research in Agriculture Livestock and Fisheries 2017, 4, 77-90.

70. Forman, E.; Peniwati, K. Aggregating individual judgments and priorities with the analytic hierarchy process. European Journal of Operational Research 1998, 108, 165-169.

71. Muthumperumal, C.; Stalin, N.; Das, A.; Swamy, P.S. Chemical profiling of leaf essential oil, Antioxidant potential and Antibacterial activity of Syzygium lanceolatum (Lam.) Wt. \& Arn. (Myrtaceae). Free Radicals \& Antioxidants 2016, 6.

72. Castillo, C. The archaeobotany of Khao Sam Kaeo and Phu Khao Thong: the agriculture of late prehistoric southern Thailand. Doctoral thesis, 2013.

73. Phengklai, C. A synoptic account of the Fagaceae of Thailand. Thai Forest Bulletin (Botany) 2006, 53-175.

74. Sang, D.T.; Ogata, K.; Mizoue, N. Use of edible forest plants among indigenous ethnic minorities in Cat Tien Biosphere Reserve, Vietnam. Asian Journal of Biodiversity 2012, 3.

75.Zhang, X.; Ye, W.-H.; Cao, H.-L.; Wang, Z.-F.; Shen, H.; Lian, J.-Y. Isolation and characterization of microsatellites in Chinese white olive (Canarium album) and cross-species amplification in Canarium pimela. Conservation genetics 2009, 10, 1833.

76. Wittmann, N.; Hoang, H.T.; Hung, L.T.; Pistorius, T.; Roth, M. Silvicultural Studyfor Coastal Restoration in Vietnam: Freiburg, 2019.

77. Aryal, K.P.; Poudel, S.; Chaudhary, R.P.; Chettri, N.; Chaudhary, P.; Ning, W.; Kotru, R. Diversity and use of wild and non-cultivated edible plants in the Western Himalaya. Journal of ethnobiology and ethnomedicine 2018, 14, 10.

78.Zhang, Y.; Di Long; Wang, J.; Li, Q.; Wang, Z.; Lin, W.; Yuan, G. Morphological and molecular identification of Colletotrichum siamense, a novel leaf pathogen associated with Sterculia lanceolata recorded in China. J Phytopathol 2020, 168, 451-459.

79. Wu, J.; Fang, X.; Yuan, Y.; Dong, Y.; Liang, Y.; Xie, Q.; Ban, J.; Chen, Y.; Lv, Z. UPLC/QTOF-MS profiling of phenolics from Canarium pimela leaves and its vasorelaxant and antioxidant activities. Revista Brasileira de Farmacognosia 2017, 27, 716-723.

80. Hong, D.T.H. Threatened Tree Species Across Conservation Zones in a Nature Reserve of North-western Vietnam. PhD Thesis, 2017. 
81. Lim, T.K. Edible Medicinal and Non-Medicinal Plants 2013.

82. Tran, V.D.; Osawa, A.; Nguyen, T.T. Recovery of Vegetation Structure and Species Diversity after Shifting Cultivation in Northwestern Vietnam, with Special Reference to Commercially Valuable Tree Species. ISRN Ecology 2011, 2011, 1-12.

83. Wiart, C. Medicinal plants of Asia and the Pacific; CRC/Taylor \& Francis: Boca Raton, 2006. 84. Kamle, M.; Mahato, D.K.; Lee, K.E.; Bajpai, V.K.; Gajurel, P.R.; Gu, K.S.; Kumar, P. Ethnopharmacological Properties and Medicinal Uses of Litsea cubeba. Plants (Basel, Switzerland) 2019, 8 .

85. Sam, H.V. Indigenous knowledge of Muong and Dao ethnic minority groups on medicinal plants in Ba Vi National Park, Vietnam. Ha Noi: Rufford Small Grants program 2010.

86. Sam, V.H. Uses and conservation of plant diversity in Ben En National Park, Viet Nam, 2009.

87. Thin, N.N. The vegetation of Cucphuong national park, Vietnam. SIDA, Contributions to Botany 1997, 719-759.

88. Ito, C.; Kondo, Y.; Wu, T.S.; Furukawa, H. Chemical constituents of Glycosmis citrifolia (Willd.) Lindl. Structures of four new acridones and three new quinolone alkaloids. Chemical \& pharmaceutical bulletin 2000, 48, 65-70.

89. Guan, Y.; Wang, D.; Tan, G.T.; van Hung, N.; Cuong, N.M.; Pezzuto, J.M.; Fong, H.H.S.; Soejarto, D.D.; Zhang, H. Litsea Species as Potential Antiviral Plant Sources. The American journal of Chinese medicine 2016, 44, 275-290.

90. Hoang, V.D.; Tan, G.T.; Zhang, H.-J.; Tamez, P.A.; van Hung, N.; Cuong, N.M.; Soejarto, D.; Fong, H.H.; Pezzuto, J.M. Natural anti-HIV agents—part I: (+)-demethoxyepiexcelsin and verticillatol from Litsea verticillata. Phytochemistry 2002, 59, 325-329.

91. Cham, B.T.; Linh, N.T.T.; Anh, N.T.H.; Quan, T.D.; Tam, N.T.; Thien, D.D.; Le Nhung, T.H.; van Sung, T.; Son, N.T.; Delfino, D.V. Chemical constituents of Peltophorum pterocarpum stems. Vietnam Journal of Chemistry 2020, 58, 569-574.

92. Dao, P.T.A.; Le Quan, T.; Mai, N.T.T. Constituents of the Stem of Nauclea orientalis. Natural Product Communications 2015, 10.

93. Sharma, R.; Kishore, N.; Hussein, A.; Lall, N. Antibacterial and anti-inflammatory effects of Syzygium jambos L. (Alston) and isolated compounds on acne vulgaris. BMC complementary and alternative medicine 2013, 13, 292.

94. Mazlan, N.A.; Mediani, A.; Abas, F.; Ahmad, S.; Shaari, K.; Khamis, S.; Lajis, N.H. Antioxidant, antityrosinase, anticholinesterase, and nitric oxide inhibition activities of three malaysian macaranga species. TheScientificWorldJournal 2013, 2013, 312741.

95. Deng, Y.; Chin, Y.-W.; Chai, H.-B.; Blanco, E.C. de; Kardono, L.B.S.; Riswan, S.; Soejarto, D.D.; Farnsworth, N.R.; Kinghorn, A.D. Phytochemical and Bioactivity Studies on Constituents of the Leaves of Vitex Quinata. Phytochemistry letters 2011, 4, 213-217. 
96. Dai, D.N.; Thang, T.D.; Ogunwande, I.A.; Lawal, O.A. Study on essential oils from the leaves of two Vietnamese plants: Jasminum subtriplinerve C.L. Blume and Vitex quinata (Lour) F.N. Williams. Natural product research 2016, 30, 860-864.

97. Padma, P.; Chansouria, J.P.; Khosa, R.L. Polyalthia cerasoides-a possible antistress drug. Indian Journal of Natural Products 2000, 16, 20-23.

98. Tekuri, S.; Pasupuleti, S.; Konidala, K.; Pabbaraju, N. Pharmacological Effects of Polyalthia cerasoides (Roxb.) Bedd.: a brief Review. J Complement Med Res 2019, 10, 38.

99. John, J.; K A, S.; P R, R.; Kumar, N.A. Screening of Antidiarrheal Properties and Phytochemicals of Four Rare Plants Used in Traditional Medicine TRADITIONAL MEDICINE. J Biol Sci Opin 2016, 3, 266-270.

100. Siemonsma, J.S.; Niniek, W.-S. Plant resources of South-East Asia. Proceedings of the first PROSEA International Symposium, May 22-25, 1989, Jakarta, Indonesia 1989.

101. Tue Tinh. Collection of 3033 Eastern Traditional Medical Plants: Old traditional book; Y hoc \& Suc khoe.

102. Tang, W.; Eisenbrand, G. Chinese Drugs of Plant Origin: Chemistry, Pharmacology, and Use in Traditional and Modern Medicine; Springer Berlin: Berlin, 2013.

103. Baliga, M.S.; Meera, S.; Rai, M.P.; Saldanha, E.; Pais, S.; Jayachander, D.; Palatty, P.L. Use of the Ayurvedic Drug Triphala in Medical Conditions Afflicting Older Adults. In Foods and Dietary Supplements in the Prevention and Treatment of Disease in Older Adults: Elsevier, 2015, pp. 135-142.

104. Nguyen, Q.V.; Nguyen, A.D.; Wang, S.-L. Screening and evaluation of $\alpha$-glucosidase inhibitors from indigenous medicinal plants in Dak Lak Province, Vietnam. Research on Chemical Intermediates 2017, 43, 3599-3612.

105. Adinortey, M.B.; Galyuon, I.K.; Asamoah, N.O. Trema orientalis Linn. Blume: A potential for prospecting for drugs for various uses. Pharmacognosy reviews 2013, 7, 67-72.

106. Mpiana, P.T.; Ngbolua, K.N.; Mudogo, V.; Tshibangu, D.S.; Atibu, E.K.; Tshilanda, D.D.; Misengabu, N.M. Antisickle erythrocytes haemolysis properties and inhibitory effect of anthocyanins extracts of Trema orientalis (ULMACEAE) on the aggregation of human deoxyhemoglobin S in vitro. Journal of Medical Sciences 2011, 11, 129-137.

107. Hanum, F.; Hamzah, N. The use of medicinal plant species by the Temuan tribe of Ayer Hitam Forest, Selangor, Peninsular Malaysia. Pertanika J. Trop. Agric. Sci 1999, 22, 85-94.

108. Inafor, S. Medicinal Properties of Bornean Orangutan Food Plants in Gunung Beratus Protected Forest: The First International Conference of Indonesian Forestry Researchers (INAFOR): East Kalimantan, Indonesia, 2011.

109. Reddy, Y.Y. A Glimpse of Vietnam's Forest Wealth and Medicinal Plants-Based Traditional Medicine. Journal of Human Ecology 2005, 17, 293-299. 
110. Sam, V.H.; Nanthavong, K.; Kessler, P. Trees of Laos and Vietnam: A Field Guide to 100 Economically or Ecologically Important Species. blum - j plant tax and plant geog 2004, 49, 201-349.

111. Ket, V.N.; Cho, J.-H. Plant Genetic Resources in Lam Dong province-Vietnam: Brief in medicine plants and wild orchids situation. Korean Journal of Plant Resources 2009, 22, 571583.

112. Tinh, N.; Pollisco, F.S.; Casilla, R.C. Effects of Extraction on Wettability and Gluability of Apitong (Dipterocarpus Grandiflorus Blanco). The Journal of Adhesion 1977, 9, 63-71.

113. Morimura, K.; Gatayama, A.; Tsukimata, R.; Matsunami, K.; Otsuka, H.; Hirata, E.; Shinzato, T.; Aramoto, M.; Takeda, Y. 5-O-glucosyldihydroflavones from the leaves of Helicia cochinchinensis. Phytochemistry 2006, 67, 2681-2685.

114. Wickens, G.E. Edible nuts; Food and Agriculture Organization of the United Nations: Rome, 1999.

115. Park, I.-K.; Kim, K.-H.; Choi, K.-S.; Kim, C.-S.; Choi, I.-H.; Park, J.-Y.; Shin, S.-C. Nematicidal activity of plant essential oils and components from garlic (Allium sativum) and cinnamon (Cinnamomum verum) oils against the pine wood nematode (Bursaphelenchus xylophilus). Nematol 2005, 7, 767-774.

116. Bouhdid, S.; Abrini, J.; Amensour, M.; Zhiri, A.; Espuny, M.J.; Manresa, A. Functional and ultrastructural changes in Pseudomonas aeruginosa and Staphylococcus aureus cells induced by Cinnamomum verum essential oil. Journal of applied microbiology 2010, 109, 1139-1149.

117. Akbar, S. Cinnamomum verum J. Presl. (Lauraceae). In Handbook of 200 Medicinal Plants; Akbar, S., Ed.: Springer International Publishing: Cham, 2020, pp. 645-661.

118. Vogl, O.; Mitchell, J.D. Oriental Lacquer. 11. Botany and Chemistry of the Active components of Poisonous Anacardiaceae. Journal of Macromolecular Science, Part A 1996, $33,1581-1599$.

119. Kajita, T.; Kamiya, K.; Nakamura, K.; Tachida, H.; Wickneswari, R.; Tsumura, Y.; Yoshimaru, H.; Yamazaki, T. Molecular phylogeny of Dipetrocarpaceae in southeast Asia based on nucleotide sequences ofmatK, trnL Intron, andtrnL-trnF intergenic spacer region in chloroplast DNA. Molecular Phylogenetics and Evolution 1998, 10, 202-209.

120. Shiva, M.P.; Jantan, I. Non-timber forest products from dipterocarps. A Review of Dipterocarps-Taxonomy, ecology and silviculture (S. Appanah and JM Turnbull, eds.). CIFOR/FRIM. Centre for International Forest Research, Bogor, Indonesia 1998, 187-197.

121. Bongers, F.; Poorter, L.; Hawthorne, W.D.; Sheil, D. The intermediate disturbance hypothesis applies to tropical forests, but disturbance contributes little to tree diversity. Ecology letters 2009, 12, 798-805.

122. Alder, D.; Synnott, T.J. Permanent sample plot techniques for mixed tropical forest; Oxford Forestry Institute, University of Oxford, 1992. 
123. Tegene, A.S.; Gamo, F.W.; Cheche, S.S. Woody Vegetation Composition, Structure, and Community Types of Doshke Forest in Chencha, Gamo Gofa Zone, Ethiopia. International Journal of Biodiversity 2018, 2018, 1-16.

124. Lamprecht, H. Silviculture in the tropics: Tropical forest ecosystems and their tree species: possibilities and methods for their long-term utilization; Deutsche Gesellschaft für Technische Zusammenarbeit GTZ: Eschborn, 1989.

125. Viet, Q.D.; Nam, A.T. Commercial collection of NTFPs and households living in or near the forests. Ecological Economics 2006, 60, 65-74.

126. Vedeld, P.; Angelsen, A.; Bojö, J.; Sjaastad, E.; Berg, G.K. Forest environmental incomes and the rural poor. Forest Policy and Economics 2007, 9, 869-879.

127. Tyagi, R.; Churcgate, M. Role of Mountain Women in Environment Governance in India. The Indian Society of Ecological Economics 2006.

128. Byers, E.; Sainju, M. Mountain Ecosystems and Women: Opportunities for Sustainable Development and Conservation. Mountain Research and Development 1994, 14, 213.

129. Deka, S.; Tripathi, O.P.; Paul, A. Perception-based assessment of ecosystem services of Ghagra Pahar forest of Assam, Northeast India. Geology, Ecology, and Landscapes 2019, 3, 197-209.

130. Triantaphyllou, E.; Parlos, P.M. Multi-criteria decisio-making methods: A comparative study; Kluwer Academic Publishers: Dordrecht, 2010, 320.

131. Parrotta, J.; Yeo-Chang, Y.; Camacho, L.D. Traditional knowledge for sustainable forest management and provision of ecosystem services. International Journal of Biodiversity Science, Ecosystem Services \& Management 2016, 12, 1-4. 
Chapter 7. General Summary, Contributions and Recommendations

\subsection{Summary}

In this work, four main objectives have been accomplished: (1) identifying and evaluating tree species, stand structures, and the influences of topographical conditions on the distribution of tree species, and species richness in natural forests; (2) optimizing the analysis of different optical satellite images for land cover and forest type classification by vegetation indices and land-use; (3) assessing soil qualities in areas with differing land-uses and topographic aspects; (4) assessing the demand and potential supply concerning Non-Timber Forest Products as ecosystem services of the natural forests as well as the perceptions of local people, with a respect to landscapes restoration in the study area.

1) The influence of the topography on tree species diversity, their distribution, and the composition of natural lowland forests in Central Vietnam is summarized as follows:

Species richness, species diversity, stand density, and basal area were significantly different at lower and at higher elevation, as well as at shallow and at steep slope. The lower elevation and shallow slope exposed higher species richness and diversity. The species diversity both in the lower elevation and the shallow slope were higher. The forests stocking on higher elevation and steep slope exposed a larger mean basal area but fewer individuals per ha, obviously as a result of forest disturbance and successional processes. Insofar, elevation had more influence on species richness, stand density, species diversity, basal area, and tree family distribution than had slope. The factor slope was found to have a weak correlation with species richness, stand density, and basal area. Elevation was the key factor influencing the species richness, the stem density, and the species dominance.

The bigger diameter classes of trees were generally found more frequently in undisturbed and in less disturbed forests as well as in higher elevation. However, the ratio of the tree height classes - ranging between $13 \mathrm{~m}$ and $19 \mathrm{~m}$ - was higher in disturbed forests and in lower elevation. The variation of forest structures in different forest types and elevations showed features of forest formation and successional processes which are typically after deforestation and/or degradation. 
Species composition among elevations and slopes was also significantly different in terms of species dominance and species abundance. The composition of the most abundant and dominant species of the respective plots did not fully represent these of the entire topographic range presented in the study area.

2) Land cover and forest type classification using the Random Forest Algorithm and the vertical/horizontal structure relationships with the values of vegetation indices of the lowland tropical forests are summarized as follows:

The multiple spectral bands for land cover and land use classification obtained from Random Forest Classifier on Sentinel-2 imagery demonstrated a higher accuracy than those of the Landsat8 imagery. Such Sentinel-2 images showed a high potential for landscape and forest type classification as basis for conservation and management purposes in tropical lowland forests. A time series classification based on Sentinel-2 imagery, combined with ground-truth samples, is seen as an effective tool to distinguish natural forest areas. This contributes to forest land cover mapping since the Random Forest Classifier showed more consistency among land cover classes in Sentinel-2.

Seven different vegetation indices were extracted from the Sentinel-2 imagery and showed significant differences between classified forest types based on ground truth and training data sample plots. The four defined vegetation indices (EVI, DVI, PVI, and TNDVI) were derived from the reflectance of the forest canopy by red and near-infrared bands, and are considered to be possible and useful indicators to assess canopy horizontal structures of lowland forest.

3) Quality indicators of soil in differing agricultural land-uses and topographic aspects were assessed and summarized as follows:

The soil organic content and the soil total nitrogen content in all land-use types belong to the category "poor" to "medium" in comparison to other regions in Vietnam. Most of the soil quality indicators were significantly influenced by different land-use systems. The soil organic content of agricultural land and of plantation forests were higher and differed significantly to grasslands and natural forests. The soil total nitrogen content in grasslands, plantation forests and agricultural land show no differences; however, they are significantly higher than these of natural forests. Soil 
indicators decreased with soil depth. Nevertheless, the $\mathrm{pH}$-values in agricultural land are highest and show significant differences compared to the other land-uses. Lime application obviously limits the soil acidity. Differences in $\mathrm{pH}$-values between the two soil depths were observed both in grasslands and natural forests. No differences of soil organic content and topographic aspects were found. Nevertheless, the soil organic content differs in the eastern and the western locations.

4) The distribution of medicinal trees differed significantly in the undisturbed forests, the less disturbed forests, and the disturbed forests. This difference was not found for differing elevation. A significant difference of resin/oil providing tree species was found in undisturbed and disturbed forests, but not at all in the less disturbed forests.

Multiple methods are suitable for evaluating the awareness and perceptions local people in various target groups with differing interests reflects a precise view of choices on different perceptions. The assessment-based target groups could lead to long-term perspectives for the natural forest's improvement. Disaster risk mitigation and restoration of natural forests, among other activities, work towards a mutually reinforcing convergence and to the enrichment of nontimber forest products as a second priority. The involvement of various stakeholders in any decision, based on different perceptions with in a mutual understanding of opportunities and the value of multifunction, is important for natural forest landscape restoration. Such a process is of fundamental importance for national strategies.

\subsection{Contributions}

The study contributes to the following:

a) it identifies the influences of topographic conditions on species richness, diversity, distribution, and species composition (as dependent variables) at different micro-topographic attributes as an important step for forest type classification and determination of forest- formation characteristics in the tropical lowland natural forests of Central Vietnam.

b) it identifies and compiles a list of potential NTFPs tree species for food, medicines, and resin/oil production; and listing of multiple-use tree species with forest structural parameters from different forest types and elevations-based classification as a basis for landscape restoration. 
Management, enrichment activities, and understanding the perceptions are all key elements for the restoration of the natural forest landscape, especially in connection to ecosystem provisioning services and human well-being.

c) it integrates the soil qualities under different land-use types in the area as important elements for goods production and ecosystem services. As it benefits the human well-being, the soil quality assessment contributes remarkably to land-use planning and production development in such a mountainous area. The impacts of slope, elevation, farming system, and soil texture accounted for the differences in these soil indicators.

d) it optimizes the application of multiple bands of satellite images for land cover classification by using Random Forest Algorithms, facilitating a better-performing land cover classification image with vertical and horizontal structures of tropical lowland forests in Central Vietnam with the further possible support from vegetation indices.

e) it enables land cover and land use classification with open source of satellite images via the support of machine learning algorithms.

f) it offers insights into the awareness of local people concerning forestry issues through differences in assessment-based perceptions. Such observations demonstrate the needs of nontimber forest products from natural forests towards acceptance for forest landscape restoration to meet local people's demands being applicable to sustainable forest management, land use planning, environmental protection, nature conservation, landscape restoration, and mitigation of natural disasters.

Furthermore, the work supports approaches for forest management, forest restoration, conservation practices of biodiversity-based topographic conditions, land use planning, proper identification of dominant tree species using vegetation indices' values, and land cover and land use classification using open-sourced satellite images.

Besides advantages also few limitations exist. The availability of a free cloud cover is one of essential challenges concerning satellite imagery in the tropical lowland forests where humidity and clouds are frequent. Free and open sources of cloud-free satellite images are not always 
available including the Lidar and Radar. Further, these may be too costly or of insufficient resolution (eMODIS NDVI V6) for consistent monitoring and for time series analyses in lowland tropical areas. The elaboration within one thesis lacks of long observation periods and of funding.

\subsection{Recommendations}

The following is recommended:

a) The mapping of micro-site natural forest disturbances based on the topographic conditions of the endemic and dominant tree species can contribute to conservation and management activities in different ecological habitats. Using high-resolution satellite images and determining the most dominant species can contribute to an appropriate conservation, restoration, and management strategy for the area.

b) As the optical images are limited for the classification of forest structures the use of radar sensor imagery with p-band and/or the L-band plus the ground truth data analyses provide better results.

c) Further research should cover more ground truth sample plots with time series analyses to match vegetation indices-based forest types with stand structures of dominant/abundant tree species.

d) For landscape restoration the assessments should be on a larger scale. A time series assessment will help to define better evidence-based perceptions.

e) Further studies may target the chlorophyll contents of differing dominant/abundant tree species as a possibly important trait of tree species composition and distribution. 
Annex 1. An ecosystem services based-demand questionnaire

Questionnaire No:

\section{QUESTIONNAIRE FOR ECOSYSTEM SERVICES}

Interviewer:

Date of interview:

Longatitude:

Latitude:
Interviewee

Village:

Commune:

District:

Province:

This questionnaire aims to collect data, information on forest ecosystem services provisioning and demanding of indigenous human being, frequency, approaches and forest provisioning products. This questionnaire is divided into 5 catergorise for the above purpose.

\section{General information}

$1.1 \quad$ Gender

$1.2 \quad$ Age

1.3 Ethnic group

$\square$ Kinh

$\square$ Hre

1.4 Religion

What (if yes):

1.5 Main Occupation

1.6 Education

1.7 Marriage status

1.8 Family individual
$\square$ Male
$\square$ Female
$\square 18-20$
$\square 21-29$
$\square$ 40-49
$\square$ 50-59

$\square$ 30-39

$\square 60$ 
1.9 Permanent settlement

$\square$ Permanant

Period settlement

1.10 Household income group?

$$
\begin{aligned}
& \square<2 \text { year } \\
& \square>10 \text { year }
\end{aligned}
$$$$
\square 2-5 \text { year }
$$$$
\square \text { 6-9 year }
$$

1.11 What are the main activities bring income?
$\square$ Agriculture practice
$\square$ Husbanday
$\square$ Aquaculture
$\square$ NTFP business
$\square$ Exloitation and transporting
$\square$ Hunting
$\square$ Small business
$\square$ Other...

\section{Land and Production Practices}

2.1 What kind of lands are most common to your family?
$\square$ Paddy field
$\square$ Cropland
$\square$ Plantation forest
$\square$ Forest land
$\square$ Unforested land $\quad \square$ Fruit tree
$\square$ Grass
$\square$ Aquaculture

2.2 How much land allocated to your family?
$\square$ 1- 3ha
口 4-6 ha
$\square$ 7-10ha
$\square>10$ ha

2.3 Forest area allocated (if there is)?

Protected forest..........ha Production forest..........ha

\section{Plantation}

forest.............ha

$2.4 \quad$ What are your main $\quad \square$ Rice

plantation species

$\square$ Rubber

$\square$ Acasia

$$
\square \quad \square \text { Casava }
$$

$\begin{array}{ll}\square & \square \\ \text { Fruit } & \text { Vegetables }\end{array}$ tree

Other

2.5 Distance from your house to allocated land?
$\square 1-5 \mathrm{Km}$
$\square$ 5-10 Km
口 >10 Km

2.6 Ranking the importance of cultivation practice 1-5: 1 = Less Important, 2= Moderate Important, $3=$ Important, 4= High Importance, 5= Very hight important

Paddy

Bennien tree

Natural forest

Plantation

Unforested land

Perennial trees

Shub

Grass

Aquaculture 
2.7 Ranking the importance of species 1-5: 1 = Less Important, 2= Moderate Important, 3= Important, 4= High Importance, 5= Very hight important

Paddy

Maise

Casava

Rubber

Fruit tree

Vegetatble

Acasia

Other

2.8 Ranking the importance of husbandary practice 1-5: $1=$ Less Important, $2=$ Moderate Important, $3=$ Important, 4= High Importance, 5= Very hight important

$\begin{array}{lcc}\text { Cow } & 1 & 2 \\ \text { Bufallo } & \square & \square \\ \text { Goat } & \square & \square \\ \text { Chicken } & \square & \square \\ \text { Pig } & \square & \square \\ \text { Other } & \square & \square \\ \text { Rankg } & \square & \square\end{array}$

2.9 Ranking the importance of forest land 1-5: $1=$ Less Important, $2=$ Moderate Important, 3= Important, 4= High Importance, 5= Very hight important

$\begin{array}{llllll}\text { Natural forest } & 1 & 2 & 3 & 4 & 5 \\ \text { Plantation forest } & \square & \square & \square & \square & \square \\ \text { Oher } & \square & \square & \square & \square & \square\end{array}$

Other

2.10 Ranking the satisfication of common production activities 1-5: $1=$ Less satisfied, $2=$ Moderate satisfied, $3=$ satisfied, $4=$ High satisfied, 5= Very hight satisfied

Paddy

Bennien tree

Natural forst

Plantation forest

Unforested forest

Perennial trees

Shrubs

Grass

Aquaculture

Hand made production

Tourism hotspot attraction

2.11 Ranking the importance of these activities 1-5: $1=$ Less Important, 2= Moderate Important, 3= Important, 4= High Importance, 5= Very hight important

Timber logging

Fuelwood collecting

Shifting cultivation

Herb collection

$\begin{array}{lllll}1 & 2 & 3 & 4 & 5 \\ \square & \square & \square & \square & \square \\ \square & \square & \square & \square & \square \\ \square & \square & \square & \square & \square \\ \square & \square & \square & \square & \square \\ \square & \square & \square & \square & \square \\ \square & \square & \square & \square & \square \\ \square & \square & \square & \square & \square \\ \square & \square & \square & \square & \square \\ \square & \square & \square & \square & \square \\ \square & \square & \square & \square & \square \\ \square & \square & \square & \square & \square\end{array}$

$\begin{array}{ll}1 & 2 \\ \square & \square \\ \square & \square \\ \square & \square \\ \square & \square\end{array}$


Honey collection

Honey production

Mushroom collection

Bamboo shoot

Wild vegetatable

Bamboo

Tournament sampling

Hunting

Raising wild animal

Other

$\begin{array}{ll}\square & \square \\ \square & \square \\ \square & \square \\ \square & \square \\ \square & \square \\ \square & \square \\ \square & \square \\ \square & \square\end{array}$

2.12 What forest products are usually collected, frequency and area? (note: area to be marked on map)

Products

Yes Season Yearl Month Week Dail Area

Timber

Food

Bamboo shoot

Herb

Fuelwoods

Hunting

Honey

Bamboo

Tournament tree

Ampelocalamus patellaris

Livistona cochinchinensis

Dioscorea persimilis

Amomum xanthioides

Arenga pinnata

Calamus siphonospathus

Calamus sp

Scaphium macropodum

Prashorea chinensis Mushroom

Other mushroom

Orchid sp

Homalomena occulta

Musa acuminata

Pandanus odoratissimus

Dianella ensifolia

Alpinia conchigera

2.13 What are the collected products used for?

$\begin{array}{ll}\text { Products } & \text { Household usage } \\ \text { Timber } & \square \\ \text { Food } & \square \\ \text { Bamboo shoot } & \square \\ \text { Herb } & \square \\ \text { Fuelwoods } & \square \\ \text { Hunting } & \square \\ \text { Honey } & \square \\ \text { Bamboo } & \square \\ \text { Tournament tree } & \square \\ \text { Ampelocalamus } & \square \\ \text { patellaris } & \end{array}$

Sell-out Both

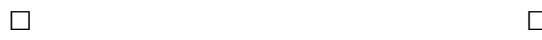

$\square$

$\square$

$\square$

Herb

Fuelwoods

Hunting

Honey

amboo

Ampelocalamus

patellaris 
Livistona

cochinchinensis

Dioscorea persimilis

Amomum xanthioides

Arenga pinnata

Calamus

siphonospathus

Calamus sp

Scaphium macropodum

Prashorea chinensis

Mushroom

Others mushroom

Orchid sp

Homalomena occulta

Musa acuminata

Pandanus odoratissimus

Dianella ensifolia

Alpinia conchigera

2.14 Quantity per collection time

Products

Kg/M/M2/M3/Animal Products

/tree/liter

Timber

Calamus siphonospathus

Food

Calamus sp

Bamboo shoot

Scaphium macropodum

Herb

Prashorea chinensis

Mushroom

Fuelwoods

Another mushroom

Hunting

Orchid sp

Honey

Homalomena occulta

Bamboo

Musa acuminata

Tournament tree

Pandanus odoratissimus

Ampelocalamus

Dianella ensifolia

patellaris

Livistona

cochinchinensis

Dioscorea

Alpinia conchigera

persimilis

Amomum xanthioides

Arenga pinnata

2.15 Where are markets (Domestic market (D.M) or External Market (Ex.M)

Products

Timber

Food
D.M Ex.M

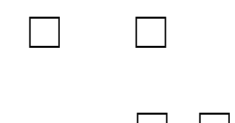

Price (around)

Calamus

siphonospathus

Calamus sp
$\mathrm{Kg} / \mathrm{M} / \mathrm{M} 2 / \mathrm{M} 3 /$ animal/ tree/liter 
Bamboo shoot

Herb

Fuelwoods

Hunting

Honey

Bamboo

Tournament tree

Ampelocalamus

patellaris

Livistona

cochinchinensis

Dioscorea

persimilis
Scaphium

macropodum

Prashorea

Mushroom

Other

mushroom

Orchid sp

Homalomena

occulta

Musa acuminata

Pandanus

odoratissimus

Dianella

ensifolia

Alpinia

conchigera

Amomum

xanthioides

Arenga pinnata

\section{Cultural services}

3.1 Are there any tourism activities in your village/commune?
$\square$ Yes
$\square$ No

3.2 Do you join any tourism activities
$\square$ Yes
$\square$ No

3.3 Ranking the importance of tourism activities 1-5: $1=$ Less Important, $2=$ Moderate Important, $3=$ Important, 4= High Importance, 5= Very hight important

Tourism attraction

Handicraft production

Selling forest products

Others

3.4 Do you provide some of above-mentioned tourism activities? (question 3.3)

$$
\text { Yes }
$$

No

3.5 If yes, do you earn any income/year? (VNĐ/year)

Yes $\square$

No

3.6 Ranking the satisification of tourism activities 1-5: $1=$ Less Important, 2= Moderate Important, $3=$ Important, 4= High Importance, 5= Very hight important

$$
123
$$

$\begin{array}{llll}2 & 3 & 4 & 5 \\ \square & \square & \square & \square \\ \square & \square & \square & \square \\ \square & \square & \square & \square \\ \square & \square & \square & \square\end{array}$

\section{Forest Landscape Information}

4.1 Do you experience about landslide in this area?

Yes

No

4.2 How often do you see?

Annually

2-5 year

6-10 year

$>10$ year

4.3 Can you and family or people in your area assess to clean water resources? 
$\square$ Yes

$\square$ No

Shortage of clean water? $\square$ Yes

$\square$ No

4.4 Do you involve or do see someone collecting forest products?

$\square$ Yes $\quad \square$ No

4.5 Do you think forest resource is getting less to extinction?

Yes $\square \quad$ No $\square \quad$ No idea

4.6 Since when you experience forest resource is get less?

Last 2 years $\quad 5$ year $\quad 10$ year $>10$ year

4.7 Do you think that natural forest landscape being important?

Yes $\square \quad$ No

4.8 Ranking the important of forest landscapes: 1-5: $1=$ Less Important, 2= Moderate Important, $3=$ Important, 4= High Importance, 5= Very hight important

$\begin{array}{llrrr}1 & 2 & 3 & 4 & 5\end{array}$

4.9 Do you wish to have better natural forest management, protection for more provision to serve local people in the area?
$\square$ Yes
$\square$ No
$\square$ Other idea
$\square$ No idea

4.10 Please rank the importance of forest landscape rehabilitation: Ranking the important of forest landscapes: 1-5: 1 = Less Important, 2= Moderate Important, 3= Important, 4= High Importance, 5= Very hight important

$$
1
$$

$$
2
$$$$
3
$$

\section{Questions for experts (group interview)}

5.1 Please list all tree species that you think most suitable to rehabilitate forest landscape in this area

5.2 What guidelines from governments do you think most important for forest landscape rehabilitation?

3.3 What guidelines from governments do you think not applicable (why) for forest landscape rehabilitation?

\section{Thank you very much for your contribution to the questionnaire!}

